ANDRÉ PERPIGNAN VIVIANI DE CAMPOS

\title{
DESENVOLVIMENTO DE UM COMPRESSOR RADIAL PARA TURBINA A GÁS DE PEQUENO PORTE
}


ANDRÉ PERPIGNAN VIVIANI DE CAMPOS

\section{DESENVOLVIMENTO DE UM COMPRESSOR RADIAL PARA TURBINA A GÁS DE PEQUENO PORTE}

Dissertação apresentada à Escola Politécnica da Universidade de São Paulo para a obtenção do título de Mestre em Engenharia

Área de concentração:

Engenharia Mecânica de Energia e Fluidos

Orientador: Prof. Dr. Guenther Carlos Krieger Filho 
Este exemplar foi revisado e corrigido em relação à versão original, sob responsabilidade única do autor e com a anuência de seu orientador.

São Paulo, 24 de maio de 2013.

Assinatura do autor

Assinatura do orientador

FICHA CATALOGRÁFICA

Campos, André Perpignan Viviani de Desenvolvimento de um compressor radial para turbina a gás de pequeno porte / A.P.V. de Campos. - versão corr. -- São Paulo, 2013. $150 \mathrm{p}$.

Dissertação (Mestrado) - Escola Politécnica da Universidade de São Paulo. Departamento de Engenharia Mecânica.

1. Turbinas a gás 2 . Compressor radial I. Universidade de São Paulo. Escola Politécnica. Departamento de Engenharia Mecânica II. t. 
"You live and learn. At any rate, you live." Douglas Adams 


\section{Agradecimentos}

Primeiramente, gostaria de agradecer ao meu orientador, por sua ajuda, ensinamentos e por ter confiado em mim para realização deste projeto.

Aos professores João Barbosa e Jayme Ortiz pelos valiosos conselhos e contribuição durante o exame de qualificação.

Agradeço aos caros colegas e amigos do LETE pelo companheirismo e ajuda durante todo o tempo em que trabalhamos juntos.

Agradeço também pelo apoio incondicional de meus pais, sempre me incentivando e confiando em minhas escolhas.

À minha namorada, Elisa, por dividir comigo as dificuldades, alegrias e conquistas, além de seu suporte indispensável para minha motivação e perseverança.

Aos meus bons amigos Felipe, Diego, Âmbar, Rufus, aos companheiros da EESC e muitos outros, por me apoiarem e distraírem nos momentos certos.

Por fim, agradeço à FAPESP por ter concedido a bolsa que possibilitou o financiamento deste projeto. 


\section{RESUMO}

O desenvolvimento de tecnologia na área de turbomáquinas é essencial ao desenvolvimento da indústria nacional e o Laboratório de Engenharia Ambiental e Térmica da Escola Politécnica da Universidade de São Paulo tem compreendido ações para este propósito. Este trabalho tem por objetivo desenvolver um compressor para uma turbina a gás de pequeno porte de $500 \mathrm{~kW}$, primeiro passo para o projeto e construção da turbina como um todo. A partir da análise do ciclo termodinâmico e da análise de adimensionais, o tipo de compressor a ser utilizado foi determinado. Optou-se pelo projeto de um compressor centrífugo. Iniciou-se o projeto através de análise e correlações unidimensionais com previsão de desempenho, definindo algumas geometrias iniciais a serem avaliadas nas fases seguintes. Realizou-se a análise bidimensional do impelidor com a ferramenta computacional Vista TF que utiliza o método de curvatura de linhas de corrente. Por fim, a geometria tridimensional foi definida com uso de simulações de dinâmica de fluidos computacional. De acordo com as simulações, o compressor projetado tem desempenho condizente com os requisitos impostos.

Palavras-chave: Compressor centrífugo, Turbomáquinas, CFD. 


\begin{abstract}
Technology development in turbomachinery is essential to the national industry development and the Laboratory of Environmental and Thermal Engineering of the Polytechnic School of the University of São Paulo is engaged on this purpose. This work intends to design a compressor for a small $500 \mathrm{~kW}$ gas turbine, the first step in the whole turbine design and construction. The compressor type was determined from thermodynamical cycle and adimensional analysis. The centrifugal type compressor was chosen. The design was initialized using one-dimensional analysis and correlations with performance prediction models, defining initial geometries to be evaluated in the upcoming design phases. The impeller was analyzed with a two dimensional computational tool named Vista TF, which uses the streamline curvature method. The tridimensional geometry was defined using computational fluid dynamics. According to the simulations, the design compressor performs satisfying the imposed requirements.
\end{abstract}

Keywords: Centrifugal Compressor, Turbomachinery, CFD. 


\section{LISTA DE ILUSTRAÇÕES}

Figura 1 - Diagrama de Cordier, com diâmetro específico Ds e velocidade específica Ns. Adaptado de Dixon e Hall (2010).

Figura 2 - Gráfico do coeficiente de carga pelo coeficiente de vazão mostrando as regiões adequadas a cada tipo de turbomáquina que consome trabalho, com linhas de velocidade específica constante. Adaptado de Baines (2010). 11

Figura 3 - Vista explodida de um compressor centrífugo. O impelidor se encaixa de modo a alinhar sua saída à entrada do difusor. Adaptado de Baskharone (2006)....13

Figura 4 - Esquema da metodologia de projeto apontada por Casey (1994)..........15 Figura 5 - Dados da pesquisa paramétrica dispostos num gráfico da razão de

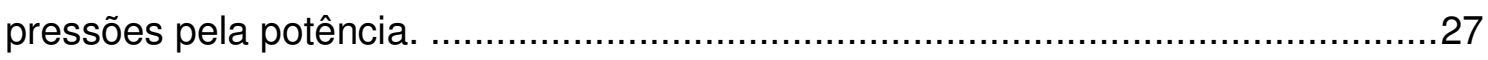

Figura 6 - Esquema do ciclo adotado, com uma turbina de potência......................28

Figura 7 - Gráfico da vazão mássica $(\mathrm{kg} / \mathrm{s})$ em função da potência para os dados coletados na pesquisa paramétrica. $O$ valor obtido com os cálculos do ciclo Brayton está mostrado em verde.

Figura 8 - Gráfico do diâmetro específico pela velocidade específica com curvas de nível de eficiência e indicação sobre os tipos de fluxo dos compressores. Extraído de Balje (1981). 32

Figura 9 - Diagrama de Cordier com indicação das regiões adequadas a cada tipo de compressor. Adaptado de Dixon e Hall (2010).

Figura 10 - Linha de Cordier definida pela equação de Casey; Zwyssig e Robinson (2010). A linha contínua é a principal, enquanto as tracejadas definem a faixa de valores que apontam as turbomáquinas mais eficientes. .35

Figura 11 - Componentes de um compressor centrífugo. Vista frontal (esquerda) e vista meridional (direita). Adaptado de Aungier (2000). 39

Figura 12 - Localização do perfil ou superfície meridional no impelidor de um compressor centrífugo. Adaptado de Boyce (2003).

Figura 13 - Comportamento idealizado da velocidade absoluta e das pressões estática e total ao longo de um compressor centrífugo. Adaptado de Boyce (2003).41 Figura 14 - Relação entre as eficiências isentrópica e politrópica (total-total), de acordo com a Eq. 39 para vários valores de razão de pressões. 50 
Figura 15 - Mapa de desempenho genérico de um compressor centrífugo. Adaptado de Whitfield e Baines (1990). 52

Figura 16 - Triângulos de velocidades na entrada (acima) e saída (abaixo) numa pá de rotor. Adaptado de Whitfield e Baines (1990) 56

Figura 17 - Efeito do escorregamento no triângulo de velocidades. A linha tracejada indica o triângulo que haveria caso não houvesse escorregamento. Adaptado de Dixon e Hall (2010). 58

Figura 18 - Relação genérica entre o coeficiente de carga (head) e coeficiente de escoamento com o efeito do ângulo de sweep. Adaptado de Boyce (2003). 60 Figura 19 - Difusor radial de canal com indicações de suas regiões principais. Adaptado de Cumpsty (2004) 63

Figura 20 - Difusor radial com aerofólios. As regiões são similares às do difusor de canal da Fig. 19.

Figura 21 - Dimensões genéricas do perfil meridional do impelidor. Dimensões indicadas são definidas no projeto unidimensional.

Figura 22 - Gráfico relacionando o número de Mach na saída do impelidor com a velocidade adimensional de rotação do impelidor. São mostrados os efeitos do ângulo de backsweep da saída do impelidor. Adaptado de Whitfield e Baines (1990).

68

Figura 23 - Gráfico relacionando o número de Mach na saída do impelidor com o número de Mach relativo na entrada do impelidor. São mostrados os efeitos da razão de pressões e da razão entre o raio do shroud na entrada e o raio na saída. Adaptado de Whitfield e Baines (1990). 71

Figura 24 - Gráfico da razão entre altura das pás na saída e o raio do impelidor na saída pela velocidade adimensional do impelidor. O gráfico mostra ainda o efeito da razão de pressões, do número de Mach relativo na entrada, do número de Mach na saída e da razão entre o raio do shroud na entrada e o raio na saída. Adaptado de Whitfield e Baines (1990). 72

Figura 25 - Gráfico do número de Mach relativo pelo número de Mach absoluto, ambos na entrada do impelidor. O gráfico mostra ainda o efeito do ângulo relativo do escoamento na entrada e da expressão envolvendo a vazão mássica adimensional, velocidade de rotação adimensional e a razão hub/shroud na entrada. Adaptado de Whitfield e Baines (1990) 
Figura 26 - Dados empíricos relacionando o número de pás do impelidor e a razão de pressões. Adaptado de Xu e Amano (2012a).............................................. Figura 27 - Relação entre altura das pás e RMS de sua espessura para a entrada dos impelidores. Dados de Xu e Amano (2012a). 79

Figura 28 - Relação entre altura das pás e RMS de sua espessura para a saída dos impelidores. Dados de Xu e Amano (2012a). 80

Figura 29 - Fluxograma do método unidimensional de projeto preliminar utilizado. .82 Figura 30 - Relação entre massa e diâmetro de impelidores. Adaptado de Xu e Amano (2012a). 94

Figura 31 - Sistema de coordenadas sobre as linhas de corrente utilizado pelo programa computacional com método de curvatura de linhas de corrente. Adaptado de Cumpsty (2004). 98

Figura 32 - Contorno com os valores de número de Mach absoluto para a geometria "A". Cálculo realizado com código bidimensional. 101

Figura 33 - Contornos de número de Mach absoluto para a geometria "B" com 3,55 $\mathrm{kg} / \mathrm{s}$ de vazão mássica (esquerda) e a geometria "B4" com 3,6 kg/s (direita). Vazões máximas antes do choke. 102

Figura 34 - Contornos de número de Mach absoluto para a geometria "C" com 3,9 $\mathrm{kg} / \mathrm{s}$ de vazão mássica (esquerda) e para a geometria "C3" com vazão de projeto $4,13 \mathrm{~kg} / \mathrm{s}$ (direita).

Figura 35 - Comparação entre os contornos de número de Mach para as geometrias "D" (esquerda) e "D5" (direita). A curva do hub foi modificada. 103

Figura 36 - Gráfico do número de Mach relativo pela posição na passagem (0 refere-se à entrada e 1 à saída do impelidor) ao longo do hub para as geometrias "D" e "D5" para as superfícies de sucção, pressão e média das pás. 104

Figura 37 - Representação vetorial da força centrípeta, cuja reação é a força centrífuga. Adaptado de Schobeiri (2005). 110

Figura 38 - Representação vetorial da aceleração de Coriolis. Adaptado de Schobeiri (2005). 111

Figura 39 - Exemplo das geometrias de impelidor (acima) e difusor (abaixo) sem suas carcaças (shroud). Linhas mostram a extensão dos domínios computacionais. A malha computacional do hub no impelidor e difusor é mostrada. Superfícies em verde são entradas e em vermelho saídas. 
Figura 40 - Contorno do número de Mach ao longo do compressor na rotação e vazão de projeto $(4,13 \mathrm{~kg} / \mathrm{s})$. Impelidor à esquerda e difusor à direita da figura.

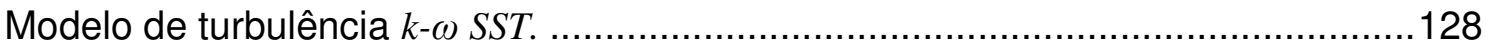

Figura 41 - Contorno de pressão total sobre a superfície média na direção circunferencial no ponto de projeto. Duas pás do impelidor e duas palhetas do difusor são mostradas. Modelo de turbulência $k-\omega S S T$. 129

Figura 42 - Linha de Cordier definida pela equação de Casey; Zwyssig e Robinson (2010). A linha contínua é a principal, enquanto as tracejadas definem a faixa de valores que apontam as turbomáquinas mais eficientes. $\mathrm{O}$ compressor projetado se situa no ponto verde. 130 Figura 43 - Geometria final do compressor projetado sem as carcaças que cobrem impelidor e difusor. 


\section{LISTA DE TABELAS}

Tabela 1 - Vantagens e desvantagens das configurações de ângulo de sweep. Adaptado de Boyce (2003).

Tabela 2 - Faixas utilizadas para os parâmetros variados durante o projeto unidimensional e as referências que ajudaram a determiná-las. 80

Tabela 3 - Dimensões das geometrias selecionadas a partir do projeto unidimensional, com suas eficiências isentrópicas e razões de pressões indicadas. Comparação com o compressor descrito e testado pelos trabalhos de McKain e Holbrook (1982) e Skoch et al. (1997) .95

Tabela 4 - Resultados das previsões uni e bidimensionais para a eficiência isentrópica do impelidor. 105

Tabela 5 - As abordagens possíveis para dedução das equações de conservação e as formas das equações resultantes.

Tabela 6 - Resultados das simulações com modelo $k-\omega$ SST com diversas vazões mássicas.

Tabela 7 - Resultados sumarizados de eficiência isentrópica e razão de pressões previstas pelos modelos utilizados. Valores dos modelos 1D e 2D referem-se apenas ao impelidor. 


\section{LISTA DE SÍMBOLOS}

$A$ - área / coeficiente da equação de Casey; Zwyssig e Robinson (2010)

$A_{R}$ - razão de áreas do difusor

$a$ - velocidade do som

$B$ - aproximação ao coeficiente central da equação de quantidade de movimento

excluindo-se o termo transiente / coeficiente da equação de Casey; Zwyssig e

Robinson (2010)

$B_{2}$ - coeficiente de bloqueio

$b$ - altura da passagem

$C$ - velocidade absoluta / constante da lei de parede

$C_{f}-$ coeficiente de atrito

$C_{p}$ - coeficiente de pressão

$c_{p}$ - calor específico a pressão constante

$c_{v}$ - calor específico a volume constante

$D$ - diâmetro

$D_{f}-$ fator de difusão

$D_{s}$ - diâmetro específico

$e$ - energia interna / espessura das pás

$F_{x}$ - força na direção $x$

$f$ - fator de atrito

$g$ - aceleração da gravidade

$H$ - carga (head)

$h$ - entalpia

$I$ - rotalpia 
$k$ - condutividade térmica / energia cinética turbulenta

$k_{s}$ - rugosidade

$k_{1,2,3,4}$ - coeficientes da equação de Casey; Zwyssig e Robinson (2010)

$L_{a x}-$ comprimento axial do impelidor

$L_{c}$ - porcentagem de perda de pressão na câmara de combustão

$L_{d}$ - comprimento médio da passagem do difusor

$L_{e}$ - perda de pressão na exaustão / comprimento médio da passagem do impelidor

$L_{m}$ - comprimento meridional médio do impelidor

$\dot{m}$ - vazão mássica

$M_{u}$ - velocidade adimensional da ponta do rotor

$N$ - rotação

$N_{s}$ - velocidade específica

$P$ - pressão

$P_{k}$ - produção de energia cinética turbulenta

$P_{R}-$ razão de pressões totais

$Q$ - vazão volumétrica / calor

$\dot{Q}-$ fluxo de calor

$R$ - constante dos gases ideais

$r-$ raio

Re - número de Reynolds

$S$ - termo fonte

$s$ - entropia

$T$ - temperatura

$t$ - tempo

$t_{1,2}$ - coeficientes da equação de Casey; Zwyssig e Robinson (2010) 
$U$ - velocidade tangencial / componente de velocidade

$u$ - energia interna / velocidade na direção $x$

$u^{*}$ - adimensional da velocidade tangencial à parece

$V$ ou $v$-volume / velocidade na direção $y$

$\vec{v}-$ vetor velocidade

$W-$ trabalho / velocidade relativa

$\dot{W}$ - potência

$w$ - velocidade na direção $z$

$y^{*}$ - adimensional da distância à parede

$\Delta y$ - distância à parede

$Z$ - número de pás do impelidor

$Z_{d}$ - número de palhetas do difusor

$z$ - altura com relação a um referencial

$\alpha$ - ângulo absoluto do escoamento com relação à direção meridional

$\beta$ - ângulo relativo do escoamento com relação à direção meridional

$\Gamma$ - coeficiente de difusão

$\gamma$ - razão dos calores específicos

$\varepsilon$ - dissipação da energia cinética turbulenta

$\varepsilon_{\text {esteira }}$ - fração do comprimento da saída do impelidor no qual há esteira

$\epsilon$ - folga entre as pás do impelidor e sua carcaça

$\eta$ - eficiência

$\theta$ - adimensional da vazão mássica

$\theta_{c}$ - ângulo de divergência equivalente do difusor

$\kappa$ - razão espaço-corda da equação de Came e Robinson (1999) / constante de Von Kármán 
$\lambda$ - fator de trabalho

$\lambda_{v}$ - segunda viscosidade

$\mu$ - fator de escorregamento

$\mu_{d}$ - viscosidade dinâmica

$\mu_{t}-$ viscosidade turbulenta

$v$ - razão entre os raios no hub e shroud na entrada no impelidor

$\xi$ - propriedade escalar genérica

$\rho$ - densidade

$\tau$ - torque

$\tau_{a b}-$ tensões viscosas

$\tau_{\omega}$ - tensão de cisalhamento na parede

$\phi$ - coeficiente de escoamento

$\Psi_{\text {low,med,high }}$ - coeficientes da equação de Casey; Zwyssig e Robinson (2010)

$\Psi_{\mathrm{s}}$ - coeficiente de carga (head)

$\omega$ - taxa específica de dissipação

$\vec{\omega}$ - vetor velocidade angular

\section{Índices subscritos}

$(t-e)$ - total - estática

$(t-t)-$ total - total

0 - condição de estagnação

1 - entrada do compressor / entrada do impelidor

2 - saída do compressor / saída do impelidor

3 - entrada da turbina / entrada do difusor

4 - saída da turbina e entrada da turbina de potência / saída do difusor 
5 - saída da turbina de potência

A-superfície

at - atrito viscoso

atd - atrito no disco

$B$ - relativo à pá (blade)

$b$ - relativo a forças de empuxo (buoyancy)

$c$ - referente ao compressor

$c g$ - carga

$d$ - relativo ao difusor

fol - folga

$h-h u b$

hid - hidráulico

$I$ - referente ao impelidor

inc - incidência

$i p$ - ponto de integração

isen - isentrópica

isot - isotérmica

$m$ - eficiência mecânica do eixo / direção meridional

mis - mistura

$p$ - politrópica

ploss - perda de pressão

$R N G$ - referente ao modelo de turbulência $R N G$ k- $\varepsilon$

rec - recirculação

$s$ - referente ao estágio de compressão / relativo ao shroud / processo isentrópico

$t-$ turbina 
$t p$ - turbina de potência

$u p$ - no ponto a montante (upwind)

$V C$ - volume de controle

vaz - vazamento

$x$ - na direção $x$

$\theta$-direção circunferencial

\section{Índices sobrescritos}

$(\cdot)^{\prime}$ - grandeza relativa, no referencial rotativo

$(\cdot)^{\theta}$ - tipo de discretização temporal

$b$ - gases queimados

$o$ - relativo à iteração anterior

$T-$ tangencial / transposto

\section{Siglas}

CDS - Esquema de Diferenças Centrais (Central Difference Scheme)

CFD - Dinâmica de Fluidos Computacional (Computational Fluid Dynamics)

LDA - Anemometria a Laser Doppler (Laser Doppler Anemometry)

LETE - Laboratório de Engenharia Ambiental e Térmica

MVF - Método dos Volumes Finitos

PIV - Particle Image Velocimetry

RANS - Reynolds Averaged Navier-Stokes

RMS - Root Mean Square

SST - Shear Stress Transport 


\section{SUMÁRIO}

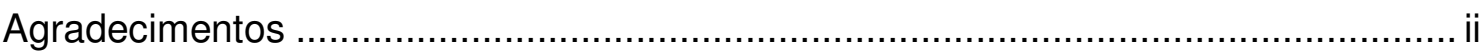

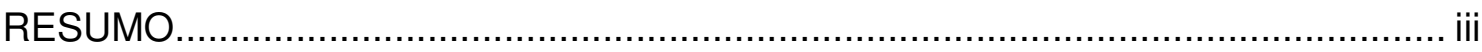

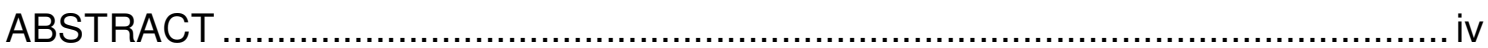

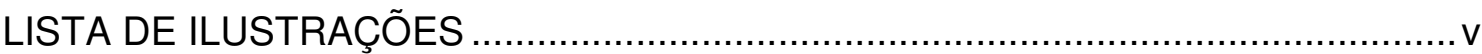

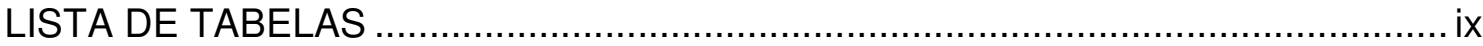

LISTA DE SÍMBOLOS

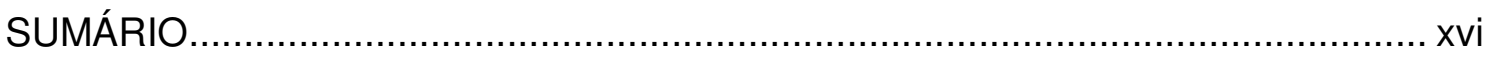

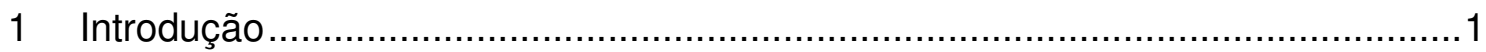

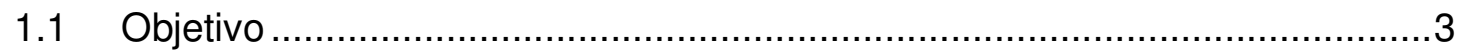

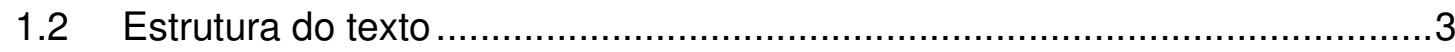

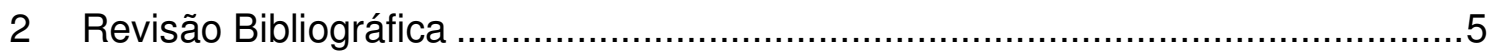

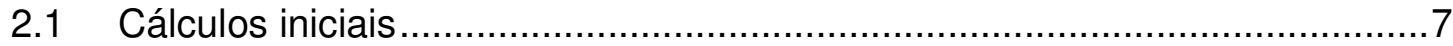

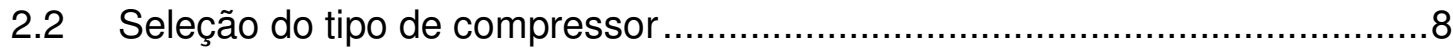

2.3 Fundamentos de compressores centrífugos …………………………....12

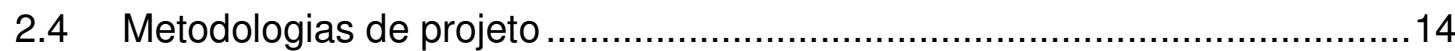

2.5 Correlações e métodos unidimensionais de projeto....................................18

2.6 Dinâmica de fluídos computacional.........................................................20

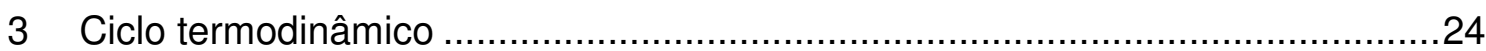

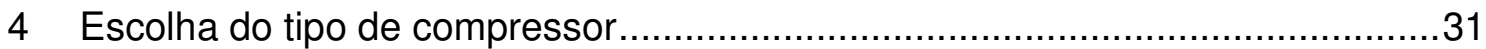

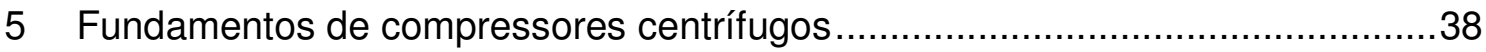

5.1 Equações e conceitos básicos .............................................................42

5.2 Grandezas adimensionais .................................................................... 44

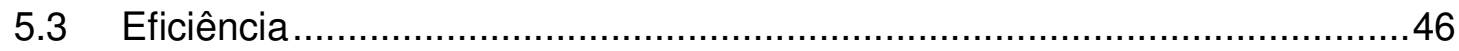

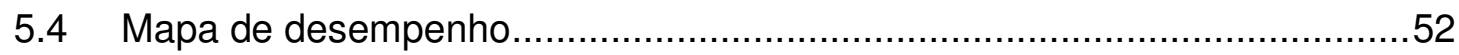

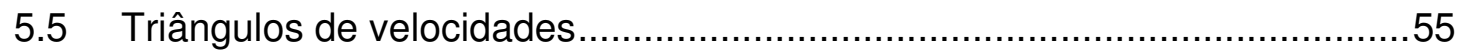

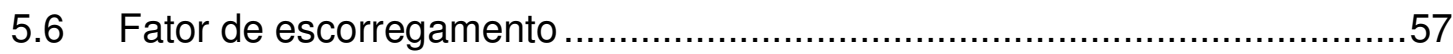




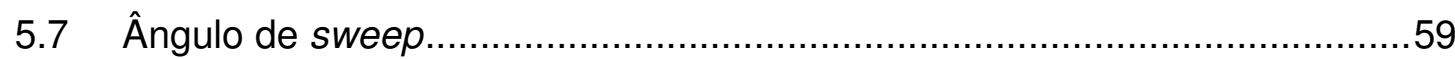

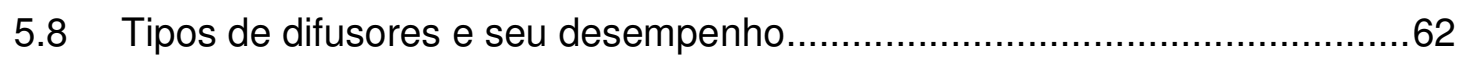

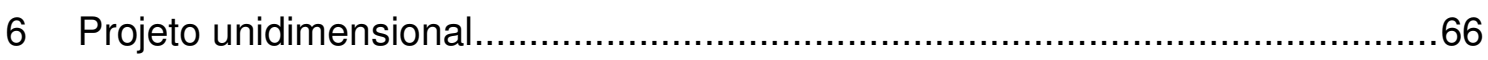

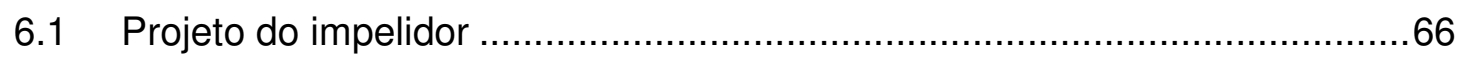

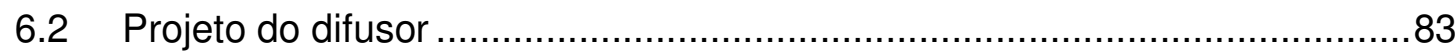

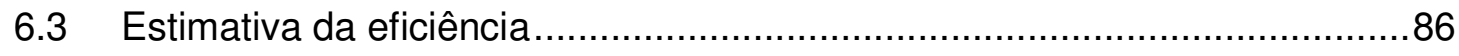

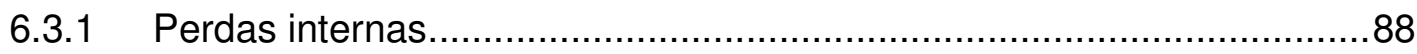

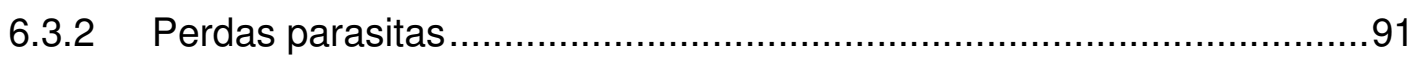

6.4 Resultados do projeto unidimensional.....................................................93

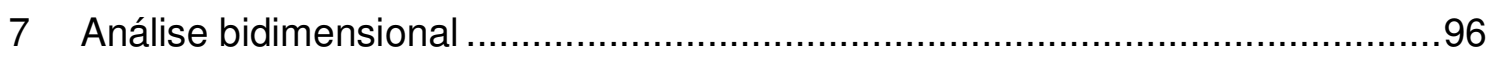

7.1 As equações de equilíbrio radial e o método de curvatura das linhas de

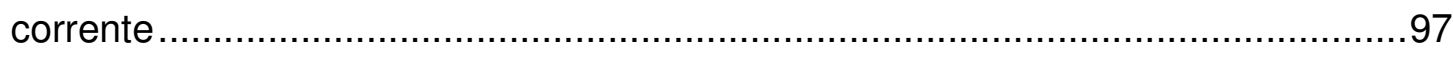

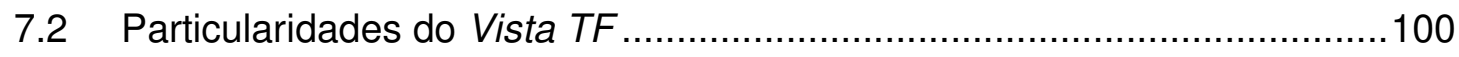

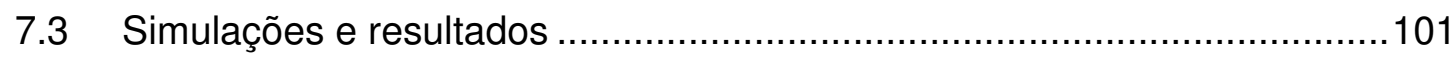

8 Análise tridimensional - Dinâmica de fluidos computacional..............................106

8.1 Equações fundamentais e o método dos volumes finitos..............................106

8.2 Estrutura do código utilizado .............................................................113

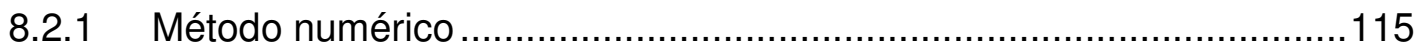

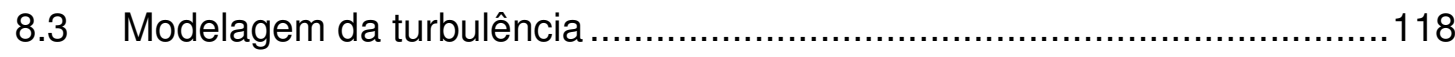

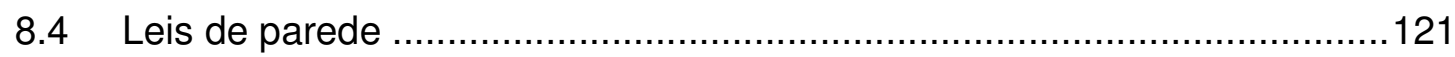

8.5 Condições de contorno .....................................................................123

8.6 Convergência e malhas computacionais ...................................................124

8.7 Resultados e o compressor projetado .....................................................126

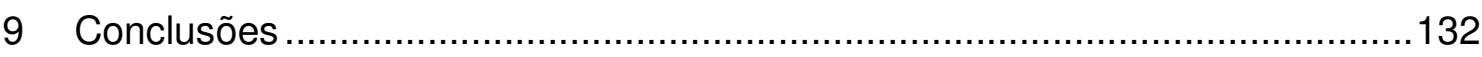

9.1 Sugestões para projetos futuros e melhoria do compressor .......................133

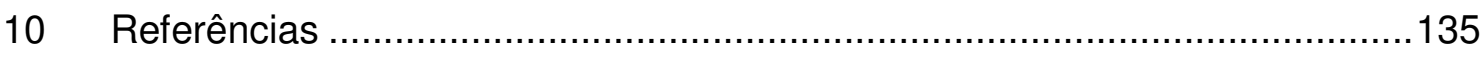

Apêndice A - Rotina computacional do projeto unidimensional ..............................144 


\section{INTRODUÇÃO}

A utilização de turbomáquinas está presente em muitos segmentos da indústria. Elas são empregadas na transferência de energia, na geração elétrica, na indústria aeronáutica, petrolífera ou química, sendo seu desempenho vital a essas atividades. Por esse motivo, muitos estudos foram e são conduzidos relacionando-se ao processo de projeto, à previsão de desempenho, à utilização de materiais, à fabricação e a muitas outras áreas em turbomáquinas.

Turbomáquinas podem ser definidas como dispositivos cuja energia mecânica é trocada com um fluido de escoamento contínuo através de ação dinâmica de pás rotativas (BASKHARONE, 2006; DIXON; HALL, 2010). Faz-se importante ressaltar que a energia pode ser transferida tanto da máquina ao fluido quanto o contrário.

As turbinas a gás são um tipo particular de turbomáquina, classificado como motor de combustão interna. Em turbinas a gás, a energia é extraída do processo de combustão, gerando potência de eixo e/ou empuxo. Para que sejam atingidas eficiências que justifiquem seu uso, turbinas a gás têm os compressores como um de seus componentes críticos. Os compressores têm por função fornecer à câmara de combustão o ar com alta pressão, evitando-se perdas e irreversibilidades tanto quanto possível, ou seja, elevando a eficiência do compressor ao mais alto patamar (GIAMPAOLO, 2009). A própria eficiência térmica da turbina a gás está diretamente ligada à razão de pressões gerada pelo compressor (MORAN; SHAPIRO, 2009).

Este trabalho apresenta o projeto de um compressor e é o primeiro passo para o projeto e construção de um sistema de potência com turbina a gás para gerar 500 kW. Esta iniciativa irá aprofundar e sedimentar os conhecimentos no projeto, simulação e refinamento de turbomáquinas no Laboratório de Engenharia Ambiental e Térmica (LETE) da Escola Politécnica da Universidade de São Paulo, que tem realizado pesquisa na área de turbinas a gás (AIROLDI, 2009; CAMPOS; SACOMANO FILHO; KRIEGER FILHO, 2012; SOUZA, 2008).

O desenvolvimento de tecnologia na área de turbinas a gás é de grande importância devido à sua aplicação em setores estratégicos como a aeronáutica e a geração de energia, que suportam 0 desenvolvimento de diversos outros setores. $O$ 
conhecimento gerado, além de auxiliar a indústria nacional, poderá servir como base para a formação de profissionais aptos a avaliar turbomáquinas, podendo então atuar em avaliações de aquisições e manutenção dos equipamentos.

Além disso, a fabricação de máquinas mais eficientes tem sido uma necessidade crescente não somente pela economia que isso representa, mas pelas recentes exigências impostas pela sociedade visando à conservação do meio ambiente. Este trabalho será fundamental para que projetos futuros possam estudar os pormenores do funcionamento dos compressores, servindo como base para sua otimização.

A classificação por "tamanho" das turbinas a gás é usualmente feita em função de sua potência, apesar de não haver consenso em tal classificação. A turbina a gás para a qual o compressor tratado neste trabalho foi projetado é considerada de pequeno porte tendo a potência pretendida de 500 kW (BOYCE, 2006), ou uma miniturbina (GIAMPAOLO, 2009). Em ambos os casos, tal potência a coloca acima da categoria de microturbina.

A escolha em começar pelo compressor tem base no fato de seu projeto ser considerado mais difícil e complexo que, por exemplo, a seção de expansões do sistema (WILSON; KORAKIANITIS, 1998). Dessa forma, é interessante que se dê mais atenção ao compressor, destinando mais recursos ao seu projeto. Ao se iniciar o projeto da turbina a gás pelo compressor há menos restrições e requisitos, provendo mais liberdade ao seu projeto, aumentando as possibilidades para alcançar altas eficiências.

Assim como em quase todas as aplicações de engenharia, o projeto de compressores não é um problema com solução única. O grande número de variáveis envolvidas e a impossibilidade em se prever com exatidão o comportamento de um fluido ao passar pelo compressor transformam o projeto em um processo complexo. A abordagem utilizada para lidar com essa dificuldade pode ser a utilização de modelos, desenvolvidos para predizerem o desempenho de um compressor, que impõem simplificações aos fenômenos reais ou se baseiam em experimentos.

Os modelos disponíveis para previsão de desempenho necessitam de entradas que, freqüentemente, precisam ser assumidas e ter sua influência avaliada posteriormente. Esse fato, em conjunto com erros introduzidos pelas simplificações adotadas nos modelos, faz com que o processo de projeto não seja linear e nem 
simples. Modelagens mais complexas, como as análises tridimensionais em CFD, têm o potencial de fornecer previsões mais próximas à realidade (CASEY, 1994), apesar de isso depender fortemente do uso correto de tais ferramentas. Porém, modelagens mais complexas necessitam de maior detalhamento dos dados de entrada, impossibilitando seu pronto uso desde o começo do projeto. Além disso, o tempo gasto para que essas ferramentas forneçam resultados é muito maior, dificultando seu uso na avaliação da influência de variáveis específicas no desempenho do projeto.

\subsection{ObJetivo}

O objetivo principal deste trabalho é apresentar um projeto aerotermodinâmico de um compressor a ser utilizado em uma turbina a gás capaz de desenvolver $500 \mathrm{~kW}$ para geração elétrica. Serão detalhados os métodos e ferramentas utilizados, assim como o embasamento teórico pertinente. Será apresentada a geometria do compressor projetado, assim como a previsão de seu desempenho.

\subsection{ESTRUTURA DO TEXTO}

O texto dessa dissertação foi diagramado de maneira a apresentar os conceitos e resultados numa seqüência lógica, facilitando a compreensão do leitor. O capítulo dois apresenta uma revisão da literatura pertinente às atividades que compõe esta dissertação. Os principais tópicos foram divididos em seções para facilitar a leitura e posterior consulta.

O terceiro capítulo é dedicado à descrição dos cálculos do ciclo termodinâmico da turbina a gás a ser projetada. Esses cálculos são necessários para iniciar o projeto do compressor. 
O capítulo quatro detalha como foi feita a escolha pelo uso de um compressor radial. Nele estão apresentados a teoria e métodos utilizados para fundamentar essa escolha.

O capítulo cinco é dedicado à apresentação dos conceitos fundamentais sobre compressores centrífugos, o tipo de compressor selecionado. Julgou-se que este capítulo é necessário para embasar as discussões apresentadas em capítulos seguintes.

O capítulo seis apresenta os métodos dos modelos unidimensionais de projeto, com o equacionamento e observações pertinentes. Os resultados obtidos no projeto unidimensional são apresentados ao final do capítulo.

O capítulo sete expõe a ferramenta computacional utilizada durante o projeto bidimensional. Os resultados e decisões decorrentes da análise bidimensional são discutidos. Da mesma forma, o capítulo oito mostra a teoria de dinâmica de fluidos computacional (CFD) pertinente ao trabalho, assim como os resultados conseguidos. O capítulo se encerra apresentando a geometria final do compressor.

Por fim, o capítulo nove apresenta as conclusões do trabalho e as sugestões para trabalhos futuros e melhoria do compressor projetado. O capítulo dez lista as referências utilizadas durante todo o texto. 


\section{REVISÃo BIBLIOGRÁFICA}

A literatura acerca do projeto de compressores é extensa e envolve diversas áreas do conhecimento. Ao longo da história, os métodos empregados em projetos de turbomáquinas evoluíram. Molinari e Dawes (2006) realizaram uma revisão sobre a evolução do processo de projeto de compressores indicando cronologicamente o surgimento de técnicas. Este trabalho auxilia a compreender a origem, assim como a importância de cada técnica de projeto atualmente.

Esses autores reportam que as primeiras teorias aerodinâmicas dedicadas a compressores foram desenvolvidas na década de 1920, com base em experimentos em túnel de vento com aerofólios em cascata, método ainda usado e que rendeu os resultados mais significativos para compressores axiais até a década de 1960. De forma geral, a tendência era empregar generalizações baseadas em empirismos. Essa abordagem foi a principal ferramenta de projeto até a década de 1960, apesar de esforços desde a década de 1940 para compreensão dos fenômenos físicos.

Até a década de 1960, a previsão de desempenho era bastante limitada pela baixa compreensão física dos escoamentos. A partir dessa época, foram realizados esforços para relacionar as correlações empíricas com teorias de termodinâmica e fluidodinâmicas básicas. Os ciclos ideais passaram a ter maior importância ao serem corrigidos com as tentativas em prever as perdas associadas aos projetos. Até a década de 1980, dados experimentais e abordagens teóricas desempenhavam papéis de igual importância, sempre com tentativas de generalização, com uso de correções e grandezas adimensionais.

Molinari e Dawes (2006) destacaram ainda a ascensão dos computadores e métodos numéricos entre as décadas de 1970 e 1980. Esse fato adicionou possibilidades ao projeto de compressores, com soluções numéricas às equações mais complexas e soluções rápidas de modelos unidimensionais. Com o uso de computadores aumentando após a década de 1980, a dinâmica de fluidos computacional ganhou ainda mais participação nos projetos. Novas técnicas experimentais também têm sido importantes para compreensão mais detalhada do escoamento. Dentre elas têm destaque o PIV (Particle Image Velocimetry) e LDA 
(Laser Doppler Anemometry), com medições mais detalhadas e úteis inclusive à validação dos modelos matemáticos e computacionais.

A partir desse panorama, os autores analisaram as diferentes abordagens de metodologias de projeto e como o progresso das técnicas de projeto as afetam. Essa análise está incorporada à seção 2.4 deste capítulo.

Como mostrado no Cap. 4 dessa dissertação, o tipo de compressor escolhido para o projeto foi o centrífugo. De maneira similar ao que foi realizado por Molinari e Dawes (2006) para compressores em geral, Krain (2005) fez uma revisão com enfoque mais histórico sobre compressores centrífugos. Ele salientou que, por ser empregado praticamente desde o início da utilização industrial das turbomáquinas, o desenvolvimento desse tipo de compressor caminhou ao lado do desenvolvimento das próprias turbomáquinas.

As primeiras tentativas de aplicação de compressores centrífugos em turbinas a gás foram realizadas no começo do século XX. Grandes avanços, porém, vieram com a aplicação aos motores aeronáuticos. Os primeiros motores a jato utilizavam compressores centrífugos e levaram seu desenvolvimento a um novo patamar, com razões de pressão próxima de 4 , enquanto os projetos anteriores alcançavam apenas 2,5 .

Krain (2005) afirmou que as contribuições à melhoria dos compressores centrífugos têm sido feitas através de três maneiras principais: empírica, teórica e experimental. Essas três abordagens não seguiram uma seqüência linear e nem tiveram sua proporção de utilização mantida ao longo do tempo.

Dados empíricos estão fortemente presentes na literatura e no conhecimento detido por fabricantes. Por muito tempo, os dados empíricos tiveram importância maior que a aplicação teórica, pela dificuldade em tal aplicação, assim como salientaram Molinari e Dawes (2006). Krain (2005) destacou o princípio da similaridade (discutido em maiores detalhes na seção 2.2 e no Cap. 4 desta dissertação), que, através de parâmetros adimensionais, é capaz de prover boas noções ao projetista com base em projetos anteriores, mesmo que estes tenham dimensões e condições de operação distintas. Segundo o autor, essa abordagem teve grande impacto nos projetos. 
Nos últimos anos, os códigos computacionais de dinâmica de fluidos têm ajudado a prever o desempenho e a analisar os pormenores aerodinâmicos dos compressores centrífugos. Entretanto, Krain (2005) afirmou que ainda é preciso dedicar mais esforço à validação dos códigos. Apesar de as novas técnicas experimentais terem avançado em precisão e no tipo de dados adquiridos, o autor destacou que ainda é necessário realizar experimentos que comprovem os fenômenos envolvidos. Krain (2005) acredita que há muito que progredir, especialmente em compressores com razões de pressão altas (maiores que 5) com relação à eficiência e faixa de operação. Isso mostra que estudos como o realizado nesta dissertação podem contribuir à melhoria dos compressores radiais.

Tanto Molinari e Dawes (2006) quanto Krain (2005) salientaram que a estratégia para realização dos processos de projeto é de fundamental importância a este trabalho e essa revisão contempla tal tema na seção 2.4 deste capítulo. A determinação das etapas de projeto, assim como seus respectivos objetivos é capaz de alterar os resultados de maneira decisiva.

Nas seções seguintes deste capítulo, a literatura sobre os aspectos mais importantes deste trabalho está analisada e detalhada. Em algumas seções foi dada alguma ênfase a trabalhos nacionais, uma vez que esta dissertação tenciona inserirse neste cenário.

\subsection{CÁLCULOS INICIAIS}

Antes de projetar-se qualquer componente específico de uma turbina a gás é necessário levantar dados acerca dos requisitos e desempenho do sistema completo. Para tanto, é usual realizar análises do ciclo termodinâmico empregado. Moran e Shapiro (2009) apresentaram o ciclo Brayton e a teoria termodinâmica básica que o embasa. Tal ciclo é muito utilizado para representação de turbinas a gás. Através da análise do ciclo Brayton é possível estimar, ainda que de forma grosseira, o fluxo mássico necessário e a eficiência global do sistema. A compreensão acerca do ciclo termodinâmico é fundamental inclusive para entender de que maneiras o ciclo real se afasta dessa idealização e como atuam as perdas. 
Saravanamuttoo; Rogers e Cohen (2001) refinaram o uso do ciclo ideal ao introduzir estimativas para as perdas no ciclo, tornando a análise mais fiel à realidade. Essa foi a principal referência utilizada nesta dissertação para realizar os cálculos preliminares. Esses modelos de perdas são bastante simples e não acrescentam dificuldades consideráveis aos cálculos. Há modelos de perdas mais sofisticados, especialmente quando se trata de projeto de componentes. Porém, não é possível utilizá-los nos cálculos iniciais do ciclo, uma vez que são necessárias informações mais precisas do que as disponíveis nessa etapa. Foram assumidos valores conservadores para as perdas e os cálculos foram realizados seguindo ainda 0 trabalho de Balje (1981), o qual é importante especialmente à escolha do tipo de compressor, discutida na seção seguinte do presente trabalho.

Mesmo em cálculos simples, os valores de parâmetros precisaram ser assumidos, uma vez que o único requisito fechado inicialmente para o projeto é a potência de 500 kW. Para balizar as escolhas, uma pequena pesquisa paramétrica foi conduzida, valendo-se de dados disponibilizados por Brezonick (2003) e Giampaolo (2009). Os dados utilizados foram potência, razão de pressões e fluxo mássico de vários modelos comerciais de turbinas a gás com diversas aplicações.

\subsection{SELEÇÃO DO TIPO DE COMPRESSOR}

Os compressores de turbomáquinas podem ser classificados quanto à direção do fluxo de ar. Dessa forma, os compressores podem ser radiais (centrífugos), axiais, ou ainda de fluxo misto. Nos compressores axiais, o fluido mantém-se na direção axial, ao longo do eixo de rotação, enquanto nos radiais o fluido entra na direção axial e sai radialmente.

De forma geral, os compressores radiais são utilizados em motores de menor porte, devido a problemas relacionados a velocidades sônicas, grande área frontal requerida e baixa eficiência em razões de pressão muito altas (TREAGER, 1979). Os compressores axiais têm como vantagem o alcance de maiores razões de pressão devido à possibilidade de empregar um grande número de estágios. Porém, o aumento de pressão por estágio é menor, e a eficiência a vazões menores é mais 
baixa (BALJE, 1981). Uma avaliação detalhada deve ser feita para a escolha do tipo de compressor, assim como do número de estágios e o número de palhetas de cada estágio.

A decisão acerca do tipo de fluxo do compressor (e das turbomáquinas em geral) é de grande importância para o projeto e pode estar condicionada a muitos fatores. Entre eles estão a experiência do fabricante e dos projetistas com um dado tipo, restrições de área frontal, imposições de custo de fabricação ou manutenção e outros (CUMPSTY, 2004). O artigo de Baines (2010) abordou de maneira bastante simples e instrutiva a questão da escolha da configuração, fornecendo uma visão geral sobre ela. $\mathrm{O}$ autor introduziu o conceito de análise dimensional, a base do princípio da similaridade.

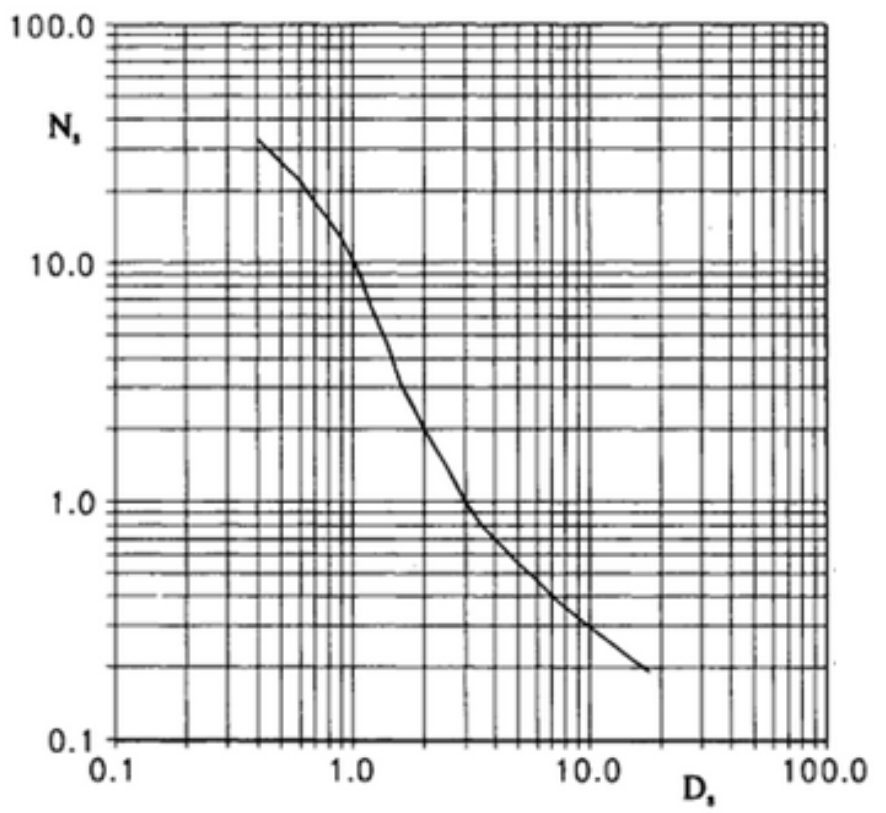

Figura 1 - Diagrama de Cordier, com diâmetro específico $\left(\mathrm{D}_{\mathrm{s}}\right)$ e velocidade específica $\left(\mathrm{N}_{\mathrm{s}}\right)$. Adaptado de Dixon e Hall (2010).

O método de pré-projeto para a escolha da configuração mais difundido se baseia no princípio da similaridade entre turbomáquinas. Tal princípio enuncia que turbomáquinas com geometria e condições de operação análogas têm desempenhos equivalentes (BALJE, 1981; LOGAN JR., 1993). Cordier (1955) analisou o desempenho de diversos tipos de turbomáquinas que representavam 0 estado da arte. Ele tentou encontrar relações entre grandezas adimensionais e os tipos de fluxo. Ao representar a velocidade específica $\left(N_{S}\right)$ pelo diâmetro específico 
$\left(D_{S}\right)$ das diversas máquinas, percebeu-se que elas se acomodavam numa linha razoavelmente definida em escalas logarítmicas, surgindo assim o diagrama (ou linha) de Cordier, assim como mostrado na Fig. 1. Diâmetro e velocidade específicos são definidos pelas Eqs. 1 e 2, respectivamente, onde $H$ é a carga (head), $Q$ é a vazão volumétrica e $g$ é a aceleração da gravidade. Ambas são grandezas adimensionais.

$$
\begin{aligned}
& D_{s}=\frac{D(g H)^{1 / 4}}{\sqrt{Q}} \\
& N_{s}=\frac{N \sqrt{Q}}{(g H)^{3 / 4}}
\end{aligned}
$$

Balje (1981), a referência mais significativa, desenvolveu mais profundamente este tipo de gráfico e gerou curvas de nível com as eficiências alcançadas por diâmetro e velocidade específicos dados. Esses gráficos tornaram-se uma ferramenta de préprojeto. Essa abordagem é descrita por muitos outros trabalhos como uma maneira de determinar o tipo de máquina a ser utilizada (BAINES, 2010; BOYCE, 2003, 2006; CASEY, 1994; CASEY; ZWYSSIG; ROBINSON, 2010; DIXON; HALL, 2010; DUFOUR, 2006; EPPLE; DURST; DELGADO, 2011; WHITFIELD; BAINES, 1990; WRIGHT, 1999).

Dixon e Hall (2010) apresentam essa abordagem baseando-se no trabalho de Csanady (1964), que, paralelamente a Balje (1981), é uma das referências que mais desenvolveram esse assunto, indicando qual tipo de máquina é mais recomendável para velocidade ou diâmetro específicos dados. Tanto o trabalho de Balje (1981) quanto o de Dixon e Hall (2010) foram utilizados para embasar a escolha do compressor nesta dissertação.

Contudo, alguns autores apontaram limitações a esse método. Whitfield e Baines (1990) afirmaram que é preciso ter-se em mente que o diagrama de Cordier é feito, obviamente, com base no estado da arte dos projetos, dificultando melhorias e o uso de soluções inovadoras. É preciso ter atenção ao período no qual o diagrama utilizado foi criado. Além disso, Whitfield e Baines (1990) alertaram para a possibilidade de as máquinas estudadas para fazer o diagrama não terem sido 
projetadas priorizando a máxima eficiência. Isso porque, freqüentemente, projetos têm restrições e requisitos de outra natureza, como tamanho, custo de fabricação ou desempenho off-design. Mesmo assim, no caso de não haver uma rica base de dados anteriores, o diagrama de Cordier, os gráficos de Balje ou outros ábacos baseados em grandezas adimensionais são um bom ponto de partida. O próprio Baines (2010) reafirmou a importância desses métodos.

As faixas de operação ótimas para cada configuração podem ser razoavelmente bem definidas também por outras variáveis adimensionais, como o coeficiente de vazão e o coeficiente de carga. Devido a suas definições matemáticas (apresentadas no Cap. 4 dessa dissertação), os adimensionais velocidade e diâmetro específicos, e os coeficientes de vazão e carga são intercambiáveis (CASEY; ZWYSSIG; ROBINSON, 2010). A definição de dois deles automaticamente define os outros dois. O gráfico apresentado por Baines (2010), adaptado à Fig. 2, mostra esquematicamente as faixas ótimas para diversos tipos de turbomáquinas que absorvem trabalho com relação aos coeficientes de vazão e carga.

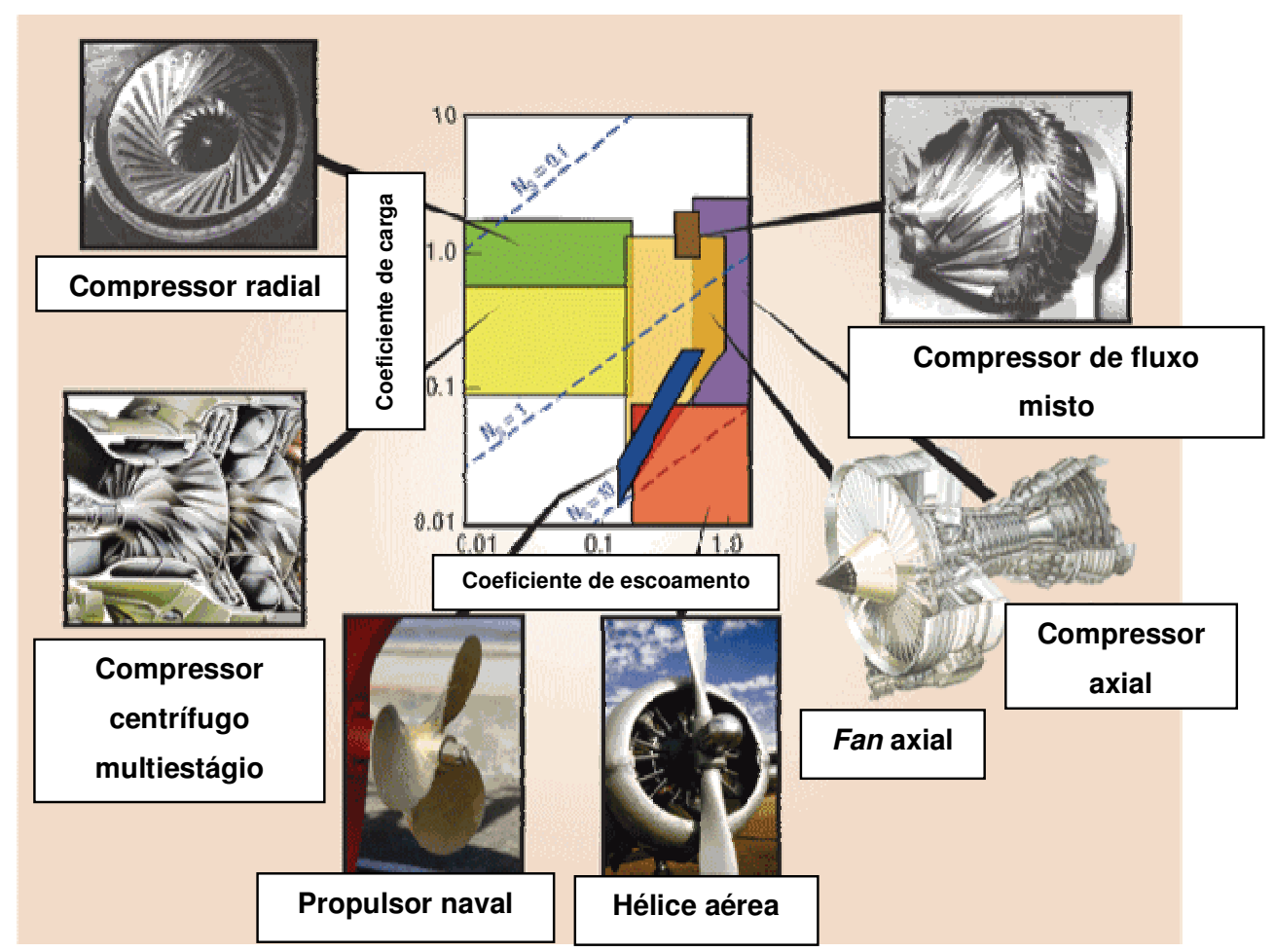

Figura 2 - Gráfico do coeficiente de carga pelo coeficiente de vazão mostrando as regiões adequadas a cada tipo de turbomáquina que consome trabalho, com linhas de velocidade específica constante. Adaptado de Baines (2010). 
Mais recente que o trabalho de Balje (1981), o estudo realizado por Casey; Zwyssig e Robinson (2010) trouxe uma interessante revisão sobre o diagrama de Cordier, analisando inclusive seu significado físico. Os autores mostraram por que a linha de Cordier tem, tipicamente, o formato em "s".

Casey; Zwyssig e Robinson (2010) fizeram uma revisão das equações propostas para o diagrama de Cordier e propuseram uma nova equação para a linha de Cordier com base em dados mais recentes. A equação define uma faixa de valores, uma vez que os autores consideram que a definição de uma única linha de Cordier não é fiel à real dispersão dos dados. Essa equação foi utilizada nesta dissertação para estimar o diâmetro do compressor, uma vez que possui uma base de dados mais recente.

Com intenção similar, o trabalho de Epple; Durst e Delgado (2011) apresentou uma tentativa de chegar ao diagrama de Cordier através de inferência teórica. Os autores mostraram através de análises de considerações geométricas básicas, partindo de triângulos de velocidade e relações termodinâmicas, é possível chegar próximo aos diagramas de Cordier construídos com dados empíricos. Esse trabalho ajudou a mostrar que o diagrama de Cordier é, de fato, uma ferramenta útil ao projeto e que tem bases nos princípios das turbomáquinas e não apenas em empirismos.

\subsection{FUNDAMENTOS DE COMPRESSORES CENTRÍFUGOS}

A partir da escolha pelo compressor centrífugo, julgou-se necessário expor alguns fundamentos de seu funcionamento neste trabalho. Há muitas referências com fins didáticos que reúnem informações acerca desse tipo de compressor. Porém, o presente trabalho manteve o foco nas referências que vinculam esse tipo de informação com questões relacionadas diretamente ao projeto. No Cap. 5 desta dissertação estão reunidos os conceitos mais pertinentes à realização do projeto.

Dixon e Hall (2010) e Saravanamuttoo; Rogers e Cohen (2001) apresentaram de forma bastante clara e sucinta os princípios básicos do funcionamento dos compressores centrífugos e como ele se relaciona com o equacionamento termodinâmico. Os conceitos de fator de escorregamento, mapa operacional, com 
surge e choke, e fatores de desempenho em compressores foram discutidos. Além disso, uma rotina básica de projeto foi apresentada, com algumas correlações utilizadas no projeto aqui apresentado.

Ainda no domínio dos textos básicos, o trabalho de Boyce (2003) forneceu informações qualitativas muito úteis ao projeto de compressores centrífugos em linhas gerais. Boa parte da obra não aborda modelagens matemáticas complexas, dando foco, por exemplo, às tendências causadas pela modificação de parâmetros geométricos. Por ter apresentado tão claramente esse tipo de dados, esse trabalho se destaca e foi muito útil para guiar decisões.

Ao realizar o projeto, os primeiros resultados dos métodos unidimensionais forneceram definições acerca das dimensões principais do impelidor e difusor. Porém, para definir a curvatura do plano meridional, a angulação do canal e a distribuição de espessura das pás, mais informações foram requeridas. Esses aspectos estão diretamente ligados a fundamentos do funcionamento dos compressores que foram abordados principalmente por Cumpsty (2004), mas com elementos importantes também em Whitfield e Baines (1990), Xu (2007) e Xu e Amano (2012a). Uma representação de um compressor centrífugo pode ser vista na Fig. 3.

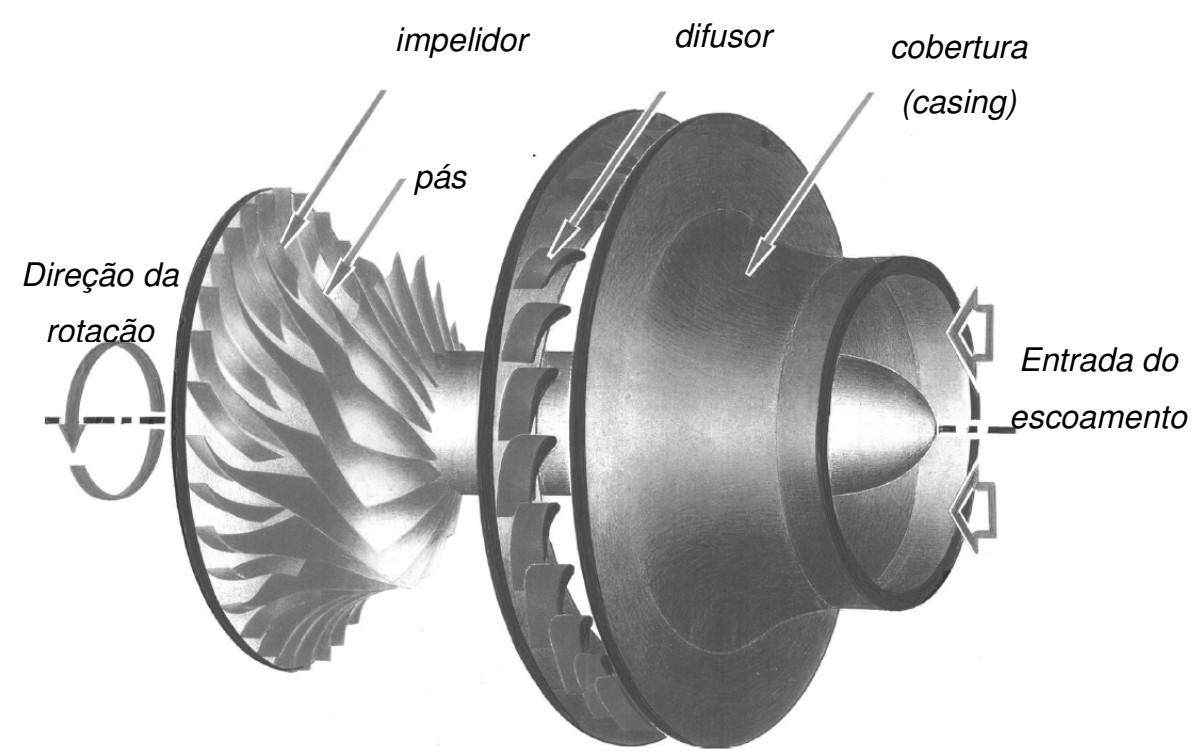

Figura 3 - Vista explodida de um compressor centrífugo. O impelidor se encaixa de modo a alinhar sua saída à entrada do difusor. Adaptado de Baskharone (2006). 
O trabalho de Cumpsty (2004) explorou a caracterização da tridimensionalidade dos escoamentos. $\mathrm{O}$ autor defendeu seus pontos de vista com base no equacionamento de dinâmica de fluidos e em estudos experimentais, tanto sobre a operação de compressores quanto com técnicas de visualização do escoamento. Não se trata de um guia de projeto, mas de apontamentos importantes sobre o comportamento físico dos escoamentos em compressores.

Cumpsty (2004) forneceu mais informações sobre os impelidores quando tratou de compressores centrífugos. Cumpsty (2004) salientou que a compreensão acerca dos fenômenos físicos em difusores é menor e que não há comparações bem embasadas quanto aos tipos de difusor ou suas variáveis de projeto. Os fundamentos sobre difusores foram descritos até certo ponto por Aungier (2000) e Dixon e Hall (2010). O trabalho de Japikse e Baines (1998) ofereceu uma visão mais clara por abordar o conceito e funcionamento de diversos tipos de difusores. Os autores abordaram o assunto com o uso abundante de dados experimentais, sempre relacionando os conceitos à operação real.

\subsection{Metodologias de PROJETO}

Este trabalho considera que projetar um compressor significa determinar uma geometria que, através de métodos confiáveis de previsão, indique ser capaz de atender aos requisitos impostos. Preocupações com processo de fabricação, escolha de materiais, esforços mecânicos ou cálculos de vibração não fazem parte do escopo. As estratégias adotadas para alcançar este objetivo têm importância fundamental. A maneira de conduzir o projeto, com suas fases e ferramentas, é de grande importância para seu sucesso (DIXON; HALL, 2010).

Came e Robinson (1999) realizaram uma revisão sobre o projeto de compressores centrífugos. Os autores apresentaram uma visão geral acerca do processo de projeto, indicando que a complexidade das ferramentas deve aumentar ao longo de seu desenvolvimento. Além disso, eles introduziram diversas correlações a serem usadas no projeto preliminar, discutidas na seção seguinte desta dissertação. 
Segundo os autores, o projeto deveria começar com 0 projeto preliminar unidimensional, havendo a previsão de desempenho e um loop para definição dos melhores valores para alguns parâmetros (diâmetros principais, comprimento axial, ângulos de entrada e saída do impelidor, por exemplo). Após esta primeira etapa, se iniciam as análises bidimensionais, nas quais será definido o formato do canal meridional do impelidor e difusor. Da mesma forma que no projeto unidimensional, é preciso haver previsão de desempenho que indique que o projeto bidimensional está pronto.

Como fase final, Came e Robinson (1999) apontaram as análises tridimensionais, compostas por análises estruturais e de CFD. Segundo eles, o projeto 3D deve determinar os últimos parâmetros restantes, como distribuição angular e de espessura das palhetas.

A visão de Casey (1994) sobre o modelo de processo mais eficaz é bastante similar à de Came e Robinson (1999), porém difere na repetição das fases. Segundo ele, se as análises tridimensionais indicarem que o desempenho não satisfaz os requisitos, pode ser necessário retornar ao desenvolvimento unidimensional. O autor deu mais ênfase à importância do projeto unidimensional, apontando que, dependendo do tipo de falha que possa ocorrer nesta fase, não há nada que se possa fazer nas seguintes para corrigir e atingir os objetivos. Por esta razão, há a possibilidade de retornar às análises mais básicas, mesmo já tendo alcançado análises tridimensionais. É esta a visão adotada no projeto descrito por esta dissertação e está sumarizada no esquema da Fig. 4.

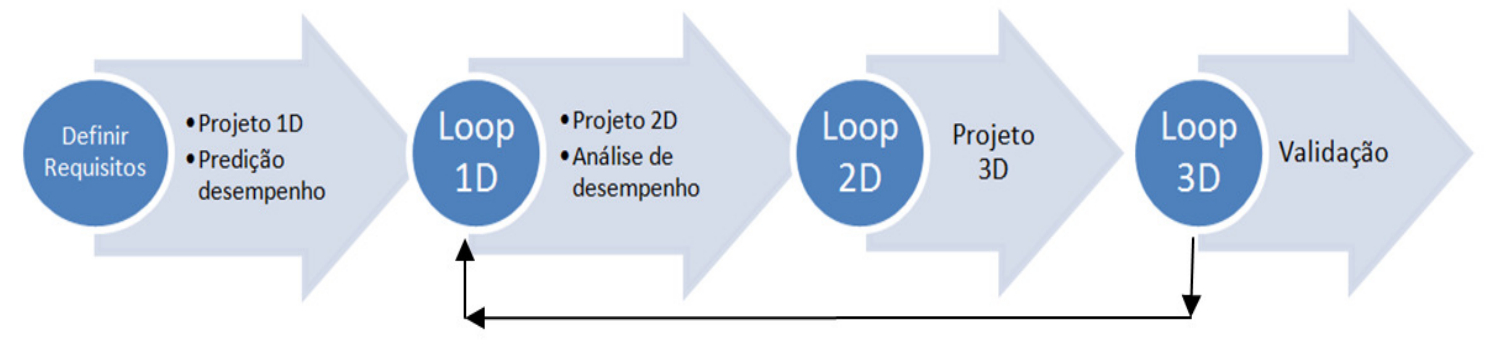

Figura 4 - Esquema da metodologia de projeto apontada por Casey (1994).

Apesar de ter definido a abordagem adotada por este projeto, é importante saber que há ainda outras possibilidades. Molinari e Dawes (2006) fizeram uma 
interessante análise sobre as atuais metodologias de projeto, além de propor um novo processo de projeto. Eles apontaram a existência de três abordagens diferentes: projeto por análise, otimização de projeto e projeto por sensibilidade (em tradução livre).

A primeira abordagem, projeto por análise, se caracteriza pela presença bem definida do projeto preliminar, sem a possível realimentação indo das fases mais avançadas às anteriores, aproximando-se mais à definição de Came e Robinson (1999). Novamente, segundo Molinari e Dawes (2006), o projeto preliminar tem grande importância, pois nele são decididas as principais características do projeto, usualmente através de correlações e cálculos envolvendo os triângulos de velocidade médios através da linha média.

O número de etapas envolvidas no projeto por análise não é fixo, uma vez que pode haver desdobramentos. Os autores apontaram que o projeto pode ser visto como um processo de duas etapas (projeto preliminar e projeto dos componentes) ou de quatro etapas. Neste último caso tem-se o projeto preliminar, o projeto throughflow, o projeto bidimensional e, por fim, o tridimensional. O projeto throughflow está bem definido nos trabalhos de Cumpsty (2004) e Denton e Dawes (1999), tratando-se da avaliação do escoamento na superfície definida entre hub e tip, entre as pás. Dessa forma, nesta fase é introduzida a dimensão radial, no caso de compressores axiais, ou, similarmente, o efeito da razão de hub-tip e do perfil meridional em compressores centrífugos.

O projeto bidimensional considera o perfil das pás, definindo sua espessura e linha de camber de modo a garantir o desempenho preconizado pelo projeto preliminar através de outros modelos de previsão de desempenho. Tipicamente, o projeto tridimensional se utiliza de dinâmica de fluidos computacional (CFD) e vem em último lugar nesta abordagem de processo de projeto. Isso se deve à premissa de que seu uso é demorado e caro, além de necessitar informações mais detalhadas vindas das fases anteriores.

Esta abordagem parece ter sido utilizada ou fazer parte de vários trabalhos. Dentre eles podem ser citados os de Carrillo (2010), Carrillo et al. (2010), Kurauchi (2012), Moura (2008), Nascimento et al. (2008), Velásquez e Nascimento (2010) e Velásquez et al. (2010). Todos esses trabalhos estão relacionados ao esforço de criar programas computacionais de projeto baseados em correlações e análise 
unidimensional, tanto de compressores quanto de turbinas radiais. O desempenho previsto das geometrias criadas por estes programas foi comparado com dados da literatura e simulações em CFD na tentativa de validá-los como ferramentas de projeto preliminar.

Cabe destacar o trabalho de Kurauchi (2012) por sua semelhança com esta dissertação. Esse trabalho visou apresentar um projeto de um compressor centrífugo a ser aplicado na compressão de gás natural. Apesar de possuir requisitos diferentes devido à aplicação em gasodutos, o processo de projeto foi muito similar ao realizado no presente trabalho. Foi seguido o processo de projeto sugerido por Came e Robinson (1999).

A segunda abordagem apontada por Molinari e Dawes (2006), otimização de projeto, tem a intenção de, idealmente, avaliar todas as soluções de projeto possíveis. Seu foco é determinar os parâmetros de desempenho e controlá-los de acordo com a variação sistemática das variáveis de projeto. Esta abordagem provê resultados ótimos, porém deve ser baseada em métodos com custo computacional adequado ao grande número de soluções analisadas, sendo esta sua principal limitação. $O$ uso de CFD, por exemplo, ainda é limitado devido ao considerável custo computacional.

A última abordagem apontada por Molinari e Dawes (2006) é a de projeto por sensibilidade. Nela, é gerada uma matriz de sensibilidade que contém os efeitos causados por mudanças na geometria. Ao inverter esta matriz tem-se, em tese, a geometria para um dado desempenho requerido. Novamente, os custos computacionais são uma limitação. Além disso, os autores destacaram as dificuldades em lidar com um único objetivo de desempenho, ao invés da necessária análise dos trade-offs.

É interessante destacar alguns dos muitos trabalhos que exploraram as duas últimas abordagens citadas por Molinari e Dawes (2006). O trabalho de Romualdo (2011) apresentou a otimização de um impelidor centrífugo através de um método de programação não linear e através de um algoritmo genético. A metodologia proposta por Whitfield e Baines (1990) foi utilizada para o projeto inicial do impelidor, a mesma utilizada no presente trabalho. Na mesma linha, os trabalhos de Ando (2010, 2011) apresentaram um programa de otimização para compressores axiais baseado em um algoritmo genético. A previsão de desempenho das geometrias analisadas foi realizada com um programa computacional desenvolvido pelos integrantes do grupo 
de pesquisa e baseado no método de streamline curvature, uma simplificação que calcula equações invíscidas.

Percebe-se que esses trabalhos não lidam diretamente com códigos de CFD em seu estado mais completo e detalhado no processo de otimização, justamente por conta dos custos computacionais e dificuldades na integração. Apesar disso, alguns esforços têm sido feitos na inclusão do CFD no processo de otimização. O trabalho de Van den Braembussche et al. (2012) descreveu um sistema de otimização que utiliza CFD em algumas iterações para avaliar se a otimização está caminhando como o modelo de previsão mais simples aponta. Esta seja talvez a tendência atual nos projetos de compressores e turbomáquinas em geral.

\subsection{CORRELAÇÕES E MÉTODOS UNIDIMENSIONAIS DE PROJETO}

De acordo com todas as abordagens para metodologia de projeto, cálculos unidimensionais são sempre necessários em algum grau no projeto preliminar. Como o escoamento em compressores tem características altamente tridimensionais, abordagens unidimensionais não são capazes de reproduzi-lo com grande exatidão. Por este motivo, os métodos unidimensionais costumam ser acompanhados por correlações com fundamentação principalmente empírica.

Estes métodos são o ponto de partida para o projeto após a definição do ciclo termodinâmico e a escolha da configuração do compressor, uma vez que fornecem os parâmetros principais da geometria sem precisarem de muitos dados como entrada. Não se tratam, porém, de métodos fechados, com algoritmos rígidos. Os métodos contam com o discernimento do projetista para assumir valores necessários ao andamento dos métodos.

Talvez a abordagem mais utilizada em turbomáquinas radiais seja a proposta por Whitfield e Baines (1990), na qual há um mecanismo para a determinação das dimensões principais do impelidor do compressor radial. A abordagem se vale de relações envolvendo termodinâmica básica e triângulos de velocidade, além do intenso uso de correlações empíricas. O método necessita que alguns parâmetros sejam arbitrados, mas provê ábacos para guiar as escolhas. A recomendação dos 
autores é tentar minimizar os números de Mach, tanto na saída quanto na entrada, relativos e absolutos. Essa abordagem foi utilizada e seu equacionamento está descrito no Cap. 6.

Aungier (2000) apresentou um trabalho com soluções similares, mas contendo diferenças, especialmente na base de dados empregada e, conseqüentemente, nas correlações empíricas. Este trabalho também abordou o projeto de difusores, algo que não foi sistematizado por Whitfield e Baines (1990). As diretrizes de Aungier (2000), assim como recomendações de Came e Robinson (1990), foram utilizadas em lacunas deixadas por Whitfield e Baines (1990).

Uma das referências mais relevantes para o projeto do difusor é o trabalho de Cumpsty (2004). O autor descreveu com detalhes boa parte do que se sabe sobre difusores para compressores centrífugos. Velásquez et al. (2010) afirmam ter utilizado diretrizes fornecidas por Japikse e Baines (1998), apesar de esses autores não terem recomendado uma abordagem sistemática de projeto. Aungier (2000) apresentou correlações muito úteis ao projeto de difusores.

Em alguns pontos do desenvolvimento foram incluídas abordagens propostas por outros esquemas de projeto, mas sem aplicá-los por completo. As principais contribuições vieram dos trabalhos de Al-Zubaidy (1995), Dufour (2006) e Swain (1992).

Além dessas referências, muitas correlações e deduções vindas de diversos trabalhos foram utilizadas. Came e Robinson (1999), Rodgers (2000), Swain (1992) e Xu e Amano (2012a) indicaram maneiras para determinar o número inicial de pás para o impelidor, sendo interessante notar a discrepância entre seus resultados. Os ângulos de entrada e saída do impelidor, assim como os números de Mach, foram analisados por Casey (1994), Dalbert et al. (1999) e Rusch e Casey (2012), fornecendo diretrizes para sua escolha. Dessa forma, a junção dessas referências resultou em algumas geometrias a serem avaliadas com o uso de CFD.

A previsão do desempenho baseando-se em grandezas unidimensionais é importante para avaliar os projetos unidimensionais. Tal previsão é usualmente feita com correlações que estimam diversos tipos de perdas. Whitfield e Baines (1990) apresentaram alguns modelos de perdas, assim como Aungier (2000). Porém, o trabalho de Oh; Yoon e Chung (1997) foi utilizado na presente dissertação por ter 
avaliado diversos modelos e tê-los confrontado com resultados experimentais. Os autores chegaram a um conjunto de perdas recomendadas para impelidores centrífugos. Romualdo (2011) fez uso desses modelos em um processo de otimização de geometria.

\subsection{DINÂMICA DE FLUÍDOS COMPUTACIONAL}

Assim como ficou evidente na revisão feita na seção 2.4 sobre metodologias de projeto, não há consenso sobre quanto do projeto deve ser realizado com o uso de CFD e nem em que momento do projeto é mais vantajoso aplicá-la. $O$ desenvolvimento da dinâmica de fluidos computacional ao longo do tempo tem mudado os parâmetros dessa discussão, enquanto novos modelos tornam-se mais precisos e o tempo computacional diminui com máquinas mais velozes. De qualquer forma, é inegável que o uso da dinâmica de fluidos computacional é praticamente mandatório no projeto de turbomáquinas há um tempo considerável (DENTON; DAWES, 1999).

A compreensão acerca do funcionamento básico dos códigos de CFD é importante para seu correto uso e interpretação de resultados. O trabalho de Tomita (2009) auxilia bastante nesse sentido. Nele foi reportado o desenvolvimento de um código de CFD com o objetivo principal de ser aplicado na análise de turbomáquinas. Obviamente, as soluções não são idênticas às empregadas no código comercial utilizado nesta dissertação, mas há muitas similaridades. O código foi baseado no método dos volumes finitos e o trabalho aborda diferentes esquemas de integração espacial e temporal. O modelo de turbulência de uma equação Spalart-Allmaras foi implementado. O código foi, por fim, validado com casos conhecidos da literatura.

Mais simples e sucinto, o trabalho de Souza (2011) forneceu conceitos básicos de dinâmica de fluidos computacional para o uso em turbomáquinas. Além da revisão com o equacionamento básico, foi apresentado um proveitoso tutorial com recomendações sobre a simulação de turbomáquinas empregando o código Ansys CFX, utilizado nesta dissertação. 
A aplicação de CFD às turbomáquinas tem algumas particularidades, especialmente as vinculadas ao movimento rotativo, causando a interação entre domínios estacionários e rotativos. As diferentes abordagens para simular essas interações estão bem sumarizadas no trabalho de Aghaei tog; Tousi e Soltani (2007). Usualmente, a maior parte das simulações realizadas utiliza uma abordagem de regime permanente. Isso representa uma simplificação, uma vez que a interação entre as partes móveis e fixas de uma turbomáquina causa fenômenos tipicamente transientes (DIXON; HALL, 2010). Há duas principais abordagens para regime permanente na simulação de turbomáquinas: mixing planes (ou stage) e frozen rotor ("plano de mistura" e "rotor estático", em tradução livre).

Na primeira, mixing planes, as partes estacionária e móvel têm malhas separadas e o problema é resolvido exatamente como regime permanente usual para cada uma das partes. Na interface entre as malhas, a transmissão de informações é feita através de médias espaciais que entram como condições de contorno na malha a jusante. Esta foi a abordagem usada por Tomita (2009).

A abordagem frozen rotor, simula o movimento rotativo entre as partes através de transformações de coordenadas, mas mantendo a posição das malhas fixa. Esta estratégia é capaz de reproduzir algumas características transientes, uma vez que há transmissão de fenômenos, como ondas de choque, através da interface. Porém, não há variação do posicionamento das estruturas criadas por estes fenômenos, uma vez que as simulações são em regime permanente. Dessa forma, os resultados em termos de previsão de desempenho costumam ser piores que com o uso de mixing planes, pois as médias utilizadas nesta abordagem simulam melhor as variáveis de desempenho que têm características integrais. Contudo, o frozen rotor é mais útil à análise do escoamento, por não suprimir fenômenos locais (SILVA; MOURA; SU, 2010).

De acordo com Denton (2010), essas simplificações representam uma das limitações impostas à capacidade de predição dos códigos de CFD. Denton (2010) tratou de diversas dificuldades que limitam os resultados do CFD em turbomáquinas. Ele destacou alguns aspectos que ainda precisam de melhor desenvolvimento, como modelagem de transição à turbulência, simulação na região de tip clearance ou a dificuldade em estabelecer algumas condições de contorno, como a intensidade de turbulência à entrada. 
Mais importante ao escopo desta dissertação, outra grande fonte de incertezas é a modelagem de turbulência. Muitos trabalhos se dedicaram a estudar diferentes modelos de turbulência e tentaram validá-los para uma dada aplicação.

O trabalho de Moura (2008) se propunha a estudar um impelidor centrífugo e foram realizados testes com diversos modelos de turbulência numa geometria cujo desempenho foi divulgado na literatura. Foi utilizado o mesmo Ansys CFX empregado no presente trabalho, no qual foram testados os modelos $k-\varepsilon$, RNG $k-\varepsilon$, $k-\omega$ SST e SSG. O trabalho concluiu que o modelo RNG $k-\varepsilon$ foi o que melhor previu o desempenho do impelidor com dados experimentais.

Similarmente, Simões (2009) realizou testes de modelos de turbulência para o caso do Rotor 37, geometria de compressor axial projetada e testada pela NASA. Neste caso foram testados os modelos de turbulência $k-\varepsilon$ padrão, $k-\omega$ e $k-\omega$ SST. A conclusão do trabalho foi que o modelo $k-\omega$ SST foi superior em sua capacidade de predição se comparado aos outros dois.

A NASA usualmente divulga experimentos destinados à posterior validação de códigos computacionais. O conjunto de trabalhos que mais se aproxima da aplicação desenvolvida nesta dissertação trata de um compressor centrífugo projetado para ter razão de pressões de 4:1. O trabalho de McKain e Holbrook (1982) reportou as coordenadas da geometria desenvolvida. Posteriormente, o trabalho de Skoch et al. (1997) apresentou dados experimentais sobre o escoamento nesse impelidor com medições via anemometria a laser. Outro trabalho, ainda vinculado à NASA e realizado por Larosiliere; Skoch e Prahst (1997), apresentou os resultados de simulações em CFD comparadas aos experimentos utilizando a mesma geometria. O modelo de turbulência utilizado pelos autores foi o modelo de comprimento de mistura de Baldwin-Lomax, que, surpreendentemente, alcançou resultados considerados bons pelos autores. A grande maioria dos trabalhos aconselha o uso de modelos de duas equações (AGARD, 1998; DENTON, 2010; DENTON; DAWES, 1999; SOUZA, 2011).

O relatório realizado por AGARD (1998), órgão de pesquisa ligado à OTAN, tratou da validação de CFD para componentes de turbomáquinas. No que tange aos modelos de turbulência, a conclusão do trabalho reportou melhores resultados de modelos de duas equações se comparados aos modelos de comprimento de mistura, como é esperado. A comparação entre os resultados dos modelos de duas 
equações mostrou uma pequena vantagem do modelo $k-\varepsilon$ e algumas de suas variações.

Percebe-se então que não há um consenso sobre o melhor modelo de turbulência a ser empregado para a simulação de compressores. Os tipos de compressores e suas condições operacionais variam muito, de maneira que não há domínio de nenhum modelo. Dessa forma, os trabalhos que reportaram aplicações similares à dessa dissertação foram base para as decisões tomadas, destacando-se os trabalhos supramencionados de Moura (2008), Souza (2011) e os vinculados à NASA. 


\section{CICLO TERMODINÂMICO}

Antes de partir ao projeto de componentes de uma turbina a gás é necessário impor os requisitos a serem atendidos pelo sistema. No caso, a única imposição inicial é a potência de $500 \mathrm{~kW}$. Os cálculos mais simples e que exigem menos informações são os vinculados ao ciclo Brayton. Este ciclo é uma idealização do funcionamento de turbinas a gás na qual os processos envolvidos são aproximados.

O ciclo Brayton padrão é composto por quatro etapas. A primeira corresponde ao trabalho feito pelo compressor no fluido e é representada por uma compressão isentrópica. A combustão é representada por um processo de adição de calor isobárico. A passagem pela seção de turbinas é modelada justamente como o oposto da passagem pelo compressor, sendo uma expansão isentrópica. Por fim, o escape e retorno às condições de entrada são representados por um processo isobárico com rejeição de calor.

Essas simplificações possibilitam relações entre as variáveis de estado entre os quatro pontos (MORAN; SHAPIRO, 2009). Partindo da primeira e segunda leis da termodinâmica, é possível estabelecer essas relações. Utilizando o balanço de energia para uma substância pura, compressível e simples submetida a um processo internamente reversível é possível escrever a Eq. 3, assim como mostraram Moran e Shapiro (2009). Com a definição da entalpia aliada à Eq. 3, chega-se à Eq. 4. Ambas estão aqui expressas na base mássica.

$$
T d s=d u+P d v
$$

$$
T d s=d h-v d P
$$

Mesmo tendo sido derivadas a partir da hipótese de processo internamente reversível, variações de entropia advindas da integração dessas equações valem para qualquer processo, uma vez que a entropia é uma propriedade e não depende do caminho do processo (MORAN; SHAPIRO, 2009). Ao considerar a aplicação dessas equações a um gás ideal, assim como assume o ciclo Brayton, as relações apresentadas pelas Eqs. de 5 a 7 são aplicáveis e podem ser incorporadas às Eqs. 
3 e 4 . Ao integrar essas equações, considerando ainda que os calores específicos são constantes, têm-se as Eqs. 8 e 9

$$
\begin{aligned}
& d u=c_{v}(T) d T \\
& d h=c_{p}(T) d T \\
& P v=R T \\
& s\left(T_{2}, v_{2}\right)-s\left(T_{1}, v_{1}\right)=c_{v} \ln \frac{T_{1}}{T_{2}}+R \ln \frac{v_{1}}{v_{2}} \\
& s\left(T_{2}, P_{2}\right)-s\left(T_{1}, P_{1}\right)=c_{p} \ln \frac{T_{1}}{T_{2}}+R \ln \frac{P_{1}}{P_{2}}
\end{aligned}
$$

Ao considerar processos isentrópicos, como a compressão e a expansão do ciclo Brayton, e a formulação dos calores específicos constantes para gases ideais a partir da razão entre eles $(\gamma)$, obtêm-se as relações entre as variáveis apresentadas pelas Eqs. 10 e 11. Estas relações também valem para a condição de estagnação.

$$
\begin{aligned}
& \frac{T_{2}}{T_{1}}=\left(\frac{P_{2}}{P_{1}}\right)^{(\gamma-1) / \gamma} \\
& \frac{T_{2}}{T_{1}}=\left(\frac{v_{1}}{v_{2}}\right)^{\gamma-1}
\end{aligned}
$$

Para a análise do trabalho realizado, calor trocado e conseqüente inferência sobre o fluxo mássico necessário, basta realizar um balanço energético por unidade de massa. Este balanço energético por unidade de massa em regime permanente é apresentado na Eq. 12.

$$
\frac{\dot{W}}{\dot{m}}=\frac{\dot{Q}}{\dot{m}}+\left(h_{1}-h_{2}\right)+\left(\frac{C_{1}^{2}-C_{2}^{2}}{2}\right)+g\left(z_{1}-z_{2}\right)
$$


Pode-se não considerar a energia cinética ou potencial, simplificando a Eq. 12. Como compressão e expansão são consideradas adiabáticas, enquanto combustão e exaustão são consideradas trocas de calor isobáricas, as Eqs. 13 e 14 representam o primeiro e segundo casos, respectivamente.

$$
\begin{aligned}
& \frac{\dot{W}}{\dot{m}}=h_{1}-h_{2} \\
& \frac{\dot{Q}}{\dot{m}}=h_{1}-h_{2}
\end{aligned}
$$

Por se tratar de um gás ideal e ter-se $c_{p}$ constante, a variação de entalpia pode ser escrita em função das temperaturas. Dessa forma, as Eqs. 13 e 14 podem ser reescritas na forma das Eqs. 15 e 16.

$$
\begin{aligned}
& \frac{\dot{W}}{\dot{m}}=c_{p}\left(T_{1}-T_{2}\right) \\
& \frac{\dot{Q}}{\dot{m}}=c_{p}\left(T_{1}-T_{2}\right)
\end{aligned}
$$

Com esse equacionamento básico é possível proceder aos cálculos. Torna-se necessário fixar valores para a temperatura na entrada na turbina $T_{03}$ e para a razão entre as pressões de saída e entrada do compressor a fim de chegar à estimativa da vazão mássica. A temperatura de entrada na turbina foi estimada através de informações do trabalho de Han; Dutta e Ekkad (2000). A temperatura para uma turbina sem sistema de resfriamento tem um valor de aproximadamente $1150 \mathrm{~K}$. Considerou-se a ausência de sistema de resfriamento por conservadorismo e para não comprometer o futuro projeto a ser realizado no LETE.

Conduziu-se uma pesquisa paramétrica para fundamentar a escolha da razão de pressões usando dados de turbinas a gás comerciais disponibilizados por Brezonick (2003) e Giampaolo (2009). Os dados que constam nessas referências são potência, razão de pressões, fluxo mássico e temperatura de exaustão. A pesquisa foi limitada a uma potência de $5000 \mathrm{~kW}$. O limite não ficou mais próximo aos 500 kW 
pretendidos para que se pudesse ter uma melhor visualização quanto à tendência dos dados.

Os dados de razão de pressões em função da potência estão dispostos no gráfico da Fig. 5. Tomando-os como base, escolheu-se uma razão de pressões de 4. Apesar de haver valores mais altos na região de $500 \mathrm{~kW}$ de potência, sabe-se que razões de pressões mais altas tendem a tornar o projeto mais difícil (BOYCE, 2003). A intenção foi impor um requisito relativamente confortável, uma vez que não há experiência prévia no LETE neste tipo de projeto.

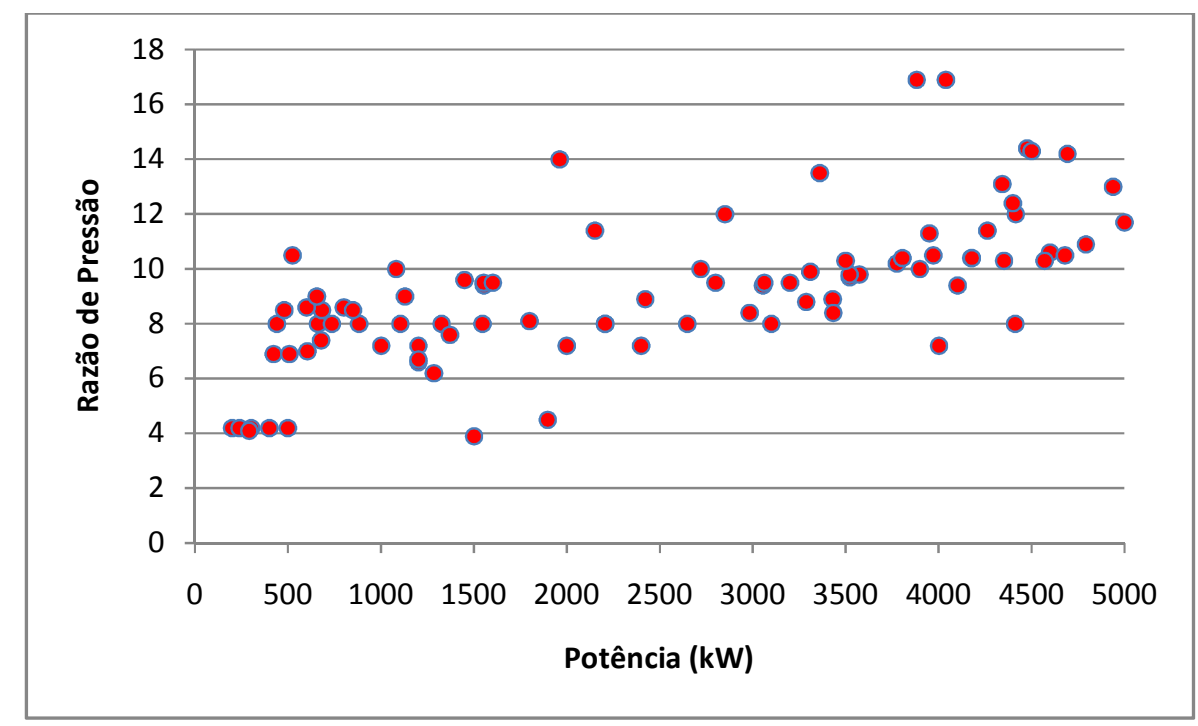

Figura 5 - Dados da pesquisa paramétrica dispostos num gráfico da razão de pressões pela potência.

A partir desses valores e das Eqs. de 8 a 14, é necessário impor o desenho do ciclo. A configuração mais simples seria ter num mesmo eixo compressor, turbina e gerador elétrico, de modo que um único rotor de expansão gerasse trabalho para alimentar o compressor e o gerador elétrico. Esta configuração foi descartada como resultado de experiências anteriores realizadas no LETE (SOUZA, 2008). Os sistemas de geração elétrica costumam ter limitações de rotação que estabeleceriam uma rotação máxima ao compressor ou o uso de complexos sistemas de redução.

Para deixar o projeto mais livre e priorizar o projeto dos componentes, optou-se pela configuração com turbina de potência. Essa configuração está esquematizada na Fig. 6. Com ela, há duas seções de turbinas com eixos independentes, a primeira 
para fornecer trabalho ao compressor e a segunda, ligada ao gerador (carga), deve gerar os $500 \mathrm{~kW}$ pretendidos.

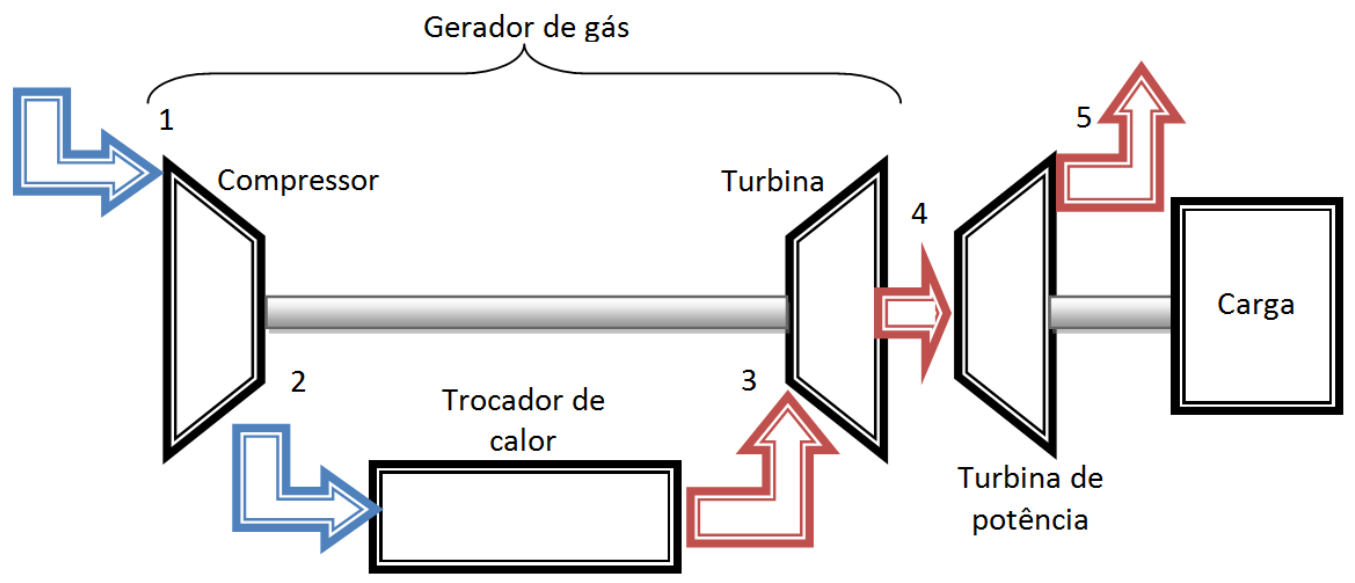

Figura 6 - Esquema do ciclo adotado, com uma turbina de potência.

Tendo definidos os valores pendentes e o desenho do ciclo, calculou-se a vazão mássica necessária de acordo com o ciclo Brayton. O valor encontrado foi de 2,38 $\mathrm{kg} / \mathrm{s}$. Este valor foi comparado com os dados da pesquisa paramétrica. A comparação com a vazão mássica mostrou que o valor está abaixo do empregado por modelos comerciais da mesma faixa de potência (aproximadamente $2 \mathrm{~kg} / \mathrm{s}$ abaixo, em média), assim como mostra a Fig. 7. Isso era esperado, uma vez que se trata de um dado obtido com uso de um ciclo ideal.

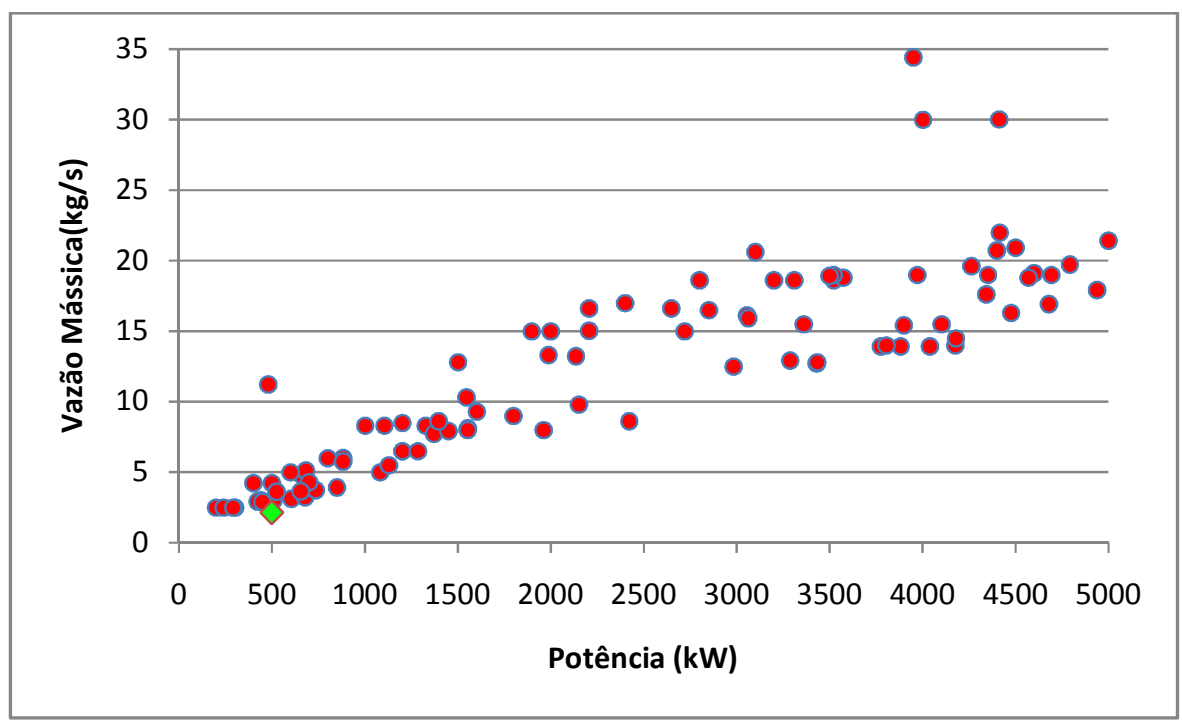

Figura 7 - Gráfico da vazão mássica $(\mathrm{kg} / \mathrm{s})$ em função da potência para os dados coletados na pesquisa paramétrica. $\mathrm{O}$ valor obtido com os cálculos do ciclo Brayton está mostrado em verde. 
Com isso, ficou clara a necessidade de incluir perdas no ciclo ideal. Para ter uma melhor estimativa da vazão, perdas indicadas no trabalho de Saravanamuttoo; Rogers e Cohen (2001) foram adicionadas ao cálculo. Esta abordagem é bastante simples e aproximada. Há muitos modelos mais precisos, mas que necessitam de dados sobre os componentes do sistema, ainda não disponíveis nessa etapa.

Foram incluídas no cálculo as eficiências isentrópicas do compressor e turbinas (definidas no Cap. 5 desta dissertação), eficiência mecânica dos eixos e perdas de pressão na câmara de combustão e na exaustão. A definição dos valores para estas variáveis foi feita com base nas recomendações de Saravanamuttoo; Rogers e Cohen (2001). As eficiências isentrópicas total-total do compressor $\eta_{c}$ e turbinas $\eta_{t}$ foram assumidas como 85\% e 80\%, respectivamente. Essa eficiência está definida na seção 5.3 do presente trabalho. A eficiência mecânica $\eta_{m}$ adotada foi de $99 \%$, enquanto a perda de pressão na câmara $L_{c}$ foi de $6 \%$ e a perda de pressão no escape $L_{e}$ foi de 0,03 bar.

As Eqs. de 17 a 25 mostram a seqüência utilizada para chegar à nova estimativa da vazão mássica e como as equações anteriores foram modificadas introduzindo as eficiências e perdas. Os índices numéricos subscritos se referem às posições mostradas na Fig. 6.

$$
\begin{aligned}
& T_{02}=\frac{T_{01}}{\eta_{c}}\left[P_{R}^{(\gamma-1) / \gamma}-1\right]+T_{01} \\
& W_{c}=\frac{c_{P}\left(T_{02}-T_{01}\right)}{\eta_{m}} \\
& T_{04}=T_{03}-\frac{W_{c}}{c_{P}^{b}} \\
& T_{03}-T_{04}=\eta_{t} T_{03}\left[1-\left(\frac{1}{P_{03} / P_{04}}\right)^{\left(\gamma_{b}-1\right) / \gamma_{b}}\right] \\
& P_{04}=P_{R}\left(P_{01}-L_{c} \cdot P_{01}\right) \frac{P_{04}}{P_{03}}
\end{aligned}
$$




$$
\begin{aligned}
& P_{05}=P_{01}+L_{e} \\
& T_{05}=T_{04}-\eta_{t} T_{04}\left[1-\left(\frac{1}{P_{04} / P_{05}}\right)^{\left(\gamma_{b}-1\right) / \gamma_{b}}\right] \\
& W_{t p}=c_{P}^{b}\left(T_{04}-T_{05}\right) \eta_{m} \\
& \dot{m}=\frac{500 \mathrm{~kW}}{W_{t p}}
\end{aligned}
$$

A partir da temperatura de entrada do compressor, da razão de pressões e da eficiência isentrópica do compressor foi possível calcular a temperatura de saída do compressor. Com este dado aliado à eficiência mecânica calculou-se o trabalho requerido no compressor, que seria o mesmo da turbina responsável por fornecerIhe tal trabalho não fosse a consideração da eficiência mecânica.

Determinando o trabalho da primeira turbina, calcula-se a temperatura de entrada na turbina de potência. Ao calcular a temperatura de saída dessa turbina, se pode, finalmente, impor a potência requerida e encontrar o fluxo mássico necessário.

O valor encontrado foi de $4,13 \mathrm{~kg} / \mathrm{s}$, mais condizente com os valores da pesquisa paramétrica. Tendo então a estimativa para a vazão mássica e fixado o requisito de razão de pressões foi possível proceder ao projeto do compressor, objetivo final desta dissertação. 


\section{ESCOLHA DO TIPO DE COMPRESSOR}

A escolha do tipo de compressor é o primeiro passo a ser tomado no projeto (CUMPSTY, 2004). Autores como Cumpsty (2004) e Whitfield e Baines (1990) afirmaram que esta escolha depende em grande parte da experiência dos projetistas e do fabricante com um dado tipo, além da base de dados vinda de projetos anteriores. Como no presente trabalho essas circunstâncias não se aplicam, uma vez que não há extensa experiência ou qualquer base de dados, buscaram-se métodos para realizar a escolha.

O projeto e a análise de compressores usualmente lidam com diversas grandezas adimensionais, úteis para comparação de desempenho entre diferentes projetos. O uso de adimensionais se encaixa no contexto do princípio da similaridade. A interessante revisão sobre esse princípio realizada por Dufour (2006) mostra suas origens, além de explicar o uso das grandezas adimensionais. Dufour (2006) apresenta no âmbito das turbomáquinas o enunciado do teorema dos $\pi$ 's de Buckingham (BUCKINGHAM, 1914). Tal enunciado pode ser simplificado da seguinte maneira: um fenômeno físico descrito por $n$ grandezas físicas expressas por $p$ unidades fundamentais pode ter uma solução adimensional em função de $n-p$ funções adimensionais das $n$ grandezas físicas.

Considerando o tipo de fluxo das turbomáquinas (axial, radial ou misto) como um parâmetro também regido por adimensionais, Cordier (1955) analisou a relação entre algumas grandezas e o tipo de fluxo e encontrou uma relação com velocidade e diâmetro específicos. Balje (1981) aplicou o princípio da similaridade às turbomáquinas de maneira mais detalhada, definindo um conjunto de adimensionais capazes de, segundo ele, sumarizar os fenômenos e definir o desempenho de uma turbomáquina em uma dada operação. Dessa forma, o princípio da similaridade mostra que turbomáquinas com geometria e condições de operação análogas têm desempenhos equivalentes (BALJE, 1981; LOGAN JR., 1993).

Assim como salientado na revisão bibliográfica do Cap. 2, duas grandezas adimensionais regem o tipo de fluxo. Casey; Zwyssig e Robinson (2010) mostraram que podem ser utilizadas quaisquer duas variáveis entre velocidade específica, diâmetro específico, coeficiente de vazão e coeficiente de carga. Porém, a linha de 
Cordier é definida por um gráfico do diâmetro pela velocidade específica que acomoda dados de projetos considerados estado da arte. A Fig. 1 mostra um exemplo do diagrama de Cordier. O diâmetro específico está definido pela Eq. 1, enquanto a velocidade específica pela Eq. 2, na forma apresentada por Balje (1981). Nessas equações, $H$ representa a carga (head), que representa o trabalho necessário ao compressor, sendo expressa em unidade de comprimento por sua origem no projeto de bombas hidráulicas no qual o trabalho é representado pela diferença de altura da coluna de líquido entre entrada e saída da bomba (AUNGIER, 2000). O conceito de carga vem de simplificações na Eq. 12, que representa a primeira lei da termodinâmica. Ao considerar o sistema adiabático e isotérmico e desprezando a energia cinética, pode rearranjar a Eq. 12 como abaixo:

$$
-\frac{\dot{W}}{g \dot{m}}=\left(z_{2}-z_{1}\right)
$$

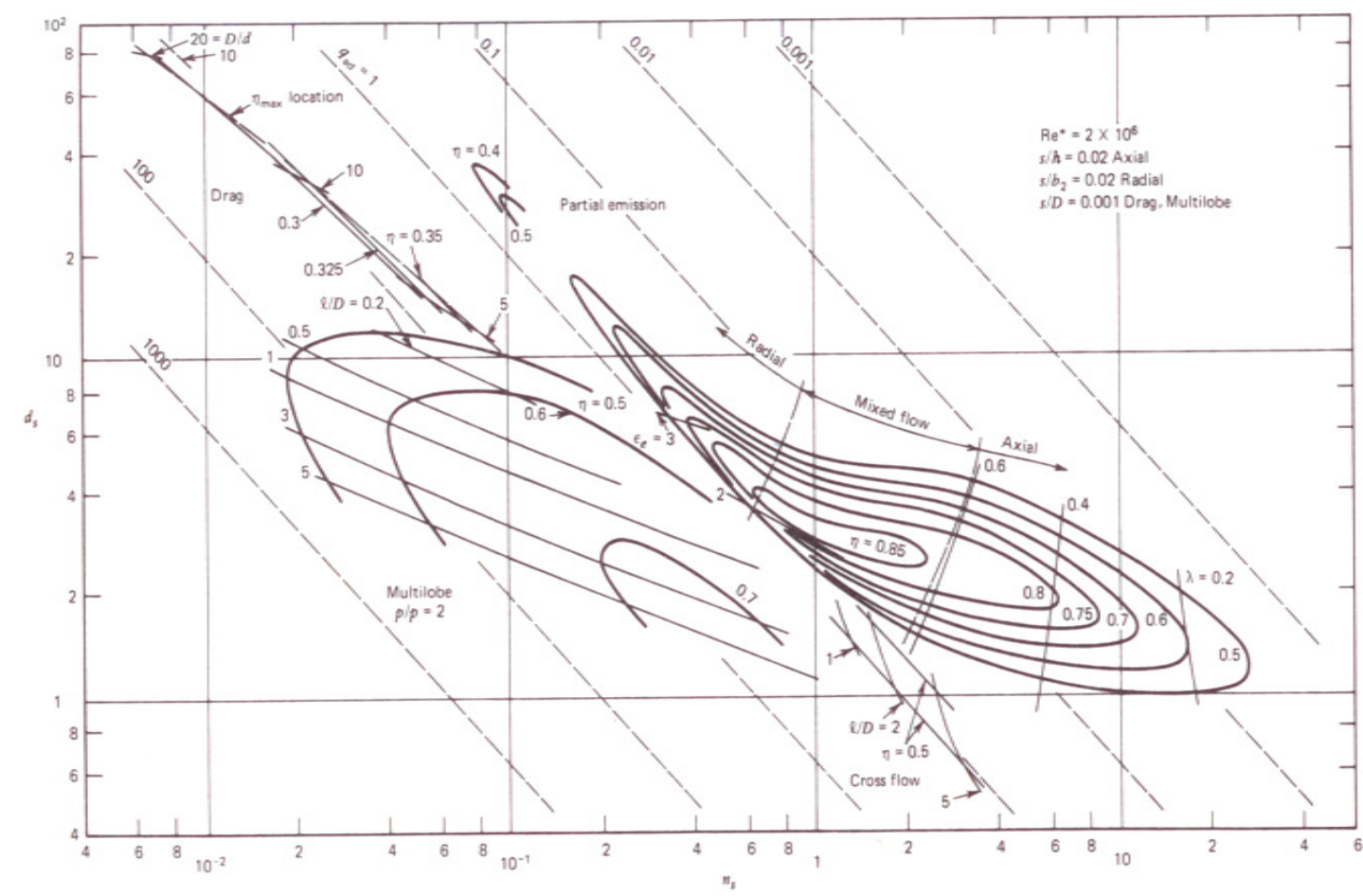

Figura 8 - Gráfico do diâmetro específico pela velocidade específica com curvas de nível de eficiência e indicação sobre os tipos de fluxo dos compressores. Extraído de Balje (1981).

A diferença de altura $\left(z_{2}-z_{1}\right)$ é a carga. Portanto, tem-se uma representação proporcional ao trabalho (ou potência) em unidade de comprimento. 
Os cálculos mostrados no capítulo anterior são capazes de fornecer a vazão volumétrica e a carga, restando apenas a rotação e o diâmetro para ter a velocidade e o diâmetro específicos. A velocidade de rotação foi imposta com base na experiência com a micro turbina a gás construída no LETE. Velocidades muito altas de rotação geram dificuldades no projeto dos eixos, e, apesar disso não ser uma preocupação direta desta dissertação, decidiu-se por uma rotação inicial moderada.

Optou-se por uma rotação inicial de 15000 rpm, sendo que esta rotação não foi mantida até o final do projeto. Como está mostrado no Cap. 6, recalculou-se a velocidade específica no projeto unidimensional, reiterando esse valor.

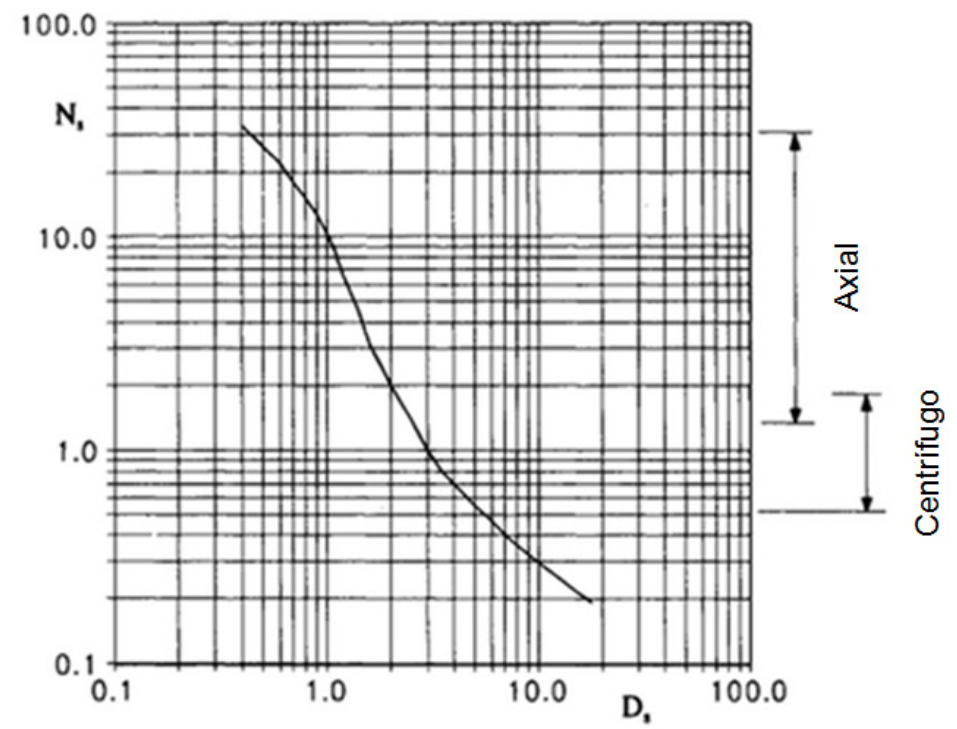

Figura 9 - Diagrama de Cordier com indicação das regiões adequadas a cada tipo de compressor. Adaptado de Dixon e Hall (2010).

A rotação escolhida forneceu uma velocidade específica de 0,65. Este valor tem maior eficiência em compressores radiais, de acordo com o gráfico da Fig. 8 extraído de Balje (1981). Esse gráfico apresenta curvas de nível com as eficiências possíveis. O mesmo tipo de compressor é apontado pelo gráfico da Fig. 9, que consta no trabalho de Dixon e Hall (2010) e é baseada no trabalho de Csanady (1964), um dos pioneiros neste tipo de estudo, ao lado de Balje (1981).

$$
D_{s}=\frac{D(g H)^{1 / 4}}{\sqrt{Q}}
$$




$$
N_{s}=\frac{N \sqrt{Q}}{(g H)^{3 / 4}}
$$

Dessa forma, determinou-se o uso de um compressor radial para a turbina a gás a ser projetada. O diagrama de Cordier é ainda útil para estimar o diâmetro do impelidor. Porém, para isso foi utilizada a equação desenvolvida por Casey; Zwyssig e Robinson (2010). A equação se baseia no coeficiente de carga e está apresentada aqui pela Eq. 26. Ela se relaciona com diâmetro e velocidade específicas através da relação da Eq. 27.

Como é possível perceber, são definidas três equações devido à variação dos parâmetros $\Psi_{\text {low }}, \Psi_{\text {med }}$ e $\Psi_{\text {high }}$. Os autores defendem que a linha de Cordier seria na verdade uma faixa de valores, e essas equações definem esta faixa, assim como mostrado na Fig. 8.

$$
\begin{aligned}
& \Psi_{\mathrm{s}}=\Psi_{\text {med }}(1-A)+\Psi_{\text {high }} A+\left(\Psi_{\text {med }}-\Psi_{\text {low }}\right) B \\
& D_{s} N_{s}=\frac{2}{\sqrt{\Psi_{\mathrm{s}}}}
\end{aligned}
$$

Na Eq. 26 os coeficientes são dados pelas seguintes relações:

$$
\begin{aligned}
& A=\frac{1}{1+e^{-t_{1}}} ; t_{1}=k_{1}\left(k_{2}+\log _{10} N_{s}\right) \\
& B=e^{-t_{2}} ; t_{2}=k_{3}\left(k_{4}+\log _{10} N_{s}\right) \\
& \Psi_{\text {low }}=0,45 \pm 0,1 \\
& \Psi_{\text {med }}=0,55 \pm 0,15 \\
& \Psi_{\text {high }}=0,02 ; 0,01 ; 0,005 \\
& k_{1}=4 ; k_{2}=-0,3 ; k_{3}=5 ; k_{4}=1
\end{aligned}
$$


Casey; Zwyssig e Robinson (2010) dizem que sua equação é apropriada para estimar o diâmetro de máquinas radiais ou mistas, uma vez que a faixa de valores é mais estreita que para o caso das máquinas axiais, presentes na porção à direita do gráfico da Fig. 10. Dessa forma, a estimativa inicial do diâmetro ficou em 420 mm. Este valor foi utilizado para balizar os resultados do projeto unidimensional.

O equacionamento proposto por Casey; Zwyssig e Robinson (2010) tem rigor conceitual além do caráter empírico da linha de Cordier. Os autores explicaram os motivos para o formato característico do diagrama recorrendo à física do escoamento nos compressores.

Fixando uma velocidade específica, o diâmetro específico torna-se função do coeficiente de carga, assim como evidencia a Eq. 27. Lembrando que o coeficiente de carga representa o aumento de pressão no compressor, para um valor baixo de tal coeficiente, é normal ter baixa eficiência. Isso ocorre porque pouco trabalho é realizado no escoamento e as perdas por atrito estão presentes, por serem inevitáveis, havendo uma razão entre perdas e trabalho alta.

Ao aumentar gradualmente o coeficiente de carga, as perdas por atrito mantêm-se quase inalteradas. Contudo, com mais trabalho realizado sobre o fluido e maior deflexão do escoamento, a eficiência vai aumentando. Essa tendência é mantida até que o aumento de coeficiente de carga cause o aumento da carga aerodinâmica e, conseqüentemente, taxas maiores de crescimento das perdas.

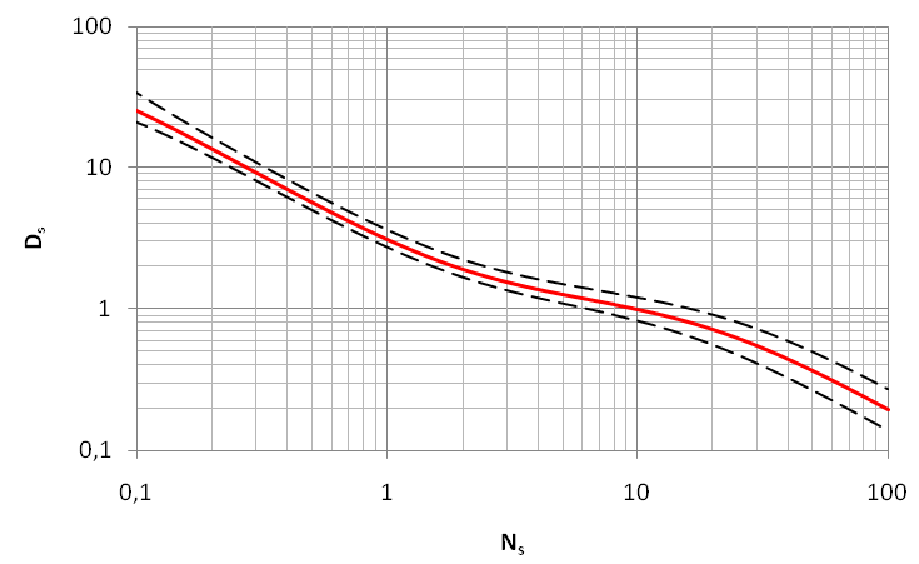

Figura 10 - Linha de Cordier definida pela equação de Casey; Zwyssig e Robinson (2010). A linha contínua é a principal, enquanto as tracejadas definem a faixa de valores que apontam as turbomáquinas mais eficientes. 
Casey; Zwyssig e Robinson (2010) explicaram que, para uma certa faixa de coeficiente de carga (e, conseqüentemente, diâmetro específico), ao aumentar o coeficiente de carga, as perdas vindas da separação do escoamento não têm aumento significativo e o trabalho aplicado ao fluido cresce a uma taxa maior. Isso faz com que seja alcançada a máxima eficiência para a velocidade específica fixada. Ao sair dessa faixa, os aumentos do coeficiente de carga causam acréscimo muito grande nas perdas por conta de separação do escoamento, conseqüência das grandes cargas aerodinâmicas, resultantes do gradiente de pressão nas pás.

Tendo em mente os fenômenos que causam a existência da linha de Cordier a uma velocidade específica constante, é possível passar à compreensão do formato do diagrama. Como se pode perceber, a carga aerodinâmica é fator fundamental à eficiência dos compressores, assim como salienta Casey (1994). Sendo muito pequena, o compressor não realiza trabalho suficiente ao fluido e, sendo muito grande, a carga aerodinâmica gera separação do escoamento e perdas elevadas.

É justamente o efeito das forças centrífugas na carga das pás o responsável pelo formato em "s" da linha de Cordier, que, por sua vez, mostra seus efeitos diretamente sobre o coeficiente de carga. Casey; Zwyssig e Robinson (2010) mostraram no próprio diagrama de Cordier que as máquinas radiais ficam postadas numa linha com coeficiente de carga quase constante. Isso acontece porque, na região de velocidade específica entre 0,5 e 1, coeficientes de carga muito altos conseguidos com impelidores sem backsweep geram muitas perdas e margem operacional estreita devidas às características centrífugas do escoamento. Para melhorar estes aspectos, emprega-se o backsweep (assim como explicado na seção 5.7) que acaba por nivelar o coeficiente de carga para máxima eficiência.

O mesmo acontece para as máquinas axiais, porém com um valor muito mais baixo de coeficiente de carga. Máquinas axiais pouco elevam a pressão por estágio, sendo que o carga é quase nulo no caso de algumas hélices e ventiladores que têm a função de gerar certa vazão no escoamento (CASEY; ZWYSSIG; ROBINSON, 2010).

Dessa forma, as duas extremidades com inflexões similares da linha de Cordier são formadas justamente por estes dois casos com coeficiente de carga quase constante. Na zona intermediária, situam-se principalmente máquinas de fluxo misto, nas quais o efeito centrífugo sobre a carga varia de acordo com o projeto. Dessa 
forma, o coeficiente de carga varia gradualmente, alterando a inflexão da curva loglog no centro do diagrama.

Portanto, a linha de Cordier tem fundamentos físicos e não puramente estatísticos. É importante ter essa noção para utilizá-la corretamente e saber explicar possíveis desvios no projeto, que podem acontecer devido a vários tipos de restrições. 


\section{FUNDAMENTOS DE COMPRESSORES CENTRÍFUGOS}

A escolha pelo projeto de um compressor centrífugo fez com que fosse necessário compreender os princípios e as particularidades do funcionamento desse tipo de compressor. Eles recebem este nome (podendo ser chamados também de radiais) por conta da direção tomada pelo fluido ao passar por ele. $O$ ar entra na direção axial e deixa o compressor radialmente.

Os compressores centrífugos são utilizados em motores aeronáuticos, turbocompressores automotivos, transporte de fluidos em dutos, geração de energia elétrica e muitas outras aplicações, especialmente em turbinas a gás pequenas (BOYCE, 2006). Esse tipo de compressor é classificado como compressor dinâmico, em oposição aos compressores de deslocamento positivo. Compressores dinâmicos têm fluxo contínuo, enquanto os de deslocamento positivo trabalham usualmente com movimentos alternativos (BOYCE, 2003).

Dentro da categoria dos compressores dinâmicos há ainda os compressores axiais e os de fluxo misto, assim como já comentado no capítulo anterior. As vazões mássicas para as quais o uso de compressores centrífugos é mais adequado que o uso de compressores axiais são tipicamente menores (AUNGIER, 2000), havendo limitação à potência das turbinas a gás que utilizam compressores centrífugos. Os compressores centrífugos apresentam algumas vantagens perante os axiais, podendo ter maior aumento de pressão por estágio e usualmente possuindo margem operacional mais ampla (BOYCE, 2003; TREAGER, 1979). Além disso, é freqüente que os centrífugos sejam mais simples construtivamente, até por serem empregados em menor número de estágios, sendo mais baratos tanto na fabricação quanto na manutenção de seus componentes.

Esse tipo de compressor é composto por ao menos dois componentes: o impelidor e o difusor. O impelidor é a parte rotativa, na qual o trabalho da turbina é aplicado, tendo a função de transferir energia ao fluido. No impelidor o fluido tem sua direção principal alterada, saindo dele radialmente. Ele é formado por pás que delimitam os sulcos pelos quais o fluido deve passar. Comumente chama-se a entrada do impelidor de indutor, sendo a parte na qual o escoamento, que entra essencialmente na direção axial, começa a ser formado. 
Para que a geometria do impelidor seja definida, é preciso determinar o perfil meridional das pás, a linha de câmber das pás, a distribuição de espessura das pás e o número de pás do impelidor (VERSTRAETE; ALSALIHI; VAN DEN BRAEMBUSSCHE, 2010). O perfil (ou superfície) meridional é uma projeção da geometria da pá em um plano que passa pelo impelidor radialmente, passando pelo eixo de rotação do compressor, assim como ilustra a Fig. 12.

A linha das pás que fica mais próxima ao eixo de rotação, é chamada de hub. É através dele que as pás se ligam ao corpo do impelidor. A linha que define a extremidade das pás é chamada de shroud. Sendo assim, o perfil meridional inclui a definição dos perfis de hub e shroud.
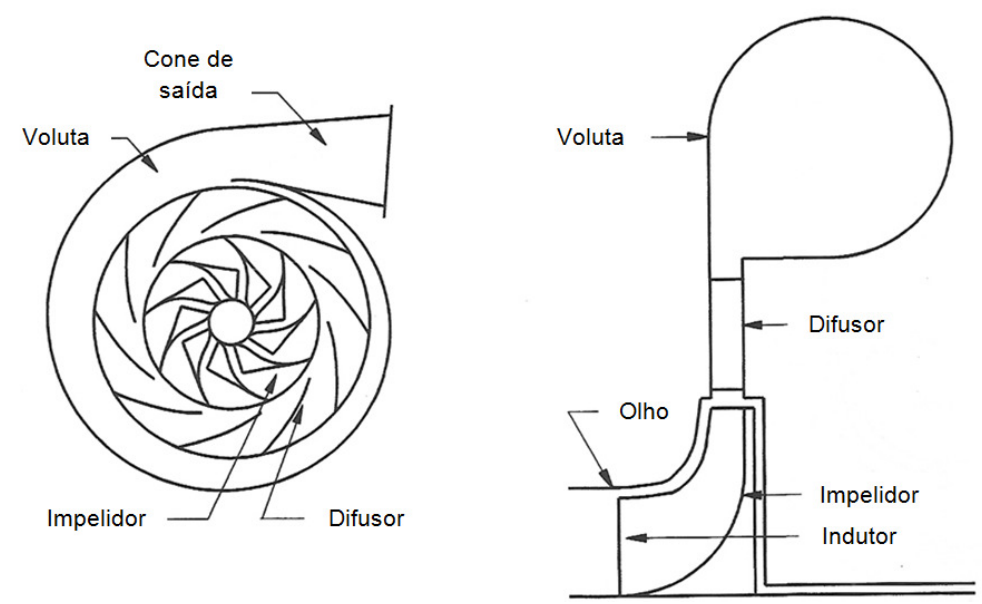

Figura 11 - Componentes de um compressor centrífugo. Vista frontal (esquerda) e vista meridional (direita). Adaptado de Aungier (2000).

A linha de câmber das pás define a curvatura das linhas da superfície meridional, além da angulação do caminho percorrido pelos gases no impelidor. A curvatura das pás na saída do impelidor é parâmetro importante e rege várias características operacionais dos compressores. A seção 5.6 se dedica a explicar a influência desse ângulo no desempenho. Por fim, a espessura das pás é determinante para fatores construtivos e dinâmicos, assim como para as características de bloqueio (blockage) (CUMPSTY, 2004).

O impelidor pode receber uma cobertura que fica fixa a ele, tendo a função de evitar que o escoamento saia do gas path. Nesse caso, diz-se que o impelidor é shrouded, em oposição à configuração mais convencional, chamada de unshrouded (CUMPSTY, 2004). Sem a cobertura há o chamado tip leakage, que é o escoamento 
do fluido através do espaço deixado entre o impelidor e sua carcaça estacionária, causando perdas.

Além de suprimir o tip leakage, o uso de impelidores shrouded diminui a carga axial no impelidor e tende a evitar problemas com vibrações. Porém, o aumento de massa gera restrições devido às tensões mecânicas, limitando a velocidade de rotação e assim dificultando o projeto. Por esses motivos, o compressor projetado nesta dissertação é do tipo unshrouded.

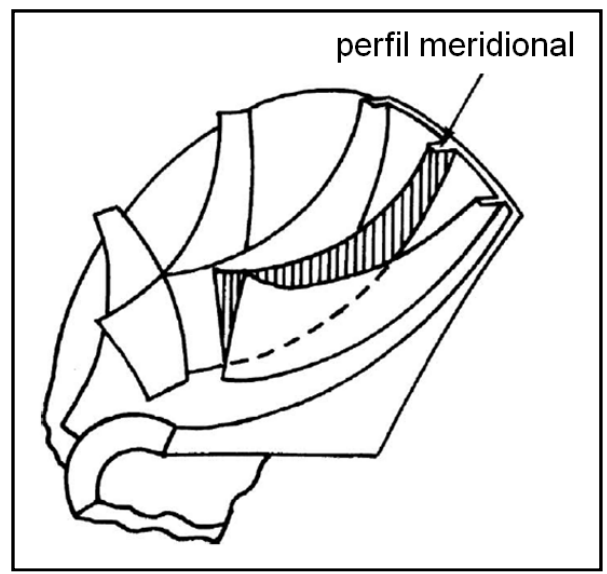

Figura 12 - Localização do perfil ou superfície meridional no impelidor de um compressor centrífugo. Adaptado de Boyce (2003).

No caso unshrouded, a folga deixada entre as partes (tip clearance) é um fator que determina a magnitude dessas perdas, especialmente quando comparado com a altura das pás. Porém, é importante salientar que a escolha do tip clearance passa principalmente por requisitos construtivos e dinâmicos, como o movimento axial do eixo e as características de vibração do sistema.

O difusor é o segundo componente sempre presente nos compressores centrífugos e é estacionário. Ao passar pelo difusor, o escoamento sofre aumento de pressão estática e redução da energia cinética, saindo a velocidades mais baixas que as da saída do impelidor. O difusor tem a função de transformar parte dessa energia cinética em pressão estática (DIXON; HALL, 2010). Não há adição de trabalho e, portanto, não há aumento na pressão total. A Fig.13 ilustra qualitativa e idealmente o comportamento de algumas variáveis ao passar por um estágio centrífugo.

Os difusores podem ser de diversos tipos, como cônicos, anulares, de canal ou radiais (JAPIKSE; BAINES, 1998). A aplicação a compressores radiais tende a 
manter o escoamento na direção radial e, neste caso, o difusor pode ou não ter palhetas (vanes). O desenho da Fig. 11 mostra o caso com palhetas.

De forma geral, os difusores com palhetas possuem margem operacional menor e maior aumento na pressão estática se comparados aos sem palhetas, ou vaneless (CUMPSTY, 2004). A restrição ao escoamento é maior nos difusores com palhetas, havendo maior possibilidade de choke (explicado na seção 5.5). Dessa forma, neste tipo de difusor torna-se muito importante que as características do impelidor sejam compatíveis com relação ao fluxo mássico e às velocidades.

Em algumas aplicações o compressor pode conter uma espécie de coletor para direcionar o escoamento que sai do difusor. Essa estrutura é chamada de voluta e também pode ser vista na Fig. 11. Além de direcionar o escoamento, essa estrutura ainda age como um difusor, uma vez que a largura do duto sofre aumento gradual.

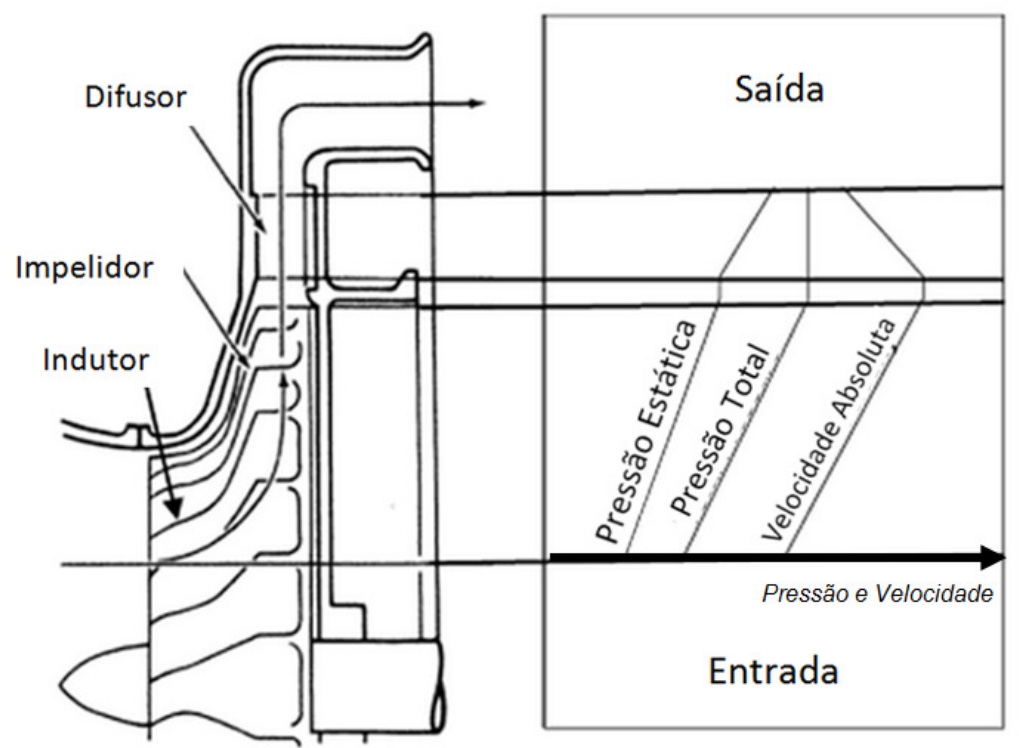

Figura 13 - Comportamento idealizado da velocidade absoluta e das pressões estática e total ao longo de um compressor centrífugo. Adaptado de Boyce (2003).

A modelagem do desempenho dos compressores centrífugos é uma questão complexa. Modelagens mais simples apresentam grandes limitações, enquanto modelar com menos simplificações pode dar resultados melhores, como no caso do CFD, mas requer mais tempo e informações do projeto. Isso acontece porque o escoamento em compressores centrífugos é extremamente complexo, regido por uma grande diversidade de fenômenos e com características altamente 
tridimensionais (CUMPSTY, 2004), fazendo com que simplificações apresentem desvios. Dentre os fenômenos e características, o escoamento nos compressores centrífugos pode apresentar separação, grande influência da camada limite, regiões transônicas, ondas de choque, escoamento secundário muito relevante (normal ao escoamento primário) e coexistência de jato e esteira (jet-wake flow) na saída do impelidor (CUMPSTY, 2004).

Nas seções seguintes são apresentados alguns conceitos importantes relacionados ao desempenho e às escolhas de projeto em compressores centrífugos. Também é abordado o embasamento necessário à compreensão dos métodos unidimensionais de projeto.

\subsection{EQUAÇÕES E CONCEITOS BÁSICOS}

A análise feita nos estágios iniciais do projeto obviamente contém simplificações. Porém, as aproximações e algumas das correlações utilizadas são embasadas por princípios físicos e não apenas empirismos. Ao formular as equações para o projeto preliminar apresentado no Cap. 6, Whitfield e Baines (1990) utilizaram alguns desses princípios.

A equação da continuidade foi empregada para relacionar as áreas de entrada e saída, seja de todo o estágio de compressão do impelidor ou do difusor. Esta equação está em sua forma mais completa no Cap. 8, sobre dinâmica de fluidos computacional, porém, é aqui apresentada para um volume de controle em regime permanente pela Eq. 28.

$$
\dot{m}=\rho_{1} C_{1} A_{1}=\rho_{2} C_{2} A_{2}
$$

A segunda lei de Newton também foi utilizada, relacionando vazão mássica e velocidade (ou massa e aceleração) à força aplicada, como na Eq. 29. No caso de um compressor, o torque está relacionado às forças na direção circunferencial (definida na seção 5.5) e ao braço de aplicação da força, dado pelos raios na entrada e saída, assim como na Eq. 30. 


$$
\begin{aligned}
& \sum F_{x}=\dot{m}\left(C_{x 2}-C_{x 1}\right) \\
& \tau=\dot{m}\left(r_{2} C_{\theta 2}-r_{1} C_{\theta 1}\right)
\end{aligned}
$$

Para calcular a potência específica a ser relacionada com os requisitos do projeto, basta multiplicar o torque pela velocidade de rotação e dividi-lo pela vazão mássica, chegando à equação de trabalho de Euler (DIXON; HALL, 2010). No caso do impelidor, podem ser escritas suas velocidades de rotação na localização considerada, assim como na Eq. 31. Esta equação é utilizada diretamente com os triângulos de velocidades (seção 5.5).

$$
\frac{\dot{W}}{\dot{m}}=U_{2} C_{\theta 2}-U_{1} C_{\theta 1}
$$

A equação da energia é outro conceito básico pertinente ao projeto preliminar que foi utilizado com algumas simplificações. Novamente, a forma completa que é calculada numericamente via CFD está apresentada no Cap. 8. A partir da primeira lei da termodinâmica (Eq. 32) é possível escrever a Eq. 10, já apresentada. Assumindo que o compressor é adiabático e desprezando os termos gravitacionais tem-se a Eq. 33, utilizando a nomenclatura da Fig.16, na seção 5.5 .

$$
\begin{aligned}
& \oint(d Q-d W)=0 \\
& \frac{\dot{W}}{\dot{m}}=\left(h_{2}+\frac{1}{2} C_{2}^{2}\right)-\left(h_{1}+\frac{1}{2} C_{1}^{2}\right)=h_{02}-h_{01}
\end{aligned}
$$

Ao igualar as Eqs. 31 e 33, chega-se à Eq. 34. Aplicando a lei dos cossenos, assim como mostraram Whitfield e Baines (1990), é possível rearranjá-la assim como na Eq. 35.

$$
h_{2}-h_{1}=\left(U_{2} C_{\theta 2}-\frac{1}{2} C_{2}^{2}\right)-\left(U_{1} C_{\theta 1}-\frac{1}{2} C_{1}^{2}\right)
$$




$$
h_{2}+\frac{1}{2} W_{2}^{2}-\frac{1}{2} U_{2}^{2}=h_{1}+\frac{1}{2} W_{1}^{2}-\frac{1}{2} U_{1}^{2}
$$

Como é possível notar, trata-se de um equacionamento que se mantém constante através do impelidor. Dixon e Hall (2010) definiram como rotalpia a propriedade dada por $I=h+(1 / 2) W^{2}-(1 / 2) U^{2}$, que, portanto, é constante num compressor adiabático.

\subsection{GRANDEZAS ADIMENSIONAIS}

No Cap. 4 já foi mencionada a serventia do uso de grandezas adimensionais no projeto e na avaliação de desempenho de turbomáquinas. Análise dimensional pode ser definida como o procedimento no qual as variáveis que regem um sistema físico são reduzidas a grupos adimensionais. Tal método pode ser usado para comparar máquinas de diversos tipos, prever o desempenho de uma máquina baseada num projeto já existente e construída em escala diferente ou operando em condições diversas ou ainda para auxiliar na escolha de parâmetros do projeto, visando atender aos requisitos impostos (BOYCE, 2006).

Whitfield e Baines (1990) afirmaram que uma turbomáquina pode ter seu desempenho e comportamento solucionado sob a forma de uma função como a da Eq. 36, que é dependente de dez variáveis. A mesma função pode ser representada por seis adimensionais, seguindo a idéia de análise adimensional, assim como na Eq. 37.

$$
\begin{aligned}
& f\left(D_{2}, N, \dot{m}, P_{01}, P_{02}, T_{01}, T_{02}, R, \gamma, \mu\right)=0 \\
& f\left(\frac{P_{02}}{P_{01}}, \frac{T_{02}}{T_{01}}, \frac{\dot{m} \sqrt{R T_{01}}}{P_{01} D_{2}^{2}}, \frac{N D_{2}}{\sqrt{R T_{01}}}, \frac{\dot{m}}{\mu_{d} D_{2}}, \gamma\right)=0
\end{aligned}
$$

A partir dessa análise, os autores definiram uma estratégia de projeto preliminar, apresentada no Cap. 6. Para facilitar a posterior relação com as variáveis de projeto e tornar os adimensionais mais significativos, Whitfield e Baines (1990) redefiniram o 
terceiro e quarto adimensionais da função, que são ligados à vazão mássica e à rotação. Para tanto, foram definidos o parâmetro adimensional de vazão mássica (Eq. 38) e a velocidade adimensional do impelidor (Eq. 39).

$$
\begin{aligned}
& \theta=\frac{\dot{m} \sqrt{R T_{01} / \gamma}}{P_{01} D_{2}^{2}(\pi / 4)} \\
& M_{u}=\frac{U_{2}}{a_{01}}=\frac{N D_{2} \pi}{60 \sqrt{\gamma R T_{01}}}
\end{aligned}
$$

Para o caso de compressores, é bastante razoável considerar a razão de calores específicos $\gamma$ constante, de modo a retirá-la da Eq. 37. Além disso, o número de Reynolds pode ser retirado da função, desde que tomados os devidos cuidados uma vez que esse tem valores altos em turbomáquinas, sendo que pequenas mudanças em sua magnitude tem pouca influência sobre o desempenho (WHITFIELD; BAINES, 1990). Por fim, a razão de temperaturas pode ser substituída pela eficiência isentrópica, porque a razão de pressões é função tanto da razão de temperaturas quanto da eficiência. Tem-se então a função da Eq. 40.

$$
f\left(P_{R}, \eta, \theta, M_{u}\right)=0
$$

Quando não se deseja realizar comparações entre diversos compressores não há necessidade de manter a distância característica $D_{2}$ na equação de $\theta$. Também é possível abandonar as constantes do gás por se estar trabalhando sempre com o mesmo fluido. Dessa forma, chega-se então à Eq. 41, e o termo relativo à vazão mássica deixa de ser adimensional. Como será visto no Cap. 6, é a partir da definição da vazão mássica que o método de projeto tem dimensões do impelidor como saída.

$$
f\left(P_{R}, \eta, \frac{\dot{m} \sqrt{T_{01}}}{P_{01}}, M_{u}\right)=0
$$

Assim como foi apresentado no Cap. 4, há outras opções para parâmetros adimensionais e eles são capazes de sintetizar tendências de comportamento. 
Foram definidos diâmetro e velocidade específicos (Eqs. 24 e 25, respectivamente) que formam o diagrama de Cordier e comentou-se que eles são intercambiáveis com os coeficientes de escoamento (flow) e de carga.

Aungier (2000) e Casey; Zwyssig e Robinson (2010) utilizaram a definição da Eq. 42a para o coeficiente de carga, enquanto Whitfield e Baines (1990) adotaram a Eq. 42b. Para o coeficiente de escoamento Casey; Zwyssig e Robinson (2010) usaram a Eq. 43a, enquanto Aungier (2000) e Whitfield e Baines (1990) a Eq. 43b. Essas diferenças não alteram a natureza e comportamento desses adimensionais, mas podem mudar consideravelmente seu valor.

$$
\begin{aligned}
& \Psi_{\mathrm{s}}=\frac{\Delta h_{0 s}}{U_{2}^{2}} \\
& \Psi_{\mathrm{s}}=\frac{\Delta h_{0 s}}{(1 / 2) U_{2}^{2}} \\
& \phi=\frac{Q}{4 r_{2}^{2} U_{2}} \\
& \phi=\frac{Q}{\pi r_{2}^{2} U_{2}}
\end{aligned}
$$

Os adimensionais apresentados nesta seção são utilizados ao longo do projeto, tanto nos métodos preliminares quanto para a comparação entre diversas geometrias candidatas. Além disso, eles servem para estudar alguns parâmetros de projeto, assim como feito na seção 5.7 com o ângulo de sweep.

\subsection{EFICIÊNCIA}

A eficiência é certamente um dos parâmetros mais utilizados para qualificar o desempenho dos compressores. Eficiência é definida genericamente como uma razão que compara o processo realmente desempenhado pela máquina analisada com uma idealização do processo (MORAN; SHAPIRO, 2009). 
No caso dos compressores, a definição genérica evolui para a expressão da Eq. 44, assim como apresentou Cumpsty (2004). Essa abordagem não se refere mais a processos reais e ideais, mas a "compressores".

$$
\eta=\frac{\text { trabalho aplicado ao compressor ideal }}{\text { trabalho aplicado ao compressor real }}
$$

A definição apresentada por Whitfield e Baines (1990), mostrada na Eq. 45, talvez seja mais adequada por manter o rigor conceitual. Ao invés de citar um "compressor ideal", essa definição é focada no processo ideal, cuja definição, por sua vez, varia. Além disso, atenção é dada à definição dos estados inicial e final entre os quais o processo ideal faria a transição, sendo muito importante para não haver erros na comparação entre eficiências (MORAN; SHAPIRO, 2009).

$$
\eta=\frac{\text { trabalho aplicado num processo ideal entre dois estados definidos }}{\text { trabalho aplicado no caso real }}
$$

Dessa forma, para calcular a eficiência de um compressor é necessário definir que tipo de idealização será adotado, além dos estados inicial e final considerados. Usualmente utiliza-se o estado de estagnação na entrada do compressor, utilizando temperatura e pressão totais (CUMPSTY, 2004; DIXON; HALL, 2010). Isso acontece porque se considera que a energia cinética do fluido pode ser utilizada (ou convertida) pelo compressor. Na saída, não há um consenso, podendo ser utilizadas tanto a condição de estagnação quanto a estática. Torna-se importante deixar claro qual condição foi assumida no cálculo da eficiência.

Quanto ao processo ideal, há algumas opções. As de uso mais comum são os processos isentrópico e politrópico. O primeiro dá origem à eficiência isentrópica, por vezes chamada de adiabática, e corresponde ao processo de compressão assumido no ciclo Brayton, como relatado no Cap. 3. Como mostrado no balanço energético da Eq. 10, o processo de compressão adiabática pode ser representado com a variação de entalpia e energia cinética caso desconsidere-se a energia potencial gravitacional, o que é bastante razoável. Ao usar a entalpia de estagnação a energia cinética é incorporada a ela. Tem-se então que a eficiência isentrópica pode ser escrita como na Eq. 46 comparando-se o processo ideal ao real. 


$$
\eta_{i s e n(t-t)}=\frac{h_{02 s}-h_{01}}{h_{02}-h_{01}}
$$

Nessa forma, a expressão não tem correspondência com o processo físico real, uma vez que não é possível relacioná-lo com $h_{02 s}$ (CUMPSTY, 2004). Para tornar a expressão da eficiência isentrópica aplicável, pode-se considerar o gás ideal e $C_{p}$ constante, e utilizar a expressão da Eq. 47 que relaciona temperatura e pressão num processo isentrópico. Lembrando que $P_{02 s}=P_{02}$ e da relação mostrada na Eq. 2, é possível escrever a eficiência isentrópica assim como na Eq. 48.

$$
\begin{aligned}
& \frac{T_{02 s}}{T_{01}}=\left(\frac{P_{02 s}}{P_{01}}\right)^{(\gamma-1) / \gamma} \\
& \eta_{i s e n(t-t)}=\frac{P_{R}^{(\gamma-1) / \gamma}-1}{\left(T_{02} / T_{01}\right)-1}
\end{aligned}
$$

A eficiência isentrópica pode ainda ser definida com a condição estática na saída. Neste caso a expressão é dada pela Eq. 49.

$$
\eta_{i s e n(t-e)}=\frac{\left(P_{2} / P_{01}\right)^{(\gamma-1) / \gamma}-1}{\left(T_{02} / T_{01}\right)-1}
$$

O processo politrópico é outro processo idealizado que pode ser utilizado para definir eficiência. A eficiência isentrópica não permite que sejam comparadas máquinas com razões de pressões diferentes, uma vez que é dependente desse parâmetro (CUMPSTY, 2004; WHITFIELD; BAINES, 1990).

A definição formal da eficiência politrópica é dada pela Eq. 50. Trata-se da comparação entre as variações de entalpia ideal e real numa compressão infinitesimal (WHITFIELD; BAINES, 1990).

$$
\eta_{p}=\lim _{\partial h \rightarrow 0} \frac{\partial h_{s}}{\partial h}
$$


Utilizando a Eq. 2 considerando um processo isentrópico, é possível obter a relação da Eq. 51. Utilizando a definição da Eq. 50 e utilizando a Eq. 51, chega-se à relação da Eq. 52. Ao considerar-se a eficiência politrópica constante para o processo, podese então integrar a Eq. 52, resultando na Eq. 53, da qual se isola a eficiência politrópica numa forma com variáveis mensuráveis (Eq. 54).

$$
\begin{aligned}
& \partial h_{s}=\frac{\partial P}{\rho} \\
& \partial h=\frac{1}{\eta_{p}} \frac{\partial P}{\rho} \\
& \frac{T_{02}}{T_{01}}=\left(\frac{P_{02}}{P_{01}}\right)^{(\gamma-1) / \eta_{p} \gamma} \\
& \eta_{p}=\frac{\gamma-1}{\gamma} \frac{\ln P_{R}}{\ln \left(T_{02} / T_{01}\right)}
\end{aligned}
$$

É possível relacionar as eficiências isentrópica e politrópica em uma só expressão como na Eq. 55. Para o caso dos compressores, a eficiência politrópica é sempre maior que a isentrópica para uma dada razão de pressões, como é possível notar no gráfico da Fig. 14.

$$
\eta_{\text {isen }}=\frac{P_{R}^{(\gamma-1) / \gamma}-1}{P_{R}^{(\gamma-1) / \eta_{p} \gamma}-1}
$$

Tanto o processo isentrópico ideal quanto o politrópico são adiabáticos. Em alguns casos, a transferência de calor tem um papel muito importante no processo de compressão, como em compressores com vários estágios e resfriamento intermediário. Nestes casos, é conveniente utilizar uma formulação de eficiência diferente. O processo de compressão isotérmica pode ser utilizado como a idealização que serve como base de comparação. A eficiência isotérmica é definida pela razão entre o trabalho que é realmente transferido e o trabalho que seria transferido num processo reversível e isotérmico. 


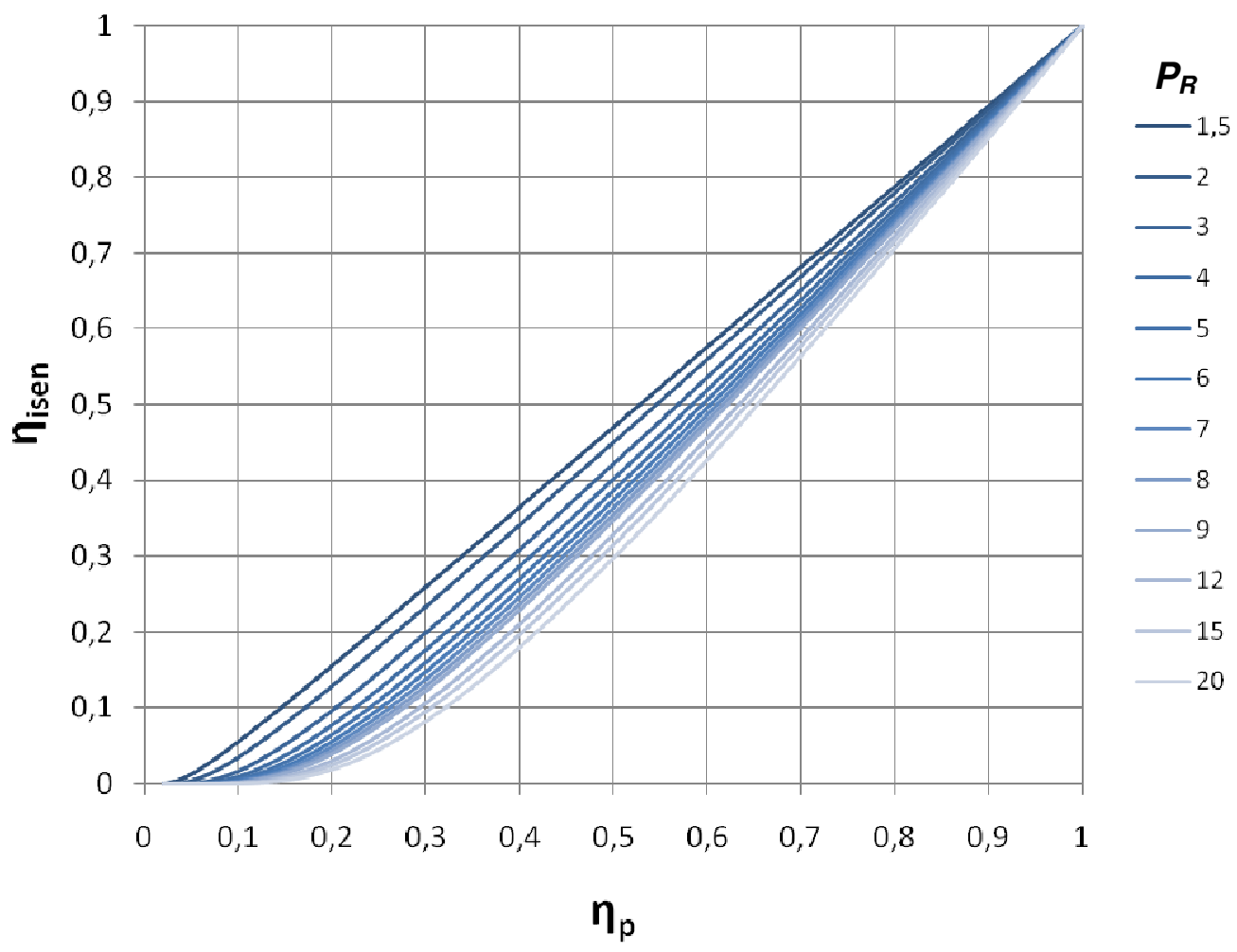

Figura 14 - Relação entre as eficiências isentrópica e politrópica (total-total), de acordo com a Eq. 39 para vários valores de razão de pressões.

A Eq. 10 pode ser escrita em sua forma infinitesimal como na Eq. 56, considerando a entalpia de estagnação e a ausência de energia potencial gravitacional. Há uma inversão nos sinais para que o trabalho no compressor seja considerado positivo, assim como propuseram Whitfield e Baines (1990).

$$
\frac{d \dot{W}}{\dot{m}}=\frac{d \dot{Q}}{\dot{m}}+d h_{0}
$$

Segue da segunda lei da termodinâmica que, para um processo reversível, $\dot{d} Q=$ $T d s$, e, como num processo isotérmico $d h_{0}=0$, é possível escrever a Eq. 57. Ao combiná-la com a Eq. 2 e integrando-a, chega-se ao trabalho no processo reversível e isotérmico na Eq. 58.

$$
\frac{d \dot{W}}{\dot{m}}=T d s
$$




$$
\frac{\dot{W}}{\dot{m}}=-R T \cdot \ln \left(P_{R}\right)
$$

Dessa forma, a eficiência isotérmica pode ser escrita como na Eq. 59, através da comparação com o trabalho real. Nessa equação, $T$ é a temperatura do ambiente com o qual há troca de calor (ou do processo isotérmico).

$$
\eta_{\text {isot }}=\frac{-R T \cdot \ln \left(P_{R}\right)}{\dot{W}_{\text {real }}}=\frac{-R T \cdot \ln \left(P_{R}\right)}{h_{02}-h_{01}-\dot{Q} / \dot{m}}
$$

Cumpsty (2004) mostrou ainda que pode ser conveniente formular a eficiência através da perda de pressão. Nessa formulação, a eficiência é a razão entre o aumento de pressão real e o aumento que seria conseguido através de um processo ideal. Cumpsty (2004) utilizou um processo isentrópico, além da hipótese de gás ideal.

Dessa forma, é possível escrever os ganhos de pressão ideal e real em função da temperatura. A eficiência em termos de perda de pressão seria então a comparação entre a temperatura que seria alcançada caso a pressão real tivesse sido elevada através de um processo isentrópico $T_{02 s}$ e a temperatura que realmente foi alcançada ao fim do processo $T_{02}$. A expressão da eficiência nesses termos está representada pela Eq. 60 .

$$
\eta_{\text {ploss }}=\frac{\left(T_{02 s} / T_{01}\right)^{(\gamma-1) / \gamma}-1}{\left(T_{02} / T_{01}\right)^{(\gamma-1) / \gamma}-1}
$$

Além das formas mostradas para a eficiência há muitos coeficientes de perdas e maneiras para introduzir perdas nos modelos. Alguns deles serão introduzidos posteriormente no presente trabalho quando forem necessários à compreensão.

Foi utilizada a eficiência isentrópica total-total para comparar o desempenho das geometrias testadas nesta dissertação. Não se julgou necessário utilizar a eficiência politrópica por haver comparação entre máquinas diferentes na mesma condição de operação e com mesma razão de pressões pretendida. A eficiência politrópica foi apenas utilizada para avaliar diversos pontos de operação da geometria final. 


\subsection{MAPA DE DESEMPENHO}

O projeto de compressores começa considerando-se as condições de ponto de projeto. Entende-se por ponto de projeto a condição de operação do compressor para a qual ele é requerido principalmente, em termos de vazão mássica e razão de pressões. Contudo, não é possível manter sempre as mesmas condições, ou pode ser um requisito ter uma grande amplitude de condições.

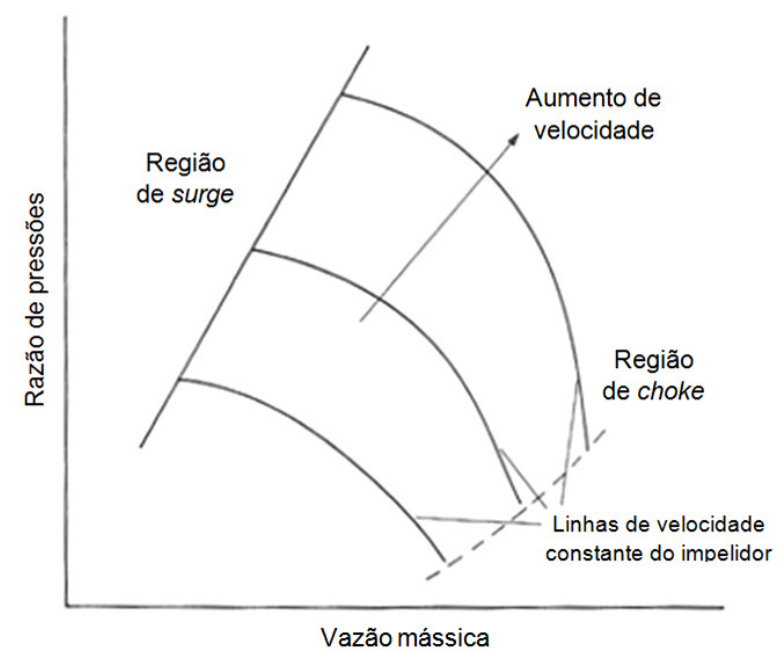

Figura 15 - Mapa de desempenho genérico de um compressor centrífugo. Adaptado de Whitfield e Baines (1990).

No projeto realizado no presente trabalho considerou-se principalmente o ponto de projeto. Isso foi feito porque o tipo de operação na geração elétrica não requer grandes margens de operação e, além disso, não foi possível fixar requisitos para a margem de operação. Em aplicações diferentes, como automotiva ou aeronáutica, a variação das condições de entrada são muito grandes, assim como o desempenho requerido em cada modo de operação.

Compreender os mapas operacionais e as características dos seus limites é útil ao projeto, mesmo que o foco seja apenas o ponto de projeto. A eficiência varia de acordo com as regiões do mapa de desempenho e é útil saber se o compressor opera próximo a regiões de baixa eficiência em seu ponto de projeto, para que se possa reposicioná-lo. 
Os mapas de desempenho são usualmente desenhados em gráficos da razão de pressões pela vazão mássica com contornos de eficiência. Os limites da zona de operação são dados pelas condições de surge e de choke, sendo a primeira caracterizada por vazões mássicas baixas e a segunda por vazões altas. A Fig. 15 mostra o formato usual de um mapa de desempenho.

$\mathrm{Na}$ condição de surge a operação torna-se instável com o escoamento pulsando através do compressor, havendo refluxos. Tal condição é o limite da mínima vazão mássica para uma dada rotação. O surge é um fenômeno complexo que depende de todo o sistema ao qual o compressor está ligado (AUNGIER, 2000).

Whitfield e Baines (1990) citaram alguns parâmetros que têm influência sobre o surge:

- Incidência do escoamento no indutor

- Ângulo de sweep

- Swirl do escoamento na entrada do compressor

- Número de pás no impelidor e de palhetas no difusor

- Gradiente da pressão ao longo do compressor

- Incidência no bordo de ataque das palhetas do difusor

O estudo do surge é muito complexo e foge do escopo proposto no presente trabalho, necessitando de simulações transientes para ser constatado. No entanto, algumas recomendações dadas por Cumpsty (2004) e Whitfield e Baines (1990) para tentar evitar uma margem de surge estreita demais no projeto foram levadas em conta.

O choke acontece quando o escoamento atinge velocidade sônica em alguma seção, usualmente no difusor ou na região mais estreita do impelidor. A vazão mássica é limitada superiormente por esta condição. Se ela acontece numa passagem estacionária, não há como aumentar a vazão mássica, seja diminuindo a pressão a jusante, seja aumentando a rotação. A razão de pressões tende a cair perto dessa condição por conta do grande aumento nas perdas.

Dixon e Hall (2010) realizaram uma simples análise para determinar quando o choke ocorre na entrada do compressor, no impelidor e no difusor a partir da análise das diferenças entre as velocidades do escoamento e do som. Para a entrada, a análise é feita igualando a velocidade absoluta à velocidade do som, assim como na Eq. 61 . 


$$
\begin{aligned}
& C=a=\sqrt{\gamma R T} \\
& \frac{T_{0}}{T}=1+\frac{\gamma-1}{2} M^{2} \\
& \frac{\rho_{0}}{\rho}=\left(1+\frac{\gamma-1}{2} M^{2}\right)^{1 /(\gamma-1)}
\end{aligned}
$$

Para um gás ideal, valem as relações das Eqs. 62 e 63. Ao impor número de Mach igual a 1 e aplicar a equação da continuidade, chega-se à Eq. 64, que representa a vazão mássica no choke da entrada do compressor.

$$
\frac{\dot{m}}{A}=\rho_{0} a_{0}\left(\frac{2}{\gamma+1}\right)^{(\gamma+1) / 2(\gamma-1)}
$$

Para o impelidor, o choke ocorre quando a velocidade relativa atinge a velocidade do som. Torna-se conveniente utilizar o conceito de rotalpia. Considerando o caso sem prewhirl, tem-se que $C_{\theta 1}=0$, assim como mostrado na seção 5.5. Assim, a rotalpia é $I_{1}=h_{1}+1 / 2 C_{1}^{2}=h+1 / 2\left(W^{2}-U^{2}\right)$. Como o número de Mach das Eqs. 62 e 63 é definido em relação à velocidade absoluta, pode-se usar a relação mostrada pela rotalpia na Eq. 62 para tê-la em função das velocidades relativa e de rotação. A Eq. 65 apresenta essa substituição e usa ainda que $W=\sqrt{\gamma R T}$. Ao assumir o escoamento isentrópico e utilizar novamente a equação da continuidade com a Eq. 65, chega-se à Eq. 66.

$$
\begin{aligned}
& \frac{T}{T_{01}}=\left(\frac{2}{\gamma+1}\right)\left(1+\frac{U^{2}}{2 c_{p} T_{01}}\right) \\
& \frac{\dot{m}}{A}=\rho_{01} a_{01}\left[\frac{2+(\gamma-1)\left(U^{2} / a_{01}^{2}\right)}{\gamma+1}\right]^{(\gamma+1) / 2(\gamma-1)}
\end{aligned}
$$


Percebe-se que a vazão que causa o choke depende da velocidade de rotação, além da área considerada, obviamente. Por este motivo, observa-se o choke a diversas vazões mássicas no mapa de desempenho.

No caso do difusor, vale a mesma Eq. 64 encontrada para a entrada, uma vez que se trata de uma passagem estacionária. Contudo, o escoamento é afetado pela passagem no impelidor e é possível relacionar facilmente as condições de entrada no difusor com as de entrada no impelidor (DIXON; HALL, 2010).

\subsection{TRIÂNGULOS DE VELOCIDADES}

A análise de compressores centrífugos nos estágios iniciais do projeto passa por conceitos básicos como a conservação de massa, quantidade de movimento e energia, assim como evidencia a seção 5.1 sobre equações básicas aplicadas a compressores. Faz-se necessário estudar a velocidade do escoamento e de rotação do impelidor, assim como as velocidades relativas entre eles, para a correta aplicação dos conceitos e uma análise capaz de fornecer dados do desempenho do projeto.

O usual é fazer cálculos na entrada e saída do impelidor, avaliando a influência do trabalho aplicado ao fluido e a transferência de energia, em aumento de pressão ou energia cinética. Para tanto, são traçados os triângulos de velocidades, que são representações vetoriais das velocidades absoluta do escoamento $(C)$, de rotação do impelidor $(U)$ e a relativa entre elas $(W)$, assim como na notação da Fig. 16. Os triângulos são formados pela adição vetorial dessas velocidades.

Diferentemente das máquinas axiais, o sistema de coordenadas mais utilizado nos compressores centrífugos tem as componentes meridional $(m)$ e circunferencial $(\theta)$. A componente meridional segue a direção do escoamento principal no perfil meridional, apresentado na Fig. 12, enquanto a circunferencial é normal à meridional e acompanha a direção da rotação do impelidor.

Os ângulos formados entre as velocidades absolutas e a direção meridional são indicados pelo símbolo $\alpha$, enquanto os ângulos entre as velocidades relativas e a mesma direção são representados por $\beta$. Por convenção, os ângulos $\alpha_{1}, \beta_{1}$ e $\alpha_{2}$ 
mostrados na Fig. 16 são considerados positivos, assim como as velocidades $C_{1}, W_{1}$ e $C_{2}$. Já o ângulo $\beta_{2}$ e a velocidade $W_{2}$ são considerados negativos. Dessa forma, é possível escrever a Eq. 67 para ambos os triângulos.
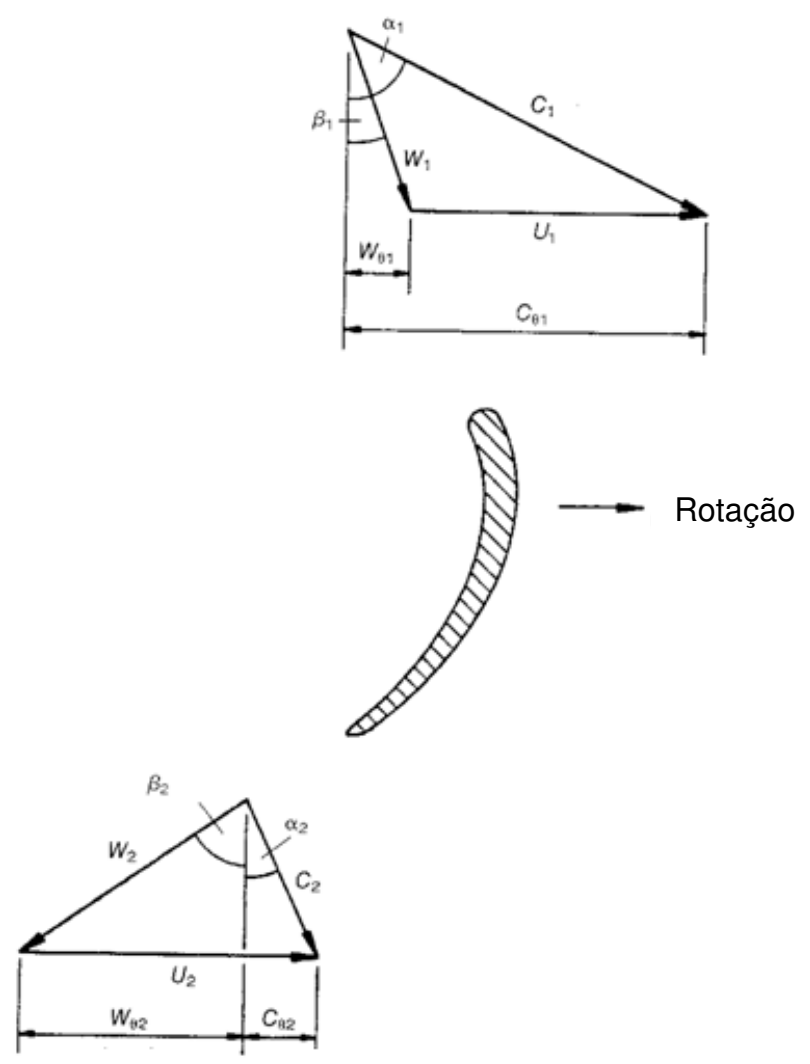

Figura 16 - Triângulos de velocidades na entrada (acima) e saída (abaixo) numa pá de rotor. Adaptado de Whitfield e Baines (1990).

$\mathrm{Na}$ fase inicial de projeto, assim como apresentado no Cap. 6, a análise dos triângulos de velocidades não é feita para muitas posições. Porém, em outras fases é importante analisar os triângulos no hub, shroud e no raio médio, uma vez que a razão entre os raios de shroud e hub pode ser consideravelmente grande em impelidores.

$$
C_{\theta}=U+W_{\theta}=U+C_{m} \cdot \tan \beta
$$




\subsection{FATOR DE ESCORREGAMENTO}

O escoamento na saída dos impelidores de compressores centrífugos não é perfeitamente guiado pelos ângulos formados por suas pás. Mesmo considerando condições ideais, sem atrito ou perdas viscosas, o triângulo de velocidades da saída do impelidor sofre uma distorção no sentido da velocidade de rotação. Tal distorção é chamada de escorregamento e está ilustrada pelo triângulo de velocidades da Fig. 17. O fenômeno não tem implicações sobre a eficiência (em qualquer formulação), uma vez que ele ocorreria mesmo num fluido ideal (WHITFIELD; BAINES, 1990). Dixon e Hall (2010) salientaram que o escorregamento não aconteceria no caso idealizado de um impelidor com número de pás infinito e com pás de espessura infinitesimal.

Cumpsty (2004) forneceu a melhor explicação encontrada para a ocorrência do escorregamento. De acordo com ele, o motivo para existir o escorregamento é conseqüência da necessidade da haver redução gradual na carga aerodinâmica das pás ao se aproximar do bordo de fuga. Para que seja satisfeita a condição de KuttaJoukowsky, a diferença de pressão entre as duas superfícies de cada pá deve ser igual a zero no bordo de fuga. Essa condição impõe que o segundo ponto de estagnação de um aerofólio deve estar localizado no bordo de fuga (HOUGHTON; CARPENTER, 2003). Assim como as pás de compressores axiais, as pás do impelidor centrífugo podem ser analisadas como aerofólios.

Como a queda de pressão até zero deve ser gradual, a carga aerodinâmica diminui próximo ao bordo de fuga, não havendo força suficiente nesta região para submeter o escoamento ao formato das pás. Como resultado disso, o escoamento médio desenvolve uma componente de velocidade (chamada de velocidade de escorregamento) no sentido contrário ao de rotação do impelidor.

Esse fenômeno tem influência considerável sobre o desempenho dos compressores e por este motivo é levado em conta durante o projeto. A velocidade absoluta diminui, enquanto a relativa aumenta, modificando as condições na entrada do difusor. A velocidade de escorregamento $C_{\theta s}$ é igual à diferença entre a componente circunferencial da velocidade absoluta no caso ideal e no caso com escorregamento, ou ainda o mesmo com as velocidades relativas. 
O escorregamento age diminuindo a razão de pressões gerada pelo compressor. Conseqüentemente, os impelidores devem ser maiores ou girar a velocidades maiores para entregar a mesma razão de pressões que haveria sem 0 escorregamento (WHITFIELD; BAINES, 1990).

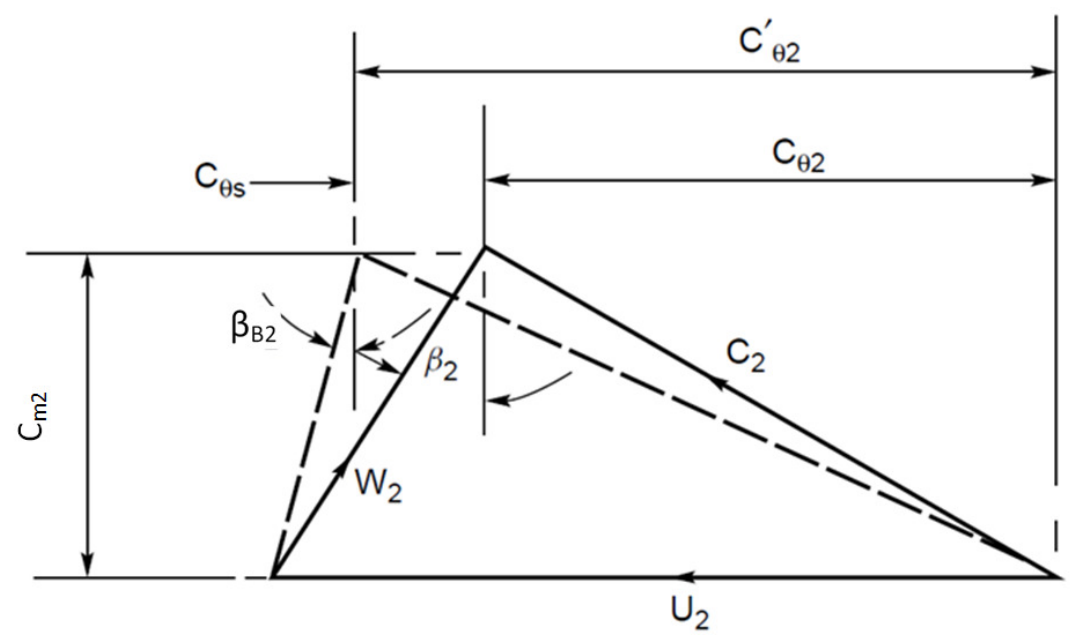

Figura 17 - Efeito do escorregamento no triângulo de velocidades. A linha tracejada indica o triângulo que haveria caso não houvesse escorregamento. Adaptado de Dixon e Hall (2010).

Com intenção de parametrizar o escorregamento e tornar a comparação de desempenho de impelidores com relação a esse fenômeno possível, criou-se o conceito de fator de escorregamento. Cumpsty (2004) e Dixon e Hall (2010) mostraram que o fator de escorregamento é definido como a razão entre as componentes circunferenciais da velocidade absoluta real e ideal, assim como mostra a Eq. 68 .

$$
\begin{aligned}
& \mu=\frac{C_{\theta 2}}{C^{\prime}{ }_{\theta 2}} \\
& \mu=1-\frac{C_{\theta s}}{U_{2}}=1-\frac{C_{\theta 2}^{\prime}-C_{\theta 2}}{U_{2}}
\end{aligned}
$$

Whitfield e Baines (1990) definiram o fator de escorregamento utilizando a velocidade de rotação do impelidor $U_{2}$. A Eq. 69 traz essa definição, que foi adotada no presente trabalho. 


$$
\begin{aligned}
& \mu=1-\frac{\pi \cdot \cos \beta_{B 2}}{Z} \\
& \mu=1-\frac{0,63 \pi}{Z} \\
& \mu=1-\frac{\sqrt{\cos \beta_{B 2}}}{Z^{0,7}}
\end{aligned}
$$

A magnitude do escorregamento é influenciada por muitos fatores e não é possível quantificá-la rigorosamente nas primeiras fases do projeto. Com a intenção de calcular o fator de escorregamento com informações básicas do projeto do impelidor foram criadas correlações. Dixon e Hall (2010) reuniram tais correlações e apresentaram sucintamente as bases que as fundamentam. Todas se utilizam do número de pás do impelidor. As correlações de Stodola, de Stanitz e de Wiesner são dadas, nesta ordem, pelas Eqs. de 70 a 72. As correlações de Stanitz e de Wiesner foram utilizadas no projeto unidimensional, assim como relatado no capítulo seguinte, e apresentaram resultados bastante similares.

Percebe-se a óbvia dependência do fator de escorregamento com relação ao número de pás. Cumpsty (2004) afirmou que um bom impelidor deve ter um número de pás suficientes para que o escorregamento não seja excessivo, apesar de o escorregamento não comprometer o projeto caso seja previsto e não representar uma perda.

\section{7 ÂNGULO DE SWEEP}

O ângulo formado pelas pás do impelidor ao final do gas path (chamado de ângulo de sweep) é um dos parâmetros geométricos mais importantes ao desempenho dos impelidores centrífugos e sua escolha tem grande influência no projeto. Não se questiona mais que impelidores com as pás viradas para trás (backsweep) na saída tenham, geralmente, maior eficiência (CUMPSTY, 2004; XU; AMANO, 2012a). Há duas maneiras principais de aumento de entalpia estática e pressão nos impelidores 
centrífugos: através do efeito centrífugo, gerado pela diferença $U_{2}^{2}-U_{1}^{2}$, e da desaceleração do escoamento relativo. Os impelidores com backsweep realizam a maior porção do aumento na pressão através do efeito centrífugo, que não tem perdas associadas, ao contrário da desaceleração do escoamento relativo (CUMPSTY, 2004).

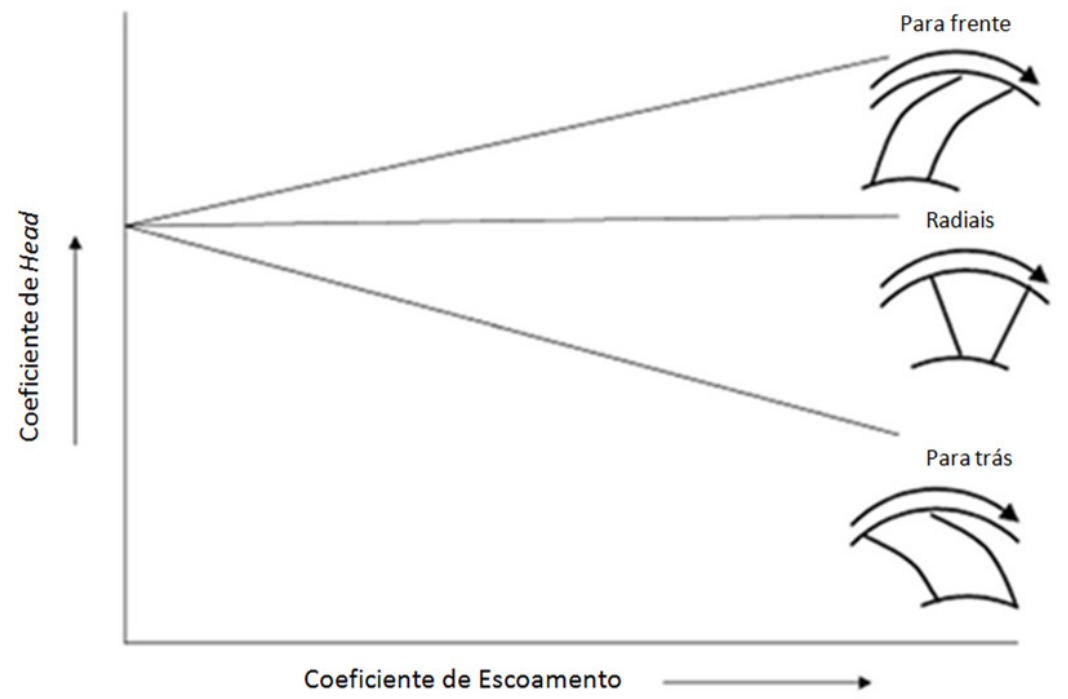

Figura 18 - Relação genérica entre o coeficiente de carga (head) e coeficiente de escoamento com o efeito do ângulo de sweep. Adaptado de Boyce (2003).

Usualmente, o requisito de desempenho do impelidor é dado na forma de razão de pressões, que utiliza as condições de estagnação. Para uma mesma velocidade de rotação, os impelidores geram razões de pressões menores quanto maior for 0 ângulo de backsweep (DIXON; HALL, 2010). Dessa forma, para a mesma razão de pressões de impelidores com pás radiais ou com inclinação para frente, os impelidores com backsweep devem operar a velocidades de rotação maiores. Isso faz com que eles tenham o efeito centrífugo mais pronunciado, o que não implica em perdas, garantindo maior eficiência (CUMPSTY, 2004).

O número de Mach na saída do impelidor não deve ser alto para não comprometer a eficiência do difusor. O uso de backsweep reduz este número. $\mathrm{E}$ tal redução é preponderante frente ao aumento no Mach da descarga causado pela necessidade em operar a rotações maiores para manter a razão de pressões (DIXON; HALL, 2010). Com isso, o backsweep traz eficiências maiores. 
A Fig. 18 mostra o efeito da curvatura das pás sobre o coeficiente de carga em função do coeficiente de escoamento. O coeficiente de carga está ligado ao trabalho aplicado ao fluido. Ao aumentar a vazão mássica, aumentando o coeficiente de escoamento, a velocidade circunferencial na saída diminui em um impelidor com backsweep proporcionalmente ao ângulo de backsweep. Dessa forma, o trabalho aplicado ao fluido diminui, assim como evidencia a Eq. 30.

Tabela 1 - Vantagens e desvantagens das configurações de ângulo de sweep. Adaptado de Boyce (2003).

\begin{tabular}{|c|c|c|}
\hline $\begin{array}{l}\text { Tipo de curvatu } \\
\text { das pás do } \\
\text { impelidor }\end{array}$ & Vantagens & Desvantagens \\
\hline Para frente & Alta transferência de energia & $\begin{array}{l}\text { Alta energia cinética na saída, } \\
\text { alto número de Mach na entrada } \\
\text { do difusor, tensões flexoras } \\
\text { complexas e dificuldade na } \\
\text { fabricação }\end{array}$ \\
\hline Radiais & $\begin{array}{c}\text { Compromisso entre } \\
\text { transferência baixa de energia e } \\
\text { alta velocidade absoluta de } \\
\text { saída, ausência de tensões } \\
\text { flexoras complexas e facilidade } \\
\text { na fabricação }\end{array}$ & Margem de surge muito estreita \\
\hline Para trás & $\begin{array}{l}\text { Baixa energia cinética na saída, } \\
\text { baixo número de Mach na } \\
\text { entrada do difusor e margem de } \\
\text { surge mais ampla }\end{array}$ & $\begin{array}{c}\text { Baixa transferência de energia, } \\
\text { tensões flexoras complexas e } \\
\text { dificuldade na fabricação }\end{array}$ \\
\hline
\end{tabular}

Por muito tempo não foi possível utilizar curvaturas na saída do impelidor por conta do aumento das tensões flexoras e a incapacidade em analisá-las ou garantir bom funcionamento e durabilidade (WHITFIELD; BAINES, 1990). Porém, com novos métodos de análise e fabricação muitos impelidores têm usado backsweep.

Faz-se necessário ponderar os efeitos da curvatura para trás. Impelidores com ângulos de backsweep muito grandes necessitam de rotações altas para alcançar a carga desejada. Além disso, a análise das tensões mecânicas é fundamental. A Tab. 1 sumariza as vantagens e desvantagens dos ângulos de sweep. 


\subsection{TIPOS DE DIFUSORES E SEU DESEMPENHO}

Assim como mencionado no início deste capítulo, os difusores são os componentes responsáveis pelo aumento da pressão estática do escoamento e diminuição de sua velocidade, preparando-o para seguir à câmara de combustão. Os difusores aplicados a compressores centrífugos são usualmente classificados como com ou sem palhetas (vaned e vaneless, respectivamente). Came e Robinson (1999) e Cumpsty (2004) afirmaram que difusores com palhetas são capazes de garantir maiores eficiências ao compressor. A contrapartida está na redução da margem operacional, na maior dificuldade do projeto e no maior custo de fabricação.

Devido à aplicação pretendida no presente trabalho não exigir grande margem operacional e haver interesse em alcançar uma eficiência tão grande quanto possível no ponto de projeto, optou-se pelo projeto de um difusor com palhetas. Came e Robinson (1999) salientaram que para compressores com razão de pressões acima de 3 , o uso de difusores palhetados é praticamente mandatório.

Os difusores com palhetas podem ser com aerofólios ou com canais. Aungier (2000) afirmou que, baseando-se em sua experiência, difusores com aerofólio tendem a ter melhor desempenho. Whitfield e Baines (1990) consideraram que a adoção de difusores com aerofólios é menos comum que difusores com canais, havendo menos bases de dados e conhecimento acerca dos primeiros.

Cumpsty (2004) salientou que não há estudos comparativos conclusivos para escolha do tipo de difusor. Além disso, esse autor considera que há pouca compreensão quanto à física envolvida nos escoamentos em difusores para que se possa sistematizar escolhas de projeto como o tipo de difusor.

O funcionamento de difusores com canais radiais é, até certa instância, mais intuitivo por sua similaridade com difusores cônicos (JAPIKSE; BAINES, 1998). A área de suas passagens aumenta proporcionalmente ao raio, desacelerando o escoamento. As dificuldades em seu projeto se encontram na determinação de seu ângulo principal e do ângulo de divergência. O primeiro depende da previsão do ângulo de saída do escoamento do impelidor, enquanto o segundo deve ser determinado de modo a evitar separações do escoamento e, ao mesmo tempo, não prolongar o comprimento da passagem em demasia. 
A geometria do difusor com canais, mostrada pela Fig. 19, é definida pelo ângulo principal, o ângulo de divergência, raio do bordo de ataque das palhetas, raio da saída e número de palhetas. O número de palhetas define o comprimento da garganta, que é a menor distância entre duas palhetas subseqüentes e normal à superfície de alguma delas.

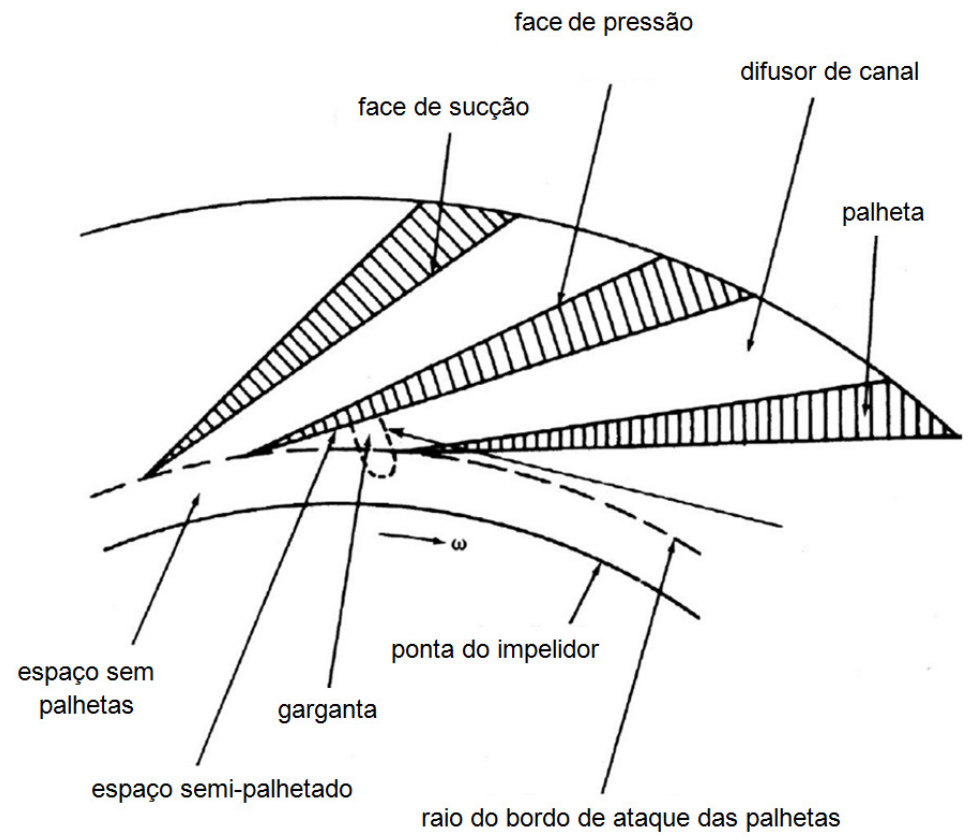

Figura 19 - Difusor radial de canal com indicações de suas regiões principais. Adaptado de Cumpsty (2004).

Nos difusores com aerofólio, o aumento da pressão estática acontece de maneira similar à dos estatores de compressores axiais. As palhetas atuam minimizando as componentes rotacionais do escoamento, aumentando a pressão estática.

Há ainda os difusores com aerofólios de baixa solidez. Estes difusores se caracterizam por pás curtas e suficientemente espaçadas de modo a não haver garganta (WHITFIELD; BAINES, 1990). Esse tipo de difusor tende a ter margens operacionais mais amplas, uma vez que a ausência de garganta retarda o choke. Entretanto, há pouca bibliografia acerca de seu projeto. Destaca-se o trabalho de Engeda (2001), que tratou de aspectos de projeto e de desempenho de difusores de baixa solidez.

Como é possível notar nas Figs. 19 e 20, há um espaço entre a saída do impelidor e o bordo de ataque das palhetas (vaneless space). Dixon e Hall (2010) apontaram três razões para haver este espaço: redução do gradiente de pressão circunferencial na saída do impelidor, suavização das variações de velocidade saída do impelidor e 
das palhetas do difusor e, por fim, redução do número de Mach para entrar nas palhetas. Whitfield e Baines (1990) citaram ainda alguns efeitos indesejáveis causados por palhetas do difusor muito próximas à saída do impelidor, como vibração e ruído aumentados e grande influência aerodinâmica do difusor sobre o impelidor.

Todas as referências consultadas apontam para a imposição do espaço sem palhetas. Contudo, a dimensão ideal desse espaço não é consenso, assim como discutido na seção 6.2 que trata do projeto unidimensional do difusor. Os valores de $r_{3} / r_{2}$ (razão entre o raio do bordo de ataque das palhetas e o raio de saída do impelidor) recomendados na literatura vão de 1,05 a 1,25 (AUNGIER, 2000; CAME; ROBINSON, 1999; CUMPSTY, 2004; DIXON; HALL, 2010; WHITFIELD; BAINES, 1990).

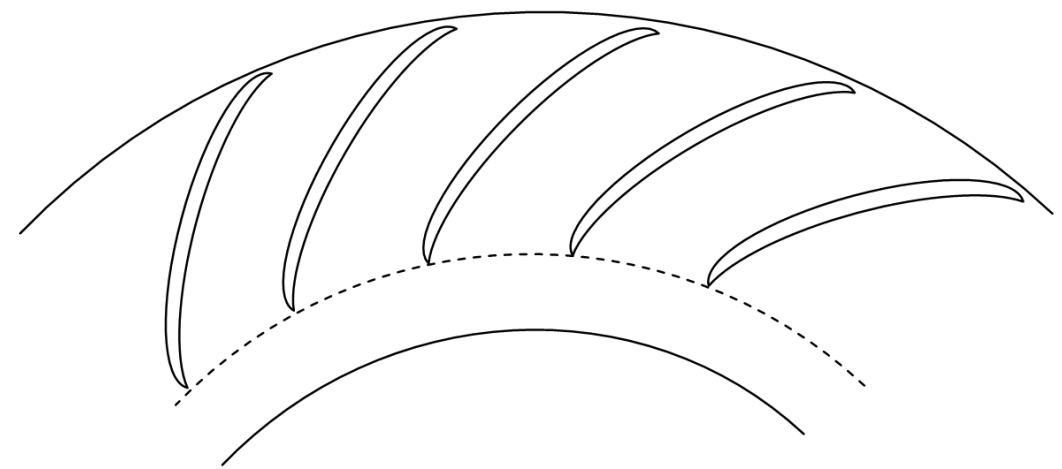

Figura 20 - Difusor radial com aerofólios. As regiões são similares às do difusor de canal da Fig. 19.

O número de palhetas do difusor $Z_{d}$ tem grande influência no desempenho do difusor (CUMPSTY, 2004; DIXON; HALL, 2010). Cumpsty (2004) afirmou que os motivos para tal influência não são conhecidos, ou ao menos não foram publicados. De forma geral, as referências consultadas concordam que o número de palhetas do difusor deve ser menor que o de pás do impelidor. Dixon e Hall (2010), por exemplo, sugeriram o uso de por volta da metade do número de pás do impelidor no difusor. Apenas Aungier (2000) forneceu uma correlação que retorna um número de palhetas do difusor superior ao número de pás do impelidor para o caso de impelidores com 10 ou menos pás.

A eficiência isentrópica da difusão pode ser formulada de acordo com Eq. 73. Os aumentos de entalpia real e isentrópico podem ser representados por relações entre 
pressão e temperatura estáticas nas saídas de impelidor e difusor. Tal formulação é conveniente uma vez que o aumento da pressão estática é avaliado.

$$
\eta_{d, \text { isen }}=\frac{h_{4 s}-h_{2}}{h_{4}-h_{2}}=\frac{\left(P_{4} / P_{2}\right)^{(\gamma-1) / \gamma}-1}{T_{4} / T_{2}-1}
$$

Para quantificar o desempenho de difusores, normalmente se utiliza o coeficiente de pressão $C_{p}$ (CUMPSTY, 2004), mostrado pela Eq. 74. Este coeficiente representa a razão entre o aumento de pressão estática e a pressão que, teoricamente, está disponível para ser transformada em pressão estática na saída do impelidor. Tal quantidade é representada pela diferença entre pressão total e pressão estática na saída do difusor. Dalbert et al. (1999) e Cumpsty (2004) salientaram que difusores com bom desempenho têm coeficiente de pressão por volta de 0,7 .

$$
C_{p}=\frac{p_{4}-p_{2}}{p_{02}-p_{2}}
$$




\section{PROJETO UNIDIMENSIONAL}

\subsection{PROJETO DO IMPELIDOR}

O projeto unidimensional do impelidor foi realizado utilizando principalmente as diretrizes fornecidas por Whitfield e Baines (1990). Assim como foi citado na revisão bibliográfica, esse método se baseia em correlações e ábacos de origem essencialmente empírica, além de princípios básicos de termodinâmica e triângulos de velocidade. Contudo, algumas relações foram adicionadas como é mostrado adiante.

Whitfield e Baines (1990) descreveram uma metodologia para o dimensionamento do impelidor tendo em mãos seu fluxo mássico, razão de pressões e assumindo alguns parâmetros. A escolha dos parâmetros é assistida por ábacos contendo, na maioria dos casos, relações com números de Mach absolutos e relativos, que devem ser controlados para não comprometer a eficiência do impelidor.

Como o objetivo dessa abordagem de processo é maximizar a eficiência, os autores começam fornecendo uma descrição qualitativa sobre as perdas. A dissipação de energia acontece principalmente por atrito, que é proporcional ao comprimento da passagem do ar no compressor e ao quadrado da velocidade relativa entre 0 escoamento e a superfície (WHITFIELD; BAINES, 1990). O vazamento através da ponta das pás (overtip leakage) é outra fonte de perdas apontada pelos autores, sendo dependente da relação entre o espaçamento entre impelidor e carcaça (tip clearance) e a altura das pás. A importância em se conhecer os mecanismos de perdas está na escolha dos parâmetros que precisam ser assumidos além da razão de pressões e fluxo mássico desejados e já determinados.

O procedimento de projeto proposto é bastante simples uma vez que tenham sido definidos alguns ângulos e parâmetros. Ao final, o projeto tem como saídas as dimensões apenas da entrada (indutor) e da saída do impelidor, sem nenhum dado acerca da curvatura do perfil meridional ou sobre a distribuição angular do chamado gas path, os sulcos do impelidor. As dimensões determinadas pelo procedimento estão mostradas na Fig. 21. 
O projeto começa especificando o ângulo absoluto $\left(\alpha_{2}\right)$ do escoamento na descarga do impelidor. Whitfield e Baines (1990) salientaram que este ângulo deve ser variado sistematicamente após a implementação das equações para avaliar sua influência. A escolha da faixa de valores a ser considerada para esse ângulo seguiu recomendações de Whitfield e Baines (1990) baseadas em outras referências que indicavam ângulos entre 60 e 70 graus e 63 e 68 graus. Todo o procedimento de projeto pressupõe um ângulo absoluto na entrada $\left(\alpha_{1}\right)$ nulo, ou seja, o escoamento não tem prewhirl.

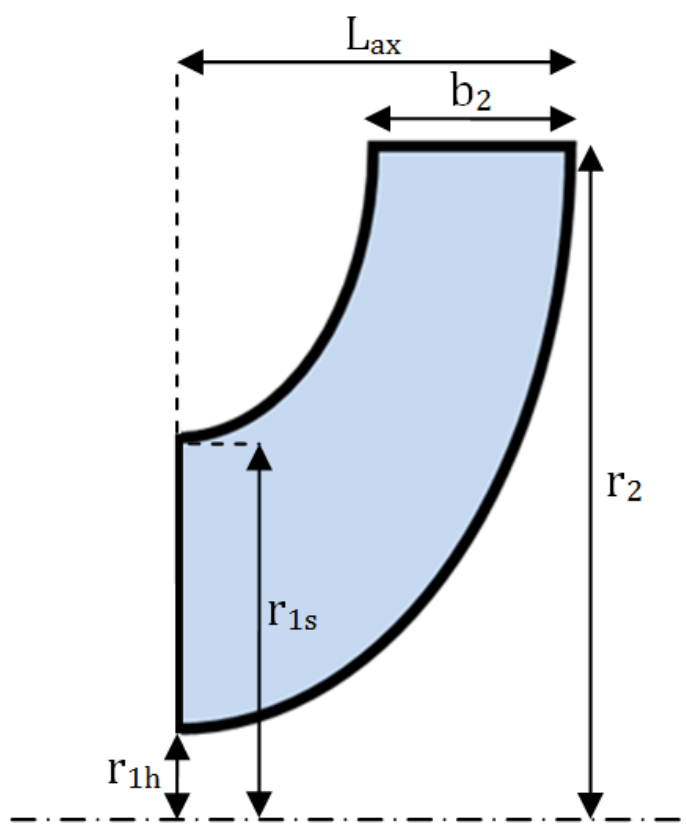

Figura 21 - Dimensões genéricas do perfil meridional do impelidor. Dimensões indicadas são definidas no projeto unidimensional.

O ângulo de sweep das pás na saída $\left(\beta_{B 2}\right)$ também precisa ser definido. A escolha deste ângulo é muito importante, assim como foi mostrado no Cap. 5. Whitfield e Baines (1990) indicam, novamente, a necessidade em avaliar a escolha inicial durante o projeto, verificando os efeitos através de variação sistemática. O número de Mach na saída do impelidor é menor quanto maior for o ângulo de backsweep mantendo-se a mesma velocidade do impelidor, assim como ilustra a Fig. 22. Essa é a razão principal para o uso de backsweep, uma vez que números de Mach menores na saída do impelidor exigem menos do difusor e o possibilita alcançar eficiências maiores. 
O último parâmetro a ser definido inicialmente é o fator de escorregamento, já descrito no Cap. 5. Optou-se por fazer com que a estimativa inicial do fator de escorregamento fosse corrigida através de correlações semi-empíricas ao longo do projeto, realizando iterações até a convergência de seu valor. Isso foi feito no presente projeto. $O$ valor inicial de $\mu=0,85$ foi utilizado a partir da recomendação de Whitfield e Baines (1990).

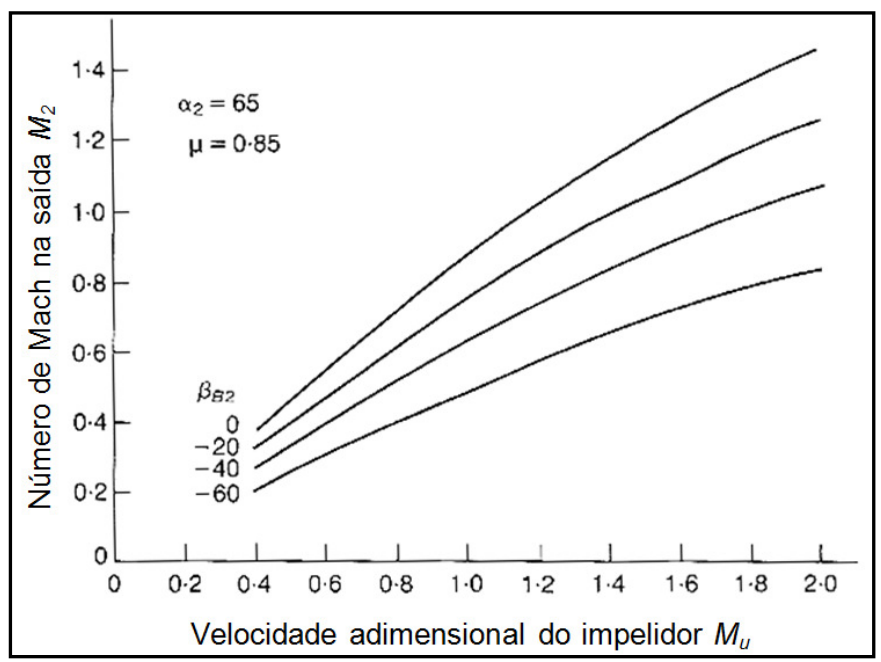

Figura 22 - Gráfico relacionando o número de Mach na saída do impelidor com a velocidade adimensional de rotação do impelidor. São mostrados os efeitos do ângulo de backsweep da saída do impelidor. Adaptado de Whitfield e Baines (1990).

Com estes parâmetros tendo valores iniciais definidos, realiza-se o cálculo do fator de trabalho, assim como definido na Eq. 75. Esse parâmetro relaciona variáveis que compõem o triângulo de velocidades da descarga, facilitando os cálculos seguintes.

Para definir totalmente o triângulo de velocidades adimensionalizado da saída do impelidor, calcula-se inicialmente a velocidade de rotação adimensionalizada $M_{u}$, assim como mostra a Eq. 76, que pode ser derivada com as Eqs. 39 e 75.

$$
\begin{aligned}
& \lambda=\frac{C_{\theta 2}}{U_{2}}=\frac{\mu}{1-\frac{\tan \left(\beta_{B 2}\right)}{\tan \left(\alpha_{2}\right)}} \\
& M_{u}=\frac{U_{2}}{a_{01}}=\sqrt{\frac{P_{R}^{(\gamma-1) / \gamma}-1}{\eta_{s, i s e n} \cdot \lambda \cdot(\gamma-1)}}
\end{aligned}
$$




$$
\begin{aligned}
& \frac{C_{\theta 2}}{a_{01}}=M_{u} \cdot \lambda \\
& \frac{C_{m 2}}{a_{01}}=\frac{C_{\theta 2}}{a_{01}} \frac{1}{\tan \left(\alpha_{2}\right)}
\end{aligned}
$$

Percebe-se que é necessário impor uma eficiência isentrópica inicial ao estágio de compressão. Isso foi feito através da eficiência estimada pelo gráfico de Balje (1981), apresentado na Fig. 8. As componentes $C_{\theta 2}$ e $C_{m 2}$ da velocidade absoluta adimensional são calculadas diretamente com a combinação das Eqs. 75 e 76, assim como mostram as Eqs. 77 e 78.

Tendo a componente $C_{\theta 2}$ e o ângulo $\alpha_{2}$, calcula-se facilmente a velocidade absoluta do escoamento $C_{2}$, assim como evidencia a Eq. 79. Até este ponto, a adimensionalização é feita utilizando $a_{01}$. Para encontrar o valor do número de Mach na saída do impelidor, é conveniente adimensionalizar com $a_{02}$. Para tanto, basta usar a relação da Eq. 81, usando a relação entre as temperaturas de estagnação mostrada na Eq. 80, que, por sua vez, foi derivada no Cap. 5. Pode-se calcular a relação entre as temperaturas de entrada e saída do impelidor considerando a eficiência de todo o estágio porque, em um escoamento adiabático, a temperatura de estagnação é constante ao longo do difusor.

$$
\begin{aligned}
& \frac{C_{2}}{a_{01}}=\frac{C_{\theta 2}}{a_{01}} \frac{1}{\operatorname{sen}\left(\alpha_{2}\right)} \\
& \frac{T_{02}}{T_{01}}=1+(\gamma-1) \frac{U_{2}}{a_{01}} \frac{C_{\theta 2}}{a_{01}} \\
& \frac{C_{2}}{a_{02}}=\frac{C_{2}}{a_{01}} \sqrt{\frac{T_{01}}{T_{02}}}
\end{aligned}
$$

O cálculo do número de Mach depende da relação entre as temperaturas estática e de estagnação, uma vez que $M_{2}=C_{2} / a_{2}$. A relação entre as temperaturas pode ser calculada através da Eq. 82, que vem do equacionamento da entalpia de estagnação, desmembrada em entalpia estática somada à energia cinética, e da 
velocidade do som $\sqrt{\gamma R T}$. Aplica-se então a Eq. 82 à Eq. 83, fornecendo o número de Mach na saída, que tem o comportamento mostrado na Fig. 22.

$$
\begin{aligned}
& \frac{T_{2}}{T_{02}}=1-\frac{(\gamma-1)}{2}\left(\frac{C_{2}}{a_{02}}\right)^{2} \\
& M_{2}=\frac{C_{2}}{a_{02}} \sqrt{\frac{T_{02}}{T_{2}}}
\end{aligned}
$$

O número de Mach relativo na saída também é importante ao projeto, devendo ser controlado. Para calculá-lo é necessário encontrar o triângulo de velocidades da descarga adimensionalizado por $a_{2}$. Portanto, o mesmo procedimento realizado para a velocidade absoluta $C_{2}$ deve ser realizado para a velocidade na ponta do impelidor $U_{2}$, para as componentes circunferencial e meridional, $C_{\theta 2}$ e $C_{m 2}$, e para a componente circunferencial da velocidade relativa $W_{\theta 2}$. As equações utilizadas para esses cálculos estão apresentadas pelas Eqs. de 84 a 88.

$$
\begin{aligned}
& \frac{U_{2}}{a_{02}}=\frac{U_{2}}{a_{01}} \sqrt{\frac{T_{01}}{T_{02}}} \\
& \frac{U_{2}}{a_{2}}=\frac{U_{2}}{a_{02}} \sqrt{\frac{T_{02}}{T_{2}}} \\
& \frac{C_{\theta 2}}{a_{2}}=\frac{C_{\theta 2}}{a_{01}} \sqrt{\frac{T_{02}}{T_{2}} \frac{T_{01}}{T_{02}}} \\
& \frac{W_{\theta 2}}{a_{2}}=\frac{C_{\theta 2}}{a_{2}}-\frac{U_{2}}{a_{2}} \\
& \frac{C_{m 2}}{a_{2}}=M_{2} \cdot \cos \left(\alpha_{2}\right)
\end{aligned}
$$


O número de Mach relativo na saída do impelidor é então calculado como a resultante das componentes $W_{\theta 2}$ e $C_{m 2}$ adimensionais, assim como fica claro no triângulo de velocidades da Fig. 16. A Eq. 89 mostra esse cálculo. As mesmas componentes fornecem ainda o ângulo relativo do escoamento na descarga $\beta_{2}$ através da expressão apresentada pela Eq. 90. A diferença entre $\beta_{2}$ e $\beta_{B 2}$ é devida ao escorregamento.

$$
\begin{aligned}
& M_{2}^{\prime}=\sqrt{\left(\frac{W_{\theta 2}}{a_{2}}\right)^{2}+\left(\frac{C_{m 2}}{a_{2}}\right)^{2}} \\
& \beta_{2}=\arctan \left(\frac{W_{\theta 2}}{a_{2}} / \frac{C_{m 2}}{a_{2}}\right)
\end{aligned}
$$

Esses cálculos terminam os cálculos da saída do impelidor. Para iniciar os cálculos relativos à entrada é necessário assumir um valor para a razão entre o raio do shroud na entrada e o raio na saída $r_{1 s} / r_{2}$. Para balizar a escolha inicial e saber qual a influência desse parâmetro, o gráfico da Fig. 23 mostra um dos efeitos. Razões menores diminuem tanto o número de Mach na saída quanto o número de Mach relativo na entrada. Dessa forma, pode ser interessante controlar e afastar o impelidor de regimes sônicos.

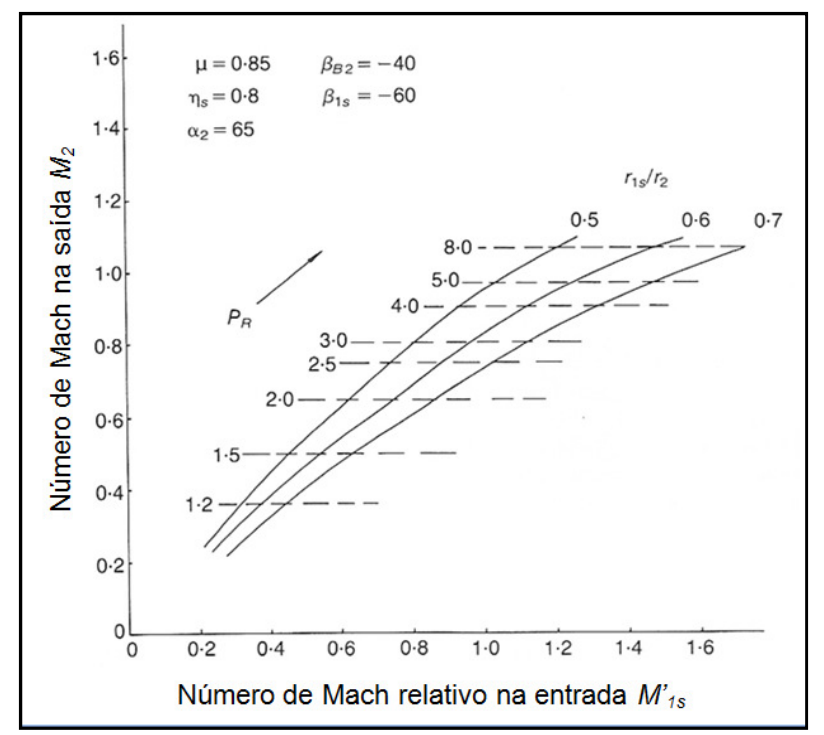

Figura 23 - Gráfico relacionando o número de Mach na saída do impelidor com o número de Mach relativo na entrada do impelidor. São mostrados os efeitos da razão de pressões e da razão entre o raio do shroud na entrada e o raio na saída. Adaptado de Whitfield e Baines (1990). 
Por outro lado, reduzir $r_{1 s} / r_{2}$ implica em aumentar $r_{2}$. Isso acontece porque as dimensões $r_{1 s}, r_{1 h}, r_{2}$ e $b_{2}$ estão vinculadas através da equação da continuidade, mostrada a seguir pela Eq. 97. O aumento de $r_{2}$ força a diminuição da altura das pás na saída $b_{2}$, de modo a manter a área constante. As razões $r_{1 s} / r_{2}$ e $b_{2} / r_{2}$ influenciam-se mutuamente, assim como ilustra a Fig. 24, resultando numa das principais escolhas do projeto preliminar. Pode-se reduzir o Mach relativo na entrada diminuindo $r_{1 s} / r_{2}$, mas isso resulta numa descarga estreita e comprida, aumentando perdas por atrito e tip leakage (WHITFIELD; BAINES, 1990). Ao optar-se por um número de Mach mais alto na entrada, há maior possibilidade de haver perdas por ondas de choque.

$$
\begin{aligned}
& \frac{U_{1}}{a_{01}}=\frac{U_{2}}{a_{01}} \frac{r_{1 s}}{r_{2}} \\
& \frac{W_{\theta 1}}{a_{01}}=-\frac{U_{1}}{a_{01}}
\end{aligned}
$$

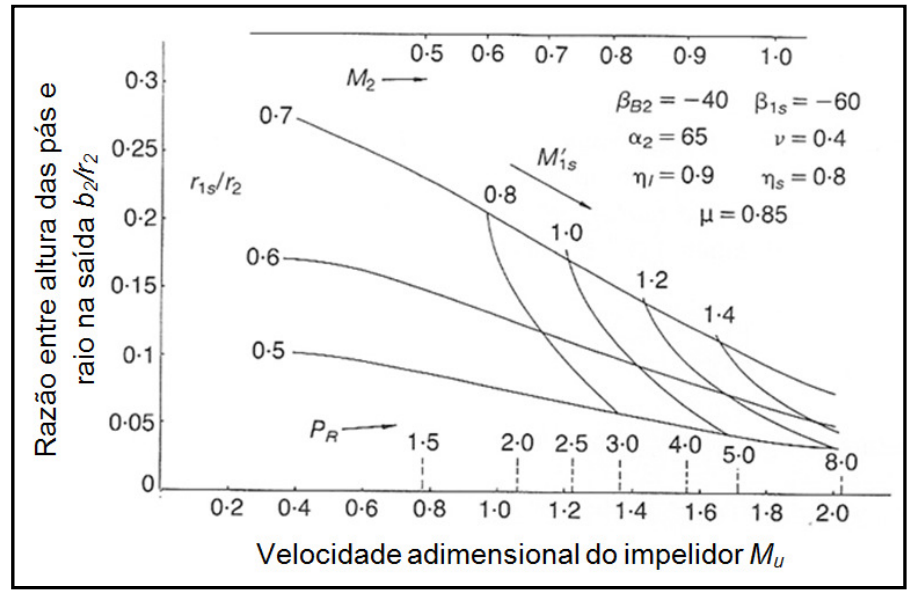

Figura 24 - Gráfico da razão entre altura das pás na saída e o raio do impelidor na saída pela velocidade adimensional do impelidor. O gráfico mostra ainda o efeito da razão de pressões, do número de Mach relativo na entrada, do número de Mach na saída e da razão entre o raio do shroud na entrada e o raio na saída. Adaptado de Whitfield e Baines (1990).

Ao assumir o valor da razão entre o raio do shroud na entrada e o raio na saída, é possível calcular a velocidade adimensional do impelidor na entrada, como expresso pela Eq. 91. Como não há prewhirl, a componente $C_{\theta 1}$ é nula, o que automaticamente iguala a componente circunferencial da velocidade relativa $W_{\theta 1}$ à velocidade do impelidor, a menos da inversão de sinais, como define a Eq. 92. 


$$
\begin{aligned}
& \frac{C_{1}}{a_{01}}=\frac{W_{\theta 1}}{a_{01}} \frac{1}{\tan \left(\beta_{1 s}\right)} \\
& \frac{W_{1 s}}{a_{01}}=\sqrt{\left(\frac{W_{\theta 1}}{a_{01}}\right)^{2}+\left(\frac{C_{1}}{a_{01}}\right)^{2}} \\
& M_{1}=\frac{C_{1}}{a_{01}} \sqrt{1-\frac{(\gamma-1)}{2}\left(\frac{C_{2}}{a_{02}}\right)^{2}} \\
& M_{1}^{\prime}=\frac{M_{1}}{\cos \left(\beta_{1 s}\right)}
\end{aligned}
$$

Nesse ponto, é preciso assumir o valor para o ângulo relativo do escoamento no shroud do indutor $\beta_{1 s}$. Esse ângulo tem valores indicados numa amplitude relativamente pequena. Whitfield e Baines (1990) indicam ângulos entre -50 e -70 graus para minimizar o número de Mach relativo na entrada. A Fig. 25 mostra o efeito desse ângulo nos números de Mach absoluto e relativo no indutor.

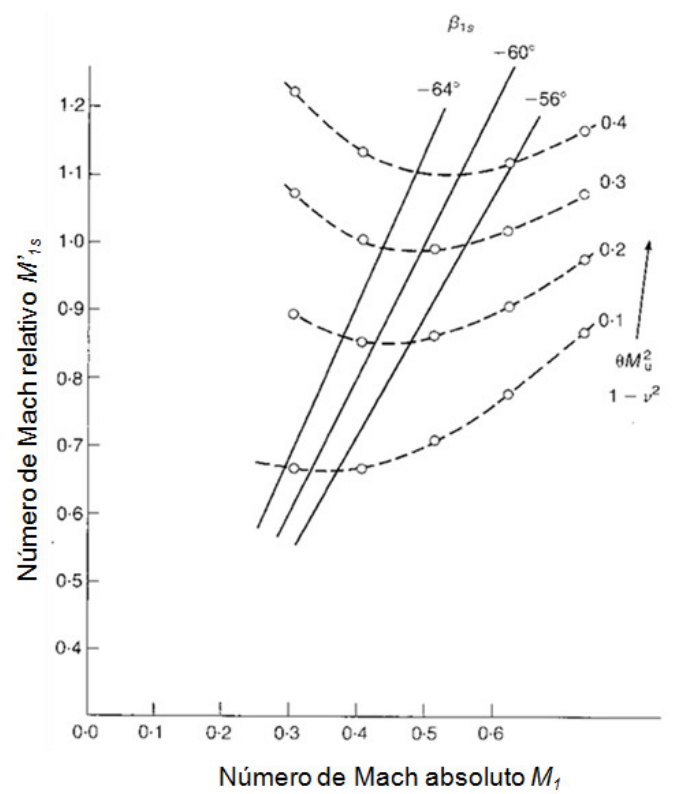

Figura 25 - Gráfico do número de Mach relativo pelo número de Mach absoluto, ambos na entrada do impelidor. O gráfico mostra ainda o efeito do ângulo relativo do escoamento na entrada e da expressão envolvendo a vazão mássica adimensional, velocidade de rotação adimensional e a razão hub/shroud na entrada. Adaptado de Whitfield e Baines (1990). 
Com o ângulo se pode definir o triângulo de velocidades adimensional da entrada e, conseqüentemente, os números de Mach absoluto e relativo na entrada. Esses cálculos são mostrados pelas Eqs. de 93 a 96.

Para relacionar as dimensões da entrada com as da saída, utiliza-se a equação da continuidade, apresentada pela Eq. 97, na qual $B_{2}$ representa o fator de bloqueio (blockage factor). Esse parâmetro é anulado no método de projeto preliminar de Whitfield e Baines (1990), tendo valor unitário. Com valores menores que um, esse fator é equivalente a um estreitamento na área de saída, que ocorre por conta da presença das pás, espessura da camada limite e possível separação do escoamento (DIXON; HALL, 2010).

Ao rearranjar a Eq. 97 é possível isolar a razão $b_{2} / r_{2}$, como mostra a Eq. 98 . Percebe-se que é necessário calcular a densidade na saída do impelidor, além de assumir um valor para a razão $v=r_{1 h} / r_{1 s}$.

$$
\begin{aligned}
& \dot{m}=\rho_{1} \cdot \pi \cdot\left(r_{1 s}^{2}-r_{1 h}^{2}\right) C_{m 1}=\rho_{2} \cdot 2 \pi r_{2} b_{2} \cdot C_{m 2} \cdot B_{2} \\
& \frac{b_{2}}{r_{2}}=\frac{1}{2} \cdot \frac{\rho_{1}}{\rho_{2}} \cdot \frac{r_{1 s}^{2}}{r_{1 h}^{2}}\left(1-v^{2}\right) \frac{C_{m 1}}{C_{m 2}}
\end{aligned}
$$

A densidade adimensional na saída do impelidor pode ser calculada através de simples relações entre pressão e temperatura. A Eq. 99 é usada para calcular a razão entre as pressões de estagnação e estática na saída do impelidor e, com uso da razão de pressões (entre as pressões totais da saída e na entrada), acha-se a pressão estática na saída adimensionalizada por $P_{01}$, como apresenta a Eq. 100. Por fim, a densidade adimensional pode ser calculada pela Eq. 101, na qual é utilizada apenas a equação de gás ideal.

$$
\begin{aligned}
& \frac{P_{02}}{P_{2}}=\left(\frac{T_{02}}{T_{2}}\right)^{\gamma /(\gamma-1)} \\
& \frac{P_{2}}{P_{01}}=P_{R} \frac{P_{2}}{P_{02}}
\end{aligned}
$$




$$
\frac{\rho_{2}}{\rho_{01}}=\frac{P_{2}}{P_{01}} \frac{T_{02}}{T_{2}} \frac{T_{01}}{T_{02}}
$$

Neste ponto do projeto preliminar é conveniente utilizar o coeficiente de escoamento e a vazão mássica adimensional. Partindo da definição de Aungier (2000) já apresentada no Cap. 5 (Eq. 43b), é possível reescrever a expressão do coeficiente de escoamento utilizando a equação da continuidade, como na Eq. 97, e chegar à Eq. 102. Whitfield e Baines (1990) definiram a vazão mássica adimensional como mostrado na Eq. 103. Para facilitar o cálculo e ainda deixá-lo independente do valor da vazão mássica, é possível unir as Eqs. 102 e 103 e utilizar a Eq. 104.

$$
\begin{aligned}
& \phi=\frac{\rho_{1}}{\rho_{01}}\left(\frac{r_{1 s}}{r_{2}}\right)^{2}\left(1-v^{2}\right) \frac{C_{1}}{a_{01}} \frac{a_{01}}{U_{2}} \\
& \theta=\frac{\dot{m}}{\pi r_{2}^{2} \rho_{01} a_{01}} \\
& \theta=\phi \frac{U_{2}}{a_{01}}
\end{aligned}
$$

Pode-se calcular então a razão $b_{2} / r_{2}$ usando a densidade adimensional na saída e a vazão mássica adimensional através da Eq. 105.

$$
\frac{b_{2}}{r_{2}}=\frac{\theta}{2 \frac{\rho_{2}}{\rho_{01}} \frac{C_{m 2}}{a_{01}}}
$$

Com esse último parâmetro adimensional, as dimensões podem ser calculadas. Para tanto, basta especificar a vazão mássica e as condições de estagnação na entrada. Através da Eq. 103, calculam-se a área na saída (Eq. 106) e o raio na saída (Eq. 107). As variáveis $b_{2}, r_{1 s}$ e $r_{1 h}$ são calculadas com base nas razões $b_{2} / r_{2}, r_{1 s} / r_{2}$ e $v$ escolhidas ou calculadas previamente. Esses simples cálculos estão mostrados nas Eqs. de 108 a 110.

$$
A_{2}=\frac{\dot{m}}{\theta \rho_{01} a_{01}}
$$




$$
\begin{aligned}
& r_{2}=\sqrt{\frac{A_{2}}{\pi}} \\
& b_{2}=\frac{b_{2}}{r_{2}} r_{2} \\
& r_{1 s}=\frac{r_{1 s}}{r_{2}} r_{2} \\
& r_{1 \mathrm{~h}}=v \cdot r_{1 s}
\end{aligned}
$$

O projeto é conduzido de maneira adimensional até o final para que seja possível variar sistematicamente os parâmetros que precisam ser assumidos. Os gráficos mostrados ao longo desse capítulo ajudam a entender o efeito de uma variável sobre a outra e há outros gráficos do mesmo tipo nos trabalhos de Casey (1994) e Whitfield e Baines (1990) que também foram utilizados. Controlaram-se os números de Mach absolutos e relativos, além de ter-se dado atenção às dimensões finais de modo que se mantivessem dentro do razoável, especialmente as razões $b_{2} / r_{2}$ e $v$. A Fig. 29 apresenta um fluxograma com as etapas do projeto descrito e sistematizado numa rotina computacional apresentada no Apêndice.

O método de Whitfield e Baines (1990) nada apontou diretamente sobre o comprimento axial do impelidor $L_{a x}$ ou o número de pás $Z$ a ser empregado. Os autores apenas citaram que o número de pás pode influenciar as características de bloqueio (blockage) do impelidor, o fator de escorregamento e o tamanho necessário do hub para acomodar as pás.

Dessa forma, foi necessário pesquisar alguma correlação para essas variáveis. Came e Robinson (1999) e Dufour (2006) apresentaram a expressão para cálculo do comprimento axial mostrada na Eq. 111. Tal expressão é dependente dos raios na entrada e saída do impelidor e do número de Mach relativo na entrada. Dufour (2006) apontou ainda que, em caso de não haver as informações requeridas, uma boa estimativa é impor $L_{a x} \approx 0,7 r_{2}$, mas no caso foi possível usar a correlação completa. 


$$
L_{a x}=2 r_{2} \sqrt{0,28\left(M_{1}^{\prime}+0,8\right)\left(1-\frac{r_{1 s}-r_{1 h}}{2 r_{2}}\right) \frac{r_{1 s}-r_{1 h}}{r_{2}}}
$$

Para o número de pás foram encontradas mais de uma correlação e foram constatados resultados díspares entre estas correlações. Rodgers (2000) propôs uma correlação envolvendo a velocidade específica e o ângulo relativo do escoamento na saída $\beta_{2}$. A velocidade específica pode ser calculada diretamente com os parâmetros calculados no projeto unidimensional com o uso da Eq. 112, enquanto a correlação de Rodgers (2000) é dada pela Eq. 113.

$$
\begin{aligned}
& N_{s}=\frac{\sqrt{\frac{\rho_{01}}{\rho_{1}} \pi \phi}}{\left(\lambda \cdot \eta_{s}\right)^{3 / 4}} \\
& Z=25 \cdot \frac{\cos \left(\beta_{2}\right)}{N_{s}}
\end{aligned}
$$

Uma correlação de Came e Robinson (1999) que utiliza o raio na saída do impelidor, uma razão espaço-corda e o comprimento axial do impelidor pode ser usada para estimar o número de pás. A razão espaço-corda ( $\kappa$ ) é bem definida para compressores axiais, nos quais a corda das palhetas e o espaçamento entre elas são relacionados na típica representação por cascata (DIXON; HALL, 2010). Came e Robinson (1999) se utilizaram desse conceito e o relacionaram com a razão de pressões, afirmando que o valor de $\kappa$ é 0,17 para uma razão de pressões igual a 6 e que fica entre 0,25 e 0,35 para razões de pressões entre 2 e 3 . A correlação pode ser escrita como na Eq. 114 para dar o número de pás.

$$
Z=\frac{\pi r_{2}}{\kappa \cdot L_{a x}}
$$

Os trabalhos de Xu (2007) e Xu e Amano (2012a) relacionaram o número de pás com a razão de pressões do compressor e tal relação foi utilizada no projeto de Moura (2008). Os autores coletaram dados de compressores reais com eficiências consideradas altas e dispuseram os resultados no gráfico da Fig. 26, no qual foi feita uma linha de tendência para guiar outros projetos. Contudo, percebe-se que a 
dispersão dos dados é muito grande e não há resolução que justifique a reta traçada.

Os autores salientaram que os diferentes números de pás em impelidores com razão de pressões iguais ou próximas são devidos aos diferentes tamanhos dos impelidores, que mediam de 2 a 45 polegadas nos dados apresentados. Com impelidores muito pequenos o número de pás é limitado. Percebe-se então que não há uma boa correlação entre as duas variáveis.

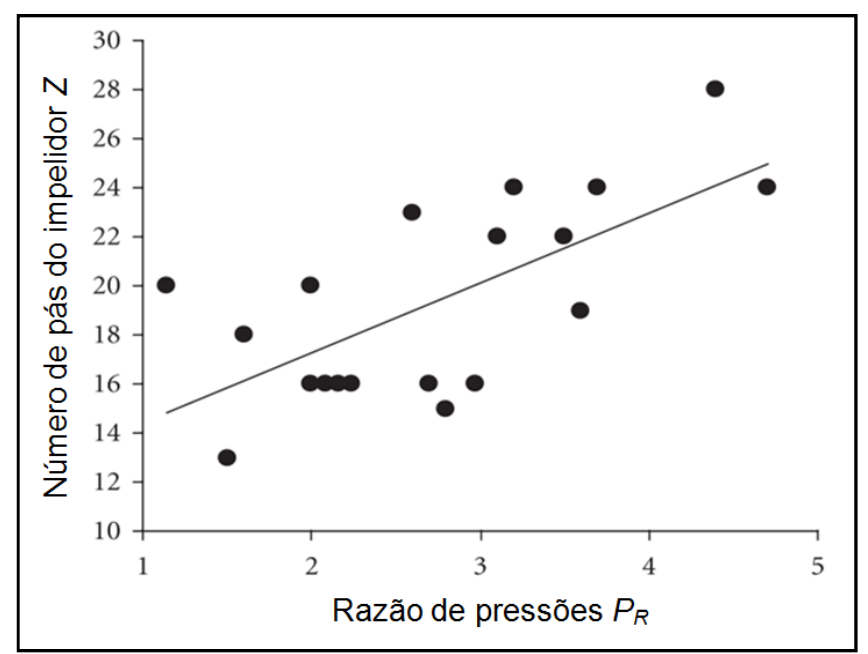

Figura 26 - Dados empíricos relacionando o número de pás do impelidor e a razão de pressões. Adaptado de Xu e Amano (2012a).

Em vista das diferenças de resultados, buscaram-se outras correlações. Dixon e Hall (2010) mostraram três correlações para rotores de turbinas radiais. Optou-se por utilizá-las apenas como parâmetro. Todas utilizam o ângulo absoluto do escoamento na entrada do rotor, equivalente ao ângulo de saída do impelidor $\alpha_{2}$. As Eqs. 115, 116 e 117 mostram as correlações de Glassman (1976), Jamieson (1955) e Whitfield (1990), respectivamente. A correlação de Jamieson (1955) define um número mínimo de pás.

$$
\begin{aligned}
& Z=\frac{\pi}{30}\left(110-\alpha_{2}\right) \tan \alpha_{2} \\
& Z=2 \pi \cdot \tan \alpha_{2}
\end{aligned}
$$




$$
Z=\frac{1}{\cos ^{2} \alpha_{2}}
$$

Os resultados obtidos por Campos e Krieger Filho (2012) sugeriram que fossem empregadas as correlações de Came e Robinson (1999) e Rodgers (2000), além dos gráficos de Xu e Amano (2012a). Dessa forma, optou-se por fazer uma média entre essas três opções, uma vez que não há indicações sobre qual delas é melhor.

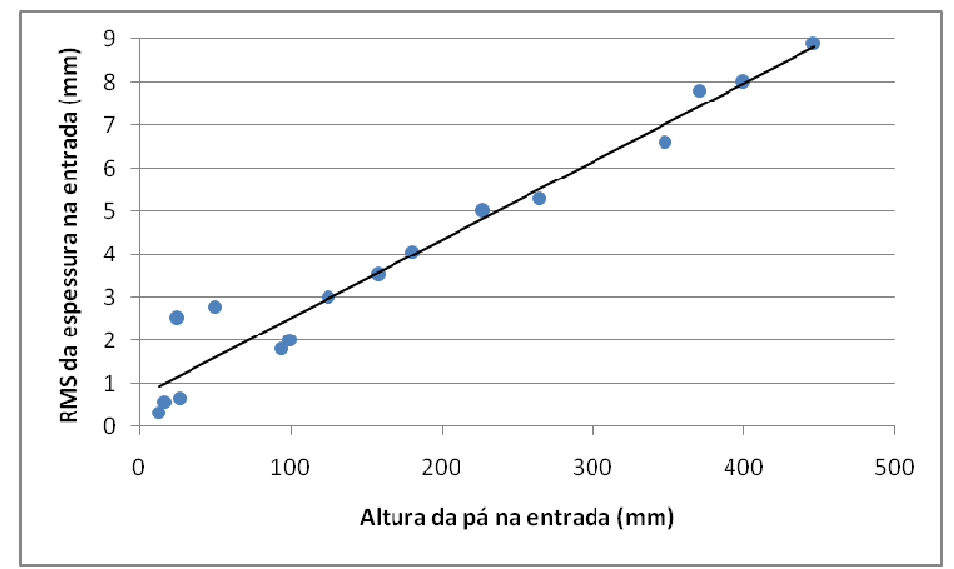

Figura 27 - Relação entre altura das pás e RMS de sua espessura para a entrada dos impelidores. Dados de Xu e Amano (2012a).

Além desses parâmetros, ainda foram incluídas no projeto unidimensional estimativas da espessura das pás através das relações apresentadas por Xu e Amano (2012a). Os autores relacionaram o RMS da espessura das palhetas na entrada e saída do impelidor com a altura das pás nessas localizações, assim como mostram as Figs. 27 e 28. Percebe-se que há maior adequação dos dados experimentais às retas do que na relação entre razão de pressões e número de pás (Fig. 26).

Apesar de representar apenas o RMS da espessura, sem a distribuição ao longo da corda, esta relação foi usada para definir o valor da espessura na entrada e saída do impelidor que foi utilizado até o final do projeto, inclusive para as simulações tridimensionais. Entre entrada e saída do impelidor, adotou-se variação linear na espessura. Trata-se apenas de uma estimativa, uma vez que a definição final da espessura está mais vinculada à análise dos esforços mecânicos no impelidor, que não faz parte do escopo da presente dissertação. 


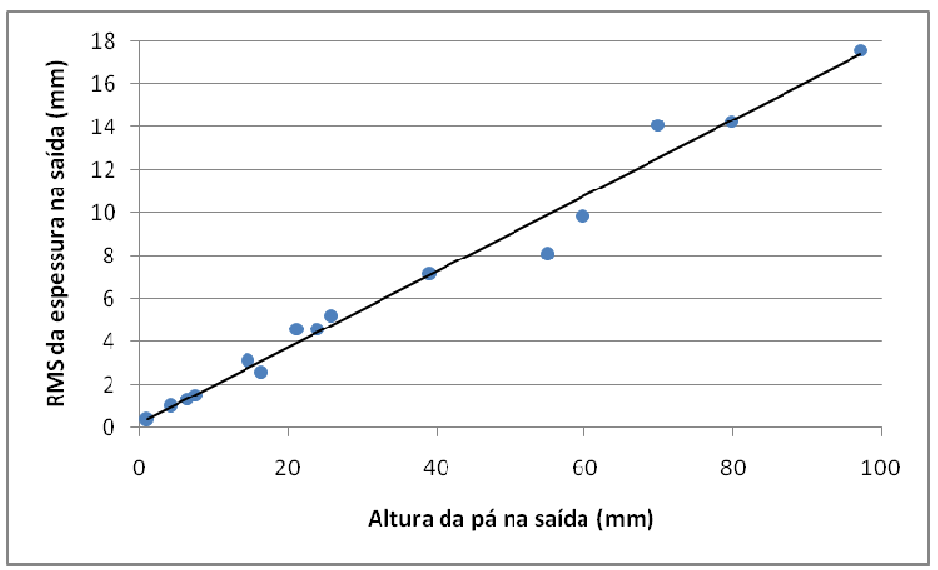

Figura 28 - Relação entre altura das pás e RMS de sua espessura para a saída dos impelidores. Dados de Xu e Amano (2012a).

O procedimento descrito para projeto foi implementado numa simples rotina feita no software MatLab, presente no Apêndice. Dessa forma, foram variados os diversos parâmetros que deveriam ser escolhidos de acordo com Whitfield e Baines (1990).

Tabela 2 - Faixas utilizadas para os parâmetros variados durante o projeto unidimensional e as referências que ajudaram a determiná-las.

\begin{tabular}{|c|c|c|}
\hline Parâmetro & Faixa adequada & Referências \\
\hline \multirow{2}{*}{$\alpha_{2}$} & \multirow{2}{*}{$60^{\circ}$ a $80^{\circ}$} & Aungier (2000) \\
\hline & & Whitfield e Baines (1990) \\
\hline$\beta_{1 S}$ & $-70^{\circ}$ a $-50^{\circ}$ & Whitfield e Baines (1990) \\
\hline \multirow{3}{*}{$\boldsymbol{\beta}_{B 2}$} & \multirow{3}{*}{$-65^{\circ}$ a $0^{\circ}$} & Cumpsty (2004) \\
\hline & & Swain (1992) \\
\hline & & Whitfield e Baines (1990) \\
\hline \multirow{2}{*}{$r_{1 s} / r_{2}$} & \multirow{2}{*}{0,4 a 0,7} & Rusch e Casey (2012) \\
\hline & & Swain (1992) \\
\hline \multirow{2}{*}{$v$} & \multirow{2}{*}{0,3 a 0,6} & Swain (1992) \\
\hline & & Vavra (1970) \\
\hline \multirow{2}{*}{$\boldsymbol{U}_{2}$} & \multirow{2}{*}{$\leq 500 \mathrm{~m} / \mathrm{s}$} & Came e Robinson (1999) \\
\hline & & Dalbert et al. (1999) \\
\hline$b_{2} / r_{2}$ & $\geq 0,08$ & AGARD (1970) \\
\hline
\end{tabular}

Os parâmetros variados foram o ângulo de saída absoluto do escoamento $\alpha_{2}$, o ângulo das pás no shroud da entrada $\beta_{1 S}$, o ângulo das pás na saída $\beta_{B 2}$, a razão 
entre os raios da entrada e saída $r_{1 S} / r_{2}$ e a razão entre os raios de hub e shroud na entrada $v$.

Algumas restrições foram impostas às entradas e saídas dos cálculos de projeto. A Tab. 2 apresenta as faixas de valores para cada variável, assim como as referências consultadas para escolha dessas faixas. Nessa tabela, há ainda as restrições impostas à velocidade da ponta do impelidor e à razão entre altura da pá na saída e o raio na saída.

Com base nas restrições impostas a rotina computacional avaliou, a partir do cálculo das perdas apresentado na seção 6.3, mais de 300 mil combinações. Mais da metade foi excluída por não atender a alguma das restrições ou resultar em valores incoerentes.

Para cada conjunto de parâmetros os cálculos apresentados são realizados os cálculos apresentados a partir da estimativa de um fator de escorregamento inicial. Com as dimensões calculadas, o valor do fator de escorregamento é recalculado até a convergência utilizando as correlações apresentadas pelas Eqs. 70 a 72 .

Feito isso, as dimensões são submetidas ao cálculo da eficiência através das estimativas de perdas, apresentadas na seção 6.3 desta dissertação. O valor encontrado para a eficiência substitui então o valor inicial estimado, que é necessário para o início do processo. Isso é feito até a convergência da eficiência. A Fig. 29 apresenta esquematicamente o processo utilizado no projeto unidimensional. 


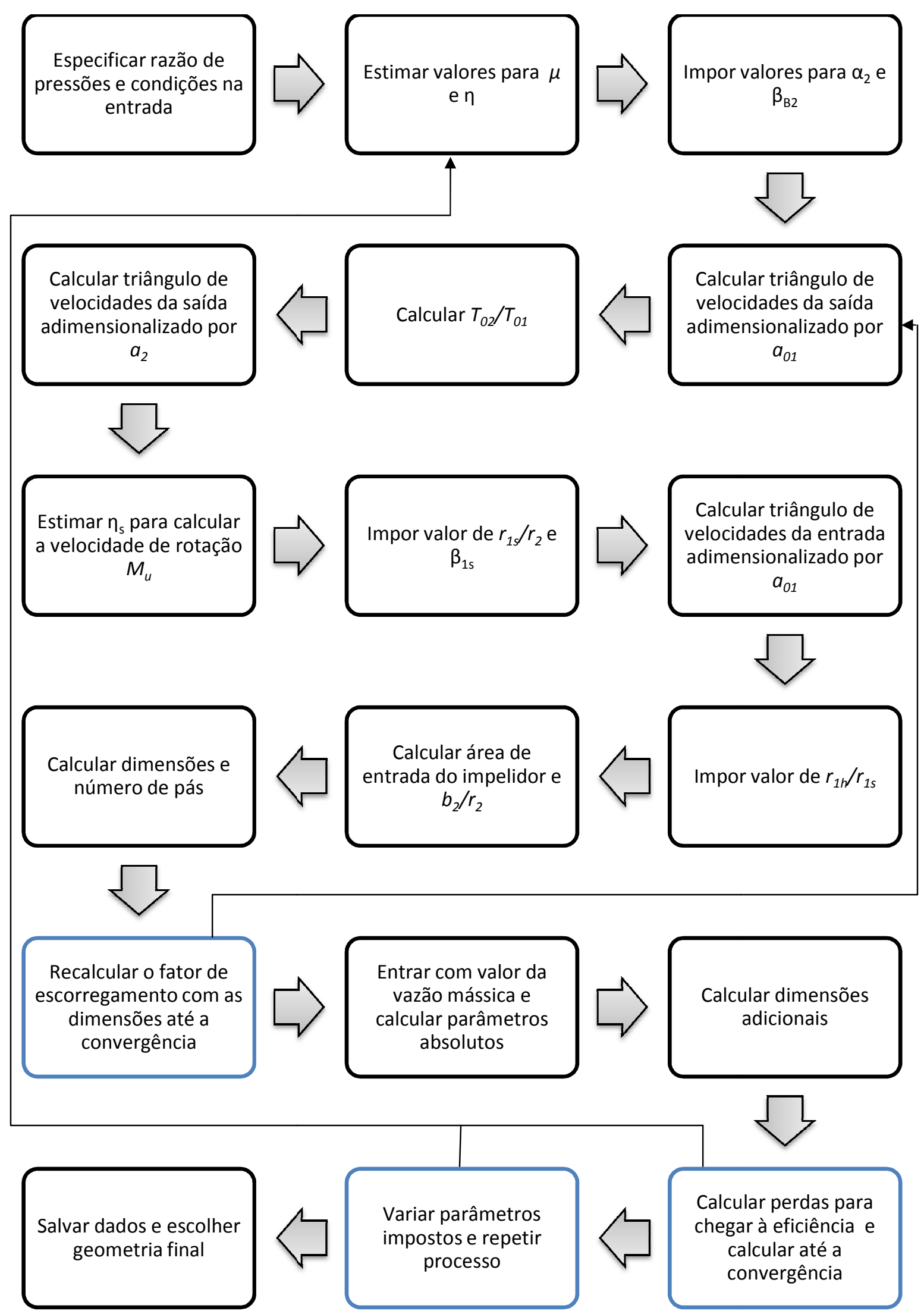

Figura 29 - Fluxograma do método unidimensional de projeto preliminar utilizado. 


\subsection{PROJeto do difusor}

A revisão realizada na literatura apontou que há um número consideravelmente menor de trabalhos tratando do projeto de difusores para compressores centrífugos em comparação aos trabalhos para impelidores. A abordagem mais orientada especificamente para o projeto foi dada por Aungier (2000), tratando do projeto de difusores com aerofólios, apesar de não ser bastante clara com alguns dos parâmetros.

A definição da geometria de um difusor com aerofólios requer o raio do bordo de ataque das palhetas $r_{3}$, o raio de saída do difusor $r_{4}$, a linha de câmber das palhetas, a distribuição de espessura das palhetas e o número de palhetas $Z_{d}$. Aungier (2000) forneceu diretrizes para a escolha da maioria desses parâmetros. Foram utilizados ainda ábacos e correlações fornecidas por Rossetti et al. (2010).

Cumpsty (2004) salientou que há evidências de que o formato da face de sucção exerce pouca influência no projeto. O mesmo ocorre para o ângulo de entrada das palhetas $\beta_{B 3}$. Cumpsty (2004) destacou a área da garganta e a razão entre o raio do bordo de ataque das palhetas e o raio de saída do impelidor $r_{3} / r_{2}$ como os parâmetros que mais influenciam o desempenho dos difusores. Esta característica é levada em conta no presente projeto, no qual as variáveis arbitradas foram as que têm menos importância ao desempenho.

O cálculo do ângulo absoluto do escoamento na entrada do difusor $\alpha_{3}$ pode ser estimado pela correlação dada por Aungier (2000), e aqui representada pela Eq. 118. As expressões foram adaptadas à convenção adotada no restante desta dissertação, com os ângulos relativos à direção meridional.

$$
\begin{array}{ll}
\alpha_{3}=90-\left[18-\frac{\left(90-\alpha_{2}-18\right)}{4}\right] & \text { se } 90-\alpha_{2} \leq 18 \\
\alpha_{3}=90-18 & \text { se } 90-\alpha_{2}>18
\end{array}
$$

Tendo estimado o ângulo $\alpha_{3}$, a correlação da Eq. 119 é utilizada para calcular a razão $r_{3} / r_{2}$. Tal correlação depende ainda do número de Mach na saída do impelidor, de modo que, quanto maior o número de Mach, maior a razão $r_{3} / r_{2}$. Esse 
fato vai de encontro a uma das funções do espaço sem palhetas, discutidas na seção 5.8, que é desacelerar o escoamento e evitar escoamento transônico no bordo de ataque das palhetas.

$$
\frac{r_{3}}{r_{2}}=1+\frac{90-\alpha_{3}}{360}+\frac{M_{2}^{2}}{15}
$$

O raio de saída do difusor $r_{4}$ pode ser estimado com a relação dada pela Eq. 120 , fornecida novamente por Aungier (2000). Nesta equação há dependência do raio de saída do impelidor e do coeficiente de escoamento, desta vez definido de acordo com a Eq. 121.

$$
\begin{aligned}
& r_{4}=(1,55+\phi) r_{2} \\
& \phi=\frac{\dot{m}}{\left(\pi \rho_{01} r_{2}^{2} U_{2}\right)}
\end{aligned}
$$

Os ângulos das palhetas na entrada e saída $\left(\beta_{B 3}\right.$ e $\left.\beta_{B 4}\right)$ também devem ser definidos. De acordo com Aungier, a imposição do ângulo $\alpha_{3}$ requer que o ângulo das palhetas na entrada $\beta_{B 3}$ seja praticamente igual. Contudo, o autor descreve um desvio $i$ com valor usual de $-^{\circ}{ }^{\circ}$ entre os ângulos do escoamento e das palhetas. Dessa forma, a Eq. 122 pode ser utilizada para definir $\beta_{B 3}$.

$$
\beta_{B 3}=i-\alpha_{3}
$$

O ângulo de saída $\beta_{B 4}$ é definido variando-se seu valor e monitorando os parâmetros $\theta_{C}$ e $A_{R}$. O primeiro é o ângulo de divergência equivalente, definido pela Eq. 123, e Aungier (2000) recomenda valores entre 3,5 e 5,5․ Na equação do ângulo de divergência, $L_{d}$ é o comprimento da passagem, que pode ser estimado com a expressão da Eq. 124. A razão de áreas $A_{R}$ tem valores indicados entre 1,4 e 2,4 e é expressa pela Eq. 125. Dessa forma, escolhe-se algum ângulo $\beta_{B 4}$ que satisfaça essas condições. 


$$
\begin{aligned}
& \theta_{C}=\arctan \left[\pi \frac{r_{4} \operatorname{sen}\left(90+\beta_{B 4}\right)-r_{3} \operatorname{sen}\left(90+\beta_{B 3}\right)}{L_{d} Z_{d}}\right] \\
& L_{d} \approx \frac{2 r_{3}\left(r_{4} / r_{3}-1\right)}{\operatorname{sen} \beta_{B 3}+\operatorname{sen} \beta_{B 4}} \\
& A_{R}=\frac{r_{4} \operatorname{sen}\left(90+\beta_{B 4}\right)}{r_{3} \operatorname{sen}\left(90+\beta_{B 3}\right)}
\end{aligned}
$$

O número de palhetas $Z_{d}$, necessário para definição do ângulo de divergência equivalente, pode ser estimado de acordo com as recomendações de Aungier (2000). De acordo com o autor, o número preferencial de pás é dado por $Z_{d}=Z \pm 1$, para os casos nos quais essa expressão deixe o difusor com um número de palhetas entre 10 e 20. A expressão está em desacordo com o indicado por Cumpsty (2004), que defendeu um número de palhetas necessariamente menor que o de pás do impelidor (Z). Dixon e Hall (2010) chegaram a afirmar ainda que um número de palhetas por volta da metade das pás do impelidor é recomendável.

De qualquer maneira, para as geometrias mais eficientes do projeto do difusor, não houve casos com $Z<21$. Para esses casos, Aungier (2000) indicou que a condição $\left|Z_{d}-Z\right| \geq 8$ deve ser satisfeita. Dessa forma, selecionou-se o número de palhetas capaz de satisfazer essa relação sempre tendo um número de palhetas menor que o de pás do impelidor.

Faz-se importante salientar que o número de palhetas do difusor está diretamente relacionado à área da garganta do difusor. Com mais dados sobre o escoamento na entrada do difusor, seria possível impor um número de pás que evitasse o choke de acordo com a faixa operacional desejada.

A linha de camber das pás foi definida de duas maneiras. Com variação linear do ângulo $\beta$ entre entrada e saída, de acordo com Rossetti et al. (2010) ou com característica logarítmica, como preconizado por Aungier (2000).

$$
\begin{aligned}
& \frac{e}{e_{\text {máx }}}=e_{0}+\left(1-e_{0}\right)\left(2 \frac{x}{c}\right)^{n} ; \quad \frac{x}{c} \leq 0,5 \\
& \frac{e}{e_{\text {máx }}}=e_{0}+\left(1-e_{0}\right)\left(2-2 \frac{x}{c}\right)^{n} ; \quad \frac{x}{c}>0,5
\end{aligned}
$$


A espessura das palhetas seguiu o formato do aerofólio NACA 66-006 apontado por Aungier (2000). A Eq. 126 representa a distribuição de espessura desse aerofólio em função da porcentagem da corda $x / c$. A espessura máxima $e_{\text {máx }}$, parâmetro necessário para definir a distribuição de espessura deve ser escolhida pelo projetista de acordo com Aungier (2000). Isso foi feito de maneira arbitrária baseando-se no aspecto usual das palhetas e mantendo a proporção com relação a $r_{4}$.

$\mathrm{Na}$ equação da espessura, têm-se os parâmetros definidos pelas Eqs. 127 e 128 . Neles, a espessura na entrada e na saída $\left(e_{B 3}\right.$ e $\left.e_{B 4}\right)$ foram estimados de acordo com dados apresentados por Japikse e Baines (1998).

$$
\begin{array}{ll}
e_{0}=\frac{\left[e_{B 3}+\left(e_{B 4}-e_{B 3}\right) x / c\right]}{e_{\text {máx }}} & \\
n=0,755\left(0,57-\frac{x}{c}\right) ; & \frac{x}{c} \leq 0,539 \\
n=1,255\left(\frac{x}{c}-0,52\right) ; & \frac{x}{c}>0,539
\end{array}
$$

Por fim, a altura das passagens $b_{3}$ foi considerada igual à altura da saída do impelidor $b_{2}$, por simplicidade. Aungier (2000) e Cumpsty (2004) recomendaram que $b_{3}$ seja menor ou igual a $b_{2}$. A altura da passagem foi mantida constante, de modo que $b_{3}$ seja igual a $b_{4}$.

\subsection{ESTIMATIVA DA EFICIÊNCIA}

Para que cada geometria gerada no processo do projeto unidimensional seja avaliada, a eficiência é calculada com base em estimativas de perdas. Whitfield e Baines (1990), assim como muitos outros autores, apresentaram alguns tipos de perdas e possíveis correlações para estimá-las. Contudo, foi empregado no presente trabalho o conjunto de perdas avaliado por Oh; Yoon e Chung (1997). Esses autores, assim como mencionado no Cap. 2, avaliaram diversas correlações disponíveis para cada tipo de perda e compararam o resultado de cada possível conjunto com dados experimentais. O resultado de tal trabalho foi um conjunto 
considerado pelos autores o mais adequado para prever o desempenho neste estágio do projeto.

De acordo com Oh; Yoon e Chung (1997), as perdas podem ser classificadas em internas ou parasitas, enquanto Dalbert et al.(1999) as consideram perdas aerodinâmicas ou parasitas. Perdas parasitas representam a diferença entre o trabalho aplicado ao impelidor do compressor e o trabalho de fato disponível às pás do impelidor (AUNGIER, 2000). Além de perdas mecânicas, as perdas parasitas estão associadas também a escoamentos secundários (BOTHA; MOOLMAN, 2005).

Dentre as perdas analisadas por Oh; Yoon e Chung (1997) as perdas por atrito no disco, recirculação e vazamento na ponta das pás são as parasitas.

Perdas internas estão relacionadas ao escoamento principal. Oh; Yoon e Chung (1997) apontam as perdas por incidência, carga nas pás, atrito viscoso, folga e mistura como perdas internas. As perdas internas afetam tanto a eficiência quanto a razão de pressões gerada pelo impelidor, enquanto as perdas parasitas afetam apenas a eficiência, assim como denotam as Eqs. 129 e 130.

$$
\begin{aligned}
& \eta_{I, \text { isen }}=\frac{\Delta h_{\text {Euler }}-\left(\Delta h_{\text {inc }}+\Delta h_{c g}+\Delta h_{a t}+\Delta h_{f o l}+\Delta h_{\text {mis }}\right)}{\Delta h_{\text {Euler }}+\left(\Delta h_{\text {atd }}+\Delta h_{\text {rec }}+\Delta h_{\text {vaz }}\right)} \\
& P_{R}=\left[\frac{\Delta h_{\text {Euler }}-\left(\Delta h_{\text {inc }}+\Delta h_{c g}+\Delta h_{a t}+\Delta h_{f o l}+\Delta h_{m i s}\right)}{c_{P} T_{01}}+1\right]^{\gamma /(\gamma-1)}
\end{aligned}
$$

As correlações que estimam as perdas são expressas por aumentos na entalpia. Para cálculo da eficiência isentrópica é feita comparação com o aumento de entalpia de Euler, definido pela Eq. 131. Trata-se do aumento entálpico que ocorreria num escoamento sem perdas viscosas.

$$
\Delta h_{\text {Euler }}=U_{2} \cdot C_{\theta 2}
$$

A seguir as expressões utilizadas para estimativa das perdas serão apresentadas. A maior parte dessas equações tem fundamentação empírica, enquanto outras se baseiam em fundamentos físicos. Contudo, não serão explicitadas suas origens 
neste trabalho, sendo que essas informações podem ser encontradas nos trabalhos citados por Oh; Yoon e Chung (1997).

Faz-se importante salientar que foram utilizadas apenas correlações para perdas no impelidor do compressor. Não foram encontradas na literatura maneiras de prever o desempenho de difusores tendo tão poucas informações sobre suas características quanto neste estágio do projeto.

\subsubsection{PERDAS INTERNAS}

Uma das perdas internas que ocorrem em compressores centrífugos é a perda por incidência. Ela ocorre devido à diferença entre os ângulos do fluido entrando no impelidor e das pás do impelidor, fazendo com que o escoamento altere rapidamente sua direção.

A Eq. 132 apresenta a equação utilizada para calcular esta perda. Percebe-se a dependência da velocidade relativa circunferencial e do definido coeficiente de perda de energia $f_{\text {inc }}$. Segundo o autor da correlação, tal coeficiente deve ter valor entre 0,5 e 0,7. Adotou-se o valor de 0,6.

$$
\Delta h_{i n c}=f_{i n c} \frac{W_{\theta 1}^{2}}{2}
$$

A perda por carga nas pás está relacionada à presença da camada limite na superfície das pás. A Eq. 133 mostra a correlação para estimar a perda, que é dependente da velocidade de rotação do impelidor $U_{2}$. A expressão depende ainda do fator de difusão, definido pela Eq. 134.

$$
\begin{aligned}
& \Delta h_{c g}=0,05 \cdot D_{f}^{2} \cdot U_{2}^{2} \\
& D_{f}=1-\left(\frac{W_{2}}{W_{1 s}}\right)+\frac{0,75 \Delta h_{\text {Euler }} / U_{2}^{2}}{\left(W_{1 s} / W_{2}\right)\left[(Z / \pi)\left(1-D_{1 s} / D_{2}\right)+2 D_{1 s} / D_{2}\right]}
\end{aligned}
$$


A terceira perda interna a ser considerada é por conta do atrito viscoso entre o fluido e as paredes do impelidor. Neste caso é necessário estimar o coeficiente de atrito $C_{f}$ para calcular a perda mostrada pela Eq. 135. Trata-se de um coeficiente que denota o cisalhamento decorrente da interação entre o escoamento e as paredes adjacentes a ele.

$$
\Delta h_{a t}=2 \cdot C_{f} \cdot \frac{L_{e}}{D_{\text {hid }}} \cdot(\bar{W})^{2}
$$

Para estimar o coeficiente de atrito estimou-se uma rugosidade $k_{s}$ de 0,046 $\mathrm{mm}$ de acordo com o exposto por Crowe; Roberson e Elger (2001) para uma superfície típica de aço. Com isso, se calcula o fator de atrito $f$, com a equação de SwameeJain, mostrada na Eq. 136, assim como apresentada por Crowe; Roberson e Elger (2001). Este fator tem seu valor igual a 4 vezes o coeficiente de atrito. O número de Reynolds necessário à essa expressão foi calculado utilizando a velocidade na ponta da pá $U_{2}$, a espessura da pá na saída $b_{2}$ e a viscosidade na saída calculada através da temperatura e densidade do ar na saída.

$$
f=\frac{0,25}{\left[\log _{10}\left(\frac{k_{s}}{3,7 D}+\frac{5,74}{R e^{0,9}}\right)\right]^{2}}
$$

Ainda na expressão da perda por atrito, há o parâmetro $\bar{W}$, uma relação entre velocidades absolutas e relativas na entrada e saída do impelidor. Como o projeto unidimensional não envolvia a velocidade relativa no hub na entrada $W_{1 h}$, adotou-se uma aproximação, assim como na Eq. 137. Foi necessário realizar também uma aproximação para o comprimento percorrido pelo escoamento $L_{e}$, ou seja, o comprimento da linha de corrente média. Tal aproximação está expressa pela Eq. 138.

$$
\bar{W}=\frac{C_{1}+C_{2}+W_{1 s}+2 W_{1 h}+3 W_{2}}{8} \approx \frac{C_{1}+C_{2}+2 W_{1 s}+3 W_{2}}{7}
$$




$$
L_{e} \approx 1,3 \sqrt{\left[L_{a x}-\left(\frac{b_{2}}{2}\right)\right]^{2}+\left[r_{2}-\left(\frac{r_{1 s}+r_{1 h}}{2}\right)\right]^{2}}
$$

O último parâmetro necessário é o chamado diâmetro hidráulico $D_{\text {hid }}$. O cálculo foi feito com a média entre os diâmetros hidráulicos da entrada e saída, representados pelas Eqs. 139 e 140, respectivamente. O diâmetro hidráulico é definido como quatro vezes a área da seção dividida pelo seu perímetro (GRAVDAHL et al., 2004).

$$
\begin{aligned}
& D_{\text {hid } 1}=\frac{4 \pi\left(r_{1 s}-r_{1 h}\right)^{2}}{2 \pi r_{1 s}} \\
& D_{\text {hid } 2}=\frac{4 \pi r_{2}^{2}}{2 \pi r_{2}}
\end{aligned}
$$

Outro tipo de perda interna levado em conta é por folga (clearance). Assim como mencionado no Cap. 5, há uma folga entre as pás do impelidor e sua cobertura para possibilitar a rotação. A tendência é que alguma porção do escoamento passe por esta folga indo dos lados de mais alta pressão aos de mais baixa das pás, havendo perda de eficiência e menos aumento de carga. A correlação para estimar essa perda é dada pela Eq. 141.

$$
\Delta h_{f o l}=0,6 \frac{\epsilon \cdot C_{\theta 2}}{b_{2}} \sqrt{\frac{4 \pi}{b_{2} \cdot Z}\left[\frac{r_{1 s}^{2}-r_{1 h}^{2}}{\left(r_{2}-r_{1 s}\right)\left(1+\rho_{2} / \rho_{1}\right)}\right] C_{\theta 2} \cdot C_{1}}
$$

Além dos parâmetros geométricos do impelidor e das velocidades, a expressão para a perda por folga utiliza a dimensão da folga $\epsilon$, evidentemente. A determinação do tip clearance em um impelidor está ligada aos processos empregados em sua fabricação, características de comportamento do material em diferentes temperaturas e velocidades, além do posicionamento conseguido em sua montagem. Nenhuma dessas características faz parte do presente projeto ou de seu escopo. Por este motivo usou-se um valor usual de folga apontado por Cumpsty (2004) de $2 \%$ da altura da pá. Fez-se a média entre entrada e saída assim como mostra a Eq. 142. 


$$
\epsilon=2 \% \cdot \frac{b_{2}+\left(r_{1 s}-r_{1 h}\right) / 2}{2}
$$

Por fim, a última perda interna avaliada por Oh; Yoon e Chung (1997) acontece por conta da mistura entre jato e esteira na saída do impelidor. Esta estrutura do escoamento, já apresentada de maneira simples no Cap. 5 desta dissertação, é bem discutida por Cumpsty (2004).

$$
\Delta h_{\text {mis }}=\frac{1}{1+\tan ^{2} \alpha_{2}}\left[\frac{1-\varepsilon_{\text {esteira }}-\left(b_{3} / b_{2}\right)}{1-\varepsilon_{\text {esteira }}}\right]^{2} \frac{C_{2}^{2}}{2}
$$

A Eq. 143 fornece a correlação para cálculo da perda por mistura. Nota-se que há dependência com relação à fração da saída na qual há esteira $\varepsilon_{\text {esteira }}$. Assumiu-se o valor de $25 \%$ com base em informações provindas de Cumpsty (2004) e Gravdahl et al. (2004).

\subsubsection{PERDAS PARASITAS}

Oh; Yoon e Chung (1997), assim como Aungier (2000), levam em conta três tipos de perdas parasitas: por atrito no disco, por recirculação e por vazamento. $O$ atrito no disco corresponde à interação do impelidor com o fluido em faces que não estão vinculadas ao escoamento a ser pressurizado, principalmente na porção traseira do impelidor.

$$
\begin{aligned}
& \Delta h_{a t d}=f_{a t d} \frac{\left[\left(\rho_{1}+\rho_{2}\right) / 2\right] r_{2}^{2} U_{2}^{3}}{4 \dot{m}} \\
& f_{a t d}=\frac{2,67}{R e_{a t d}^{0,5}} \quad \text { se } \quad R e_{a t d}<3 \cdot 10^{5} \\
& f_{a t d}=\frac{0,0622}{R e_{a t d}^{0,2}} \quad \text { se } \quad \operatorname{Re}_{a t d} \geq 3 \cdot 10^{5}
\end{aligned}
$$


A Eq. 144 apresenta a expressão para estimativa da perda por atrito no disco. O parâmetro $f_{a t d}$ é calculado de acordo com a Eq. 145 e ele é dependente do número de Reynolds calculado com a velocidade na ponta da pá $U_{2}$, o raio do impelidor na saída e a viscosidade do ar calculada na saída.

A segunda perda, por recirculação, ocorre na entrada do impelidor e está associada ao fluxo reverso. Whitfield e Baines (1990) definiram esse tipo de perda como um aumento na entalpia devido à ida de fluido com pouca quantidade de movimento da saída do impelidor (antes de entrar nas pás do difusor, no chamado vaneless space) de volta à região das pás do impelidor. Essa perda é apontada por Oh; Yoon e Chung (1997) como predominante se comparado com as outras perdas parasitas.

A Eq. 146 traz a expressão para calcular a perda por recirculação. Nela há a influência do ângulo absoluto do escoamento na saída com relação à direção meridional $\alpha_{2} \mathrm{e}$, intuitivamente, quanto maior este ângulo, maiores as perdas por recirculação. Há ainda o fator de difusão apresentado na Eq. 134.

$$
\Delta h_{r e c}=8 \cdot 10^{-5} \operatorname{senh}\left(3,5 \alpha_{2}^{3}\right) D_{f}^{2} U_{2}^{2}
$$

A última perda advém dos vazamentos que ocorrem através da junção entre impelidor e difusor ou de selos labirintos. Aungier (2000) é o autor da correlação indicada por Oh; Yoon e Chung (1997) e apresentada pela Eq. 147. Ele afirma que a essa correlação assume, com base em dados experimentais, que metade do escoamento que ocorre através do tip clearance incorre em perda.

$$
\Delta h_{v a z}=\frac{\dot{m}_{c l} U_{c l} U_{2}}{2 \dot{m}}
$$

A correlação estima a velocidade do escoamento através dos espaços $U_{c l}$ (Eq. 148) através da estimativa da diferença de pressão que causa essa velocidade $\Delta P_{c l}$ (Eq. 149). Para tanto é necessário calcular o raio meridional médio na entrada $r_{1 m}$ através da Eq. 150 e estimar o comprimento meridional do canal, o que foi feito com uso da expressão da Eq. 151. 


$$
\begin{aligned}
& U_{c l}=0,816 \sqrt{\frac{2 \Delta P_{c l}}{\rho_{2}}} \\
& \Delta P_{c l}=\frac{\dot{m}\left[r_{2} C_{\theta 2}-r_{1 m} C_{1}\right]}{\frac{\left(r_{1 m}+r_{2}\right)}{2} \cdot \frac{\left[\left(r_{1 s}-r_{1 h}\right) / 2+b_{2}\right]}{2} \cdot Z \cdot L_{m}} \\
& r_{1 m}=\frac{\left(r_{1 s}-r_{1 h}\right)}{2}+r_{1 h} \\
& L_{m} \approx 1,1 \sqrt{\left[L_{a x}-\left(\frac{b_{2}}{2}\right)\right]^{2}+\left[r_{2}-\left(\frac{r_{1 s}+r_{1 h}}{2}\right)\right]^{2}}
\end{aligned}
$$

Por fim, o último parâmetro a ser calculado é o fluxo mássico dos vazamentos $\dot{m}_{c l}$. A correlação se vale do número de pás do impelidor $Z$, densidade do ar na saída $\rho_{2}$ e dimensão da folga $\epsilon$, além dos parâmetros já calculados $U_{c l}$ e $L_{m}$.

$$
\dot{m}_{c l}=\rho_{2} \cdot Z \cdot \epsilon \cdot L_{m} \cdot U_{c l}
$$

As perdas para o difusor não foram estimadas. Foi imposta uma eficiência do estágio 5\% menor que a eficiência do impelidor como forma de estimar as perdas que ocorrem nos difusores. Os modelos de perdas encontrados para difusores requerem mais informações sobre sua geometria que o disponível nessa fase do projeto. A principal referência para estimar perdas no difusor é o trabalho de Ribi e Dalbert (2000).

\subsection{RESULTAdOS DO PROJETO UNIDIMENSIONAL}

A rotina computacional implementada fornece a lista de todas as combinações geométricas avaliadas para o impelidor formadas dentro dos intervalos apresentados pela Tab. 2. Selecionando uma das geometrias, a rotina procede ao projeto do difusor para este impelidor de acordo com o mostrado na seção 6.3. 
Por haver uma grande quantidade de combinações, há muitas opções com a mesma eficiência indicada ou com diferenças desprezíveis. Isso faz com que a escolha seja arbitrada. Foram escolhidas seis geometrias de impelidor para as quais o projeto do difusor foi conduzido como descrito na seção 6.2, assim como a análise bidimensional apresentada no Cap. 7. As geometrias de impelidor e difusor estão apresentadas na Tab. 3.

A geometria "A" foi a que teve a melhor eficiência indicada, por isso foi selecionada. As geometrias "B" e "C" foram escolhidas devido aos seus raios de saída do impelidor $r_{2}$ serem consideravelmente menores. Houve preocupação com a dimensão do compressor, corroborada pelo gráfico apresentado por Xu e Amano (2012a) na Fig. 30. Percebe-se uma grande tendência de aumento da massa do impelidor de acordo com seu raio e, se for possível, é importante escolher o menor raio.

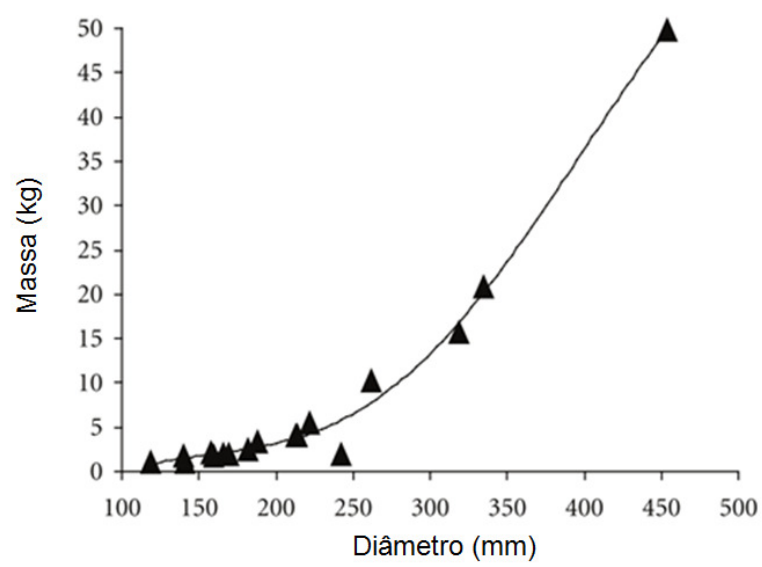

Figura 30 - Relação entre massa e diâmetro de impelidores. Adaptado de Xu e Amano (2012a).

As geometrias " $D$ " e "E" foram adicionadas após os primeiros resultados da análise bidimensional, apresentada no capítulo seguinte, fazendo uso da metodologia de projeto resumida pela Fig.4. Houve evidências de choke na entrada das outras geometrias. Escolheram-se então geometrias com menores relações entre raio do hub e do shroud $\left(\boldsymbol{r}_{\mathbf{1 H}} / \boldsymbol{r}_{\mathbf{1}}\right)$ e que tivessem boas eficiências indicadas.

Por fim, a geometria "F" foi testada por conta do ângulo de backsweep $\beta_{B 2}$, que, de maneira inesperada, foi igual a zero em outras três geometrias. As pás radiais das geometrias "A", "D" e "E" estão em desacordo com o exposto na seção 5.7 e isso 
poderia se dever a alguma deficiência do método de previsão de eficiência. Julgouse necessário testar uma geometria com ângulo de backsweep maior.

A Tab. 3 mostra, além das geometrias selecionadas, a geometria descrita por McKain e Holbrook (1982). Tal projeto foi testado por Skoch et al. (1997) e tinha vazão mássica e razão de pressões próximas às estipuladas para o presente projeto. Percebe-se que, apesar de apresentar raios (de 1 a 4 ) menores que as geometrias selecionadas, a geometria de McKain e Holbrook (1982) tem proporções similares, assim como ângulos das pás e número de pás e palhetas.

Tabela 3 - Dimensões das geometrias selecionadas a partir do projeto unidimensional, com suas eficiências isentrópicas e razões de pressões indicadas. Comparação com o compressor descrito e testado pelos trabalhos de McKain e Holbrook (1982) e Skoch et al. (1997).

\begin{tabular}{|c|c|c|c|c|c|c|c|}
\hline Geometria & A & B & C & D & E & $\mathbf{F}$ & $\begin{array}{c}\text { McKain e } \\
\text { Holbrook } \\
\text { (1982) }\end{array}$ \\
\hline$r_{1 H}(\mathrm{~mm})$ & 74,8 & 60,3 & 59,2 & 42,6 & 36,3 & 70,6 & 40,4 \\
\hline$r_{1 S}(m m)$ & 124,7 & 100,4 & 98,6 & 142,1 & 120,9 & 117,6 & 106,7 \\
\hline$r_{2}(m m)$ & 311,9 & 251,1 & 219,1 & 355,4 & 302,3 & 294,0 & 215,9 \\
\hline$r_{3}(m m)$ & 353,1 & 279,4 & 247,7 & 406,9 & 346,7 & 326,0 & 233,7 \\
\hline$r_{4}(m m)$ & 489,1 & 395,4 & 350,9 & 555,4 & 473,9 & 461,0 & 363,2 \\
\hline$L_{a x}(m m)$ & 148,4 & 126,9 & 118,3 & 220,4 & 193,6 & 143,9 & 132,1 \\
\hline$Z$ & 30 & 26 & 27 & 28 & 26 & 27 & 30 \\
\hline$Z_{d}$ & 20 & 18 & 19 & 20 & 18 & 19 & 24 \\
\hline$b_{2}(m m)$ & 24,9 & 20,1 & 17,5 & 28,4 & 24,2 & 23,5 & 19,1 \\
\hline$N(\boldsymbol{r p m})$ & 13078 & 18549 & 19857 & 12534 & 14816 & 15808 & 21789 \\
\hline$\beta_{1 s}($ graus $)$ & -60 & -50 & -50 & -60 & -50 & -60 & -55 \\
\hline$\beta_{B 2}($ graus $)$ & 0 & -30 & -10 & 0 & 0 & -35 & -30 \\
\hline$\beta_{B 3}($ graus $)$ & -73 & -73 & -73 & -73 & -73 & -73 & -80 \\
\hline$\beta_{B 4}($ graus $)$ & -56 & -59 & -61 & -53 & -55 & -58 & -40 \\
\hline$e_{1}(m m)$ & 1,56 & 1,39 & 1,38 & 2,46 & 2,19 & 1,51 & - \\
\hline$e_{2}(m m)$ & 4,50 & 3,65 & 3,20 & 5,12 & 4,37 & 4,25 & - \\
\hline$\eta_{I, \text { isen }}(\%)$ & 92,29 & 91,66 & 91,15 & 91,03 & 90,71 & 90,68 & $\begin{array}{c}83,20 \\
\text { (estágio) }\end{array}$ \\
\hline$P_{R}$ & 4,32 & 4,33 & 4,31 & 5,34 & 5,35 & 4,36 & 3,97 \\
\hline
\end{tabular}




\section{ANÁLISE BIDIMENSIONAL}

A realização do projeto unidimensional descrito no Cap. 6 é capaz de estimar as dimensões principais do perfil meridional do impelidor. Adicionando mais uma dimensão à análise, é necessário definir as curvas do perfil meridional que conectam entrada e saída do impelidor. O uso de análises tridimensionais para definir essas curvas seria possível, contudo, muito demorado, limitando as variações na geometria realizadas.

O trabalho de Xu e Amano (2012b) demonstrou a importância do formato do perfil meridional para o desempenho de impelidores centrífugos, salientando que melhorias consideráveis podem ser feitas ainda lidando apenas com apenas duas dimensões. Isso é apoiado pelos trabalhos de Came e Robinson (1999) e Casey (1994) sobre metodologias de projeto, nos quais se recomenda uma etapa bidimensional do projeto.

A abordagem mais comum para projeto bidimensional está apoiada na solução do escoamento médio no perfil meridional através da solução de uma das formas da equação de equilíbrio radial, usualmente com o método de curvatura de linha de corrente. Seguindo esta linha, Kurauchi (2012), que realizou um projeto de compressor seguindo a metodologia apresentada por Came e Robinson (1999), utilizou um programa computacional baseado no trabalho de Katsanis (1964). Com isso, Kurauchi (2012) avaliou o campo de velocidades meridional e realizou ajustes das curvas de hub e shroud deste perfil.

O campo de velocidades estimado pelo método é útil para tomada de algumas decisões. O controle do gradiente de velocidades faz-se importante por indicar possíveis regiões de separação do escoamento (CUMPSTY, 2004). Impor um perfil meridional que minimize os gradientes de velocidade tende a melhorar o desempenho do impelidor.

No presente trabalho, o uso de uma ferramenta bidimensional também teve como intenção principal a definição do perfil meridional, contudo, foi feita também uma avaliação dos resultados fornecidos pelo projeto unidimensional. Escolheu-se o software comercial Vista TF, descrito detalhadamente e projetado por Casey e Robinson (2010). A escolha foi feita por se tratar de uma ferramenta recente, que, 
além do usual cálculo do campo meridional de velocidades, possui modelos empíricos de perdas embutidos que permitem estimar a eficiência da turbomáquina.

Neste capítulo são apresentados a teoria que embasa os cálculos bidimensionais e os resultados obtidos. A dedução completa do equacionamento não compõe este trabalho. Essa dedução pode ser encontrada nos trabalhos de Baskharone (2006) e Schobeiri (2005).

\subsection{AS EQUAÇÕES DE EQUILÍBRIO RADIAL E O MÉTODO DE CURVATURA DAS LINHAS DE CORRENTE}

Estão implementadas no programa computacional Vista TF as equações da continuidade, uma equação da energia baseada na equação de Euler para turbomáquinas, algumas equações de estado possíveis e uma equação da quantidade de movimento invíscida na forma da equação de equilíbrio radial (CASEY; ROBINSON, 2010). A equação de equilíbrio radial pode ser derivada a partir das equações de quantidade de movimento em coordenadas situadas na linhas de corrente (SCHOBEIRI, 2005). Considera-se que o escoamento é axissimétrico, está em regime permanente e que o escoamento é adiabático (BASKHARONE, 2006).

As equações da quantidade de movimento nas direções meridional, circunferencial e normal à superfície formada pelas linhas de corrente são relacionadas à equação da energia e à relação de Clausius-Gibbs (Eq. 2) para chegar à equação de equilíbrio radial. A forma exata da equação de equilíbrio depende do sistema de coordenadas adotado.

Os pontos nos quais o escoamento é calculado no método de curvatura de linha de corrente são idealmente formados pela intersecção de certo número de linhas de corrente com linhas ortogonais às linhas de corrente que vão do hub ao shroud. Contudo, as linhas de corrente têm sua posição dependente da solução do escoamento, fazendo com que as linhas ortogonais definidas no início dos cálculos se transformem nas quasi-ortogonais, uma vez que não é conveniente redefinir o sistema de coordenadas a cada iteração (CUMPSTY, 2004). 
A projeção das quasi-ortogonais, que têm direção $e$, sobre o perfil meridional define o vetor unitário $q$. Tal direção é importante à equação de equilíbrio radial por ser mais conveniente defini-la em função do gradiente da velocidade meridional $C_{m}$ na direção $q$. Tais direções estão representadas na Fig. 31.
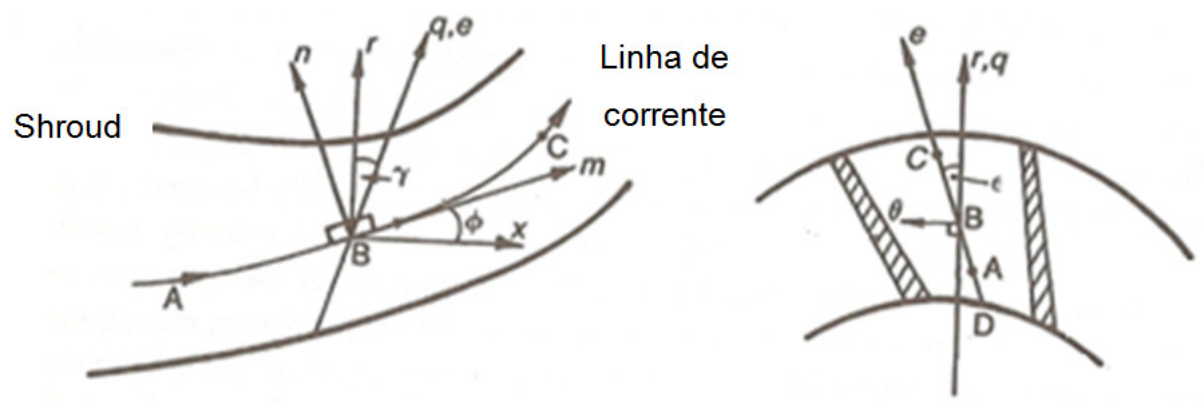

Figura 31 - Sistema de coordenadas sobre as linhas de corrente utilizado pelo programa computacional com método de curvatura de linhas de corrente. Adaptado de Cumpsty (2004).

São definidas então as acelerações na direção meridional $m$, na direção radial $r$ e na direção $n$, que representa a direção normal à linha de corrente no plano meridional. Essas acelerações compõem a aceleração na direção $q$, denotada por $a_{q}$. Faz-se necessário definir os ângulos $\gamma$, formado entre $q$ e o plano $r-\theta$, e $\phi$, que denota a inclinação de $m$ na direção axial.

A Eq. 153 apresenta a aceleração $a_{q}$. Em tal equação, $r_{m}$ é o raio de curvatura da linha de corrente projetado sobre o plano meridional, sendo calculado por $r_{m}=$ $\partial m / \partial \phi$.

$$
a_{q}=C_{m} \frac{\partial C_{m}}{\partial m} \cos [90-(\phi+\gamma)]+\frac{C_{m}^{2}}{r_{m}} \cos (\phi+\gamma)-\frac{C_{\theta}^{2}}{r} \cos (\gamma)
$$

Definindo ainda o ângulo $\epsilon$, formado entre a superfície imaginária formada pelas linhas de corrente e o plano meridional, tem-se a Eq. 154 para a aceleração na direção $e$.

$$
a_{e}=a_{q} \cos (\epsilon)+a_{\theta} \operatorname{sen}(\epsilon)
$$

Aplicando-se a equação da quantidade de movimento na superfície das linhas de corrente na direção e e considerando que $d q=d e \cdot \cos (\epsilon)$ têm-se as Eqs. 155 e 156. 


$$
\begin{aligned}
& -\frac{1}{\rho} \frac{\partial P}{\partial e}=a_{q} \cos (\epsilon)+a_{\theta} \operatorname{sen}(\epsilon) \\
& -\frac{1}{\rho} \frac{\partial P}{\partial q}=a_{q}+a_{\theta} \tan (\epsilon)
\end{aligned}
$$

Utilizando a relação de Clausius-Gibbs, apresentada na Eq. 2, na forma com entalpia de estagnação somada à energia cinética, e a expressão para $a_{q}$, dada pela Eq. 153 chega-se à Eq. 157. Ao rearranjar tal equação e substituindo a aceleração na direção $\theta$, chega-se à forma usual da equação de equilíbrio radial (Eq. 158).

$$
\begin{aligned}
T \frac{\partial s}{\partial q}-\frac{\partial h_{0}}{\partial q}+ & \frac{1}{2} \frac{\partial}{\partial q} C_{m}^{2}+\frac{1}{2} \frac{\partial}{\partial q} C_{\theta}^{2} \\
= & C_{m} \frac{\partial C_{m}}{\partial m} \operatorname{sen}(\phi+\gamma)+\frac{C_{m}^{2}}{r_{m}} \cos (\phi+\gamma)-\frac{C_{\theta}^{2}}{r} \cos (\gamma) \\
& +a_{\theta} \tan (\epsilon) \\
\frac{1}{2} \frac{\partial}{\partial q} C_{m}^{2}=\frac{\partial h_{0}}{\partial q} & -T \frac{\partial s}{\partial q}+C_{m} \frac{\partial C_{m}}{\partial m} \operatorname{sen}(\phi+\gamma)+\frac{C_{m}^{2}}{r_{m}} \cos (\phi+\gamma) \\
& -\frac{1}{2 r^{2}} \frac{\partial}{\partial q}\left(r^{2} C_{\theta}^{2}\right)+\frac{C_{m}}{r} \frac{\partial}{\partial m}\left(r C_{\theta}\right) \tan (\epsilon)
\end{aligned}
$$

A equação de equilíbrio radial pode ser resolvida através do método de curvatura de linhas de corrente, que é utilizado pelo Vista TF. Schobeiri (2005) descreveu o procedimento de cálculo passo a passo.

O cálculo se inicia com a primeira estimativa da posição das linhas de corrente. Usualmente faz-se apenas um espaçamento uniforme com a curvatura baseada nas linhas de hub e shroud. As condições fornecidas pelo usuário (pressão e temperatura totais na entrada) servem para inferir entalpia e entropia na entrada. A primeira estimativa da velocidade meridional é feita para uma das linhas de corrente (usualmente a central) com base na vazão mássica especificada. A equação de equilíbrio radial é então integrada de modo a calcular a velocidade meridional nas outras linhas de corrente na primeira estação quasi-ortogonal.

Tendo o primeiro campo de velocidades na primeira estação, verifica-se a consistência dos valores com a vazão mássica e, dependendo do desvio constatado, 
aumentam-se ou diminuem-se as velocidades. Passa-se então à próxima quasiortogonal.

O processo se repete até a convergência. Claramente, alguns detalhes do cálculo foram aqui omitidos e podem ser encontrados no trabalho de Schobeiri (2005).

\subsection{PARTICULARIDADES DO VISTA TF}

As equações solucionadas numericamente pelo método de curvatura das linhas de corrente são invíscidas e são incapazes de prever aumentos de entropia. Essa característica impossibilitaria, portanto, cálculos de eficiência e perdas. Para estimar os ganhos de entropia Casey e Robinson (2010) incluíram correlações empíricas que atuam na equação de estado variando a entropia.

Além das perdas, há formulações empíricas que estimam a influência do bloqueio causado pela presença da camada limite e para computar a diferença entre a direção do escoamento e das pás. O primeiro efeito é contabilizado na equação da continuidade, aumentando a velocidade meridional. O segundo é levado em conta modificando as componentes e ângulos da Eq. 158.

Para prover informações sobre velocidades e carregamento das pás, a solução encontrada para a superfície média deve ser estendida para outras superfícies entre as pás. Isso é feito com transformadas que levam em conta a geometria da passagem que são, novamente, correlações empíricas.

O código computacional do Vista TF também leva em conta o efeito de mistura na direção circunferencial, saindo do plano meridional. As perdas ligadas a esse tipo de transporte são usualmente ignoradas em códigos bidimensionais. A inclusão empírica desse fenômeno tende a deixar a estimativa de eficiência mais precisa.

Por fim, foi incluída uma abordagem para indicar choke no compressor. Trata-se de uma abordagem similar à apresentada na seção 5.4, na qual se determina a vazão mássica máxima. O cálculo difere na inclusão de maiores detalhes, como o bloqueio causado pela camada limite e a angulação das pás. 


\subsection{SIMULAÇÕES E RESULTADOS}

As simulações realizadas foram apenas para o impelidor, de modo a definir as curvas de seu perfil meridional. As seis geometrias pré-selecionadas tiveram suas geometrias criadas com o uso do programa BladeGen. As curvas dos perfis meridionais foram controladas através dos pontos que definem curvas de Bezier, sugeridas por Casey (1983) e embutidas no programa computacional. Foram utilizadas curvas com cinco pontos.

As mudanças nos perfis foram realizadas com objetivo de aumentar a eficiência indicada e diminuir os gradientes de velocidade para prevenir descolamentos do escoamento que não são previstos pelo Vista TF. O programa é capaz de apontar a ocorrência de choke, apesar de não apresentar uma solução para o campo de velocidades nestes casos, apenas alertando o usuário.
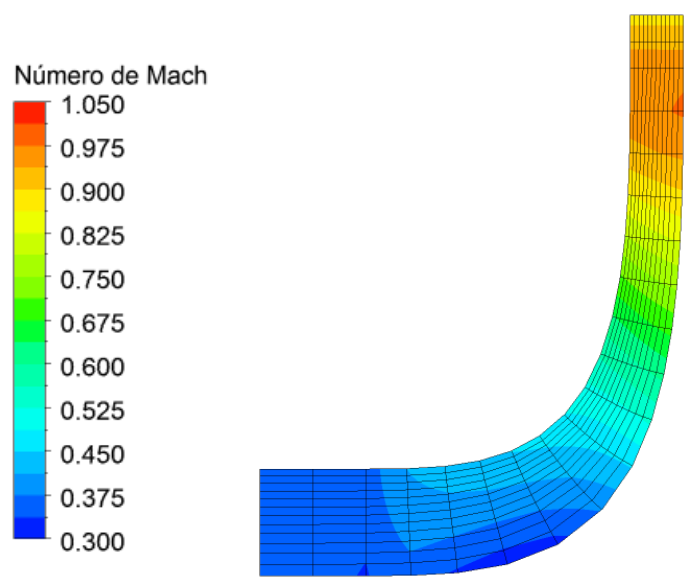

Figura 32 - Contorno com os valores de número de Mach absoluto para a geometria "A". Cálculo realizado com código bidimensional.

As geometrias selecionadas inicialmente do projeto unidimensional foram "A", "B" e "C". A primeira foi escolhida por ter tido a mais alta eficiência indicada pelo modelo de perdas unidimensional. A primeira configuração de curvas do perfil meridional para a geometria "A" foi a que alcançou a maior eficiência indicada, de 91,3\%, entre todas as testadas. 
A Fig. 32 apresenta um contorno de número de Mach para a geometria "A" com vazão mássica do ponto de projeto. É possível notar altas velocidades na saída, mas sem atingir o choke, possibilitando a alta eficiência reportada.

Para as geometrias "B" e "C", não foi possível realizar o cálculo do campo de velocidades por haver indicação de choke para a vazão mássica de projeto. A geometria "B" teve um máximo de vazão de $3,55 \mathrm{~kg} / \mathrm{s}$ sem apresentar choke. Com manipulações nas curvas do perfil meridional, chegou-se à geometria "B4" (quarta tentativa), na qual se obteve a vazão máxima de $3,6 \mathrm{~kg} / \mathrm{s}$, descartando-se o uso dessa geometria, uma vez que não seria capaz de atingir a vazão de projeto $(4,13$ $\mathrm{kg} / \mathrm{s}$ ). Ambos os perfis meridionais estão ilustrados pela Fig. 33. As eficiências isentrópicas de "B" e "B4" indicadas foram de $87,1 \%$ e 88,0\%, respectivamente.

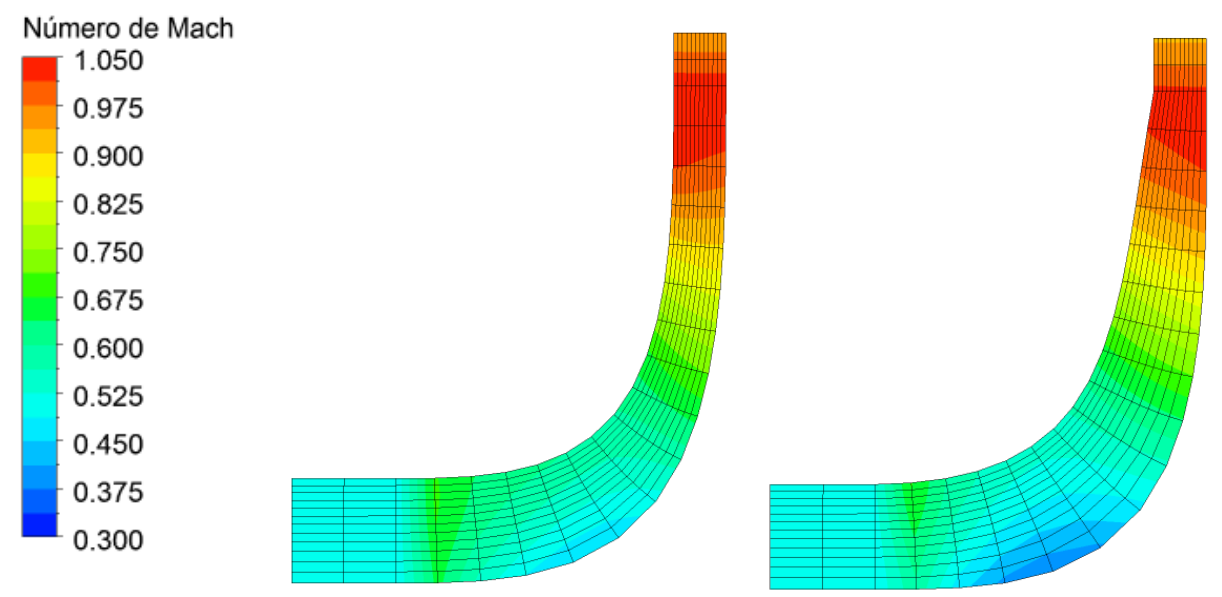

Figura 33 - Contornos de número de Mach absoluto para a geometria "B" com 3,55 kg/s de vazão mássica (esquerda) e a geometria "B4" com 3,6 kg/s (direita). Vazões máximas antes do choke.

A geometria "C" também teve choke para a vazão mássica de projeto. Sua máxima vazão foi de $3,9 \mathrm{~kg} / \mathrm{s}$, maior que a alcançada por "B". Usualmente, as características de choke do impelidor são definidas por suas áreas de entrada e saída (DIXON; HALL, 2010). Notou-se que a área de entrada era relativamente pequena tanto em "B" quanto em "C". Optou-se por aumentar essa área na geometria "C", por ter alcançado vazão mais próxima à condição de projeto. $O$ raio do hub na entrada $r_{1 H}$ foi diminuído, uma vez que a razão entre os raios de hub e shroud $(v)$ de "C" tinha o valor máximo apontado pela Tab. 2. O novo valor adotado para $r_{1 H}$ foi de $40 \mathrm{~mm}$. 

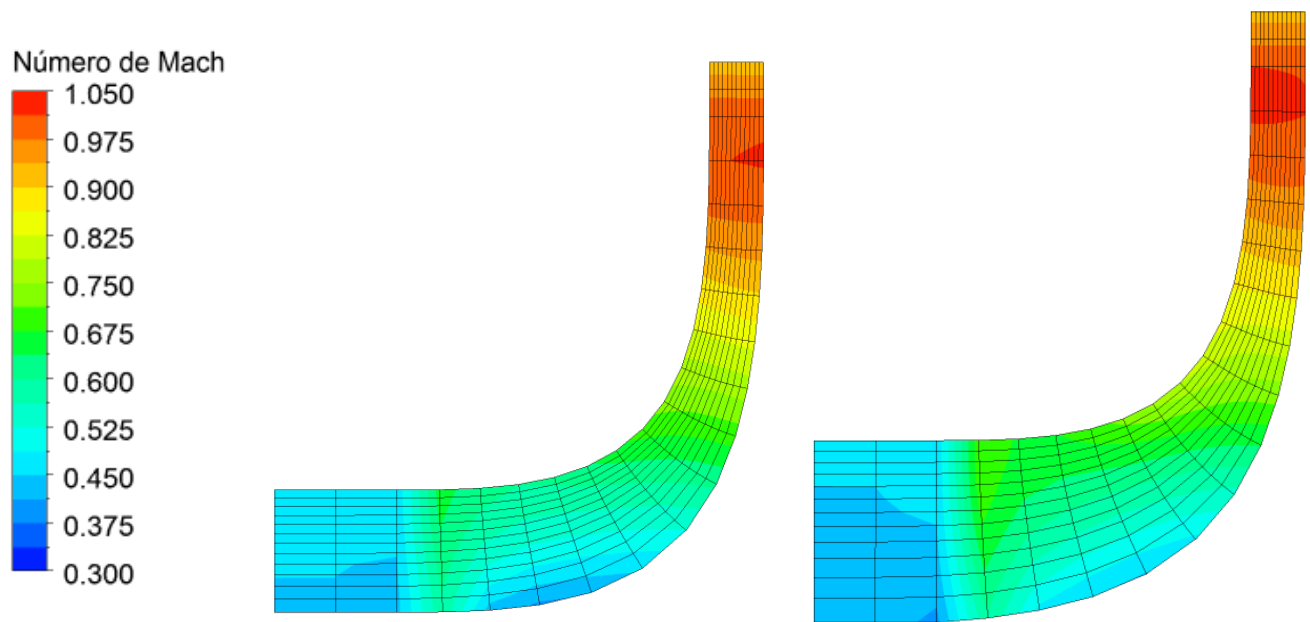

Figura 34 - Contornos de número de Mach absoluto para a geometria "C" com 3,9 kg/s de vazão mássica (esquerda) e para a geometria "C3" com vazão de projeto $4,13 \mathrm{~kg} / \mathrm{s}$ (direita).

Após variar as curvas do perfil meridional, a melhor variação foi "C3" que alcançou eficiência de $91,1 \%$. Além disso, seus gradientes de velocidade mostraram-se comparativamente mais suaves. Isso pode ser constatado no contorno da Fig. 34.

Número de Mach
\begin{tabular}{|l}
1.050 \\
0.975 \\
0.900 \\
0.825 \\
0.750 \\
0.675 \\
0.600 \\
0.525 \\
0.450 \\
0.375 \\
0.300
\end{tabular}
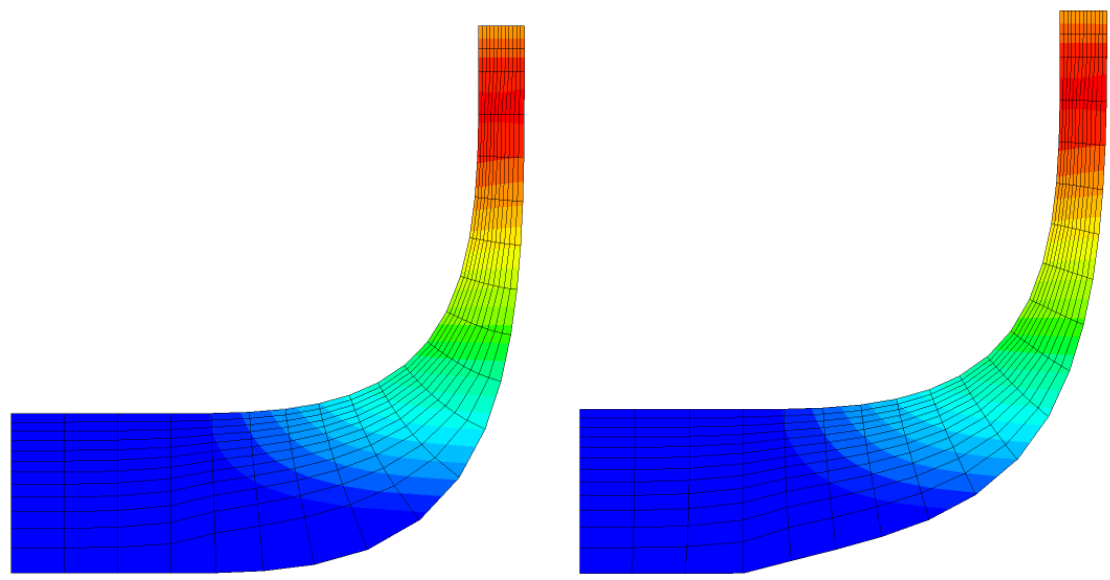

Figura 35 - Comparação entre os contornos de número de Mach para as geometrias "D" (esquerda) e "D5" (direita). A curva do hub foi modificada.

Ao analisar os resultados, decidiu-se que a razão entre os raios de hub e shroud poderia ser um parâmetro de grande importância. Dessa forma, buscaram-se geometrias nos resultados unidimensionais com valores mais baixos de $v$ e com eficiências tão altas quanto possível, sem que fosse preciso modificar as dimensões principais, como em "C3". Foram selecionadas as geometrias "D" e "E", também apresentadas na Tab. 3. 
Os resultados apresentados por elas foram similares, com eficiências isentrópicas de $90,02 \%$ e $89,35 \%$ para as melhores curvas testadas nas geometrias "D5" e "E", respectivamente. Além de terem apresentado eficiências mais baixas que "A" e "C3", os gradientes de velocidade foram mais severos, especialmente próximo ao hub. A Fig. 35 ilustra a mudança do perfil do hub para diminuir as variações de velocidade nessa região.

Observa-se que as velocidades próximas à entrada do impelidor são mais baixas se comparadas às geometrias testadas anteriormente. Este padrão se repetiu para a geometria "E". Tal fato pode denotar pouca transferência de energia ao fluido nesta região, o que pode ser atribuído justamente a uma área muito grande na entrada em conjunto com velocidades de operação muito baixas limitadas pelo raio do impelidor.

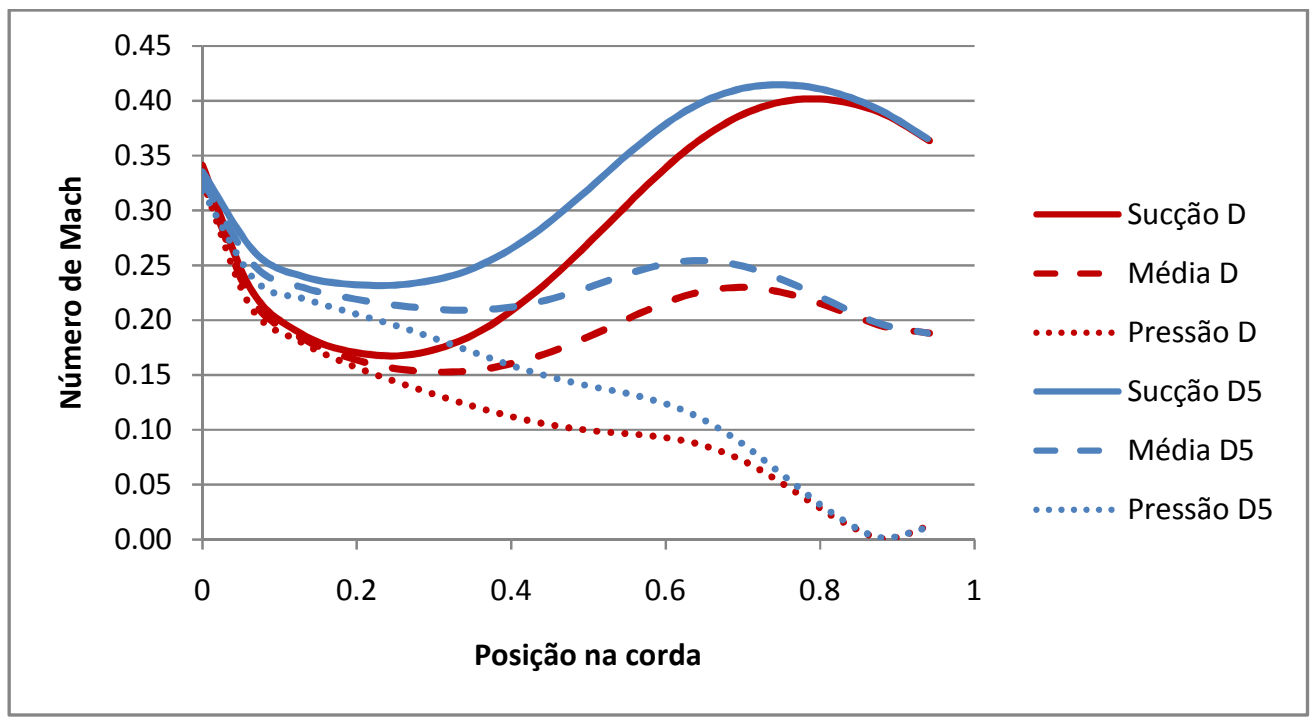

Figura 36 - Gráfico do número de Mach relativo pela posição na passagem (0 refere-se à entrada e 1 à saída do impelidor) ao longo do hub para as geometrias "D" e "D5" para as superfícies de sucção, pressão e média das pás.

O controle das velocidades como o mostrado pela Fig. 36 foi feito para todas as geometrias. Além da região do hub, foi possível monitorar a linha média e o shroud.

Por fim, a última geometria ("F") testada foi escolhida por ter ângulo de backsweep maior que as demais. A intenção foi verificar se a eficiência reportada seria maior se comparada à observada através da previsão unidimensional. Cabe mencionar que, apesar de ser um cálculo bidimensional, características tridimensionais como o ângulo de backsweep, são levadas em conta pelo Vista TF, assim como explicado 
na seção anterior. A eficiência isentrópica calculada na vazão de projeto foi de $90,19 \%$.

Com base nos resultados obtidos com as análises bidimensionais, sumarizados na Tab. 4, escolheu-se uma das geometrias para seguir ao projeto tridimensional. Assim como apontado pelo método unidimensional, a geometria " $A$ " alcançou a maior eficiência. Porém, a diferença com relação à geometria "C3", segunda melhor em eficiência, é de apenas 0,33\%. Considerou-se que tal diferença é desprezível, dadas as incertezas e simplificações do método.

Dessa forma, a escolha da geometria não foi pautada apenas na eficiência calculada. Comparando "A" com "C3", percebe-se grande diferença no tamanho geral da máquina. Enquanto " $A$ " tem $r_{4}$ de 489,1 mm, "C3" tem 350,9 mm. Tal diferença representa uma clara vantagem construtiva a "C3". Portanto escolheu-se utilizar "C3" para concluir o projeto após sua análise tridimensional

Tabela 4 - Resultados das previsões uni e bidimensionais para a eficiência isentrópica do impelidor.

\begin{tabular}{|c|c|c|c|c|c|}
\hline Geometria & A & C3 & D5 & E3 & $F$ \\
\hline$\eta_{I, \text { isen }} 1 D(\%)$ & 92,29 & 91,15 & 91,03 & 90,71 & 90,68 \\
\hline$\eta_{I, \text { isen }} 2 D(\%)$ & 91,28 & 90,95 & 90,02 & 89,35 & 90,19 \\
\hline
\end{tabular}

Adicionalmente, optou-se por modificar o projeto do difusor utilizando o ângulo de saída do escoamento reportado pela análise bidimensional. Houve pouca variação nos ângulos de entrada e saída das pás, com $\beta_{B 3}$ indo de $-73^{\circ}$ a $-71,4^{\circ}$ e $\beta_{B 4}$ de $-61^{\circ}$ a $-58^{\circ}$. 


\section{ANÁLISE TRIDIMENSIONAL - DINÂMICA DE FLUIDOS COMPUTACIONAL}

O uso de dinâmica de fluidos computacional (CFD) no projeto de turbomáquinas é extremamente comum e recomendado em algum grau por todas as metodologias de projeto revisadas na seção 2.4. Até mesmo em complexas rotinas de otimização, que antes tinham como restrição o tempo computacional, o CFD tem sido empregado (VAN DEN BRAEMBUSSCHE et al., 2012). O CFD começou a ser utilizado em projetos de engenharia na década de 1980 (SOUZA, 2011) e se caracteriza pelo emprego de modelos físico-matemáticos da mecânica de fluidos que exigem o uso da capacidade de processamento computacional para sua solução numérica.

Anderson (1995) definiu a dinâmica de fluidos computacional como a arte de substituir as integrais ou derivadas parciais das equações fundamentais que regem os escoamentos por equações algébricas discretizadas. Essas equações, por sua vez, têm a função de fornecer quando resolvidas valores numéricos para as variáveis que definem o escoamento em pontos discretos, seja no espaço ou no tempo.

Por contar com tal capacidade computacional e estar apoiado sobre métodos numéricos, o CFD pode calcular escoamentos com menos simplificações, tanto geométricas quanto fenomenológicas. No contexto do presente trabalho, o CFD é usado para cálculos tridimensionais do compressor a ser projetado. Percebe-se que se trata de uma ferramenta muito completa, sendo de grande utilidade ao projeto. Após esta breve introdução, as próximas seções se dedicam a alguns conceitos básicos da modelagem em CFD. Novamente, os princípios apresentados foram aprofundados o suficiente para embasar a discussão e compreensão dos resultados.

\subsection{EQUAÇÕES FUNDAMENTAIS E O MÉTODO DOS VOLUMES FINITOS}

As equações resolvidas numericamente através do CFD representam princípios físicos que regem a dinâmica de fluidos. Anderson (1995) apontou que o 
escoamento de fluidos é regido por três leis que estão presentes em qualquer código de CFD, sendo elas a conservação da massa, a segunda lei de Newton e a conservação da energia (ou primeira lei da termodinâmica).

A partir das leis, a dedução das equações depende do modelo de fluido adotado. Podem ser adotadas as abordagens de volume de controle ou de elemento infinitesimal de fluido, ambas com a opção de acompanhar ou não o escoamento. Apesar de não haver diferença conceitual nas equações resultantes e ser possível fazer a conversão entre um modelo e outro (ANDERSON, 1995), essa escolha interfere no método de discretização e, posteriormente, na solução numérica.

Versteeg e Malalasekera (2007) demonstraram a dedução das equações para a abordagem de elemento de fluido, tanto para o caso estacionário quanto para com o elemento em movimento com o fluido. Anderson (1995) apresentou a dedução para volumes de controle também, além de relacionar as equações para os diversos modelos, mostrando como convertê-las. A Tab. 5 sumariza as abordagens e a forma das equações que resultam de sua aplicação.

Tabela 5 - As abordagens possíveis para dedução das equações de conservação e as formas das equações resultantes.

\begin{tabular}{lc}
\hline \multicolumn{1}{c}{ Abordagem } & Forma das equações \\
\hline Volume de controle finito fixo no espaço & Integral e conservativa \\
Volume de controle finito de massa fixa movendo-se & Integral e não conservativa \\
com o escoamento & Diferencial e conservativa \\
$\begin{array}{l}\text { Elemento infinitesimal fixo no espaço } \\
\text { Elemento infinitesimal de massa fixa movendo-se } \\
\text { com o escoamento }\end{array}$ & Diferencial e não conservativa \\
\hline
\end{tabular}

Não se julgou necessário demonstrar toda a dedução neste trabalho, apenas as equações e seus significados. As equações serão mostradas para o caso de elemento infinitesimal fixo no espaço, pela facilidade de compreensão do significado físico das equações.

A Eq. 159 fornece a equação da conservação da massa por unidade de volume. O primeiro termo é a taxa de variação da massa específica no elemento. Por sua vez, o segundo termo tem o divergente para representar o saldo do fluxo de massa que sai do elemento. Esse segundo termo é chamado de advectivo. Essa equação 
mostra que a massa de fluido entrando no elemento é a mesma que deve sair dele a menos de variações na densidade.

$$
\frac{\partial \rho}{\partial t}+\operatorname{div}(\rho \overrightarrow{\boldsymbol{v}})=0
$$

A equação que traduz a segunda lei de Newton, chamada de equação da quantidade de movimento, pode ser deduzida através do balanço das forças aplicadas ao elemento de fluido. A soma das forças é então igualada à taxa temporal de variação da quantidade de movimento somada ao saldo do fluxo de quantidade de movimento que sai do elemento, similarmente aos dois termos da equação de conservação da massa.

As forças principais consideradas no balanço do elemento de fluido são a pressão, que aplica uma força normal ao elemento, e as tensões viscosas, que têm três componentes em cada face do elemento. Convencionou-se a força exercida pela pressão como negativa, sendo uma compressão. As Eqs de 160 a 162 apresentam a equação da quantidade de movimento nas direções $x, y e z$.

$$
\begin{aligned}
& \frac{\partial(\rho u)}{\partial t}+\operatorname{div}(\rho u \overrightarrow{\boldsymbol{v}})=\frac{\partial\left(-P+\tau_{x x}\right)}{\partial x}+\frac{\partial \tau_{y x}}{\partial y}+\frac{\partial \tau_{z x}}{\partial z}+S_{x} \\
& \frac{\partial(\rho v)}{\partial t}+\operatorname{div}(\rho v \overrightarrow{\boldsymbol{v}})=\frac{\partial \tau_{x y}}{\partial x}+\frac{\partial\left(-P+\tau_{y y}\right)}{\partial y}+\frac{\partial \tau_{z y}}{\partial z}+S_{y} \\
& \frac{\partial(\rho w)}{\partial t}+\operatorname{div}(\rho w \overrightarrow{\boldsymbol{v}})=\frac{\partial \tau_{x z}}{\partial x}+\frac{\partial \tau_{y z}}{\partial y}+\frac{\partial\left(-P+\tau_{z z}\right)}{\partial z}+S_{z}
\end{aligned}
$$

As equações correspondentes à segunda lei de Newton podem ser transformadas nas equações de Navier-Stokes facilmente. As equações de Navier-Stokes estão implementadas no código de CFD selecionado, assim como em praticamente todos os códigos de CFD. A primeira hipótese a ser considerada para chegar às equações de Navier-Stokes é a de fluido newtoniano. Essa hipótese implica que as tensões viscosas $(\tau)$ do fluido são proporcionais à deformação. O modelo newtoniano utiliza a viscosidade dinâmica $\left(\mu_{d}\right)$ e uma segunda viscosidade $\left(\lambda_{v}\right)$ como constantes de 
proporcionalidade. As tensões viscosas são escritas genericamente assim como nas Eqs. 163 e 164 de acordo com o modelo newtoniano.

$$
\begin{gathered}
\tau_{a a}=2 \mu_{d} \frac{\partial\left(U_{a}\right)}{\partial a}+\lambda_{v} \operatorname{div}(\overrightarrow{\boldsymbol{v}}) \\
\tau_{a b}=\mu_{d}\left(\frac{\partial\left(U_{a}\right)}{\partial b}+\frac{\partial\left(U_{b}\right)}{\partial i}\right)
\end{gathered}
$$

A segunda hipótese necessária às equações de Navier-Stokes é a relação entre a viscosidade dinâmica e a segunda viscosidade, chamada de hipótese de Stokes. Segundo tal hipótese, tem-se que $\lambda_{v}=(-2 / 3) \mu_{d}$. Ao substituir essa relação e as das Eqs. 163 e 164 nas Eqs. de 160 a 162, chega-se às equações de Navier-Stokes. Essas equações são aqui apresentadas pelas Eqs. de 165 a 167.

$$
\begin{aligned}
& \frac{\partial(\rho u)}{\partial t}+\operatorname{div}(\rho u \overrightarrow{\boldsymbol{v}})=-\frac{\partial P}{\partial x}+\operatorname{div}\left(\mu_{d} \nabla u\right)+S_{x} \\
& \frac{\partial(\rho v)}{\partial t}+\operatorname{div}(\rho v \overrightarrow{\boldsymbol{v}})=-\frac{\partial P}{\partial y}+\operatorname{div}\left(\mu_{d} \nabla v\right)+S_{y} \\
& \frac{\partial(\rho w)}{\partial t}+\operatorname{div}(\rho w \overrightarrow{\boldsymbol{v}})=-\frac{\partial P}{\partial z}+\operatorname{div}\left(\mu_{d} \nabla w\right)+S_{z}
\end{aligned}
$$

Os termos fonte $(S)$ têm a função de incluir quaisquer outras forças que possam estar presentes no escoamento. Para aplicação a compressores, as forças mais importantes que podem ser acrescidas às equações estão relacionadas à rotação do sistema. Nas turbomáquinas, as equações podem ter como base a referência estacionária ou rotativa, esta última montada no impelidor. Tomita (2009) apresentou as equações básicas para o referencial rotativo. Para que a física do problema continue correta nesse referencial, é preciso adicionar duas acelerações (e conseqüentemente forças) ao mudar o equacionamento da referência absoluta à relativa, para levar em conta a rotação mesmo estando neste referencial. 


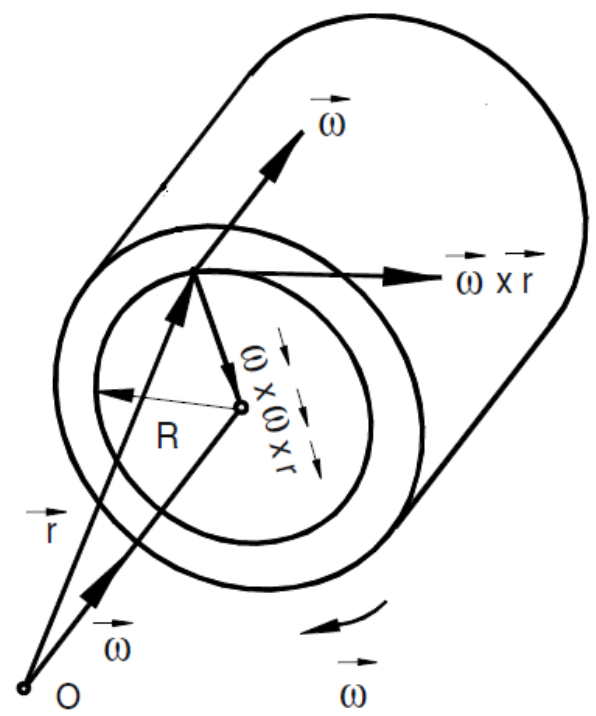

Figura 37 - Representação vetorial da força centrípeta, cuja reação é a força centrífuga. Adaptado de Schobeiri (2005).

A aceleração centrípeta e a aceleração de Coriolis foram descritas e tiveram seu equacionamento explicado no contexto das turbomáquinas por Schobeiri (2005). Essas forças são fictícias, uma vez que não estão presentes no referencial absoluto. A força centrífuga é uma reação à força centrípeta, apontando no sentido que se afasta do eixo de rotação. A Fig. 37 ilustra vetorialmente a força centrípeta. Essa força é dependente da velocidade angular e da distância ao eixo de rotação.

Por sua vez, a força de Coriolis depende da velocidade relativa. Para que a força exista, é preciso que o vetor velocidade aponte numa direção que tenda a alterar a distância ao eixo de rotação. Ou seja, a velocidade não pode ser paralela ao vetor velocidade angular. A força de Coriolis é perpendicular ao plano formado pelos vetores das velocidades angular e relativa. A Fig. 38 mostra uma esquematização vetorial da aceleração de Coriolis. $O$ termo fonte resultante da inclusão das forças centrífuga e de Coriolis é mostrado pela Eq. 168.

$$
S=\underbrace{\rho[-\overrightarrow{\boldsymbol{\omega}} \times(\overrightarrow{\boldsymbol{\omega}} \times \overrightarrow{\boldsymbol{r}})]}_{\text {força centrífuga }}+\underbrace{\rho[2(\overrightarrow{\boldsymbol{\omega}} \times \overrightarrow{\boldsymbol{W}})]}_{\text {força de Coriolis }}
$$

Para finalizar a apresentação das equações básicas, resta a equação de conservação da energia, relacionada à primeira lei da termodinâmica. Aplicando ao elemento de fluido, trata-se de igualar a taxa de aumento da energia no elemento ao 
saldo da taxa de calor adicionado somado ao saldo da taxa de trabalho aplicado ao elemento (VERSTEEG; MALALASEKERA, 2007).

A taxa de aumento de energia no elemento pode ser representada da mesma forma que nas equações anteriores, sendo o lado esquerdo da Eq. 169, aqui apresentada para o referencial fixo. O trabalho aplicado ao elemento pode ser contabilizado através do produto entre as forças aplicadas e a velocidade na direção da força. Com isso, pressão e tensões viscosas voltam ao equacionamento, de modo a ser possível aplicar as hipóteses do desenvolvimento de Navier-Stokes.

Por sua vez, o saldo da taxa de calor adicionado entra no cômputo através dos fluxos de calor nas faces do elemento. Para trazer o cálculo a variáveis tangíveis fisicamente, utiliza-se a lei de condução de calor de Fourier, através da qual o fluxo de calor é relacionado ao gradiente de temperatura. Segundo essa lei, o fluxo de calor é igual ao oposto do gradiente de temperatura multiplicado pela condutividade térmica $(k)$, que é propriedade do fluido.

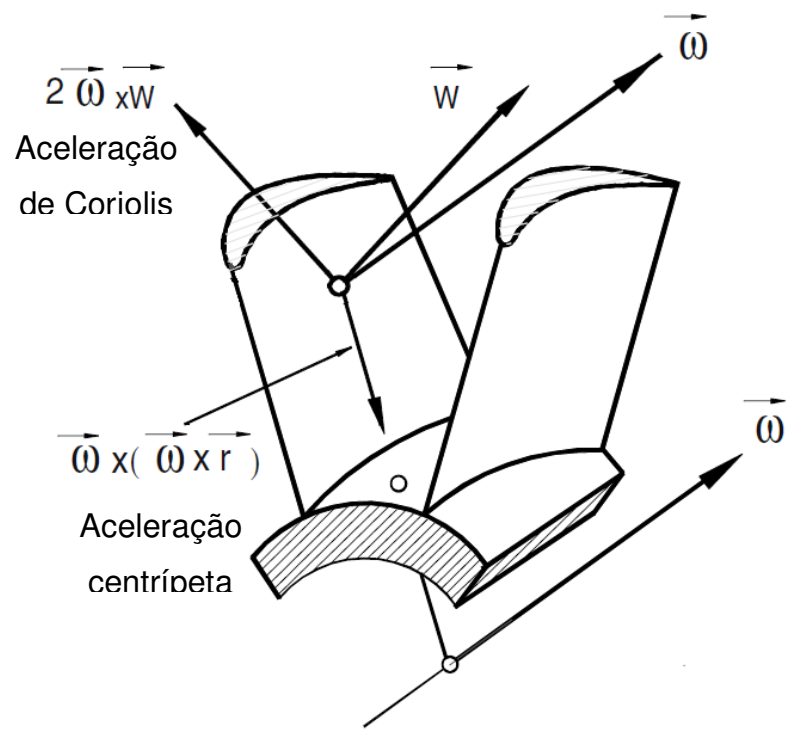

Figura 38 - Representação vetorial da aceleração de Coriolis. Adaptado de Schobeiri (2005).

Assim como mostraram Versteeg e Malalasekera (2007), é usual retirar da equação da energia a parcela referente à energia cinética, que pode ser encontrada através da multiplicação das equações de quantidade de movimento pelas velocidades na mesma direção. Dessa forma, chega-se à equação da energia interna $(e)$. 
Há outras maneiras de escrever a equação da energia, podendo deixá-la em função da temperatura ou entalpia, dependendo da aplicação. Essas formas alternativas podem ser encontradas nos trabalhos de Anderson (1995) e Versteeg e Malalasekera (2007).

$$
\begin{aligned}
\frac{\partial(\rho e)}{\partial t}+\operatorname{div}(\rho e \overrightarrow{\boldsymbol{v}}) & \\
= & -P \cdot \operatorname{div}(\overrightarrow{\boldsymbol{v}})+\operatorname{div}(k \nabla T) \\
& +\mu_{c}\left[2\left(\frac{\partial u}{\partial x}\right)^{2}+2\left(\frac{\partial v}{\partial y}\right)^{2}+2\left(\frac{\partial w}{\partial z}\right)^{2}+\left(\frac{\partial u}{\partial y}+\frac{\partial v}{\partial x}\right)^{2}\right. \\
& \left.+\left(\frac{\partial u}{\partial z}+\frac{\partial w}{\partial x}\right)^{2}+\left(\frac{\partial v}{\partial z}+\frac{\partial w}{\partial y}\right)^{2}-\frac{2}{3}[\operatorname{div}(\overrightarrow{\boldsymbol{v}})]^{2}\right]+S_{e}
\end{aligned}
$$

Percebe-se um formato similar nas equações que representam as leis que descrevem os escoamentos. A Eq. 170 apresenta esse formato básico, para o transporte de uma propriedade $\xi$. Essa equação pode ser entendida como a soma entre a taxa de aumento de $\xi$ e o saldo do entra e sai de $\xi$ do elemento de fluido se igualando à taxa de aumento de $\xi$ devido à difusão somada à taxa de aumento de $\xi$ devido a fontes.

$$
\underbrace{\frac{\partial(\rho \xi)}{\partial t}}_{\text {taxa de variação }}+\underbrace{\operatorname{div}(\rho \xi \overrightarrow{\boldsymbol{v}})}_{\text {termo advectivo }}=\underbrace{\operatorname{div}(\Gamma \cdot \nabla \xi)}_{\text {termo difusivo }}+\underbrace{S_{\xi}}_{\text {termo fonte }}
$$

Esse formato de equação foi desenvolvido a partir de um elemento infinitesimal de fluido fixo no espaço. Para transformá-la numa equação válida a um volume de controle basta integrá-la para o volume de controle, assim como na Eq. 171. Essa formulação é base inicial para o MVF apresentado na seção seguinte.

$$
\int_{V C} \frac{\partial(\rho \xi)}{\partial t} d V+\int_{V C} \operatorname{div}(\rho \xi \overrightarrow{\boldsymbol{v}}) d V=\int_{V C} \operatorname{div}(\Gamma \cdot \nabla \xi) d V+\int_{V C} S_{\xi} d V
$$

A partir dessa forma, o MVF faz uso do teorema de divergência de Gauss, que transforma a integral volumétrica numa integral sobre a área do volume de controle 
assim como na Eq. 172. Essa abordagem facilita os cálculos uma vez que as áreas das faces dos elementos são facilmente acessadas.

$$
\frac{\partial}{\partial t} \int_{V C}(\rho \xi) d V+\int_{A} \vec{n} \cdot(\rho \xi \overrightarrow{\boldsymbol{v}}) d A=\int_{A} \vec{n} \cdot(\Gamma \cdot \nabla \xi) d A+\int_{V C} S_{\xi} d V
$$

A integração das equações nos elementos de malha fornece balanços entre as faces de um mesmo elemento, ou seja, uma expressão algébrica. Com isso calculam-se os valores numéricos das propriedades no centro dos elementos. A forma da variação das propriedades ao longo dos elementos e sua relação com os valores nas faces pode seguir diversos esquemas de relação entre os elementos. Os detalhes das possíveis formas algébricas podem se encontrados em Anderson (1995). Dessa forma, é gerado um sistema de equações aproximadas cuja solução numérica é atingida através de métodos numéricos.

\subsection{ESTRUTURA DO CÓDIGO UTILIZADO}

Versteeg e Malalasekera (2007) apontaram que os códigos de CFD têm três elementos principais: pré-processador, solver e pós-processador. O código adotado para os cálculos deste trabalho (ANSYS CFX) tem essa estrutura. Através do primeiro elemento é possível definir a geometria a ser estudada, definindo malha e domínio computacionais. Além disso, neste elemento são selecionados os modelos físicos que irão representar a situação real e serão aplicados pelo solver. As propriedades do fluido e condições de contorno do domínio também devem ser especificadas pelo usuário para tornar os cálculos possíveis.

O solver é responsável por integrar as equações que regem os modelos do escoamento através de todos os elementos do domínio, discretizar as equações integrais de modo a criar um sistema algébrico e solucionar tal sistema através de métodos numéricos iterativos. O pós-processador trabalha com visualização dos resultados no domínio através de gráficos de contorno, linhas de corrente, vetores e outras formas de análise. 
Estes elementos estão presentes nos softwares comerciais escolhidos, pertencentes ao pacote da ANSYS. A definição da geometria do compressor está sendo feita com - BladeGen, software dedicado especialmente a turbomáquinas que incorpora os principais métodos de definição da geometria de impelidores e difusores. O usuário começa inserindo os dados do perfil meridional, com as mesmas dimensões definidas no projeto unidimensional do Cap. 6. Depois as linhas de câmber e da distribuição angular são definidas. Há diversas opções de parametrização dessas linhas. A que está sendo usado para o projeto é a proposta do Casey (1983), que se baseia nas curvas de Bezier. O BladeGen é utilizado também para gerar as entradas do código bidimensional Vista TF.

É possível determinar também a distribuição de espessura das pás, o que termina a definição da geometria. O último parâmetro a ser indicado pelo usuário é o número de pás que acaba por definir a largura do gas path. A geometria final da pá do impelidor ou passagem do difusor pode então ser exportada ao gerador de malhas.

As malhas geradas para as simulações foram feitas através do software TurboGrid, também especializado em turbomáquinas. As malhas são tratadas em apenas uma pá, uma vez que é possível simular o rotor inteiro através de uma condição de contorno de periodicidade. O TurboGrid permite que sejam monitorados o tamanho dos elementos, a taxa de crescimento das camadas de elementos, além de possibilitar ajustes manuais para adequar a malha à geometria. Malhas nãoestruturadas e com elementos hexaédricos estão sendo utilizadas.

Ao finalizar a malha, esta é exportada ao último passo do pré-processamento, no software CFX-Pre. Neste software o usuário define os modelos que deseja empregar à solução e as condições de contorno do domínio definido pela malha. Este software também contém facilidades e funções específicas à simulação de turbomáquinas. Nele faz-se a escolha quanto ao tipo de interação entre as partes rotativa e estacionária das malhas, além de haver opções para definição de tip clearance.

Com os modelos e condições de contorno definidos, passa-se ao CFX, o solver que realiza as iterações dos métodos numéricos. Durante o processamento do problema o usuário pode monitorar a convergência das variáveis envolvidas no cálculos, seja através do RMS (Root Mean Square) dos erros ou do máximo erro no domínio. O CFX possibilita que sejam monitoradas variáveis que incluem integração no domínio, como força aplicada numa dada direção ou o torque da turbomáquina. As iterações 
numéricas podem ser interrompidas automaticamente quando forem atingidos níveis de resíduos abaixo dos determinados no pré-processamento ou manualmente.

Por fim, o software CFD-Post permite a análise dos resultados. Há um script que pode ser ativado para análise de compressores. São gerados automaticamente gráficos de contorno, plots com vetores, gráficos de carregamento das pás, além de um relatório contendo a eficiência isentrópica do estágio, a razão de pressões alcançada e as velocidades e números de Mach médios nas entradas e saídas.

\subsubsection{MÉTODO NUMÉRICO}

Como exposto na seção 8.1, o método dos volumes finitos soluciona numericamente as equações que governam o fluido através de sua discretização. Contudo, há diversas formas de realizar a discretização e o mesmo acontece com a solução numérica. Nesta seção estão apresentados alguns aspectos importantes dos métodos numéricos implementados no código de CFD utilizado.

As equações na forma integral são discretizadas para serem resolvidas nos pontos de integração (ip), cuja localização e relação com os elementos da malha dependem do formato do elemento. Cada elemento possui alguns pontos de integração que são utilizados para determinar os valores no centro do elemento.

As Eqs. de 173 a 175 mostram a discretização. Nessas equações, o refere-se ao tempo da iteração anterior, mesmo que seja uma simulação em regime permanente. O avanço nesse tempo fictício $(\Delta t)$ pode ser entendido como o necessário para que as condições de contorno evoluam ao escoamento em regime permanente a partir das condições de contorno dadas.

$$
V\left(\frac{\rho-\rho^{o}}{\Delta t}\right)+\sum_{i p} \dot{m}_{i p}=0
$$




$$
\begin{aligned}
& V\left(\frac{\rho U_{i}-\rho^{o} U_{i}^{o}}{\Delta t}\right)+\sum_{i p} \dot{m}_{i p}\left(U_{i}\right)_{i p} \\
& =\sum_{i p}\left(P \Delta n_{i}\right)_{i p}+\sum_{i p}\left(\mu_{\mathrm{d}}\left(\frac{\partial U_{i}}{\partial x_{j}}+\frac{\partial U_{j}}{\partial x_{i}}\right) \Delta n_{i}\right)_{i p}+V \overline{S_{U_{l}}} \\
& V\left(\frac{\rho \xi-\rho^{o} \xi^{o}}{\Delta t}\right)+\sum_{i p} \dot{m}_{i p} \xi_{i p}=\sum_{i p}\left(\Gamma \cdot \nabla \xi \Delta n_{i}\right)_{i p}+V \overline{S_{\xi}}
\end{aligned}
$$

Com os cálculos nos pontos de integração, o gradiente de uma variável $\xi$ pode ser calculado nos nós dos elementos com a expressão da Eq. 176. Os termos advectivos são discretizados com a expressão da Eq. 177, na qual é utilizado o valor da variável $\xi$ no nó a montante (up). Tal expressão denota um esquema de discretização que fica entre o Upwind e o esquema de diferenças centrais (CDS). Para o último, a constante $\delta$ seria igual a 1, enquanto para o Upwind seria igual a 0 . O método chamado de High Resolution Scheme é implementado no CFX e calcula $\delta$ o mais próximo possível de 1 baseando-se nos valores dos pontos de integração vizinhos.

$$
\begin{aligned}
\nabla \xi & =\frac{1}{V} \sum_{i p}(\xi \nabla \vec{n})_{i p} \\
\xi_{i p} & =\xi_{u p}+\delta \nabla \xi \cdot \nabla \vec{r}
\end{aligned}
$$

Os termos difusivos são discretizados e calculados com o uso de funções de forma que avaliam as derivadas espaciais desses termos. O termo de gradiente de pressão também faz uso de funções de forma, uma vez que o formato das faces e seu posicionamento afetam a pressão resultante num dado ponto de integração.

O acoplamento pressão-velocidade é tratado no software através de um método similar ao de Rhie e Chow (1983) para evitar um possível padrão desacoplado dos campos de pressão (checkerboard). Uma equação similar às de quantidade de movimento é aplicada a cada ponto de integração para fornecer as velocidades de advecção, como na Eq. 178. 


$$
U_{i, i p}=\bar{U}_{i, i p}+f_{i p}\left(\left.\frac{\partial P}{\partial x_{j}}\right|_{i p}-\left.\frac{\partial \bar{P}}{\partial x_{j}}\right|_{i p}\right)-c_{i p} f_{i p}\left(U_{i, i p}^{o}-\bar{U}_{i, i p}^{o}\right)
$$

Tem-se que:

$$
f_{i p}=\frac{-V / B}{1+\frac{\rho V}{\Delta t \cdot B}}
$$

Onde $B$ é uma aproximação ao coeficiente central da equação de quantidade de movimento excluindo-se o termo transiente. A partir da conservação da massa, a compressibilidade é considerada através de uma linearização apresentada na Eq. 179, na qual a vazão mássica na iteração atual é dada. Tem-se ainda que a linearização da densidade é feita em termos da pressão como mostra a Eq. 180, na qual se faz necessário o uso de uma equação de estado para avaliar a derivada parcial da densidade em função da pressão.

$$
\begin{aligned}
& \rho U A \approx \rho U^{o} A+\rho^{o} U A-\rho^{o} U^{o} A \\
& \rho=\rho^{o}+\left.\frac{\partial \rho}{\partial P}\right|_{T}\left(P-P^{o}\right)
\end{aligned}
$$

O método implementado no $C F X$ resolve então a cada iteração um sistema composto pelas equações de quantidade de movimento, das componentes $u, v$ e $w$, e pela equação que resolve a pressão $P$. Para formar essas equações utiliza-se uma equação de estado como evidencia e, obviamente, da equação da continuidade. Após a solução desse sistema procede-se à solução das equações de outras variáveis e, por fim, a equação da energia. Ao final, caso o critério de convergência tenha sido atingido, a simulação é interrompida, caso contrário refaz-se o cálculo com os valores determinados na iteração. 


\subsection{MODELAGEM DA TURBULÊNCIA}

As equações básicas apresentadas na seção 8.1 têm uma diferença com relação às utilizadas nas simulações realizadas. O escoamento em turbomáquinas, assim como na maioria das aplicações de engenharia, está submetido aos efeitos da turbulência (DENTON, 2010). Como este fenômeno apresenta características aleatórias relacionadas a escalas muito reduzidas do movimento, o cálculo das equações para aplicações como a desse projeto sofre um tratamento estatístico para levar em conta o efeito da turbulência. Tal tratamento é uma alternativa às simulações dispendiosas e impraticáveis de todas as flutuações de velocidade, assim como na DNS (Direct Numerical Simulation) (VERSTEEG. MALALASEKERA, 2007).

A abordagem adotada é considerar que as velocidades e propriedades do escoamento são compostas por uma média somada às flutuações turbulentas. Essa abordagem dá origem às equações RANS (Reynolds Averaged Navier-Stokes). As equações não serão deduzidas aqui. Elas estão apresentadas nas Eqs. de 181 a 185 , sendo a equação da continuidade, as três componentes da equação da quantidade de movimento (agora chamadas de equações de Reynolds) e a equação genérica de transporte de um escalar, todas para um referencial fixo.

$$
\begin{aligned}
& \frac{\partial \bar{\rho}}{\partial t}+\operatorname{div}(\bar{\rho} \widetilde{\mathbf{U}})=0 \\
& \frac{\partial(\bar{\rho} \widetilde{U})}{\partial t}+\operatorname{div}(\bar{\rho} \widetilde{U} \widetilde{\mathbf{U}}) \\
& =-\frac{\partial \bar{P}}{\partial x}+\operatorname{div}\left(\mu_{c} \nabla \widetilde{U}\right)+\left[-\frac{\partial\left(\overline{\bar{\rho} u^{\prime 2}}\right)}{\partial x}-\frac{\partial\left(\overline{\bar{\rho} u^{\prime} v^{\prime}}\right)}{\partial y}-\frac{\partial\left(\overline{\bar{\rho} u^{\prime} w^{\prime}}\right)}{\partial z}\right] \\
& +S_{x} \\
& \frac{\partial(\bar{\rho} \tilde{V})}{\partial t}+\operatorname{div}(\bar{\rho} \widetilde{V} \widetilde{\mathbf{U}}) \\
& =-\frac{\partial \bar{P}}{\partial y}+\operatorname{div}\left(\mu_{c} \nabla \tilde{V}\right)+\left[-\frac{\partial\left(\overline{\bar{\rho} u^{\prime} v^{\prime}}\right)}{\partial x}-\frac{\partial\left(\overline{\bar{\rho}{v^{\prime}}^{2}}\right)}{\partial y}-\frac{\partial\left(\overline{\bar{\rho} v^{\prime} w^{\prime}}\right)}{\partial z}\right] \\
& +S_{y}
\end{aligned}
$$




$$
\begin{gathered}
\frac{\partial(\bar{\rho} \widetilde{W})}{\partial t}+\operatorname{div}(\bar{\rho} \widetilde{W} \widetilde{\mathbf{U}}) \\
=-\frac{\partial \bar{P}}{\partial z}+\operatorname{div}\left(\mu_{c} \nabla \widetilde{W}\right) \\
+\left[-\frac{\partial\left(\overline{\bar{\rho} u^{\prime} w^{\prime}}\right)}{\partial x}-\frac{\partial\left(\overline{\bar{\rho} v^{\prime} w^{\prime}}\right)}{\partial y}-\frac{\partial\left(\overline{\bar{\rho} w^{\prime 2}}\right)}{\partial z}\right]+S_{z} \\
\frac{\partial(\bar{\rho} \tilde{\xi})}{\partial t}+\operatorname{div}(\bar{\rho} \tilde{\xi} \widetilde{\mathbf{U}}) \\
=\operatorname{div}\left(\Gamma_{\xi} \nabla \tilde{\xi}\right)+\left[-\frac{\partial\left(\overline{\bar{\rho} u^{\prime} \xi^{\prime}}\right)}{\partial x}-\frac{\partial\left(\overline{\bar{\rho} v^{\prime} \xi^{\prime}}\right)}{\partial y}-\frac{\partial\left(\overline{\bar{\rho} w^{\prime} \xi^{\prime}}\right)}{\partial z}\right]+S_{\xi}
\end{gathered}
$$

Com exceção da equação da continuidade, percebe-se a presença das tensões de Reynolds em todas as equações. Sendo compostas por flutuações turbulentas, a determinação dessas tensões é um problema. O fechamento do sistema de equações só é possível com modelos capazes de modelar as tensões de Reynolds, os chamados modelos de turbulência.

Os modelos disponíveis se baseiam na hipótese de Boussinesq, que propõe que as tensões de Reynolds sejam proporcionais às deformações médias, havendo a introdução da viscosidade turbulenta $\left(\mu_{t}\right)$. Como o objetivo das simulações é garantir que o desempenho do compressor projetado esteja de acordo com o necessário e não há consenso sobre qual modelo de turbulência é mais adequado para esta aplicação, optou-se por três modelos de turbulência. Foram utilizados o modelo $k-\omega$ SST, recomendado por Simões (2009) e Souza (2011) e utilizado por Kurauchi (2012), o RNG $k-\varepsilon$, por conta das conclusões de Moura (2008), que apontou melhores resultados na simulação de impelidores com este modelo e, por fim, o $k-\varepsilon$, recomendado por AGARD (1998).

Nos modelos $k-\varepsilon$ e $R N G$ k- $\varepsilon$, há a introdução das equações de transporte da energia cinética turbulenta $\left(k=1 / 2\left(\overline{u^{\prime 2}}+\overline{v^{\prime 2}}+\overline{w^{\prime 2}}\right)\right)$ e da taxa de dissipação da energia cinética turbulenta $(\varepsilon)$. As equações de transporte dessas duas grandezas de acordo com os modelos estão apresentadas nas Eqs. 186 e 187.

$$
\frac{\partial(\rho k)}{\partial t}+\operatorname{div}(\rho k \overrightarrow{\boldsymbol{v}})=\operatorname{div}\left[\left(\mu_{d}+\frac{\mu_{t}}{\sigma_{k}}\right) \nabla k\right]+P_{k}+P_{k b}+\rho \varepsilon
$$




$$
\begin{aligned}
& \frac{\partial(\rho \varepsilon)}{\partial t}+\operatorname{div}(\rho \varepsilon \overrightarrow{\boldsymbol{v}})=\operatorname{div}\left[\left(\mu_{d}+\frac{\mu_{t}}{\sigma_{\varepsilon}}\right) \nabla \varepsilon\right]+\frac{\varepsilon}{k}\left[C_{\varepsilon 1}\left(P_{k}+P_{\varepsilon b}\right)-C_{\varepsilon 2} \rho \varepsilon\right] \\
& \mu_{t}=C_{\mu} \rho \frac{k^{2}}{\varepsilon}
\end{aligned}
$$

A viscosidade turbulenta, vinda da hipótese de Boussinesq, é relacionada às duas variáveis transportadas através da Eq. 188. As constantes do modelo $k-\varepsilon$ são dadas abaixo:

$C_{\mu}=0,09 ; \quad \sigma_{\varepsilon}=1,3 ; \sigma_{k}=1,0 ; C_{\varepsilon 1}=1,44 ; C_{\varepsilon 2}=1,92$

O modelo $R N G$ k-E tem como diferença para o $k-\varepsilon$ um termo adicional na equação de transporte da energia cinética turbulenta (Eq. 186). O termo $R_{\varepsilon}$, apresentado na Eq. 189 é subtraído no lado direito da equação. Este termo foi introduzido para modular a constante $C_{\varepsilon 2}$. O termo $\sqrt{2 S_{i j} S_{i j}}$ denota o módulo do tensor taxa de deformação médio.

$$
\begin{aligned}
& R_{\varepsilon}=\frac{C_{\mu R N G} \rho \eta^{3}\left(1-\eta / \eta_{0}\right)}{1+\beta_{R N G} \eta^{3}} \frac{\varepsilon^{2}}{k} \\
& \eta=\frac{k}{\varepsilon} \sqrt{2 S_{i j} S_{i j}}
\end{aligned}
$$

As constantes do modelo $R N G$ k- $\varepsilon$ são dadas abaixo:

$$
\begin{aligned}
& C_{\mu R N G}=0,0845 ; \beta_{R N G}=0,012 ; \sigma_{\varepsilon R N G}=\sigma_{k R N G}=0,7194 ; \\
& C_{\varepsilon 2 R N G}=1,42 ; C_{\varepsilon 2 R N G}=1,68 ; \eta_{0}=4,38
\end{aligned}
$$

O termo $P_{k}$ representa a produção de energia cinética turbulenta, sendo modelado como na Eq. 191, enquanto os termos $P_{k b}$ e $P_{\varepsilon b}$ são relacionados a forças de empuxo (buoyancy) que não foram modeladas nas simulações por não haver necessidade. 


$$
P_{k}=\mu_{t} \nabla \overrightarrow{\boldsymbol{v}} \cdot\left(\nabla \overrightarrow{\boldsymbol{v}}+\nabla \overrightarrow{\boldsymbol{v}}^{\boldsymbol{T}}\right)-\frac{2}{3} \operatorname{div} \overrightarrow{\boldsymbol{v}}\left(3 \mu_{t} \operatorname{div} \overrightarrow{\boldsymbol{v}}+\rho k\right)
$$

O modelo $k-\omega S S T$ foi desenvolvido para atuar como o $k-\omega$ em regiões próximas às paredes e como o $k-\varepsilon$ nas regiões mais distantes das paredes. Assim como no $k-\omega$ padrão, há o transporte da energia cinética turbulenta $k$ e da taxa específica de dissipação $\omega$. Faz-se uso de funções de mistura (blending functions) para ativar um ou outro modelo dependendo das características da região. Estas funções utilizam como um dos parâmetros a distância à parede. Por estas características, a formulação completa do modelo é consideravelmente extensa, contendo muitas funções e constantes, e não será totalmente descrita nesta dissertação. Os detalhes podem ser encontrados no trabalho de Menter (1994).

A equação de transporte da taxa de dissipação da energia cinética turbulenta do modelo $k-\varepsilon$ é transformada para forma do transporte da taxa específica de dissipação. A taxa específica de dissipação é definida como a taxa com a qual a energia cinética turbulenta é transformada em energia interna térmica por unidade de volume e tempo. Sua equação de transporte (Eq. 192) segue o mesmo formato das outras equações de transportes já apresentadas.

$$
\frac{\partial(\rho \omega)}{\partial t}+\operatorname{div}(\rho \omega \overrightarrow{\boldsymbol{v}})=\operatorname{div}\left[\left(\mu_{d}+\frac{\mu_{t}}{\sigma_{\omega}}\right) \nabla \omega\right]+P_{\omega}+P_{k b}-Y_{\omega}+D_{\omega}
$$

$\mathrm{Na}$ equação de transporte, $Y_{\omega}$ é o termo de dissipação de $\omega$, enquanto $D_{\omega}$ é o chamado termo de difusão cruzada. $D_{\omega}$ é resultante da transformação do modelo $k-\varepsilon$ padrão para as equações baseadas em $k$ e $\omega$.

\subsection{LEIS DE PAREDE}

O tratamento dado à formulação matemática nas regiões do domínio computacional próximas às paredes é muito importante para que as simulações sejam coerentes com os escoamentos reais, especialmente para os internos. Na simulação de 
compressores todos os componentes, obviamente, devem receber a condição de parede.

Dessa forma, o equacionamento deve ser adequado. A principal preocupação ao realizar as simulações deve ser garantir que os elementos da malha computacional próximos à parede terão suas variáveis avaliadas com um modelo adequado. Caso não seja possível garantir isso, é necessário controlar o posicionamento dos elementos.

A abordagem escolhida para as simulações é chamada de Scalable Wall Function no contexto do CFX. Tal abordagem faz uso dos parâmetros $y^{*}$ e $u^{*}$ definidos nas Eqs. 193 e 194, respectivamente, e que representam adimensionais para a velocidade tangencial e a distância à parede. Usa-se então o modelo logarítmico da lei de parede para relacionar o valor da tensão de cisalhamento na parede $\tau_{\omega}$ com a velocidade do fluido tangencial à parede $U^{T}$. Tal relação é mostrada pela Eq. 195.

$$
\begin{aligned}
& y^{*}=\frac{\rho u^{*} \Delta y}{\mu_{d}} \\
& u^{*}=C_{\mu R N G}{ }^{1 / 4} \sqrt{k} \\
& \tau_{\omega}=\frac{\rho u^{*} U^{T}}{\frac{1}{\kappa} \ln \left(y^{*}\right)+C}
\end{aligned}
$$

Essa relação é válida fora da subcamada viscosa, que fica mais próxima à parede. Por este motivo, a modelagem limita os valores de $y^{*}$ de modo que ele não possa ser inferior a 11,06. Abaixo desse valor a lei logarítmica não se aplica. Portanto, essa abordagem implementada no código do CFX evita que os elementos da malha situados mais próximos à parede que o equivalente a $y^{*}=11,06$ sejam avaliados por um modelo inadequado. De qualquer forma, o parâmetro $y^{*}$ foi monitorado e em todas as simulações realizadas seu valor não ficou abaixo do limite de 11,06. 


\subsection{CONDIÇÕES DE CONTORNO}

Anderson (1995) salientou a importância em ter condições de contorno adequadas de modo que os problemas sejam bem-postos (well-posed) e solúveis. As condições de contorno afetam toda a solução dos problemas e sua especificação depende dos objetivos das análises e dos dados disponíveis.

Moura (2008) realizou comparações entre algumas maneiras de especificá-las na simulação de impelidores centrífugos. Sua conclusão está em acordo com o recomendado por Souza (2011) e pelo próprio fabricante do CFX, que apontam a especificação da pressão total na entrada e a vazão mássica na saída como as melhores opções. Dessa forma, é possível analisar a razão de pressões do compressor (ou impelidor) e foi essa a abordagem utilizada nas simulações feitas até o momento. Além dessas variáveis, foram especificadas a temperatura na entrada e a rotação do impelidor.

Mesmo com evidências que apontam essa abordagem como a melhor opção, há uma questão discutível. A vazão mássica em um compressor depende de sua própria rotação, uma vez que o próprio compressor é responsável por gerar o escoamento. Ao especificar tanto vazão quanto rotação, não se leva em conta se tal rotação é de fato capaz de gerar a vazão.

Uma opção seria especificar pressão total na entrada e pressão estática na saída. Tal abordagem foi adotada por Kurauchi (2012) e por Velásquez et al. (2010). Contudo, assumir a pressão estática envolve, novamente, impor um parâmetro do qual não se tem conhecimento. A pressão estática na saída depende principalmente do desempenho do difusor. Dessa forma, escolheu-se utilizar a abordagem mais comum e recomendada, com vazão mássica na saída e pressão total na entrada para todas as simulações.

Todas as simulações foram realizadas com malhas simulando apenas uma das pás do impelidor e uma palheta do difusor com condição de periodicidade para levar em conta a presença das pás vizinhas. O domínio do impelidor foi definido como rotativo, informando o eixo de rotação, sentido e velocidade de rotação. As paredes do shroud do impelidor foram definidas como contra-rotativas, indicando que são estacionárias. 
A interação entre os domínios foi feita pela abordagem chamada Stage, recomendada pelo fabricante para este tipo de problema. Esta abordagem é também chamada de mixing planes, e se utiliza de médias circunferenciais com intenção de emular o comportamento médio das diferentes posições relativas entre os domínios que existem na dinâmica real. As interfaces foram adotadas em duas áreas: entre a face que delimita o domínio estendido na entrada (estacionário) e o indutor do impelidor, e entre saída do impelidor e entrada do difusor.

O domínio estendido na entrada recebeu condição de abertura (opening) na região equivalente ao shroud e condição de parede com escorregamento livre na região do hub. A pressão e temperatura totais foram especificadas na face paralela à entrada do impelidor.

\subsection{CONVERGÊNCIA E MALHAS COMPUTACIONAIS}

Em todas as simulações feitas com CFD há erros (ou resíduos) entre as iterações da solução numérica. A tendência esperada é que os resíduos diminuam ao longo das iterações, caminhando a uma solução numérica cada vez mais próxima da iteração anterior, convergindo para alguns valores.

Para interromper as iterações e considerar uma solução satisfatória, é usual estabelecer um critério de convergência. Tal critério pode ser posto no software utilizado em termos do valor máximo de erro residual no domínio para todas as equações, sendo que as iterações continuarão até que os resíduos estejam todos abaixo do valor determinado. Alternativamente, é possível estabelecer um valor máximo para o RMS dos resíduos no domínio computacional, sendo que cada equação deve estar abaixo de tal valor para que a simulação seja encerrada.

A evolução dos resíduos pode ser acompanhada durante a solução numérica, sendo apresentada sob a forma de gráfico e valores. O solver do CFX ainda dá possibilita que sejam monitoradas variáveis integrais durante as iterações. É possível acompanhar os valores, por exemplo, da força resultante em uma dada direção numa superfície definida do domínio. 

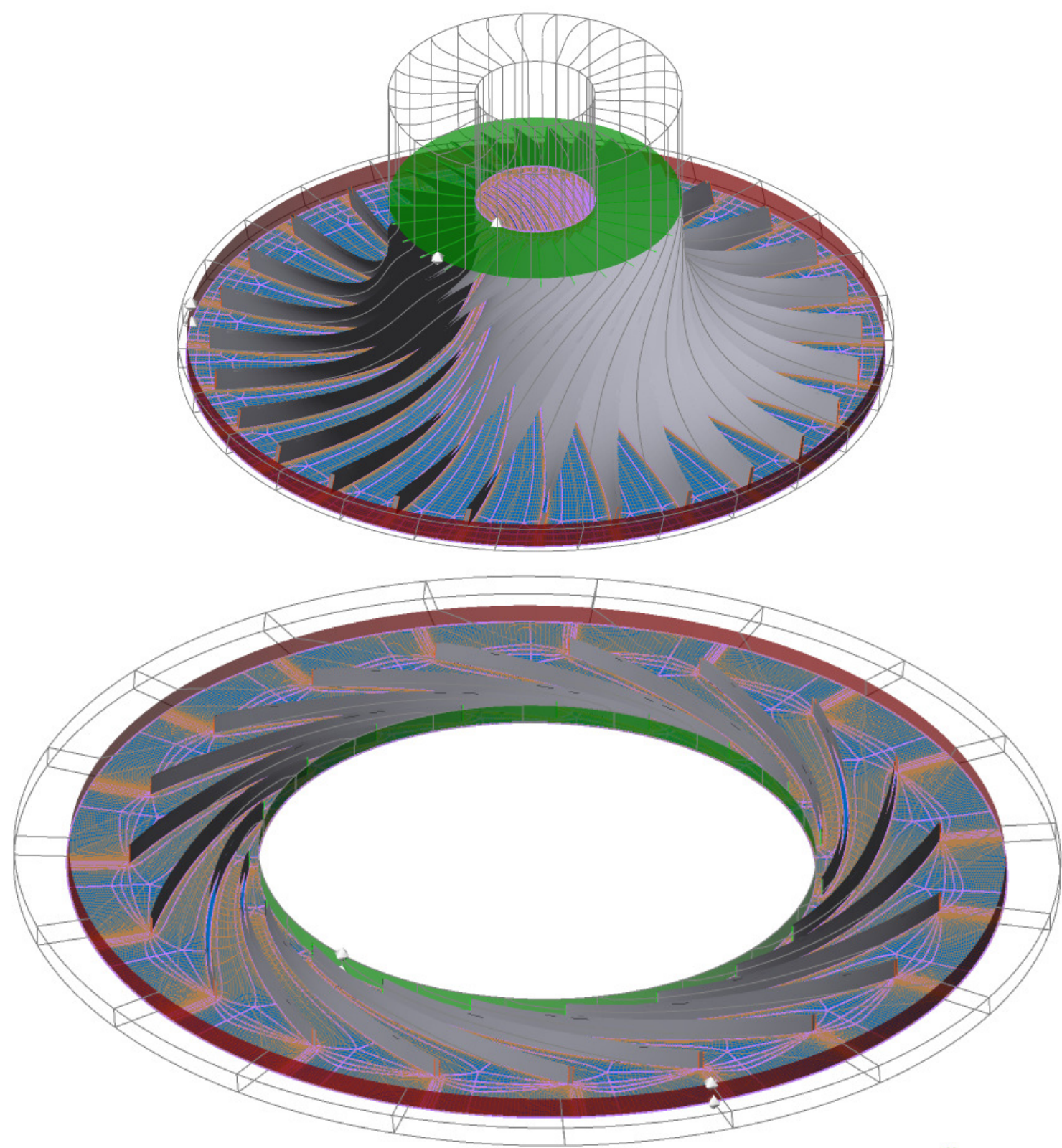

Figura 39 - Exemplo das geometrias de impelidor (acima) e difusor (abaixo) sem suas carcaças (shroud). Linhas mostram a extensão dos domínios computacionais. A malha computacional do hub no impelidor e difusor é mostrada. Superfícies em verde são entradas e em vermelho saídas.

Para as simulações com apenas um domínio, realizadas por Campos e Krieger (2012), os resíduos atingiam facilmente RMS na ordem de $10^{-6}$. Contudo, nas simulações com domínios rotativo e estacionário, por vezes as simulações divergiram. Encontrou-se uma maneira para melhorar a convergência que, posteriormente, constatou-se ser similar à reportada por Kurauchi (2012). 
Além de estender os domínios de entrada e saída, fez-se uso do controle dado pelo CFX no esquema de discretização descrito pela Eq. 177. Para alcançar a convergência, as simulações foram iniciadas com o esquema Upwind e cálculos de turbulência de primeira ordem. Após estabilização dos resíduos, o fator da Eq. 177 era aumentado de 0 para 0,5 até nova convergência. Por fim, modificava-se para o esquema de diferenças centrais (com o fator igual a 1) e cálculos de turbulência de alta ordem. Com este procedimento, todas as simulações realizadas tiveram RMS dos resíduos na ordem de $10^{-5}$, patamar no qual se considerou as soluções convergidas.

As malhas computacionais foram construídas com auxílio do programa TurboGrid. Todas as malhas são compostas por elementos hexaédricos, havendo controle sobre as linhas guia e suas intersecções para que sejam evitados elementos muito extensos ou com razão de aspecto muito grande. As ferramentas de diagnóstico que apontam a localização de elementos de baixa qualidade foram utilizadas para minimizar os erros apontados.

Para avaliar o número de elementos capaz de assegurar independência de malha, foram feitos testes simples. Utilizando o modelo $k-\omega S S T$, foram testadas malhas com 50, 100, 150 e 180 mil elementos para cada um dos domínios de impelidor e difusor. As diferenças entre as malhas de 150 e 180 mil foram consideradas desprezíveis, sendo de $0,4 \%$ na eficiência e 1,1\% na razão de pressões, sem diferenças perceptíveis nos contornos de velocidade e pressão. Portanto, as malhas utilizadas nas simulações tinham por volta de 150 mil elementos para a pá do impelidor (incluindo o domínio de entrada estacionário) e 150 mil para a palheta do difusor e sua extensão do domínio.

\subsection{RESULTADOS E O COMPRESSOR PROJETADO}

As simulações foram realizadas de acordo com o exposto nas seções anteriores. As simulações foram iniciadas com a utilização do modelo de turbulência $k-\omega S S T$, por haver um número maior de referências citando-o. O difusor teve seus ângulos de entrada e saída modificados para $\beta_{B 3}=-71,4{ }^{\circ}$ e $\beta_{B 4}=-58^{\circ}$ devido à estimativa do 
ângulo absoluto do escoamento na saída do impelidor $\alpha_{2}$ com o projeto bidimensional.

\begin{tabular}{cccc}
\begin{tabular}{c} 
Tabela 6 - Resultados das simulações com modelo $k$ - $\omega$ SST com diversas vazões mássicas. \\
\hline $\begin{array}{c}\text { Vazão Mássica } \\
(\mathbf{k g} / \mathbf{s})\end{array}$
\end{tabular} & $\begin{array}{c}\text { Eficiência } \\
\text { Isentrópica (\%) }\end{array}$ & $\begin{array}{c}\text { Eficiência } \\
\text { Politrópica (\%) }\end{array}$ & $\begin{array}{c}\text { Razão de } \\
\text { Pressões }\end{array}$ \\
\hline 4,00 & 82,47 & 86,36 & 3,84 \\
4,05 & 87,35 & 89,50 & 4,24 \\
4,13 & 89,11 & 91,16 & 4,59 \\
4,30 & 84,43 & 88,41 & 4,01 \\
\hline
\end{tabular}

Após a primeira simulação ter reportado eficiência isentrópica total-total relativamente baixa $(81,3 \%)$, os ângulos foram modificados novamente utilizando os novos dados do escoamento na saída do impelidor. Impôs-se então $\beta_{B 3}=-78{ }^{\circ} \mathrm{e}$ $\beta_{B 4}=-61^{\circ} \mathrm{com}$ auxílio das diretrizes de projeto expostas na seção 6.2. Estes ângulos foram mantidos até o final do projeto.

A simulação no ponto de projeto teve eficiência indicada de 89,11\%. O valor foi considerado satisfatório se comparado à estimativa utilizada como requisito durante o projeto de $85 \%$. A análise dos resultados indicou a ausência de velocidades supersônicas neste regime de operação, como mostra a Fig. 40, o que pode explicar em parte a boa eficiência alcançada.

A mesma Fig. 40 indica ainda o funcionamento do difusor de acordo com o esperado. As maiores velocidades são encontradas na superfície de sucção das palhetas. Contudo, é necessário destacar que o projeto do difusor pode ser melhorado. O ângulo de entrada do escoamento $\left(\alpha_{3}\right)$ e das palhetas $\left(\beta_{3}\right)$ deve ser analisado em maiores detalhes, até mesmo com o uso de simulações transientes.

A razão de pressões alcançada foi mais alta que o requisito imposto e mais alta que o previsto pelos métodos uni e bidimensionais, tendo o valor de 4,59. A Fig. 41 ilustra o aumento de pressão total ao longo do impelidor e a posterior perda de pressão total no difusor.

Tendo sido satisfeita a condição de projeto, foram testadas outras três vazões mássicas. Apesar de não terem sido impostos requisitos para a margem operacional, sabe-se que não é possível manter o compressor sempre no ponto de 
projeto. As eficiências diminuíram, tanto para as vazões menores quanto para a maior, assim como reporta a Tab. 6. A rotação foi mantida e, em conseqüência das eficiências mais baixas, as razões de pressões também caíram.

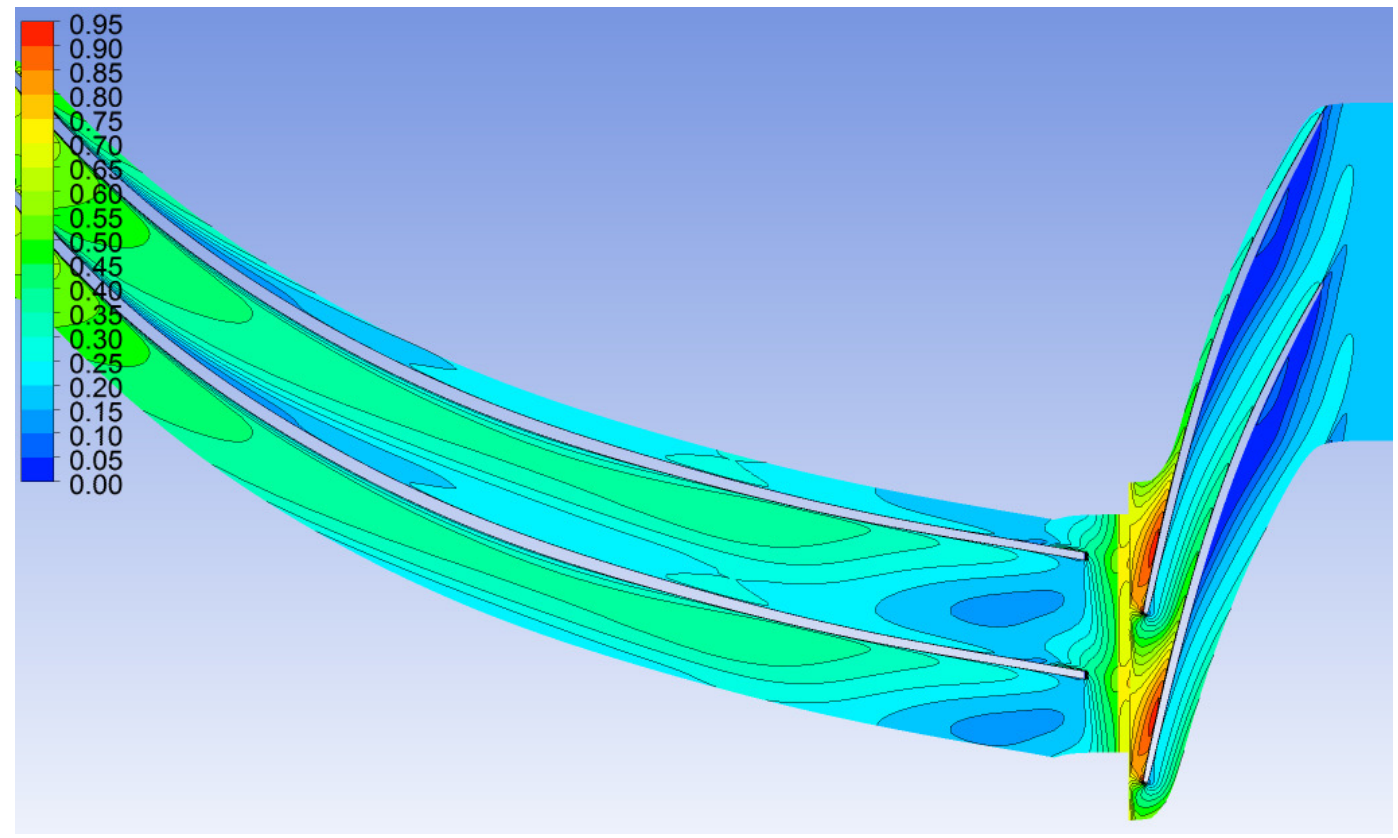

Figura 40 - Contorno do número de Mach ao longo do compressor na rotação e vazão de projeto $(4,13 \mathrm{~kg} / \mathrm{s})$. Impelidor à esquerda e difusor à direita da figura. Modelo de turbulência $k$ - $\omega S S T$.

A vazão mássica de $4,30 \mathrm{~kg} / \mathrm{s}$ apresentou número de Mach maior que a unidade. Isso indica possível proximidade do choke. As eficiências isentrópicas reportadas foram consideradas satisfatórias por não ter havido grande distanciamento dos $85 \%$ preconizados. Como se tratam de pontos de operação diferentes, com razões de pressão diferentes, a eficiência politrópica permite melhor comparação entre os pontos. Neste caso, a eficiência variou menos, tendo variação máxima de pouco menos de $5 \%$ comparando-se os quatro casos.

Não foram realizados mais testes por não haver meios para avaliar os resultados. Os requisitos relativos à margem operacional dependem, além das condições de operação, das necessidades dos outros componentes da turbina a gás (CUMPSTY, 2004). Dessa forma, recomenda-se que avaliações a este respeito sejam feitas em fases posteriores do projeto da turbina a gás.

Para haver alguma garantia quanto ao desempenho, julgou-se necessário testar outros modelos de turbulência, devido à existência de trabalhos defendendo o uso 
destes outros modelos. O ponto de projeto foi simulado com os modelos $k-\varepsilon$ e $R N G$ $k-\varepsilon$.

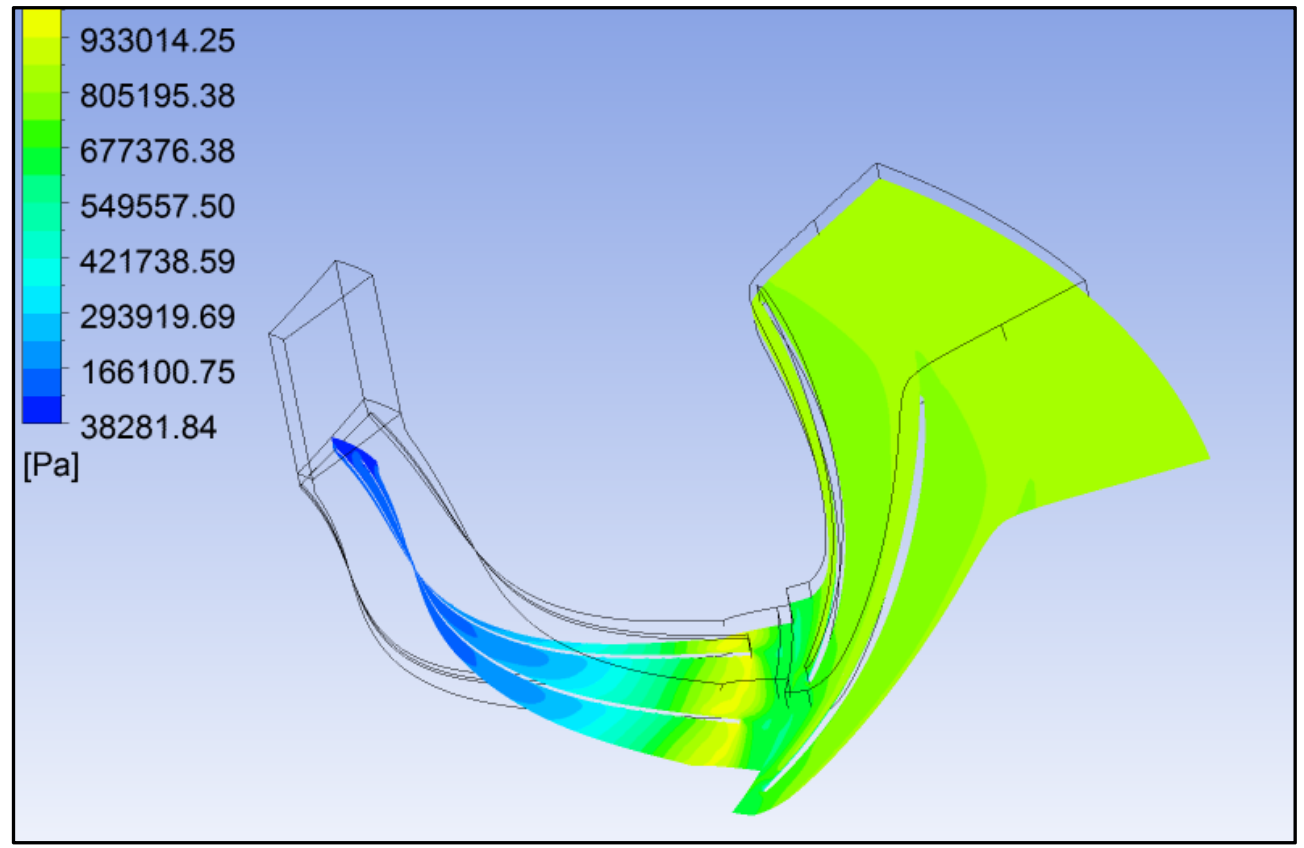

Figura 41 - Contorno de pressão total sobre a superfície média na direção circunferencial no ponto de projeto. Duas pás do impelidor e duas palhetas do difusor são mostradas. Modelo de turbulência $k-\omega$ SST.

Os resultados estão dispostos na Tab. 7. Eficiência e razão de pressões foram menores se comparadas às obtidas com o modelo $k-\omega$ SST. A análise dos resultados, sob a forma de contornos de velocidade e pressão, não apontou com clareza qual foi o efeito de mudar o modelo de turbulência sobre o escoamento.

Tabela 7 - Resultados sumarizados de eficiência isentrópica e razão de pressões previstas pelos modelos utilizados. Valores dos modelos 1D e 2D referem-se apenas ao impelidor.

\begin{tabular}{l|cc}
\hline \multicolumn{1}{c}{ Modelo } & $\begin{array}{c}\text { Eficiência } \\
\text { Isentrópica (\%) }\end{array}$ & $\begin{array}{c}\text { Razão de } \\
\text { Pressões }\end{array}$ \\
\hline 1D (impelidor) & 91,15 & 4,31 \\
2D (impelidor) & 90,95 & 4,33 \\
3D $\boldsymbol{k}-\boldsymbol{\varepsilon}$ & 86,89 & 4,11 \\
3D $\boldsymbol{R}$ NG $\boldsymbol{k}$ - $\boldsymbol{\varepsilon}$ & 87,18 & 4,48 \\
3D $\boldsymbol{k}-\boldsymbol{\omega}$ SST & 89,11 & 4,59 \\
\hline
\end{tabular}

As diferenças entre os modelos de turbulência não foram tão grandes quanto poderia se esperar, apesar de serem significativas. A eficiência isentrópica para as 
modelagens 1D e 2D estão consistentes se comparadas com as simulações 3D, uma vez que as perdas no difusor só foram levadas em conta tridimensionalmente. Julgou-se mais importante à aplicação deste projeto notar que a eficiência do projeto está com valores satisfatórios para qualquer dos modelos aplicados. Dessa forma, considerou-se que o projeto do compressor estava finalizado, considerando os objetivos da presente dissertação.

Utilizando as características geométricas do compressor e o desempenho calculado pela simulação com o modelo $k-\omega S S T$, foi possível situar o projeto diagrama de Cordier (Fig. 42) proposto por Casey; Zwyssig e Robinson (2010) apresentado no capítulo 4. É possível notar que o compressor está dentro da faixa de valores definida pelos autores.

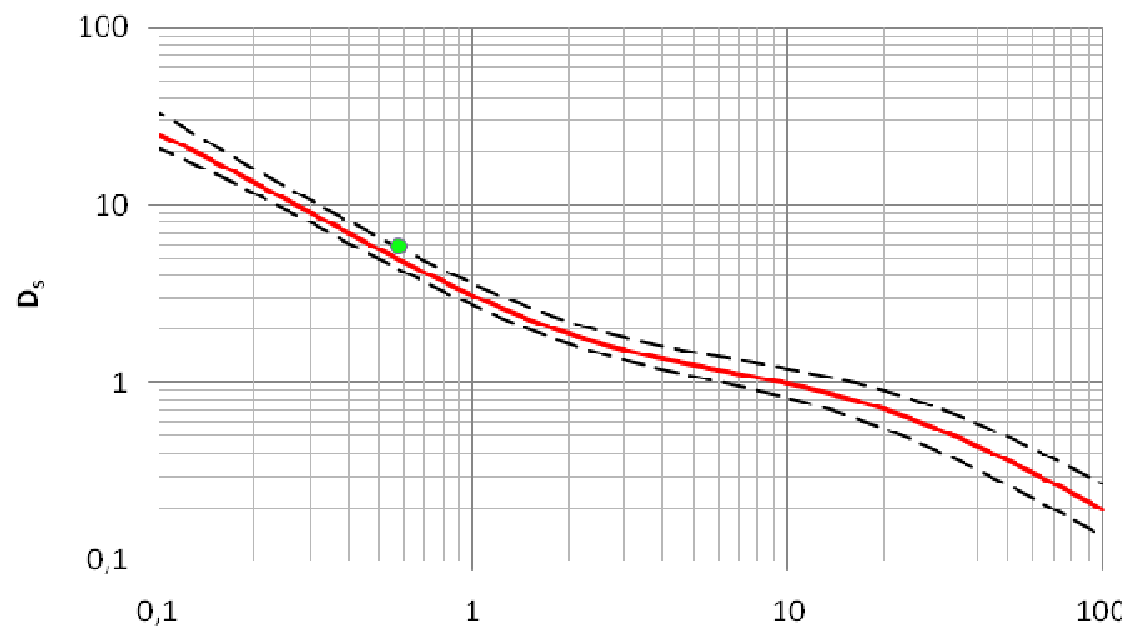

$\mathbf{N}_{\mathrm{s}}$

Figura 42 - Linha de Cordier definida pela equação de Casey; Zwyssig e Robinson (2010). A linha contínua é a principal, enquanto as tracejadas definem a faixa de valores que apontam as turbomáquinas mais eficientes. O compressor projetado se situa no ponto verde.

A Fig. 43 mostra com mais detalhes a geometria final do compressor. Assim como apontado ao longo do texto e como está exposto nas sugestões da seção 9.1, não há quaisquer garantias de que se trata da melhor geometria possível e há outros aspectos do projeto a serem estudados antes que se possa construir o compressor. Porém, pode-se afirmar que o compressor projetado atende aos requisitos aerotermodinâmicos pertinentes. 

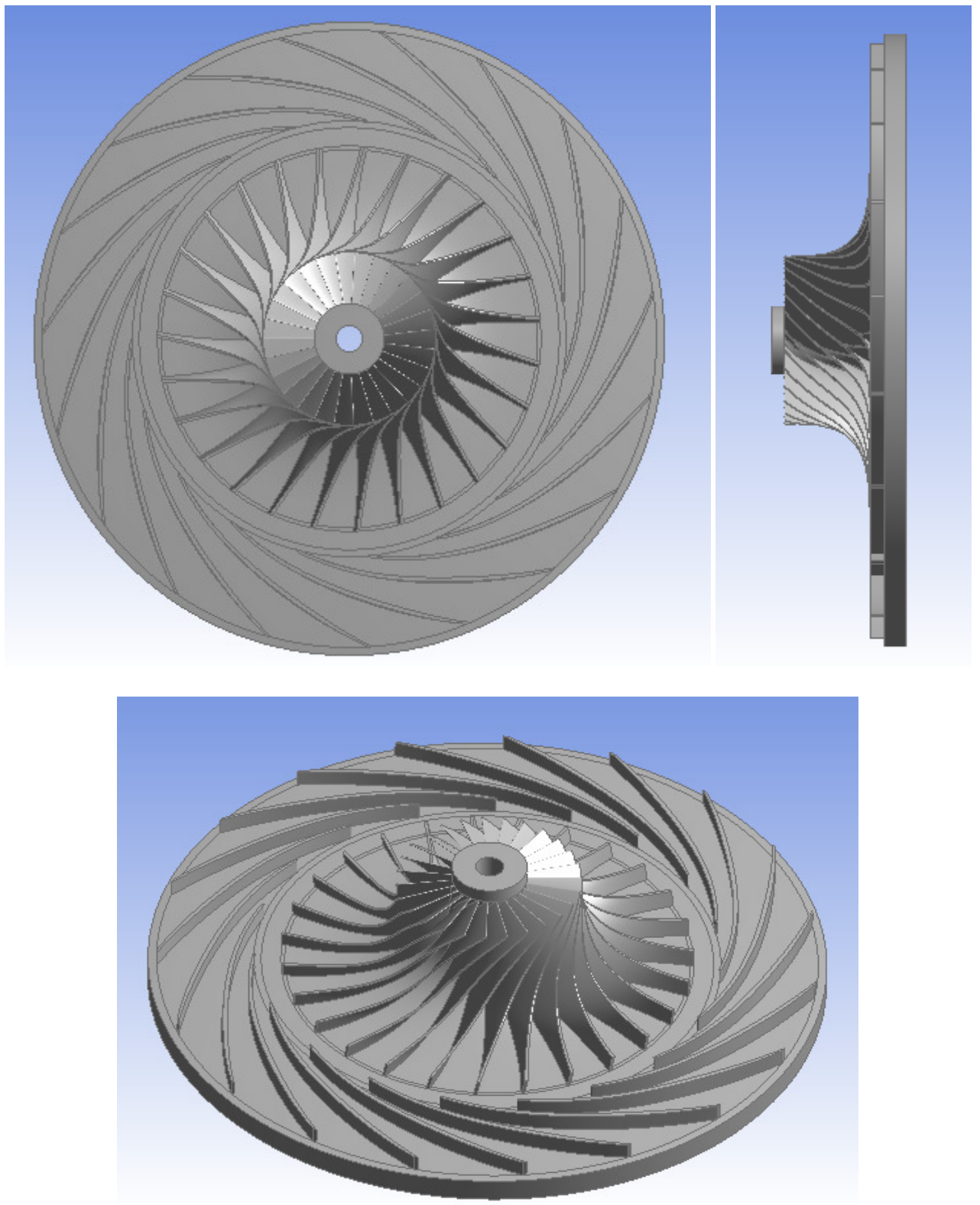

Figura 43 - Geometria final do compressor projetado sem as carcaças que cobrem impelidor e difusor. 


\section{CONCLUSÕES}

Este trabalho apresentou o projeto aerotermodinâmico de um compressor. Partindo da potência pretendida para a turbina a gás à qual o compressor deve ser integrado, chegou-se à geometria do compressor. $O$ projeto iniciou-se com uma pesquisa paramétrica com turbinas a gás disponíveis no mercado utilizada para impor requisitos adequados. A análise do ciclo termodinâmico da turbina a gás foi capaz de prover os requisitos adicionais para o compressor.

Com base nos requisitos, a escolha do tipo de compressor foi descrita. Um compressor do tipo radial foi a escolha apontada como mais adequada. A partir de tal escolha, foram estudados os conceitos e características vinculados aos compressores centrífugos cujo conhecimento é necessário ao projeto.

Iniciou-se o projeto unidimensional baseado em relações termodinâmicas, triângulos de velocidades, conceitos físicos básicos e correlações empíricas. Uma rotina computacional fez numerosas combinações dos parâmetros de entrada e calculou o desempenhou com base no modelo de perdas proposto por Oh; Yoon e Chung (1997).

Após selecionar as melhores geometrias do projeto unidimensional, estas foram simuladas usando uma ferramenta computacional baseada no método de curvatura das linhas de corrente. Nesta fase, foi possível definir as curvas do perfil meridional e ter uma estimativa do desempenho mais apurada (em teoria) que do projeto unidimensional. Escolheu-se uma das geometrias para ser testada com CFD para realizar os últimos ajustes.

Em vários momentos do projeto, notou-se a necessidade em arbitrar alguns parâmetros. Nestas situações, é importante recorrer à experiência de projetos anteriores, que, neste caso, foi encontrada na literatura. Pode-se concluir que há lacunas tanto nos procedimentos recomendados pela literatura para projeto, quanto na compreensão dos fenômenos físicos envolvidos na operação de compressores centrífugos. Estas lacunas foram mais freqüentes para os difusores se comparados aos impelidores.

Com relação ao compressor projetado, seu desempenho foi assegurado com base nas ferramentas disponíveis. As simulações tridimensionais apontaram uma 
eficiência mínima no ponto de projeto de aproximadamente $86,89 \%$ com uso do modelo de turbulência $k-\varepsilon$.

Por ter alcançado os requisitos impostos e ter descrito e discutido os métodos pertinentes, considera-se que o presente trabalho cumpre seus objetivos.

\subsection{SUGESTÕES PARA PROJETOS FUTUROS E MELHORIA DO COMPRESSOR}

Como expresso anteriormente, este trabalho inicia a intenção de projetar e construir uma turbina a gás. Dessa forma, há muitas oportunidades para pesquisa em áreas ainda não totalmente conhecidas ou divulgadas. O projeto do compressor não pode ser considerado finalizado, por terem sido levados em conta apenas os aspectos aerotermodinâmicos do projeto. Faz-se necessário investigar diversas áreas como análise da resistência mecânica, escolha dos materiais de fabricação, definição dos processos de fabricação, análise de características dinâmicas relacionadas a vibrações, etc. Além disso, uma grande tendência dos projetos atuais é o uso de mecanismos de otimização. Esse tipo de abordagem poderia ser feita no projeto atual utilizando até mesmo as ferramentas apresentadas nesta dissertação.

Para melhorar ou complementar a metodologia de projeto utilizada neste trabalho:

- Dada a dependência do projeto unidimensional com relação ao fator de escorregamento, sugere-se que seja usada uma correlação mais recente e abrangente, como a desenvolvida por Qiu et al. (2011). Tal correlação necessita de parâmetros só disponíveis em fases mais adiantadas do projeto. Dessa forma, propõe-se que o projeto unidimensional seja revisitado com uso dessa correlação ou alguma similar.

- As correlações utilizadas para o cálculo das perdas e, conseqüentemente, da eficiência durante a fase unidimensional do projeto podem ser modificadas $\mathrm{e}$ aprimoradas.

- Os métodos de projeto preliminar para difusores centrífugos não são tão bem estabelecidos quanto os métodos existentes para impelidores, mesmo considerando as diversas lacunas existentes nestes. Pode-se considerar a 
comparação de desempenho entre o difusor projetado e um difusor com canais ou de baixa solidez.

- Sugere-se a implementação de algum modelo de perdas para difusores, como o de Ribi e Dalbert (2000), no processo de projeto. Uma abordagem similar à adotada para o impelidor poderia ser feita.

Para melhorar o projeto aerotermodinâmico:

- Rotinas de otimização podem ser empregadas. O uso do Vista TF se prestaria muito bem a essas rotinas, por sua rapidez e flexibilidade (CASEY; GERSBACH; ROBINSON, 2008). O uso de CFD também é possível, assim como se vê em alguns trabalhos mais recentes. Além disso, integração dessas rotinas com análises estruturais, assim como realizado por Van den Braembussche et al. (2012) poderia contribuir com a melhoria do projeto.

- O mapa de desempenho não foi totalmente explorado. Não foi possível fixar requisitos a este mapa, uma vez que tais requisitos dependem das características dos outros componentes da turbina a gás. Sugere-se que se faça um estudo para caracterizar toda a operação do compressor e, se necessário, impor modificações.

Para concluir o projeto do compressor e proceder à construção:

- Faz-se necessário estudar os esforços mecânicos associados. Essa análise é vital para confirmar a viabilidade do projeto ou modificá-lo a contento. Parâmetros como a espessura das pás do impelidor, que influenciam 0 projeto aerotermodinâmico dependem quase totalmente dessa análise.

- A análise das características dinâmicas do compressor também é necessária. As vibrações precisam ser analisadas em conjunto com as características construtivas. O tip clearance, por exemplo, é definido com base nessa análise.

- O estudo de materiais para a construção e dos processos de fabricação adequados e capazes de reproduzir as formas e suportar os esforços também é fundamental.

- O projeto ou seleção de mancais e rolamentos para o compressor é necessário e importante ao seu desempenho. 
10 REFERÊNCIAS

AGHAEI TOG, R.; TOUSI, A. M.; SOLTANI, M. Design and CFD analysis of a centrifugal compressor for a microgasturbine. Aircraft Engineering and Aerospace Technology: An International Journal, v. 79, n. 2, p. 137-143, 2007.

AGARD. Advanced compressors. AGARD Lecture Series 39. 1970.

AGARD. Turbomachinery design using CFD. AGARD Lecture Series 195, 1994.

AGARD. CFD validation for propulsion system components. AGARD Advisory Report 355, 1998.

AIROLDI, M. L. Análise do escoamento em turbinas axiais e radiais para aplicações em microturbina a gás. 2009. 88 p. Trabalho de Graduação (Engenharia Mecânica) - Universidade de São Paulo, São Paulo, 2009.

AL-ZUBAIDY, S. N. A proposed design package for centrifugal impellers. Computers \& Structures, v. 55, n. 2, p. 347-356, 1995.

ANDERSON, J. D. Computational fluid dynamics: the basics with applications. $1^{\text {st }}$ ed. Nova lorque: McGraw-Hill, 1995. 547 p.

ANDO, V. F. Project optimisation of high-performance axial flow compressor. 2010. 107 p. Trabalho de Graduação (Engenharia Mecânica) - Instituto Tecnológico de Aeronáutica, São José dos Campos, 2010.

ANDO, V. F. Genetic algorithm for preliminary design optimisation of highperformance axial-flow compressors. 2011. 163 p. Dissertação (Mestrado) Instituto Tecnológico de Aeronáutica, São José dos Campos, 2011.

AUNGIER, R. H. Centrifugal compressors: a strategy for aerodynamic design and analysis. Nova York: The American Society of Mechanical Engineers, 2000. 315 p.

BAINES, N. C. Turbomachinery in renewable energy applications: how turbomachinery configurations are selected and what parameters drive the selection. Power Engineering, p. 58-63, Abril, 2010. 
BALJE, O. E. Turbomachines: a guide to design, selection and theory. Nova York: John Wiley \& Sons, $1981.513 p$.

BASKHARONE, E. A. Principles of turbomachinery in air-breathing engines. Cambridge: Cambridge University Press, 2006. 598 p.

BOTHA, B. W.; MOOLMAN, A. Determining the impact of the different losses on centrifugal compressor design. Research and Development Journal of The South African Institution of Mechanical Engineering, v. 21, p.23-31, 2005.

BOYCE, M. P. Centrifugal compressors: a basic guide. $1^{\text {st }}$ ed. Tulsa: PennWell Corporation, 2003. $662 \mathrm{p}$.

BOYCE, M. P. Gas turbine engineering handbook. $3^{\text {rd }}$ ed. Boston: GPP, 2006. 936 p.

BREZONICK, M. J. (Org.) Diesel and gas turbine worldwide catalog, Waukesha: Diesel and Gas Turbine Publications, 2003. 836 p.

BUCKINGHAM, E. On physically similar systems: illustrations of the use of dimensional equations. Physical Review, v. 4, n. 4, p. 345-376, 1914.

CAME, P. M.; ROBINSON, C. J. Centrifugal compressor design. Proceedings of the Institution of Mechanical Engineers, Part C: Journal of Mechanical Engineering Science, v. 213, n. 2, p. 139-155, 1999.

CAMPOS, A. P. V.; KRIEGER FILHO, G. C. One-dimensional preliminary compressor design applied to a $500 \mathrm{~kW}$ gas turbine and the effect of blade number. Proceedings of ENCIT, 2012. Apresentado a $14^{\text {th }}$ Brazilian Congress of Thermal Sciences and Engineering, Rio de Janeiro, Novembro 18-22, 2012.

CAMPOS, A. P. V.; SACOMANO FILHO, F. L.; KRIEGER FILHO, G. C. Design analysis of a micro gas turbine combustion chamber burning natural gas. ASME Conference Proceedings 2012, 2012. Apresentado a ASME TURBO EXPO, Copenhagen, Dinamarca, Junho 11-15, 2012.

CARRILLO, R. A. M. Projeto e análise de desempenho de turbinas radiais. 2010. 129 p. Dissertação (Mestrado) - Universidade Federal de Itajubá, Itajubá, 2010. 
CARRILLO, R. A. M.; VELÁSQUEZ, E. I. G; NASCIMENTO, M. A. R.; MOURA, N. R. Radial inflow turbine one and tri-dimensional design analysis of $600 \mathrm{~kW}$ simple cycle gas turbine engine. ASME Conference Proceedings 2010, v. 5, p. 477-486, 2010. Apresentado a ASME TURBO EXPO, Glasgow, Reino Unido, Junho 14-18, 2010.

CASEY, M. A computational geometry for the blades and internal flow channels of centrifugal compressors. ASME paper 82-GT-155, 1983.

CASEY, M. Computational methods for preliminary design and geometry definition in turbomachinery. In: AGARD Lecture Series, 195., 1994. Turbomachinery design using CFD. 1994.

CASEY, M.; GERSBACH, F.; ROBINSON, C. An optimization technique for radial compressor impellers. ASME Conference Proceedings 2008, v. 6, p. 2401-2411, 2008. Apresentado a ASME TURBO EXPO, Berlim, Alemanha, Junho 9-13, 2008.

CASEY, M.; ROBINSON, C. A new streamline curvature throughflow method for radial turbomachinery. Journal of Turbomachinery, v. 132, n. 3, p. 1-10, 2010.

CASEY, M.; ZWYSSIG, C.; ROBINSON, C. The Cordier line for mixed flow compressors. ASME Conference Proceedings, v. 7, p. 1-11, 2010. Apresentado a ASME TURBO EXPO, Glasgow, Reino Unido, Junho 14-18, 2010.

CORDIER, O. Ähnlichkeitsbedingungen für Strömungsmaschinen. VDI Bericht 3, v. $85,1955$.

CROWE, C. T.; ROBERSON, J. A.; ELGER, D. F. Engineering Fluid Mechanics, $7^{\text {th }}$ Ed. Nova York: John Wiley \& Sons, 2001. 714 p.

CSANADY, G. T. Theory of turbomachines. Nova York: McGraw-Hill, 1964. 378 p.

CUMPSTY, N. A. Compressor aerodynamics, $2^{\text {nd }}$ Ed. Malabar: Krieger Publishing Company, 2004. 517 p.

DALBERT, P; RIBI, B.; KMECI, T.; CASEY, M. V. Radial compressor design for industrial compressors. Proceedings of the Institution of Mechanical Engineers, Part C: Journal of Mechanical Engineering Science, v. 213, n. 1, p. 71-83, 1999. 
DENTON, J. D. Some limitations of turbomachinery CFD. ASME Conference Proceedings 2010, v. 7, p. 735-745, 2010. Apresentado a ASME TURBO EXPO, Glasgow, Reino Unido, Junho 14-18, 2010.

DENTON, J. D., DAWES, W. N. Computational fluid dynamics for turbomachinery design. Proceedings of the Institution of Mechanical Engineers, Part C: Journal of Mechanical Engineering Science, v. 213, n. 2, p. 107-124, 1999.

DIXON, S. L., HALL, C. A. Fluid mechanics and thermodynamics of turbomachinery. $6^{\text {th }}$ ed. Burlington: Elsevier, 2010. $459 \mathrm{p}$.

DUFOUR, G. Contributions à la modélisation et au calcul des écoulements dans les compresseurs centrifuges: application à la conception par lois de similitude. 2006. 292 p. Tese (Doutorado) - Institut National Polytechnique de Toulouse, Toulouse, França, 2006.

ENGEDA, A. The design and performance results of simple flat plate low solidity vaned diffusers. Proceedings of the Institution of Mechanical Engineers, Part A: Journal of Power and Energy, v. 215, n. 1, p. 109-118, 2001.

EPPLE, Ph.; DURST, F.; DELGADO, A. A theoretical derivation of the Cordier diagram for turbomachines. Proceedings of the Institution of Mechanical Engineers, Part C: Journal of Mechanical Engineering Science, v. 225, n. 2, p. 354-368, 2011.

GLASSMAN, A. J., Computer program for design analysis of radial-inflow turbines. NASA Technical Note D-8164, 1976.

GIAMPAOLO, A. Gas turbine handbook: principles and practices. $4^{\text {th }}$ ed. Georgia: The Fairmont Press, 2009. 447 p.

GRAVDAHL, J. T.; WILLEMS, F.; JAGER, B.; EGELAND, O. Modeling of surge in free-spool centrifugal compressors: experimental validation. Journal of Propulsion and Power, v. 20, n. 5, p. 849-857, 2004.

HAN, J.; DUTTA, S.; EKKAD, S. V. Gas turbine heat transfer and cooling technology. $1^{\text {st }}$ ed. Nova York: Taylor \& Francis, 2000. 646 p.

HOUGHTON, E. L.; CARPENTER, P. W. Aerodynamics for engineering students. $5^{\text {th }}$ ed. Burlington:Elsevier Butterworth-Heinimann, 2003. $590 \mathrm{p}$. 
JAMIESON, A. W. H. Gas turbines principles and practices. Chapter 9. Newnes, London, 1955.

JAPIKSE, D; BAINES. N. C. Diffuser design technology. White River Junction: Concepts ETI, Inc., 1998. 287 p.

KATSANIS, T. Use of arbitrary quasi-orthogonals for calculating flow distribution in the meridional plane of a turbomachine. NASA Technical Note D-2546, 1964.

KRAIN, H. Review of centrifugal compressor's application and development. Journal of Turbomachinery, v. 127, n. 1, p. 25-34, 2005.

KURAUCHI, S. K. Design and off-design analysis of a centrifugal compressor for natural gas. 2012. 102 p. Dissertação (Mestrado) - Instituto Tecnológico de Aeronáutica, São José dos Campos, 2012.

LAROSILIERE, L. M.; SKOCK, G. J.; PRAHST. Aerodynamic synthesis of a centrifugal impeller using CFD and measurements. NASA Technical Memorandum 107515, 25 p, 1997.

LOGAN JR., E. Turbomachinery: basic theory and applications. $2^{\text {nd }}$ ed. Nova York: Marcel Dekker, Inc., 1993. 261 p.

MCKAIN, T. F.; HOLBROOK, G. J. Coordinates for a high performance 4:1 pressure ratio centrifugal compressor. Final Report, NASA Contract NAS 3-23268, 73 p, 1982.

MENTER, F. R. Two-equation eddy-viscosity turbulence models for engineering applications. AIAA Journal, v. 32, n. 8, p. 1598-1605, 1994.

MOLINARI, M.; DAWES, W. N. Review of evolution of compressor design process and future perspectives. Proceedings of the Institution of Mechanical Engineers, Part C: Journal of Mechanical Engineering Science, v. 220, n. 6, p. 761-771, 2006.

MORAN, M. J.; SHAPIRO, H. N. Princípios de termodinâmica para engenharia. $6^{\underline{a}}$ ed. Rio de Janeiro: LTC editora, 2009. 800 p.

MOURA, N. R. Simulação fluidodinâmica computacional de desempenho de um impelidor de um compressor centrífugo. 2008. 229 p. Dissertação (Mestrado) Universidade Federal do Rio de Janeiro, Rio de Janeiro, 2008. 
NASCIMENTO, M. A. R.; VENTURINI, O. J.; LORA, E. S.; SIERRA, G. A.; RODRIGUES, L. O.; CARVALHO, H. M.; MOURA, N. R. Cycle selection and compressor design of $600 \mathrm{~kW}$ simple cycle gas turbine engine. ASME Conference Proceedings 2008, v. 1, p. 1-11, 2008. Apresentado a ASME TURBO EXPO, Berlin, Alemanha, Junho 9-13, 2008.

OH, H. W.; YOON, E. S.; CHUNG, M. K. An optimum set of loss models for performance prediction of centrifugal compressors. Proceedings of the Institution of Mechanical Engineers, Part A: Journal of Power and Energy, v. 211, n. 4, p. 331-338, 1997.

QIU, X.; JAPIKSE, D.; ZHAO, J.; ANDERSON, M. R. Analysis and validation of a unified slip factor model for impellers at design and off-design conditions. Journal of Turbomachinery, v. 133, n. 4, p. 1-9, 2011.

RHIE, C. M.; CHOW, W. L. A numeric study of the turbulent flow past an isolated airfoil with trailing edge separation. AIAA Journal, v. 21, p. 1525-1532, 1983.

RIBI, B.; DALBERT, P. One-dimensional prediction of subsonic vaned diffusers. Journal of Turbomachinery, v.122, p. 494-504, 2000.

RODGERS, C. Effects of blade number on the efficiency of centrifugal impellers. ASME Conference Proceedings 2000, 2000. Apresentado a ASME TURBO EXPO, Munique, Alemanha, Maio 8-11, 2000.

ROMUALDO, M. S. Otimização geométrica e aerodinâmica de um impelidor de compressor centrífugo. 2011. 108 p. Dissertação (Mestrado) - Universidade Federal do Rio de Janeiro, Rio de Janeiro, 2011.

ROSSETTI, A.; ARDIZZON, G.; PAVESI, G.; CAVAZZINI, G. An optimum procedure for an aerodynamic radial diffuser with incompressible flow at different Reynolds numbers. Proceedings of the Institution of Mechanical Engineers, Part A: Journal of Power and Energy, v. 224, n. 1, p. 69-84, 2010.

RUSCH, D.; CASEY, M. The design space boundaries for high flow capacity centrifugal compressors. ASME Conference Proceedings 2012, 2012. Apresentado a ASME TURBO EXPO, Copenhagen, Dinamarca, Junho 11-15, 2012.

SARAVANAMUTTOO, H. I. H.; ROGERS, G. F. C.; COHEN, H. Gas turbine theory. $5^{\text {th }}$ ed. Essex: Pearson Education Limited, 2001. 491 p. 
SCHOBEIRI, M. Turbomachinery flow physics and dynamic performance. Berlim: Springer, 2005. $522 \mathrm{p}$.

SILVA, A. C. V; MOURA, N. R.; SU, J. CFD simulation of a transonic axial-flow compressor stage. Proceedings of ENCIT, 2010. Apresentado a $13^{\text {th }}$ Brazilian Congress of Thermal Sciences and Engineering, Uberlândia, Dezembro 05-10, 2010.

SIMÕES, M. R. Simulação computacional de escoamento turbulento em compressor axial utilizando ferramenta de CFD. 2009. 111 p. Dissertação (Mestrado) - Universidade Federal do Rio de Janeiro, Rio de Janeiro, 2009.

SKOCH, G. J.; PRAHST, P. S.; WERNET, M. P.; WOOD, J. R.; STRAZISAR, A. J. Laser anemometer measurements of the flow field in a $4: 1$ pressure ratio centrifugal impeller. NASA Technical Memorandum 107541, 13 p, 1997.

SOUZA, R. C. Projeto de uma turbina de potência de uma microturbina a gás para acionamento de gerador elétrico. 2008. 41 p. Trabalho de Graduação (Engenharia Mecânica) - Universidade de São Paulo, São Paulo, 2008.

SOUZA, Z. Projeto de máquinas de fluxo: Tomo I - Base teórica e experimental. $1^{\underline{a}}$ ed. Rio de Janeiro: Editora Interciência, 2011. 178p.

SWAIN, E. The initial design of a centrifugal compressor. Journal of Engineering Design, v. 3, n.2, p.149-166, 1992.

TOMITA, J. T. Three-dimensional flow calculations of axial compressors and turbines using CFD techniques. 2009. 229 p. Tese (Doutorado) - Instituto Tecnológico de Aeronáutica, São José dos Campos, 2009.

TREAGER, I. E. Aircraft gas turbine engine technology. $2^{\text {nd }}$ ed. Nova York: McGraw-Hill Book Company, 1979. 586 p.

VAN DEN BRAEMBUSSCHE, R. A.; ALSALIHI, Z.; VERSTRAETE, T.; MATSUO, A.; IBARAKI, S.; SUGIMOTO, K.; TOMITA, I. Multidisciplinary multipoint optimization of a transonic turbocharger compressor. ASME Conference Proceedings 2012, 2012. Apresentado a ASME TURBO EXPO, Copenhagen, Dinamarca, Junho 11-15, 2012. 
VELÁSQUEZ, E. I. G; NASCIMENTO, M. A. R. Implementation of one-dimensional centrifugal compressor design code. Proceedings of ENCIT, 2010. Apresentado a $13^{\text {th }}$ Brazilian Congress of Thermal Sciences and Engineering, Uberlândia, Dezembro 05-10, 2010.

VELÁSQUEZ, E. I. G; NASCIMENTO, M. A. R; CARRILLO, R. A. M.; MOURA, N. R. One and three-dimensional analysis of centrifugal compressor for $600 \mathrm{~kW}$ simple cycle gas turbine engine. ASME Conference Proceedings 2010, v. 5, p. 471-476, 2010. Apresentado a ASME TURBO EXPO, Glasgow, Reino Unido, Junho 14-18, 2010.

VERSTEEG, H. K.; MALALASEKERA, W. An introduction to computational fluid dynamics: the finite volume method. $2^{\text {nd }}$ ed. Essex: Pearson Education Limited, 2007. 503a p.

VERSTRAETE, T.; ALSALIHI, Z.; VAN DEN BRAEMBUSSCHE, R. A. Multidisciplinary optimization of a radial compressor for microgas turbine applications. Journal of Turbomachinery, v. 132, n. 3, p. 1-7, 2010.

WHITFIELD, A. The preliminary design of radial inflow turbines. Journal of Turbomachinery, v. 112, p. 50-57, 1990.

WHITFIELD, A.; BAINES, N. C. Design of radial turbomachines. $1^{\text {st }}$ ed. Essex: Longman Scientific \& Technical, 1990. 397 p.

WILSON, D. G.; KORAKIANITIS, T. The design of high-efficiency turbomachinery and gas turbines. $2^{\text {nd }}$ ed. Nova Jersey: Prentice Hall, 1998. 593 p.

WRIGHT, T. Fluid machinery: performance, analysis, and design. $1^{\text {st }}$ ed. Flórida: CRC Press, 1999. 363 p.

$\mathrm{XU}$, C. Design experience and considerations for centrifugal compressor development. Proceedings of the Institution of Mechanical Engineers, Part G: Journal of Aerospace Engineering Science, v. 221, n. 2, p. 273-287, 2007.

$\mathrm{XU}, \mathrm{C}$; AMANO, R. S. Empirical design considerations for industrial centrifugal compressors. International Journal of Rotating Machinery - Research Article, v. 2012, p. 1-15, $2012 \mathrm{a}$. 
XU, C.; AMANO, R. S. Meridional considerations of the centrifugal compressor development. International Journal of Rotating Machinery - Research Article, v. 2012, p. 1-11, 2012b. 


\section{APÊNDICE A - ROTINA COMPUTACIONAL DO PROJETO UNIDIMENSIONAL}

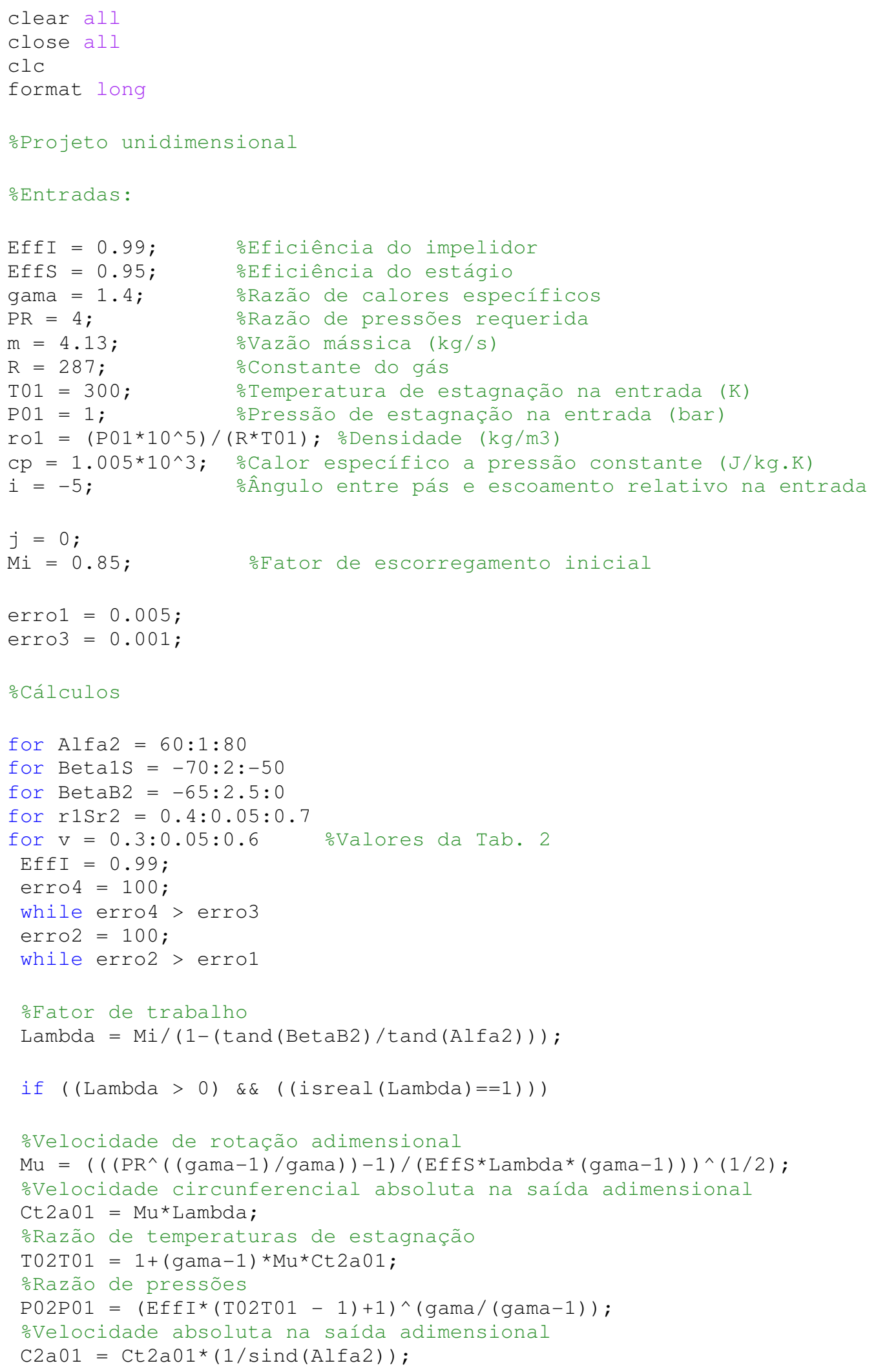




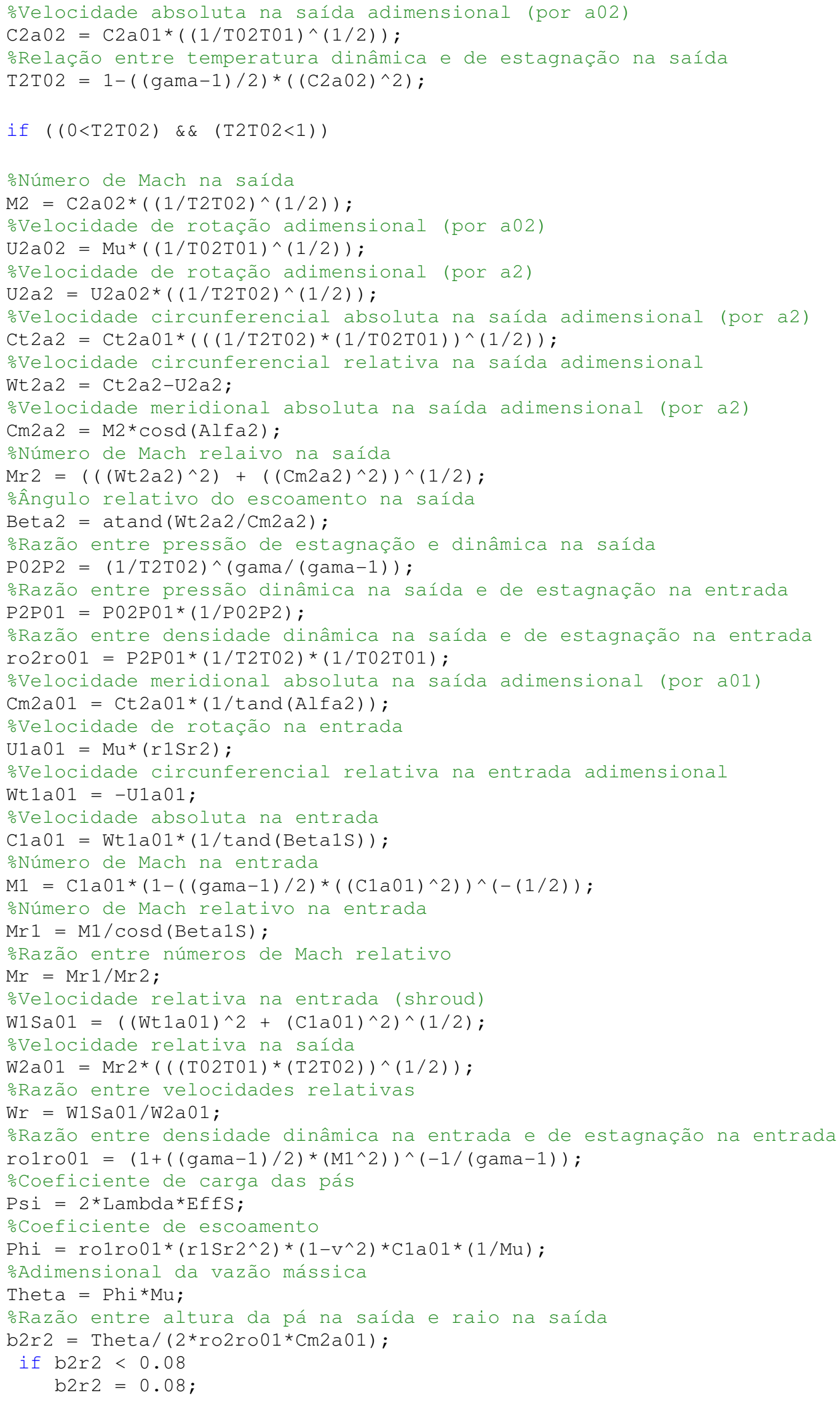




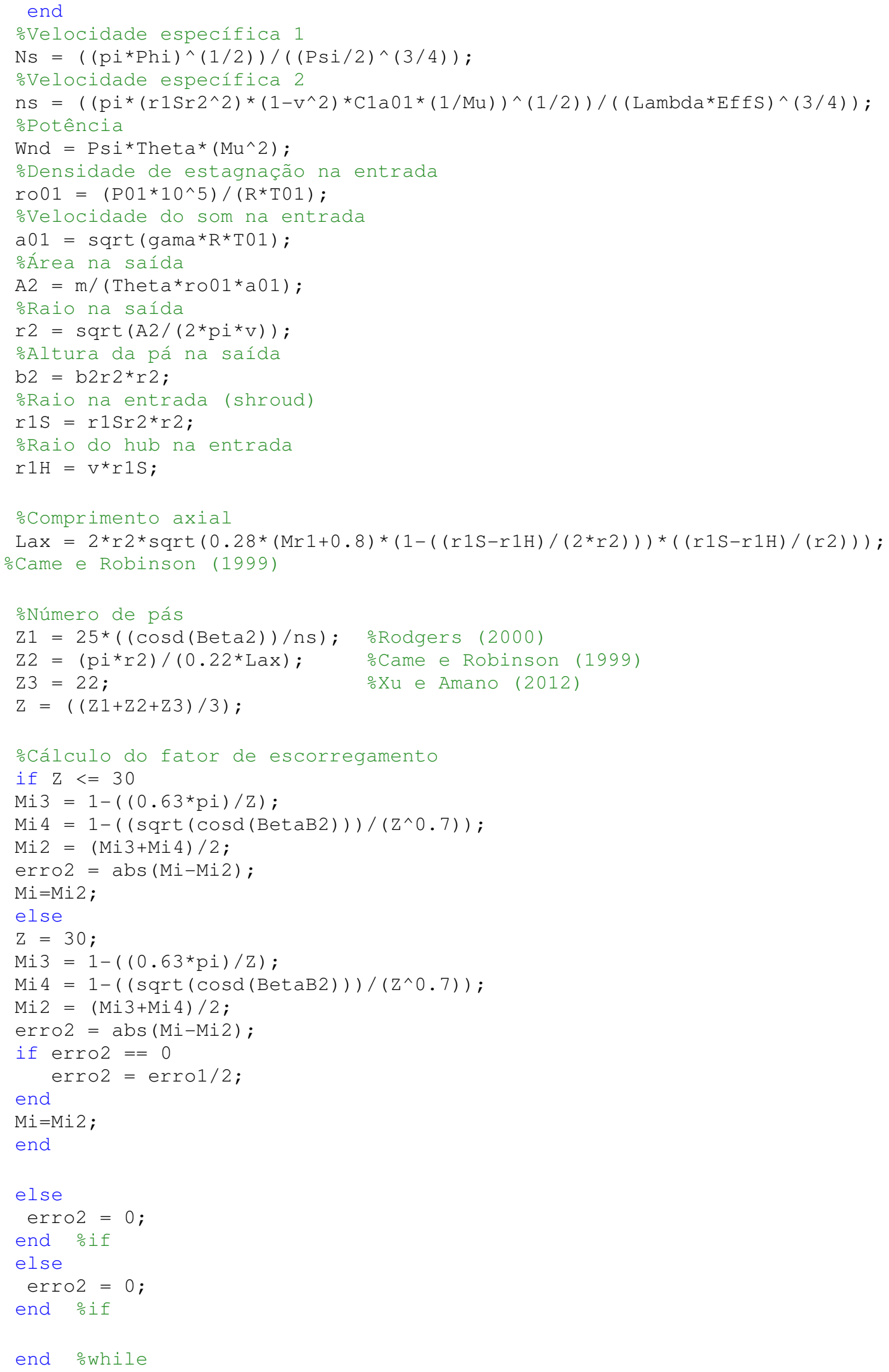




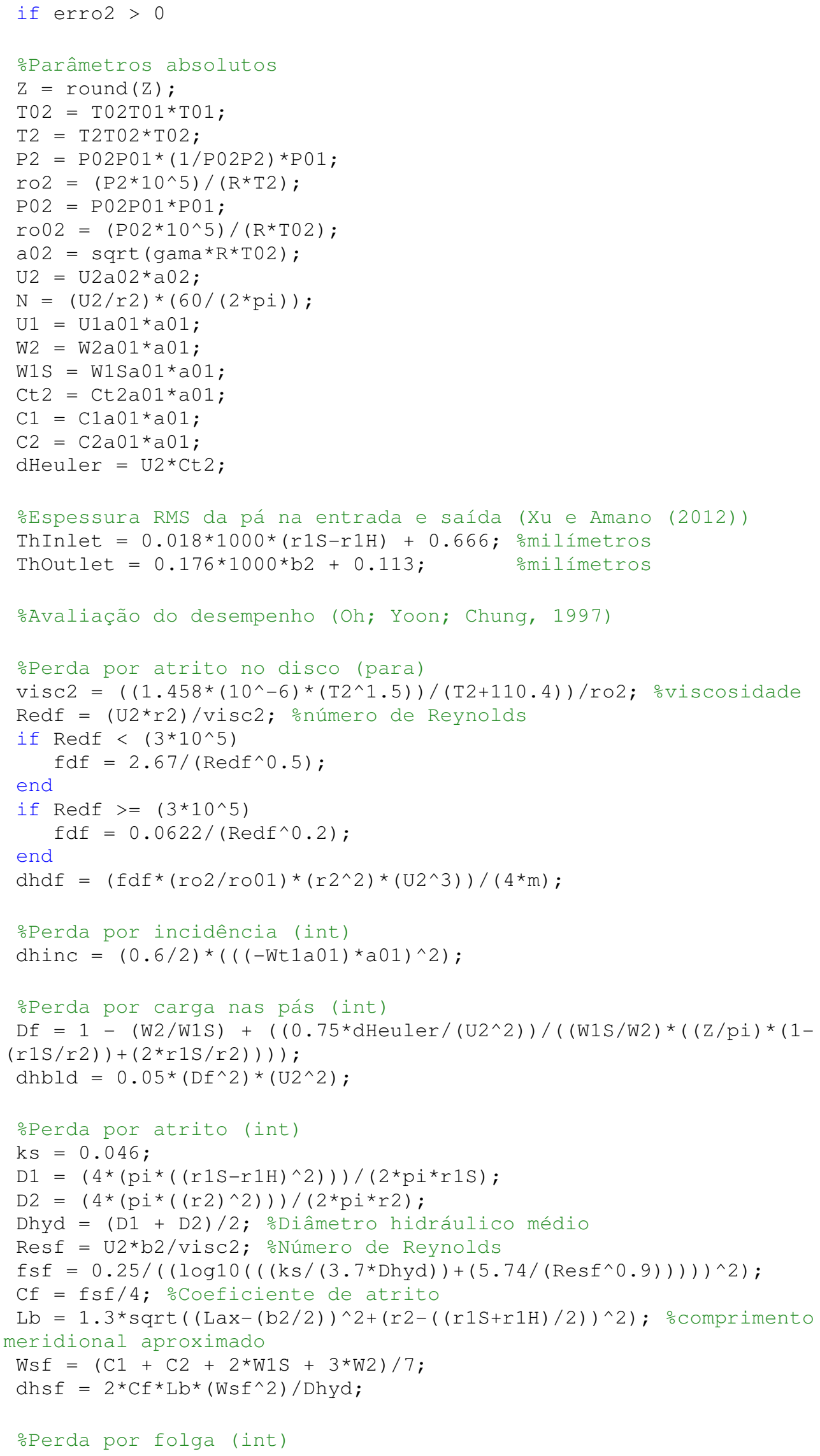




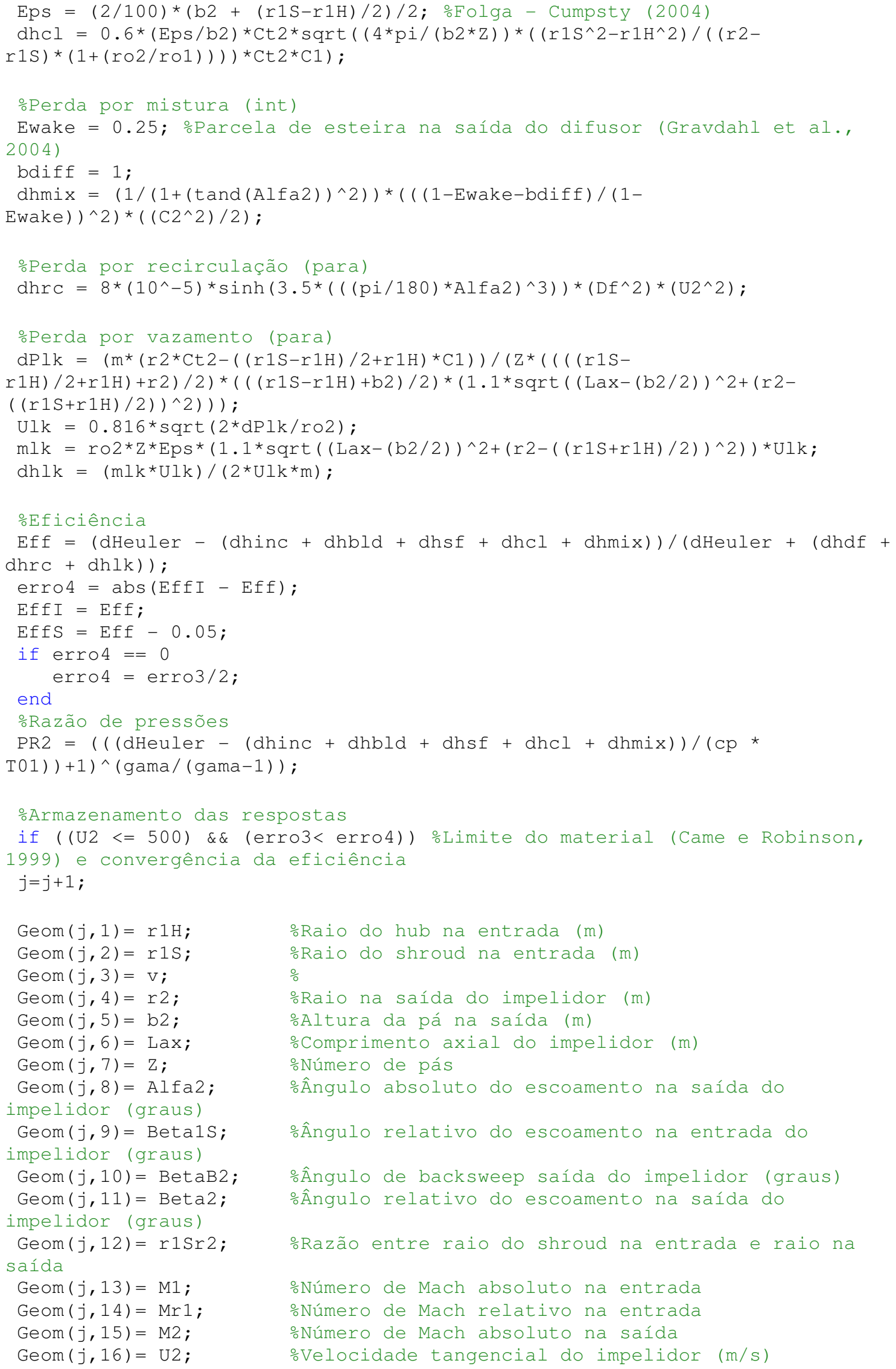




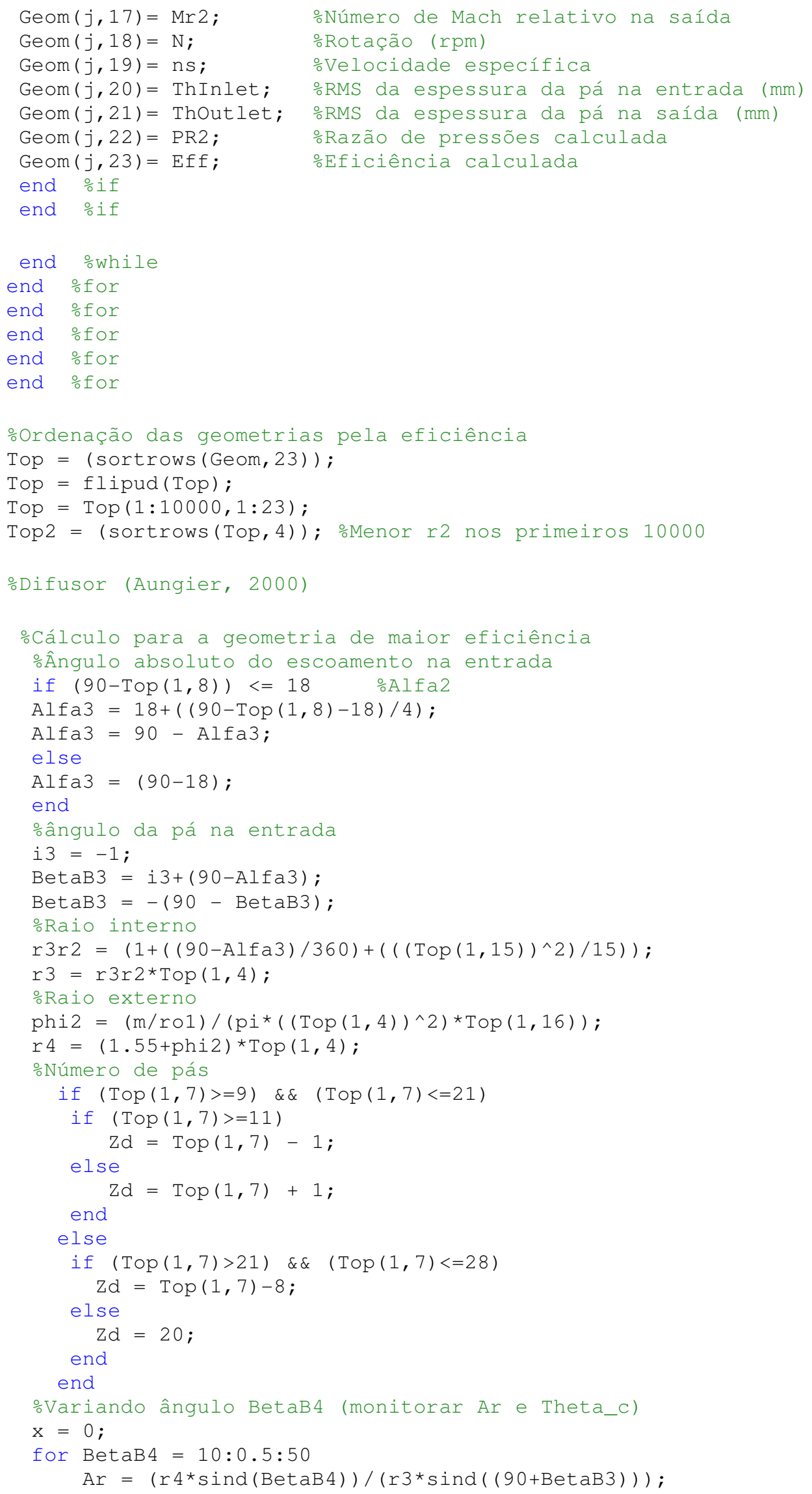




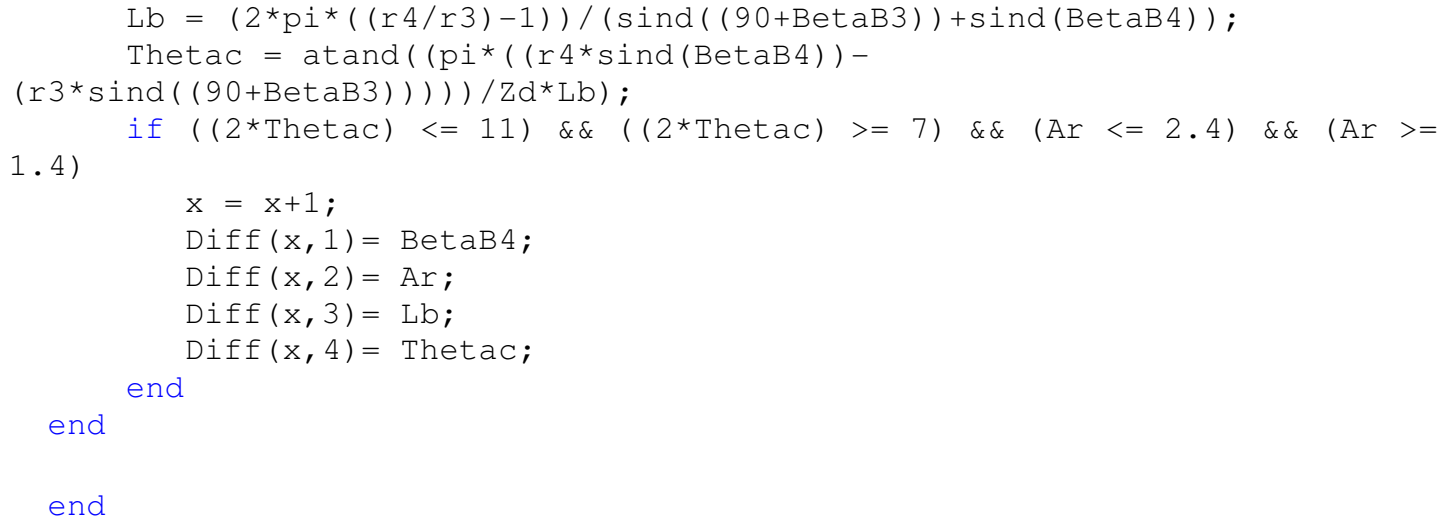

